\title{
Thermophysical Property and Phase Transformation Determination of $\gamma$-TiAl Intermetallics
}

by

Judith M. Overton, B. Eng.

A thesis submitted to the Faculty of Graduate Studies and Research in partial fulfilment of the requirements for the degree of

Master of Applied Science

Ottawa-Carleton Institute for Mechanical and Aerospace Engineering

\author{
Department of Mechanical and Aerospace Engineering \\ Carleton University \\ Ottawa, Ontario \\ Canada
}

May 2006

Copyright (C) 2006 Judith M. Overton 


$\begin{array}{ll}\begin{array}{l}\text { Library and } \\ \text { Archives Canada }\end{array} & \begin{array}{l}\text { Bibliothèque et } \\ \text { Archives Canada }\end{array} \\ \begin{array}{l}\text { Published Heritage } \\ \text { Branch }\end{array} & \begin{array}{l}\text { Direction du } \\ \text { Patrimoine de l'édition }\end{array} \\ \begin{array}{l}\text { 395 Wellington Street } \\ \text { Ottawa ON K1A ON4 }\end{array} & \begin{array}{l}\text { 395, rue Wellington } \\ \text { Ottawa ON K1A ON4 } \\ \text { Canada }\end{array}\end{array}$

Your file Votre référence ISBN: 978-0-494-18329-8 Our file Notre référence ISBN: 978-0-494-18329-8

NOTICE:

The author has granted a nonexclusive license allowing Library and Archives Canada to reproduce, publish, archive, preserve, conserve, communicate to the public by telecommunication or on the Internet, loan, distribute and sell theses worldwide, for commercial or noncommercial purposes, in microform, paper, electronic and/or any other formats.

The author retains copyright ownership and moral rights in this thesis. Neither the thesis nor substantial extracts from it may be printed or otherwise reproduced without the author's permission.
AVIS:

L'auteur a accordé une licence non exclusive permettant à la Bibliothèque et Archives Canada de reproduire, publier, archiver, sauvegarder, conserver, transmettre au public par télécommunication ou par l'Internet, prêter, distribuer et vendre des thèses partout dans le monde, à des fins commerciales ou autres, sur support microforme, papier, électronique et/ou autres formats.

L'auteur conserve la propriété du droit d'auteur et des droits moraux qui protège cette thèse. $\mathrm{Ni}$ la thèse ni des extraits substantiels de celle-ci ne doivent être imprimés ou autrement reproduits sans son autorisation.
In compliance with the Canadian

Privacy Act some supporting forms may have been removed from this thesis.

While these forms may be included in the document page count, their removal does not represent any loss of content from the thesis.
Conformément à la loi canadienne sur la protection de la vie privée, quelques formulaires secondaires ont été enlevés de cette thèse.

Bien que ces formulaires aient inclus dans la pagination, il n'y aura aucun contenu manquant.

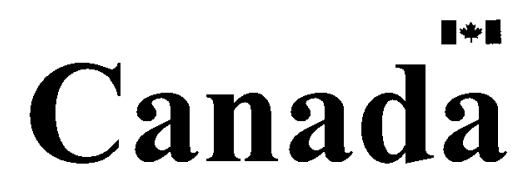




\section{Abstract}

Much research has been carried out with the goal of replacing some superalloys in gas turbine engine applications, such as low-pressure and power turbine blades, with gamma titanium aluminide $(\gamma$-TiAl) intermetallics because of the significant potential for weight savings. However, two factors have precluded the production of commercially viable $\gamma$-TiAl parts: the poor balance of mechanical properties and the lack of a processing solution for economic component production. Previous research carried out at Carleton University has shown that the directional solidification (DS) casting technique may provide a solution to both of these issues by producing a columnar microstructure that has been shown to posses an excellent balance of mechanical properties and by offering an economical manufacturing process. DS casting trials at Carleton University have produced encouraging results, but an optimum microstructure has yet to be generated. This is, in part, due to difficulties in solidification process modelling because of a lack of thermophysical data for these new materials and a poor understanding of the phase transformations that occur during solidification and subsequent cooling. The aim of the current research is to develop a better fundamental knowledge of the thermophysical properties and phase transformations of $\gamma$-TiAl intermetallics. This will be accomplished through thermal analysis using differential scanning calorimetry (DSC) to determine the phase transformations and thermophysical properties of interest as a function of composition. Eighteen (18) $\gamma$-TiAl compositions were tested and analyzed, including two binary, four ternary, seven quaternary, and five more complex alloys. Results of DSC testing is presented and discussed. 


\section{Acknowledgments}

I would like to thank my supervisors, Dr. Jonathan Beddoes and Dr. Henry Saari, for their advice, guidance, and patience while working on this project. Dr. Dongyi Seo from the Structures and Materials Performance Laboratory of the Institute for Aerospace Research, National Research Council of Canada provided a number of TiAl alloys for testing.

Thanks to Mr. Fred Barrett, a technologist at Carleton University, and to the technical staff from Netzsch for help in troubleshooting and fixing various problems with the DSC equipment.

Financial assistance for this work was provided by the National Sciences and Engineering Research Council, Materials and Manufacturing Ontario, Zonta International, and the Department of Mechanical and Aerospace Engineering at Carleton University.

Thank you to my family and friends for your encouragement and support.

This thesis is dedicated to my husband James, for his patience and encouragement throughout this project. Thank you for helping me through this. 


\section{Table of Contents}

Abstract $\quad$ ii

Acknowledgments

Table of Contents $\quad$ iv

List of Tables $\quad$ vii

List of Figures $\quad$ viii

1 Introduction 1

1.1 The Gas Turbine Engine . . . . . . . . . . . . . . . . . 3

1.2 Turbine Blades and Blade Materials . . . . . . . . . . . . 5

$1.3 \gamma$-TiAl Turbine Blades $\ldots \ldots \ldots \ldots \ldots$

1.4 Why DS Processing for $\gamma$-TiAl? . . . . . . . . . . 8

1.5 The Need for Improved Thermophysical Data . . . . . . . . . . . . 10

1.6 Thesis Objectives and Outline . . . . . . . . . . . . . . 10

$2 \quad \gamma$-TiAl Intermetallics $\quad 12$

$2.1 \gamma$-TiAl Fundamentals . . . . . . . . . . . . . . . . 13

2.1.1 Solidification Structures . . . . . . . . . . . . . . 16

2.1.2 Peritectic Reactions and TiAl Peritectics . . . . . . . . . . 17

2.1.3 Crystallography and Mechanisms of Formation . . . . . . . . 18

2.1.4 Lamellar Microstructure and Mechanical Properties . . . . . . . 20

iv 


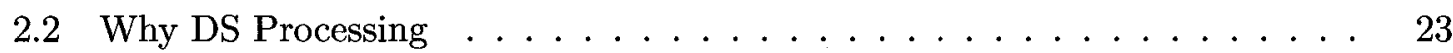

2.2.1 DS $\gamma$-TiAl Solidification Microstructures . . . . . . . . . 25

2.2.2 The Importance of Process Modelling . . . . . . . . . . . . . 25

2.2.3 Thermophysical Property Requirements for Process Modelling . . . 26

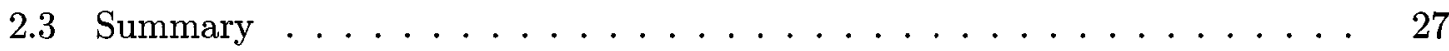

3 Thermophysical Property Determination 30

3.1 Thermal Analysis Fundamentals . . . . . . . . . . . . . . . . . . 31

3.1 .1 The History of DTA and DSC . . . . . . . . . . 31

3.1 .2 Thermal Analysis Instruments . . . . . . . . . . . . . . . 32

3.1.3 Thermal Analysis Measurements and Data . . . . . . . . . . . 32

3.2 Thermal Analysis Techniques . . . . . . . . . . . . . . . 34

3.2.1 Differential Thermal Analysis (DTA) . . . . . . . . . . . 35

3.2.2 Differential Scanning Calorimetry (DSC) . . . . . . . . . 36

3.2.3 Comparison of the Principles of DTA and DSC . . . . . . . . 39

3.2.4 A Discussion of High-Temperature Calorimetry and the Techniques Available ........................... 41

3.3 Thermal Analysis Experimental Factors . . . . . . . . . . . . . . 45

3.3.1 Instrument Calibration $\ldots \ldots \ldots \ldots \ldots . \ldots \ldots$

3.3.2 Reference Materials . . . . . . . . . . . . . . . . . . 46

3.3 .3 Crucibles ......................... 46

3.3 .4 Testing Atmosphere . . . . . . . . . . . . . . . 46

3.4 Interpretation of DTA and DSC Curves . . . . . . . . . 47

3.5 Determining Fraction of Solid . . . . . . . . . . . . . . . . 49

3.6 Undercooling and Alloy Solidification Behaviour . . . . . . . . . . 49

$3.7 \mathrm{DTA} / \mathrm{DSC}$ of TiAl in the Literature . . . . . . . . . . . . 50

3.8 The Importance of Understanding Phase Transformations . . . . . . . . . . 62

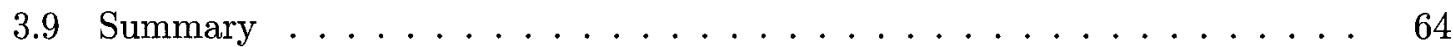

4 Thesis Objectives and Scope $\quad 65$ 
5 Thermal Analysis of TiAl using DSC $\quad 67$

5.1 Experimental Procedure . . . . . . . . . . . . . . . 67

$5.1 .1 \mathrm{TiAl}$ Compositions Tested . . . . . . . . . . . . . . 68

5.1 .2 Preparation of Samples for DSC . . . . . . . . . . . 68

5.1 .3 Crucibles and Reference Material . . . . . . . . . . . . . . 70

5.1 .4 Crucible and Sample Cleaning . . . . . . . . . . . . . 71

5.1 .5 Yttria Powder $\ldots \ldots \ldots \ldots \ldots \ldots \ldots$

5.1 .6 Weights ............................. 72

5.1 .7 Carleton University DSC Facility . . . . . . . . . . . . . . 73

5.1 .8 Baseline Correction . . . . . . . . . . . . . . . . 74

5.1 .9 Heating Programs . . . . . . . . . . . . . . 74

5.1 .10 DSC Calibration . . . . . . . . . . . . . 79

5.1 .11 Heating Rate Effects . . . . . . . . . . . . . 80

5.1 .12 Other Considerations . . . . . . . . . . . . . 82

5.1 .13 Analysis of DSC Curves . . . . . . . . . . . . . . 82

5.2 Results. . . . . . . . . . . . . . . . . . . . 82

5.2 .1 Binary Compositions . . . . . . . . . . . . . . . . 83

5.2 .2 Ternary Alloys . . . . . . . . . . . . . . . 87

5.2 .3 Complex Alloys . . . . . . . . . . . . . . . . 90

5.3 Discussion . . . . . . . . . . . . . . . . . . . . 99

6 Summary and Conclusions $\quad 107$

6.1 Future Research . . . . . . . . . . . . . . . . . . . 108

$\begin{array}{ll}\text { References } & 111\end{array}$

Appendix A Ti-Al Binary Equilibrium Phase Diagrams $\quad$ A-1

Appendix B DSC Operating Procedures for Test Setup B-1

Appendix C Sample DSC Curves $\quad$ C-1

vi 


\section{List of Tables}

1 The effects of selected alloying elements in $\gamma$-TiAl alloys. . . . . . . . . 15

2 The main thermal analysis techniques. . . . . . . . . . . . . . 34

3 Estimated phase transformation temperatures. . . . . . . . . . . . 54

$4 \quad$ Alpha transus temperatures $\left(T_{\alpha}\right)$ determined by DTA for various $\mathrm{Ti}-\mathrm{Al}$ alloys. 55

$5 \quad$ The $18 \gamma$-TiAl alloys analyzed using DSC . . . . . . . . . . . . . 69

6 Temperature calibration data for $20 \mathrm{~K} / \mathrm{min} \ldots \ldots \ldots \ldots$

7 Transformation temperatures for Ti-48Al. . . . . . . . . . . . . . . 84

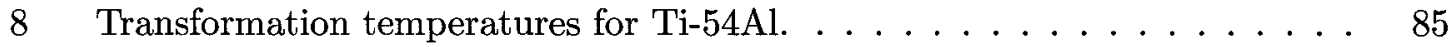

9 Transformation temperatures for Ti-47Al-2Cr. . . . . . . . . . . . 88

10 Transformation temperatures for Ti-47.5Al-3Cr. . . . . . . . . . . . 88

11 Transformation temperatures for Ti-48Al-2Cr. . . . . . . . . . . . . . 89

12 Transformation temperatures for Ti-48Al-2W . . . . . . . . . . . . 89

13 Transformation temperatures for TAMN $\ldots \ldots \ldots \ldots \ldots$

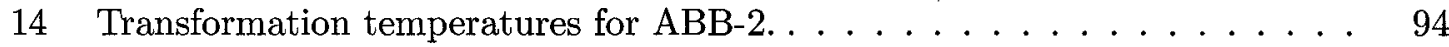

15 Transformation temperatures for TAWS. . . . . . . . . . . . . 95

16 Transformation temperatures for Ti-48Al-2Nb-2Cr. . . . . . . . . . . 95

17 Transformation temperatures for Ti-52Al-2W-0.5Si. . . . . . . . . . . 96

18 Transformation temperatures for Ti-48Al-2Cr-2Nb-0.5W . . . . . . . . 97

19 Transformation temperatures for Ti-48Al-2Cr-2Nb-1W. . . . . . . . . . 98

20 Transformation temperatures for 47 XD $\ldots \ldots \ldots \ldots \ldots \ldots$

21 Summary of the effect of alloying additions to Ti-48Al . . . . . . . . . . . 106

22 Summary of the transformation temperatures in Ti-54Al and Ti-52Al-2W-0.5Si.106

vii 


\section{List of Figures}

1 Historical trends in gas turbine materials usage. . . . . . . . . . . . . 2

2 Schematic of a simple turbo jet engine. . . . . . . . . . . . 4

3 Schematic of a two-stage low bypass turbo jet engine. . . . . . . . . . 4

4 Schematic of a three-stage high bypass ratio turbo fan engine. . . . . . . . . 4

5 Plot showing the range of specific strength as a function of temperature for

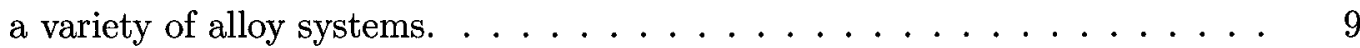

6 Plot showing specific modulus as a function of temperature for various alloys. 9

$7 \quad$ Part of the binary $\mathrm{Ti}$-Al equilibrium phase diagram. . . . . . . . . 14

8 Crystal structure of the $\gamma(\mathrm{TiAl})$ and $\alpha_{2}\left(\mathrm{Ti}_{3} \mathrm{Al}\right)$ phases. . . . . . . . 16

$9 \quad$ Two typical $\gamma$-TiAl microstructures: (a) fully lamellar and (b) duplex. . . . 18

10 The growth morphology of (a) cubic dendrites and (b) hexagonal dendrites. 18

11 Lamellar orientation formation of $\gamma$ phase on $\alpha$ phase. . . . . . . . . . 20

12 Schematic showing orientation relationship between $\gamma$ and $\alpha_{2}$ phases for lamellar formation. . . . . . . . . . . . . . . . 20

13 A TEM micrograph showing lamellar microstructure of a $\gamma$-TiAl PST crystal. 21

14 Schematic illustration of the two-phase $\gamma / \alpha_{2}$ lamellar microstructure. . . . . 22

15 Schematic illustrating the angle, $\phi$, between the lamellar orientation and the

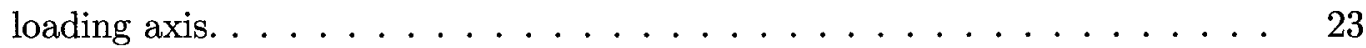

16 Yield strength and ductility as a function of $\phi . \ldots \ldots \ldots \ldots$

17 Schematic representation of three possible orientations of a crack with respect to the lamellar boundary orientation. . . . . . . . . . . . . . . . . . 24

18 The target microstructure for $\gamma$-TiAl alloys for turbine blade applications. . $\quad 25$ 
19 A generalized thermal analysis instrument. . . . . . . . . . . . . 33

20 A generalized thermal analysis curve . . . . . . . . . . . . . 33

21 A typical classical DTA apparatus. . . . . . . . . . . . . . 38

22 A typical power compensated DSC apparatus. . . . . . . . . . . . . . 38

23 A typical heat flux DSC apparatus. . . . . . . . . . . . . . 38

24 Schematic diagram of a differential thermal apparatus. . . . . . . . . . . 39

25 A hypothetical DTA curve. . . . . . . . . . . . . . 47

26 Diagram showing area method to determine fraction solid $\left(\mathrm{f}_{S}\right) \ldots \ldots$. . . . 49

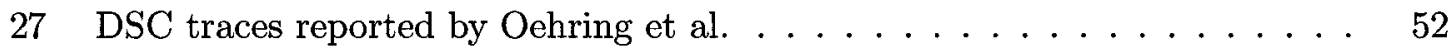

28 DSC trace reported by Ohnuma et al. ................ 53

29 Binary Ti-Al phase diagram reported by Ohnuma et al. . . . . . . . . . 55

30 Binary Ti-Al phase diagram reported by Saunders. . . . . . . . . . . . . . 56

31 Calculated mole \% vs. temperature plot for $\mathrm{Ti}-47 \mathrm{Al}-2 \mathrm{Mn}-2 \mathrm{Nb}$, reported by

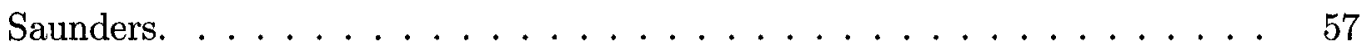

32 Calculated mole \% vs. temperature plot for Ti-47Al-2Nb-1Mn-0.5W-0.5Mo0.2 Si, reported by Saunders. . . . . . . . . . . . . . . 57

33 Calculated mole \% vs. temperature plot for Ti-47Al-2Cr-2Nb-0.5W, reported by Saunders. ............................... 57

34 DTA heat flow curves reported by Stein et al. . . . . . . . . . . . . . 59

35 DTA measurements and the calculated phase fractional change in Ti-47Al$3 \mathrm{Cr}$ reported by Hashimoto et al. . . . . . . . . . . . . . . 59

36 DTA curve for Ti-48Al-2Mn-2Nb, 30 ${ }^{\circ} \mathrm{C} / \mathrm{min}$ reported by McQuay et al. . . 61 37 DSC heating (top line) and cooling results for TAWS, reported by Saari et al. 62

38 DSC heating (top line) and cooling results for TAMN, reported by Saari et al. 62

39 Binary Ti-Al phase diagram with the solidification paths for TAWS and

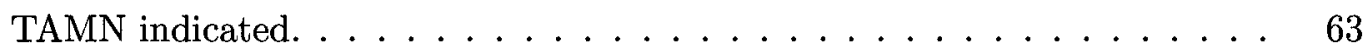

40 Schematic of DSC crucible. . . . . . . . . . . . . . . 71

41 Photo of the scale used to weigh samples for DSC tests. . . . . . . . . 72

42 Photo of the DSC equipment. . . . . . . . . . . . . . . . 74 


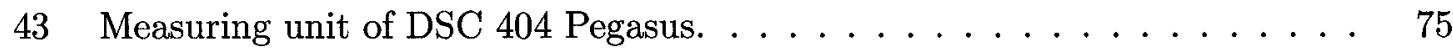

44 Side detail cutaway of the DSC 404 Pegasus measuring unit. . . . . . . . . 76

45 Detail of sample carrier system and DSC measurement head. . . . . . . . 77

46 DSC heating program, $20 \mathrm{~K} / \mathrm{min} \ldots \ldots \ldots \ldots \ldots \ldots$

47 DSC temperature calibration curve, $20 \mathrm{~K} / \mathrm{min} \ldots \ldots \ldots \ldots$

48 Sample DSC plot for one of the calibration samples. . . . . . . . . . . . . 81

49 Heating rate effect on the melting temperature of Au. . . . . . . . . . 81

50 DSC curve for Ti-48Al, 20 and $5 \mathrm{~K} / \mathrm{min} \ldots \ldots \ldots \ldots$

51 DSC curve for $\mathrm{Ti}-54 \mathrm{Al}, 20 \mathrm{~K} / \mathrm{min} . \ldots \ldots \ldots \ldots$

$52 \mathrm{DSC}$ curve for $\mathrm{Ti}-47 \mathrm{Al}-2 \mathrm{Cr}, 20 \mathrm{~K} / \mathrm{min} \ldots \ldots \ldots \ldots$. . . . . . . . 91

$53 \mathrm{DSC}$ curve for $\mathrm{Ti}-47.5 \mathrm{Al}-3 \mathrm{Cr}, 20 \mathrm{~K} / \mathrm{min} \ldots \ldots \ldots \ldots . \ldots . \ldots . \ldots 9$

54 DSC curve for Ti-48Al-2Cr, $20 \mathrm{~K} / \mathrm{min} \ldots \ldots \ldots . \ldots 2$

55 DSC curve for $\mathrm{Ti}-48 \mathrm{Al}-2 \mathrm{~W}, 20 \mathrm{~K} / \mathrm{min} \ldots \ldots \ldots \ldots \ldots \ldots$

56 DSC curve for TAMN, $20 \mathrm{~K} / \mathrm{min} \ldots \ldots \ldots \ldots \ldots$

57 DSC curve for ABB-2, $20 \mathrm{~K} / \mathrm{min} \ldots \ldots \ldots \ldots \ldots \ldots$

58 DSC curve for TAWS, $20 \mathrm{~K} / \mathrm{min} \ldots \ldots \ldots \ldots \ldots \ldots$

59 DSC curve for Ti-48Al-2Nb-2Cr, $20 \mathrm{~K} / \mathrm{min} \ldots \ldots \ldots \ldots \ldots$

60 DSC curve for Ti-52Al-2W-0.5Si, $20 \mathrm{~K} / \mathrm{min} \ldots \ldots \ldots \ldots$. . . . . . . . 102

61 DSC curve for Ti-48Al-2Cr-2Nb-0.5W, $20 \mathrm{~K} / \mathrm{min} \ldots \ldots \ldots \ldots \ldots$

$62 \mathrm{DSC}$ curve for Ti-48Al-2Cr-2Nb-1W, $20 \mathrm{~K} / \mathrm{min} . \ldots \ldots \ldots$

63 DSC curve for $47 \mathrm{XD}, 20 \mathrm{~K} / \mathrm{min} . \ldots \ldots \ldots \ldots$

64 TiAl phase diagram including binary DSC results. . . . . . . . . . . . . 104

65 Comparison of various Ti-Al-W DSC curves. . . . . . . . . . . . . 106

66 Microstructures of DS cast TAMN and TAWS . . . . . . . . . . . . 110

A.1 Ti-Al equilibrium phase diagram, from Semiatin et al. . . . . . . . . A-2

A.2 Ti-Al equilibrium phase diagram, from Murray 1987. . . . . . . . . . A-3

A.3 Ti-Al equilibrium phase diagrams by (a) Murray and (b) Kattner et al. . . A-4

A.4 Ti-Al equilibrium phase diagrams by (a) Murray and (b) Okamoto et al. . . A-5

A.5 Binary Ti-Al phase diagram reported by Saunders. . . . . . . . . . . A-6 
B.1 Photo of the DSC equipment. . . . . . . . . . . . . B-1

B.2 How to open the DSC furnace. . . . . . . . . . . B-2

B.3 Sample and reference placement in DSC sample carrier. . . . . . . . . B-3

B.4 How to close the DSC furnace. . . . . . . . . . . . . B-3

B.5 Argon gas flow meter. . . . . . . . . . . . . B

B.6 Adjusting flow of purge 1 gas. . . . . . . . . . . . B $\ldots$

B.7 Vacuum control console. . . . . . . . . . . . . . . . B-6

B.8 DSC 404C measurement software Start Standby and Start Measurement. B-7

C.1 DSC curve for Ti-48Al, consolidated PM sample, $20 \mathrm{~K} / \mathrm{min} . \ldots \ldots$. . . . C-2

C.2 DSC curve for Ti-48Al, loose PM sample, $20 \mathrm{~K} / \mathrm{min} . \ldots \ldots \ldots$. . . . . C-2

C.3 DSC curve for Ti-54Al, $20 \mathrm{~K} / \mathrm{min} . \ldots \ldots \ldots \ldots \ldots$ C $-\ldots \ldots$

C.4 DSC curve for $\mathrm{Ti}-47 \mathrm{Al}-2 \mathrm{Cr}, 20 \mathrm{~K} / \mathrm{min} \ldots \ldots \ldots \ldots \ldots$. . . . . . . .

C.5 DSC curve for Ti-47.5Al-3Cr, $20 \mathrm{~K} / \mathrm{min} \ldots \ldots \ldots \ldots \ldots$. . . . . . C-4

C.6 DSC curve for Ti-48Al-2Cr, $20 \mathrm{~K} / \mathrm{min} \ldots \ldots \ldots \ldots \ldots$. . . . . . . C-4

C.7 DSC curve for Ti-48Al-2W, $20 \mathrm{~K} / \mathrm{min} \ldots \ldots \ldots \ldots \ldots$. . . . . . . . . .

C.8 DSC curve for Ti-45Al-2W-0.1Si, $20 \mathrm{~K} / \mathrm{min} \ldots \ldots \ldots \ldots \ldots$. . . . . . .

C.9 DSC curve for Ti-45Al-2W-0.5Si, $20 \mathrm{~K} / \mathrm{min} . \ldots \ldots \ldots \ldots$. . . . . . . .

C.10 DSC curve for Ti-46Al-2Mo-2Nb (TAMN), $20 \mathrm{~K} / \mathrm{min} . \ldots \ldots$. . . . C-6

C.11 DSC curve for Ti-47Al-2W-0.5Si (ABB-2), $20 \mathrm{~K} / \mathrm{min} . \ldots \ldots \ldots$. . . . C-7

C.12 DSC curve for Ti-47.5Al-2W-0.5Si (TAWS), $20 \mathrm{~K} / \mathrm{min} \ldots \ldots \ldots$. . . . . . C-7

C.13 DSC curve for Ti-48Al-2Nb-2Cr, $20 \mathrm{~K} / \mathrm{min} . \ldots \ldots \ldots$. . . . . . C-8

C.14 DSC curve for Ti-52Al-2W-0.5Si, $20 \mathrm{~K} / \mathrm{min} . \ldots \ldots \ldots$. . . . . C-8

C.15 DSC curve for Ti-48Al-2Nb-2Cr-0.5W, $20 \mathrm{~K} / \mathrm{min} . \ldots \ldots \ldots$. . . . . . . C-9

C.16 DSC curve for Ti-48Al-2Nb-2Cr-1W, $20 \mathrm{~K} / \mathrm{min} . \ldots \ldots \ldots$. . . . . . . C-9

C.17 DSC curve for Ti-45Al-2Nb-2Mn + 0.8TiB2 (45XD), $20 \mathrm{~K} / \mathrm{min} . \quad \ldots$. . C-10

C.18 DSC curve for Ti-47Al-2Nb-2Mn + 0.8TiB2 (47XD), $20 \mathrm{~K} / \mathrm{min}$. . . . . C-10

C.19 DSC curve for Ti-47Al-2Nb-1Mn-0.5W-0.5Mo-0.2Si (TiAlWMoSi), $20 \mathrm{~K} / \mathrm{min}$. C-11 


\section{Chapter 1}

\section{Introduction}

Two phase gamma titanium aluminides ( $\gamma$-TiAl) have been under development for a number of years as potential aerospace propulsion or high temperature structural materials. There is an ongoing search for weight saving structural materials with higher operational temperature capabilities for gas turbine engines, with the goal of increasing fuel economy and operating efficiency as well as the reduction of pollutants. Alloys based on titanium aluminide intermetallics are one such candidate material. Of these intermetallics $\gamma$-TiAl offers the best combination of high temperature stiffness, creep and oxidation resistance, with a density half that of traditional nickel based superalloys. However, development has been hindered by poor room temperature toughness and a poor balance of mechanical properties. Research into the use of $\gamma$-TiAl intermetallics in aircraft gas turbine engines is ongoing.

Gas turbine engines are widely used for aerospace and industrial power generation. Applications include aircraft and marine propulsion, electrical power generation, and natural gas transmission. Because of their need for high power in relation to weight and high temperature operation to maximize efficiency, aircraft gas turbines have set the pace in gas turbine materials development [1]. Since their introduction into widespread use in the 1950s, the operating temperatures of aircraft gas turbine engines have increased significantly in order to minimise fuel consumption and increase thrust $[1,2]$. In general, to increase the efficiency and power of these engines, operating temperatures must be increased and engine 
weight must be reduced. This necessitates the use of high temperature, lightweight materials, especially for rotating components. Thus, development trends are for materials with ever increasing temperature capabilities, even at the expense of increased weight. Materials developments for gas turbine engines push the development of high temperature materials, and the materials used in aircraft gas turbine engines have changed over time. Figure 1, for example, shows historical material trends; as a result of increasing turbine inlet temperature combined with the desire to save weight particularly in rotating components, there has been a progressive change in the proportions of various materials used in the engine with the use of nickel based superalloys, titanium alloys and composites increasing over time and replacing steels and aluminum alloys. Nickel based superalloys are used almost exclusively in the hottest sections of modern aircraft gas turbine engines. However, since these materials are relatively heavy, a great deal of current research is focused on developing lighter materials to replace superalloys in some gas turbine applications. The $\gamma$-TiAl intermetallics are one such near-term candidate family of materials that offer the possibility of significant weight savings.

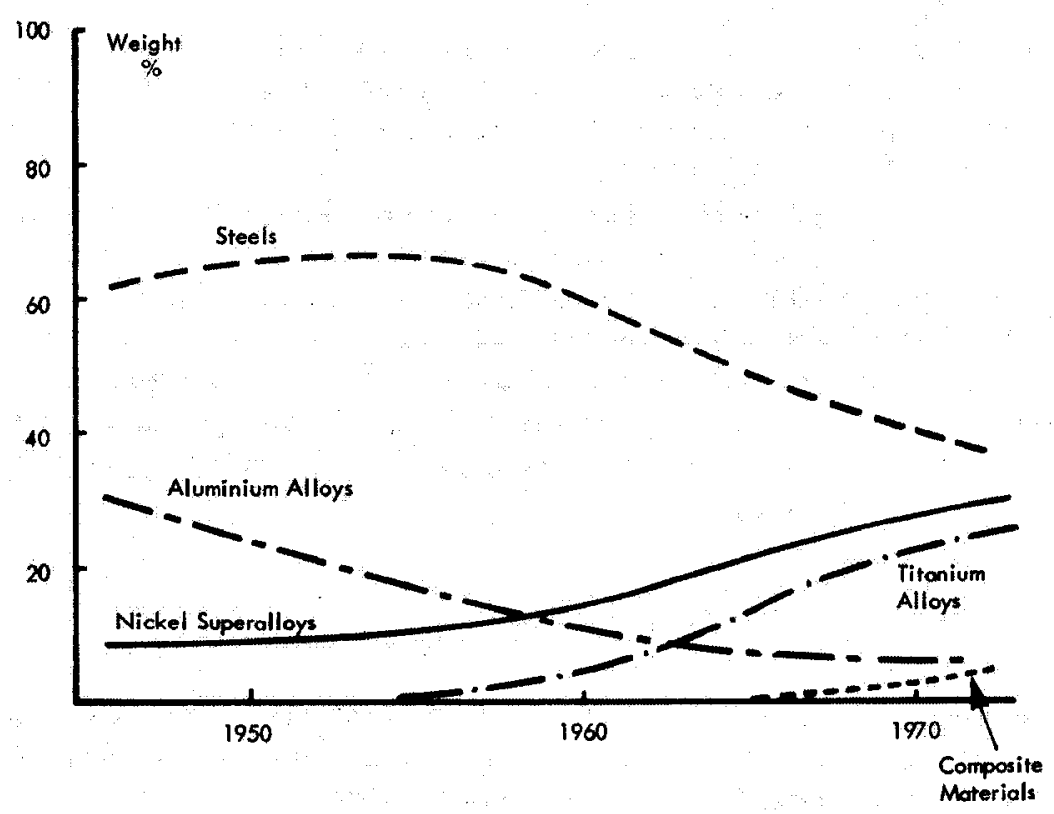

Figure 1: Historical trends in gas turbine materials usage [1]. 


\subsection{The Gas Turbine Engine}

Single stage aircraft gas turbine engines can be simplified and viewed as three main components: compressor, combustor, and turbine. The compressor pressurizes (compresses) a continuous stream of air. This high-pressure air is mixed with fuel in the combustion chamber and combusted, adding energy to the flow. The hot, high-pressure, high-velocity combustion products are expanded through the turbine which extracts energy from the flow to drive the compressor. Thrust is produced by further expansion of the combustion products through an exhaust nozzle. This scenario, which is illustrated in Figure 2, is a simple turbo jet engine. However, this type of engine has reduced propulsive efficiency at lower flight speeds since much of the energy of the high-velocity exhaust gas is dissipated by interactions with the surrounding atmosphere. Thus, modern gas turbine engines utilize multiple stages to allow part of the intake air stream to bypass the core of the engine. Mixing the bypass flow with the hot exhaust gas stream reduces the velocity of the exhaust and improves the propulsive efficiency over a simple turbo jet $[1,2]$. A low bypass ratio, two stage engine is shown in Figure 3. To further increase efficiency, high bypass ratio engines have up to $80-90 \%$ of the intake airflow bypass the core of the engine. In this arrangement, shown in Figure 4, a large fan stage at the front of the engine provides the bulk of the thrust, with the propulsive efficiency being higher because the fan moves a large volume of air at relatively low velocity. This turbofan arrangement allows for lighter engine designs with improved power to weight ratios because only a small portion of the total air stream passes through the engine core. Another type of turbine arrangement is the turboprop engine, where a power turbine is used to drive a propeller through a reduction gear-box. In this type of engine the emphasis is on shaft power rather than engine thrust.

The maximum operating temperature of a gas turbine engine is the major determining factor for engine efficiency and power. Increasing the permissible turbine inlet temperature of the engine increases the specific power output (specific thrust in the case of aircraft propulsion) [2]. Thus, there is a continuous push to increase operating temperature, which 


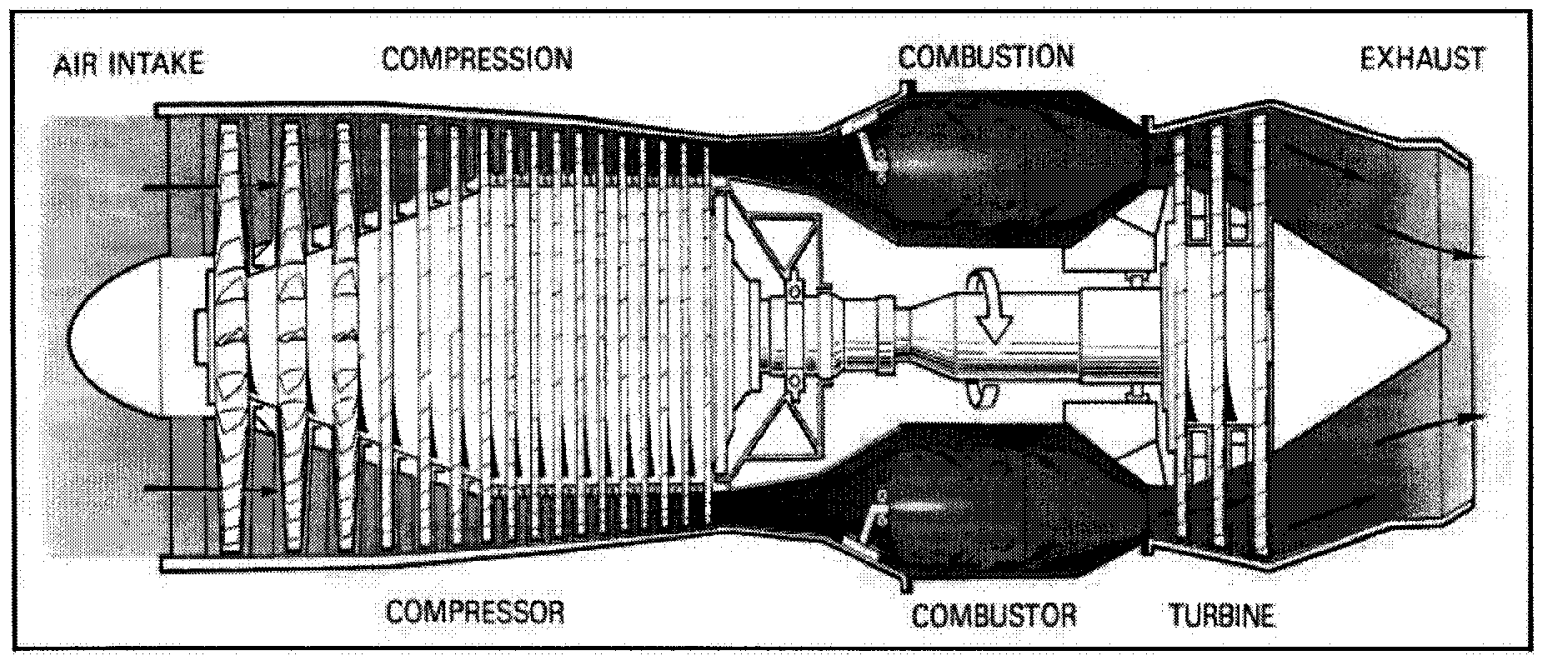

Figure 2: Schematic of a simple turbo jet engine [3].

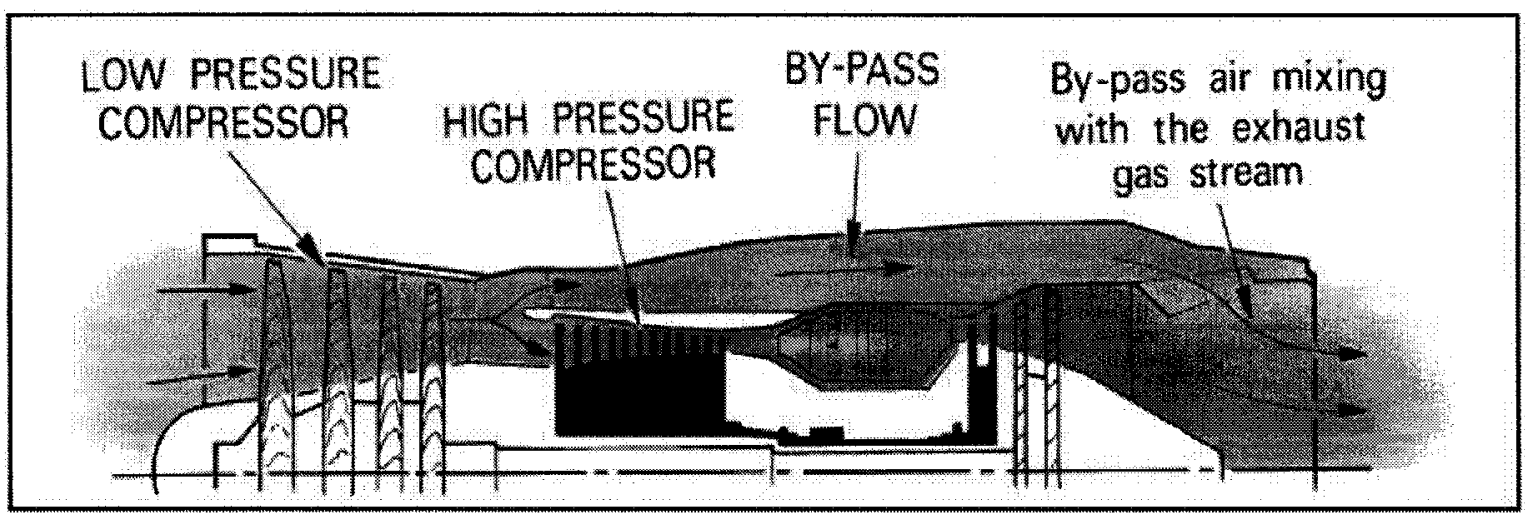

Figure 3: Schematic of a two-stage low bypass turbo jet engine [3].

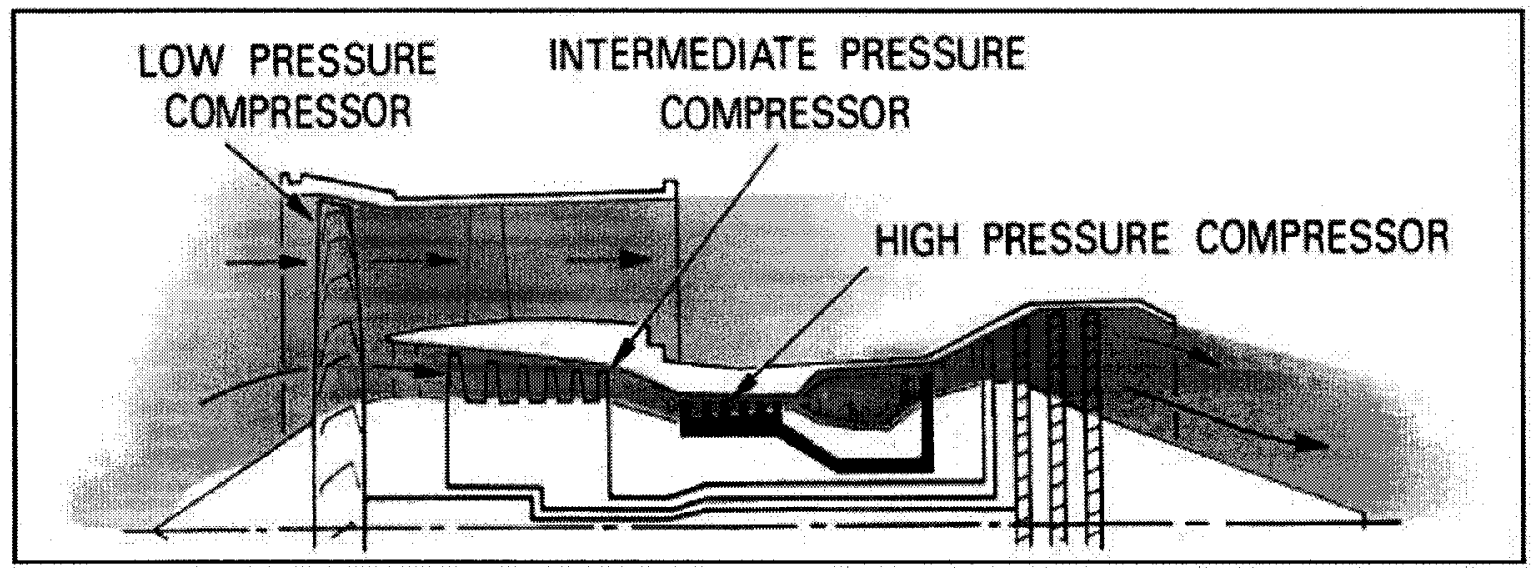

Figure 4: Schematic of a three-stage high bypass ratio turbo fan engine [3]. 
has necessitated the development of materials with higher and higher temperature capabilities. In modern gas turbine engines, where the gas stream temperature can reach $1700^{\circ} \mathrm{C}$, the highest temperatures are experienced by the nozzle guide vanes which direct the gas flow from the combustor to the turbine inlet. However, since these are stationary and are not subjected to the high rotational stresses experienced by the rotating turbine components, it is the rotating turbine blades which experience the most demanding temperature and stress conditions in the gas turbine engine. The design considerations and material choices for gas turbine blades will now be examined in more detail.

\subsection{Turbine Blades and Blade Materials}

The high pressure turbine blade operates under the most arduous conditions of temperature and stress of any component in the engine. The blades experience high temperatures and direct stress with rapid temperature transients at various points in the flight cycle. They exist in a very damaging environment since the hot gases surrounding the blades are highly oxidizing, hot corrosion occurs due to chlorides and sulphates, and wear occurs due to erosive media in the gases (sand, carbon produced in combustion, etc.). Direct stress and temperature gives rise to creep, temperature transients can cause thermal fatigue, and high cycle fatigue can occur if excitations coincide with the natural frequency of the blade. Additionally, the natural frequency will be modified as a consequence of of creep or thermal fatigue cracking in service, and this can lead to final failure of the blade [1].

The increases in turbine entry temperature over the years are due in large measure to the development of blade cooling technology. Convective cooling occurs as the cooling air is pumped through radial passages in the blade, over fins or pedestals, or impinged on the blade inner wall to increase the heat transfer potential. Since metal temperatures must be reduced to a level several hundred degrees below the local gas temperature, there can exist large difference in temperature between the hottest and coolest parts of the blade. The additional thermally induced stresses can aggravate thermal fatigue problems. These 
local surface temperature extremes can be reduced by the use of film cooling techniques, for example air passed through the blade wall via discrete holes to form a film of air on the blade surface.

Nickel base superalloys are currently the only materials possessing the properties required for most turbine blade applications, and they were specifically developed for high temperature use. The common characteristics of these alloys is long-term strength above $650^{\circ} \mathrm{C}$ and resistance to hot corrosion and oxidation. Since their development they have evolved from simple nickel-chromium alloys to complex multi-element, multi-phase systems, with operational capabilities at metal temperatures approaching $90 \%$ of their absolute melting points. The developments and improvements in nickel based superalloy technology has played a major role in increasing the operating temperature of gas turbine engines $[1,4]$.

Turbine blade processing developments have also played a role in increasing the operating temperatures of gas turbine engines. Developments such as single crystal blade casting, and investment casting with integral cooling passages have been instrumental in increasing operating temperatures. Cooled turbine blades can operate in gas temperatures well above the melting temperature of the blade material [1].

Superalloys are excellent high temperature materials, and for most engine applications they are the only material that can fulfil the job requirements. However, since they are relatively heavy alloys, there may exist other materials that are lighter but still possess adequate high temperature capabilities for some applications. $\gamma$-TiAl intermetallics are one such candidate material. 


\section{$1.3 \quad \gamma$-TiAl Turbine Blades}

Gamma titanium aluminides $(\gamma$-TiAl $)$ are a set of candidate high-temperature materials that may be used to replace nickel-based superalloys in some gas turbine engine applications. These materials have good high temperature strength, stiffness, and environmental resistance, with their main advantage being that they are about half the density of traditional nickel based superalloys. Figure 5 shows a plot of specific strength as a function of temperature, and it illustrates the regime where $\gamma$-TiAl alloys could be used to replace nickel based superalloys. Figure 6 shows a plot of specific modulus (stiffness) as a function of temperature for a variety of alloys, and it illustrates that the stiffness of $\gamma$-TiAl alloys is significantly higher than titanium alloys and nickel based superalloys.

The main applications of interest for $\gamma$-TiAl are in the low-pressure turbine blades of high-bypass ratio turbofan engines, and in the power turbine blades of turboprop and turboshaft engines. They can be used in an intermediate temperature range from about 550 to $850^{\circ} \mathrm{C}$. Traditionally these blades are made from nickel based superalloys since the temperatures they encounter are too high for titanium alloys. However, they could be made from $\gamma$-TiAl alloys. Since the design of blades often makes them thicker and heavier than necessary to resist the applied stresses (to minimize deflections, to avoid vibration frequencies, or to maximize aerodynamic efficiencies) lower density is a very desirable material property. $\quad \gamma$-TiAl alloys offer a significant weight advantage over traditional superalloys. In the case of a large engine, the GE90 for example, the weight reduction may be as high as $45 \mathrm{~kg}$ per turbine stage [5] or $136 \mathrm{~kg}$ per engine [6]. This reduction in weight translates into a significant increase in power to weight ratios and payload capacities.

However, there are technical issues which must be overcome before these materials can be put into widespread use. A poor balance of mechanical properties, most notably their low room temperature ductility, as well as the lack of a well developed and economical processing route have precluded the widespread adoption of these materials into production. 
It is thought that these two problems can be solved by using the directional solidification (DS) casting process.

\subsection{Why DS Processing for $\gamma$-TiAl?}

The possibility of producing directionally solidified (DS) $\gamma$-TiAl parts is being explored because it is thought that this processing route can be used to solve the two main problems facing the implementation of these materials into widespread use. These two problems are:

1. the production of a microstructure with a balance of mechanical properties, and

2. the development of an economical processing route for mass production of $\gamma$-TiAl parts.

If these two technical issues can be solved, then $\gamma$-TiAl parts can be used to replace nickel base superalloys in some gas turbine applications.

The DS casting process is well developed for the production of nickel based superalloy turbine blades. Investment casting of $\gamma$-TiAl parts is thought to be the most economical processing route [6], and the DS casting process may be capable of the degree of process control required to develop a microstructure with an adequate balance of mechanical properties [4]. Mechanical properties depend on microstructure, which is defined by processing and material composition. $\gamma$-TiAl forms two typical microstructures: fully lamellar $\left(\gamma / \alpha_{2}\right.$ which has good fracture toughness and creep resistance), and duplex (mix of equiaxed $\gamma$ and lamellar grains, which has good tensile properties). A project to develop Bridgman processing to cast DS TiAl is underway at Carleton University. The target microstructure gives a good balance of properties, with fully lamellar columnar grains, lamellar boundaries parallel to growth direction, and individual grains rotated about longitudinal axis [4]. However, an optimum microstructure is yet to be produced, due in part to the lack of thermophysical data for these new materials. This is mostly due to the lack of understanding of phase transformations that occur during solidification, ie. how do the phases form and what is 


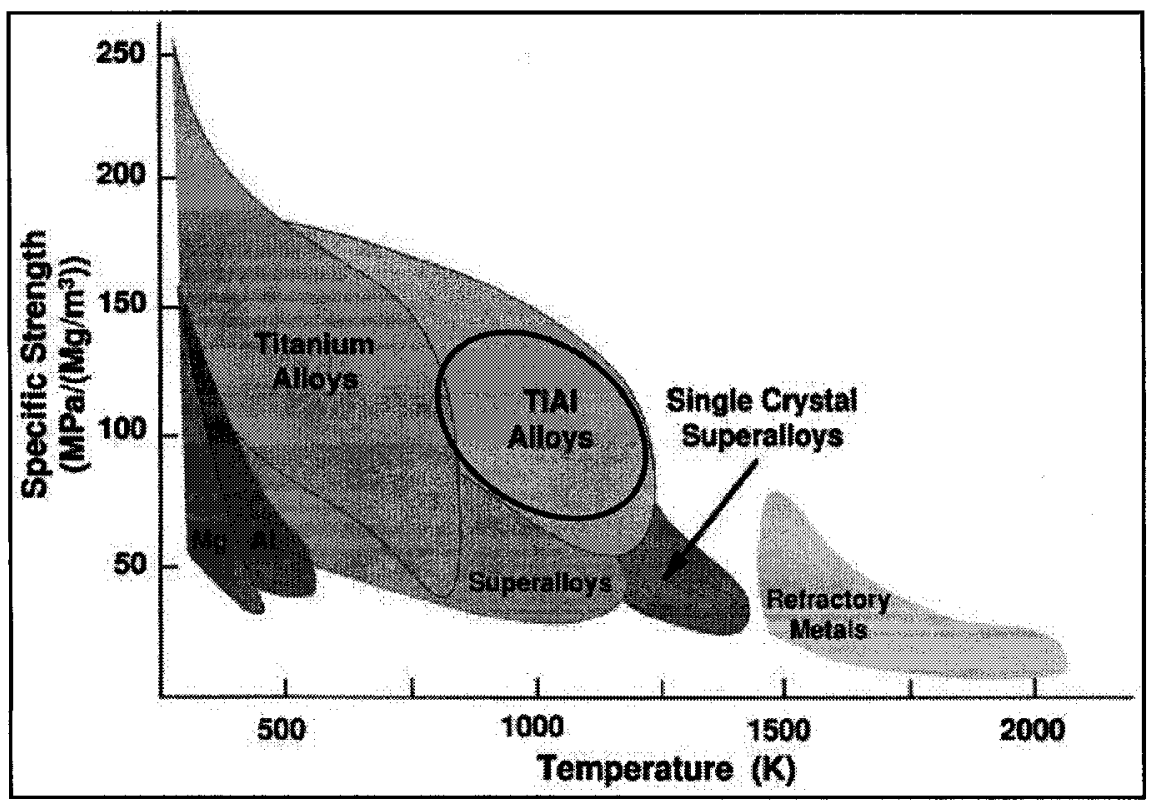

Figure 5: Plot showing the range of specific strength as a function of temperature for a variety of alloy systems. The oval region indicates where $\gamma$-TiAl alloys could replace nickel based superalloys [7].

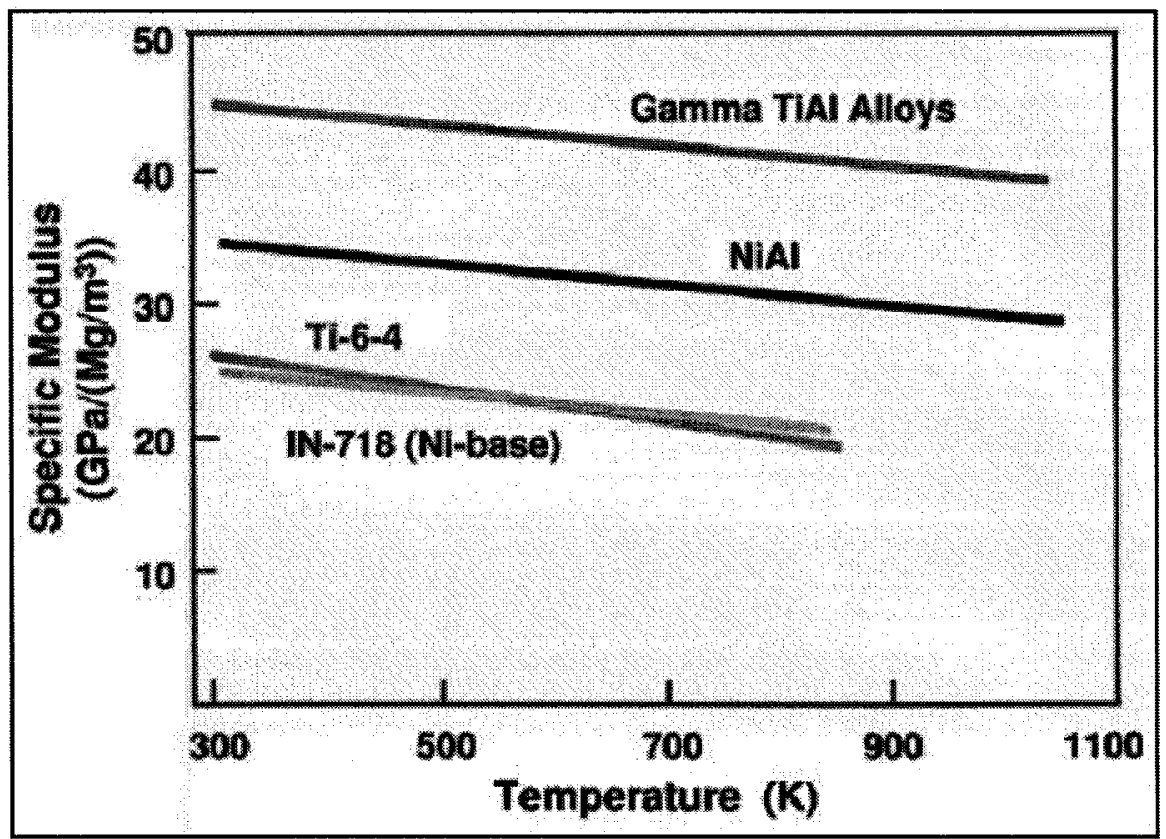

Figure 6: Plot showing specific modulus as a function of temperature for various alloys. The specific modulus of $\gamma$-TiAl alloys is significantly higher than titanium alloys and nickel based superalloys [7]. 
the solidification sequence followed in forming the final room temperature structure.

\subsection{The Need for Improved Thermophysical Data}

Reliable knowledge of thermophysical properties and phase transformations is essential for the interpretation and modelling of high temperature solidification behaviour. To perform a coupled thermal-fluid flow analysis involving a phase change typically requires, as a minimum, thermal conductivity, density, specific heat, solidus $\left(T_{S}\right)$ and liquidus $\left(T_{L}\right)$ temperatures, fraction of solid $\left(f_{S}\right)$, latent heat of fusion $\left(L_{f}\right)$, and viscosity. Some of these thermophysical properties are not readily available for new materials such as titanium aluminide intermetallics. Also, knowledge of the phase transformations that occur during solidification is required to understand the microstructures that form. Thus, the purpose of the current project is to use differential scanning calorimetry (DSC) to find some of the properties of interest as a function of composition.

\subsection{Thesis Objectives and Outline}

Within the scope of the overall research program, this thesis project was initiated with the goal of determining the thermophysical properties and phase transformations of $\gamma$-TiAl intermetallics as a function of alloy composition.

A literature review, consisting of two parts, is provided in Chapters 2 and 3. Chapter 2 reviews the research that has been conducted on $\gamma$-TiAl intermetallics, and specifically the pertinent aspects related to the directional solidification of these alloys for casting into low pressure gas turbine blades. Some of the fundamentals of these alloys are discussed, including alloy phases and microstructures, and mechanisms of solidification. The lamellar microstructure is examined in more detail since it is the structure of interest for cast turbine blades. The reasons for using directional solidification (DS) to cast TiAl parts is next discussed, including the target microstructures to produce castings with the desired 
properties, and the importance of process modelling to the DS casting process. Finally, the thermophysical property requirements for DS casting are outlined. In Chapter 3 the methods for obtaining these thermophysical properties are examined. The fundamentals of thermal analysis are discussed in general terms, including a brief history of the development of thermal analysis and the types of thermal analysis instruments and measurements. Next the thermal analysis techniques which can be used to determine the properties of interest for TiAl, specifically DTA and DSC, are discussed in more detail. Various high temperature calorimetry methods are also outlined. Some thermal analysis experimental factors are detailed next, as well as methods of interpretation of DTA and DSC curves. Finally, thermal analysis considerations for Ti-Al alloys are examined, and an overview of some of the thermal analysis and thermophysical property studies of $\mathrm{Ti}-\mathrm{Al}$ intermetallics that have been reported in the literature is given. The specific objectives of this thesis project are given in Chapter 4. The DSC equipment, materials, procedures, and results are discussed in Chapter 5. Finally, Chapter 6 summarizes the work completed and the conclusions made, and suggestions are made for possible future research. 


\section{Chapter 2}

\section{$\gamma$-TiAl Intermetallics}

This chapter of the literature review outlines some of the research that has been conducted on $\gamma$-TiAl intermetallics, and specifically the pertinent aspects related to the directional solidification of these alloys for casting into low pressure gas turbine blades. To begin, some of the fundamentals of these alloys are discussed including alloy phases and microstructures, and mechanisms of solidification. The lamellar microstructure, which is the structure of interest for cast turbine blades, is explained in more detail, including the mechanical properties of the lamellar microstructure. The reasons for using directional solidification (DS) to cast TiAl parts is next discussed, including the target microstructures to achieve the desired properties, and the importance of process modelling to the DS casting process. Finally, the thermophysical property requirements for DS casting are outlined. The processes for obtaining these thermophysical properties are discussed in Chapter 3.

$\gamma$-TiAl intermetallics are a potential replacement for superalloys and steels in several high temperature structural application in the energy, aerospace and automobile sectors. These materials are being intensively studied because of their low density, high specific strength, high specific stiffness, high temperature strength retention, and resistance to fire. They show potential for replacing heavier nickel-based superalloys in some gas turbine engine structural applications, the most promising of these being low-pressure turbine blades in high bypass ratio turbofan engines. In gas turbine engine applications, the main advantage of using $\gamma$-TiAl is in weight savings, since $\gamma$ based alloys have half the density of 
superalloys and steels, and are about $10 \%$ lighter than titanium alloys. The most favourable properties of these intermetallics are their moduli, which approach those of superalloys at operating temperatures, at half the density. Casting blades using a directional solidification (DS) technique may offer the best processing route for $\gamma$-TiAl, producing a material with a good balance of mechanical properties using an economic manufacturing technique.

\section{$2.1 \quad \gamma$-TiAl Fundamentals}

The $\gamma$-TiAl intermetallics of engineering importance are two-phase alloys with nearly stoichiometric or titanium-rich compositions that contain approximately $45-48$ at.\% $\mathrm{Al}$ and 0.1-8 at. $\%^{1}$ of secondary alloying elements such as $\mathrm{Cr}, \mathrm{V}, \mathrm{Mn}, \mathrm{Nb}, \mathrm{Ta}, \mathrm{W}, \mathrm{Mo}, \mathrm{Si}, \mathrm{C}, \mathrm{P}$, and B. The effects of these alloying additions are listed in Table 1. The two phase $\gamma$ based intermetallics are preferred because of the poor ductility and fracture toughness of the single phase $\gamma$. However, in the two phase alloys there is generally an inverse correlation between tensile properties and resistance to fracture. For this reason, microstructural control is very important in obtaining an optimum blend of properties.

The room temperature mechanical performance of these alloys may be enhanced through alloying with ternary $\beta$ isomorphous additions. For example, second generation $\mathrm{Ti}-\mathrm{Al}-\mathrm{Nb}-\mathrm{X}$ quaternary $\gamma+\alpha_{2}$ alloys were developed to alleviate shortcomings in the first generation alloys, which while retaining excellent elevated temperature specific stiffness exhibited decreased elevated temperature oxidation resistance when compared to binary $\mathrm{Ti}-\mathrm{Al}$ alloys. These second generation alloys have $\mathrm{Mn}$ or $\mathrm{Cr}$ included for enhanced ductility and $\mathrm{Nb}$ for improved strength and oxidation resistance. These newer compositions were primarily developed for investment castings [8].

Figure $7[9]$ shows the binary Ti-Al equilibrium phase diagram with the approximate

\footnotetext{
${ }^{1}$ All subsequent percentages will be given in at.\% unless otherwise noted.
} 
region of interest for $\gamma$-TiAl intermetallics highlighted. ${ }^{2}$ The phases found at room temperature in typical alloy compositions are the ordered face centred tetragonal (FCT) gamma $(\gamma, \mathrm{TiAl})$ and the ordered hexagonal close packed (HCP) alpha-2 $\left(\alpha_{2}, \mathrm{Ti}_{3} \mathrm{Al}\right)$. These crystal structures, as well as some of the important crystallographic planes and directions, are illustrated in Figure 8 [10]. In addition to the $\gamma$ and $\alpha_{2}$ phases, the body centred cubic (BCC) beta $(\beta)$ and ordered BCC (B2) can also be formed by addition of $\beta$-stabilizers. As can be seen from the phase diagram, the phases formed are very dependent on composition. That is, very small changes in Al levels have a significant impact on the fraction of each phase formed. For a given composition a variety of two-phase microstructures can be developed by applying different processing routes and/or heat treatments.

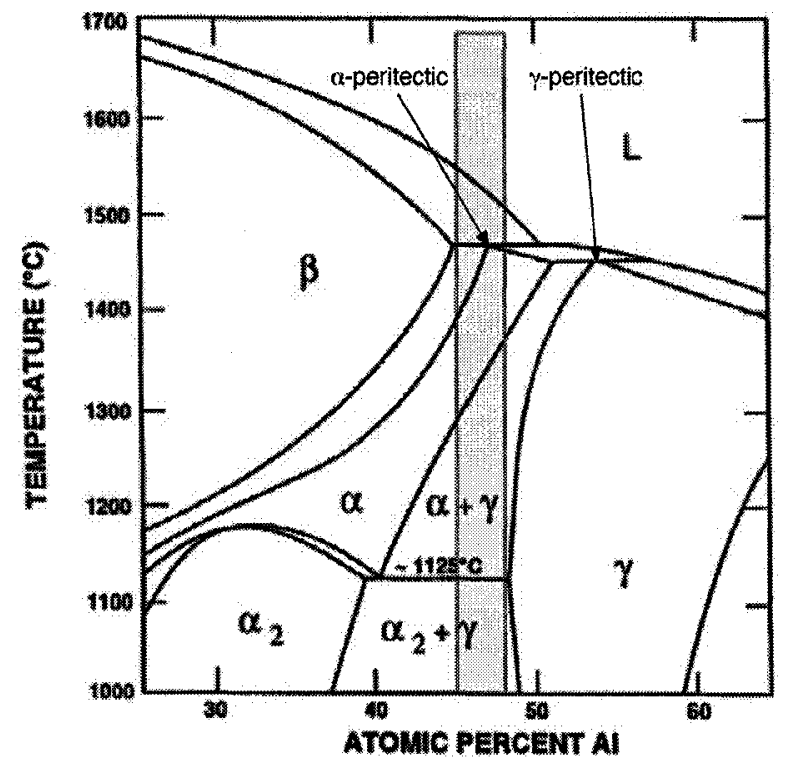

Figure 7: Part of the binary Ti-Al equilibrium phase diagram [9].

Two typical microstructures, fully lamellar and duplex, are illustrated in Figure 9 [12].

\footnotetext{
${ }^{2}$ At present there are a number of versions the the Ti-Al binary phase diagram available. Figure 7 has been taken as the "correct" Ti-Al binary phase diagram for this thesis. See Appendix A for additional Ti-Al binary phase diagrams.
} 


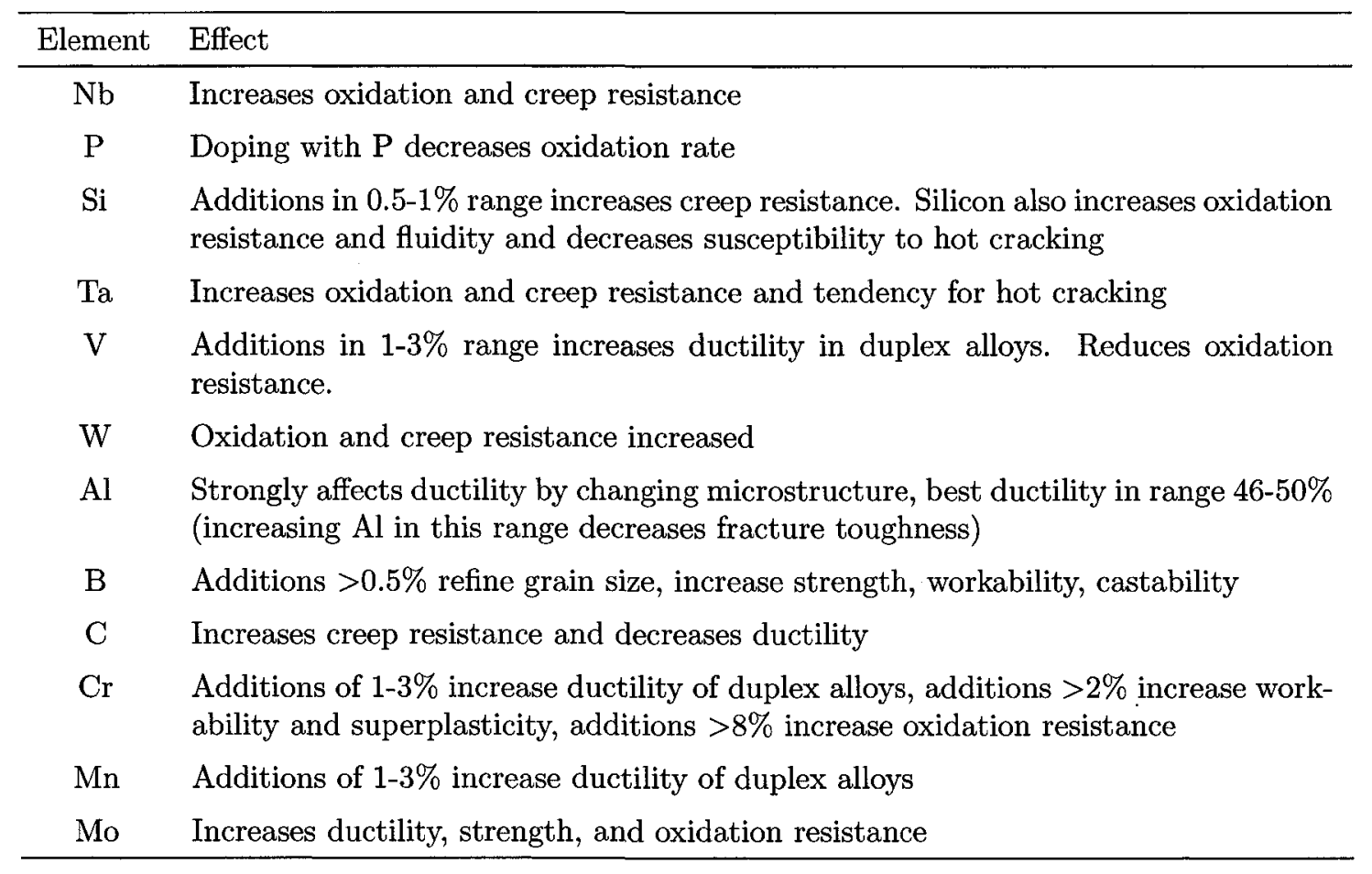

Table 1: The effects of selected alloying elements in $\gamma$-TiAl alloys [11].

As cast alloys generally exhibit a polycrystalline fully lamellar microstructure, which consists of grains with alternating layers of $\gamma$ and $\alpha_{2}$ plates of different crystallographic orientations. If this cast alloy is subsequently heat-treated or worked in the $\alpha+\gamma$ two-phase region, the fully lamellar microstructure is destroyed and a duplex microstructure, a fine mix of equiaxed $\gamma$ and lamellar grains, is formed. These two different microstructures result in materials with very different mechanical properties. Generally, duplex microstructures provide good tensile strength and ductility, while fully lamellar microstructures have poor ductility but better fracture toughness, fatigue resistance, and high-temperature creep strength. For this reason, the cast fully lamellar microstructure is more suitable for high temperature service, and has attracted more interest in the gas turbine industry. The solidification structures, specifically the formation of the lamellar microstructure, will now be discussed in more detail. 


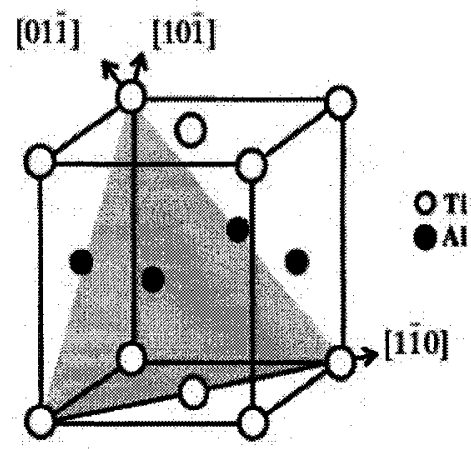

(a) FCT Y

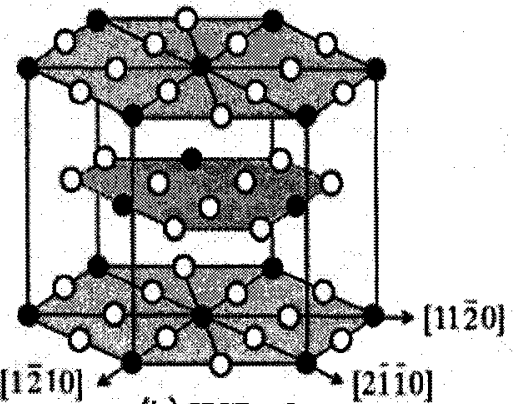

(b) HCP $\alpha 2$

Figure 8: Schematics showing the crystallographic structures of the (a) FCT $\gamma$ TiAl and the (b) HCP $\alpha_{2} \mathrm{Ti}_{3} \mathrm{Al}$ phases [10]. The (111) plane is shaded in the FCT structure while the (0001) planes are shaded in the HCP structure [10].

\subsubsection{Solidification Structures}

The lamellar microstructure is formed during cooling, after solidification, and can be explained with reference to the binary phase diagram (Figure 7). Note that the solidification path followed is very dependent on composition, and the solidification paths discussed below are only valid for equilibrium conditions. For alloy compositions up to about $49 \%$ $\mathrm{Al}$ content, $\beta$ is the primary solidification phase. Because $\beta$ is BCC, these alloys exhibit the four-fold dendrite symmetry that is expected of cubic materials, as can be seen in Figure 10(a). With reference to the phase diagram, the typical solidification sequences during cooling from the liquid (L) phase are: $L \rightarrow \beta+L \rightarrow \alpha \rightarrow \alpha+\gamma \rightarrow \alpha_{2}+\gamma$ or $L \rightarrow \beta+L \rightarrow \alpha+\beta \rightarrow \alpha \rightarrow \alpha+\gamma \rightarrow \alpha_{2}+\gamma$. The lamellar microstructure forms by the nucleation and growth of the $\gamma$ phase during cooling within the $\alpha+\gamma$ phase field. This occurs below the alpha transus temperature, $T_{\alpha},\left(\alpha \rightarrow \alpha+\gamma \rightarrow \alpha_{2}+\gamma\right)$. The $\gamma$ phase precipitates from the $\alpha$ phase producing a lamellar structure of transformed $\gamma$ and the remaining $\alpha$. Upon cooling below the eutectoid, $\alpha \rightarrow \alpha_{2}+\gamma$, additional $\gamma$ phase is formed by the thickening of existing $\gamma$ lamellae or by the creation of new $\gamma$ lamellae. The ordering of $\alpha$ to $\alpha_{2}$ generally occurs after the formation of the lamellar structure. However, for alloys with a lower $\mathrm{Al}$ content $(<40 \%)$ ordering occurs before the formation of the lamellar structure, ie. $\alpha \rightarrow \alpha_{2} \rightarrow \alpha_{2}+\gamma$. Thus, for alloys up to 
about $\mathrm{Ti}-49 \mathrm{Al}$, the final structure consists of mostly $\gamma$ lamellae, with a small volume fraction of $\alpha_{2}$ lamellae. In contrast, alloys with higher Al content (>49\%) solidify with the hexagonal $\alpha$ as the primary solidification phase. For this reason, these alloys exhibit the six-fold dendrite symmetry that is expected of hexagonal materials, as can be seen in Figure 10(b). The typical solidification sequence followed during cooling for these alloys is: $L \rightarrow \alpha+L \rightarrow \alpha+\gamma \rightarrow \gamma \rightarrow \alpha_{2}+\gamma$. The lamellar microstructure forms as described above.

For non equilibrium conditions, with more rapid cooling, solidification of TiAl will be affected by several peritectic reactions. The effect of these peritectics is discussed in more detail in the next section.

\subsubsection{Peritectic Reactions and TiAl Peritectics}

A peritectic reaction is a type of invariant reaction. It is an isothermal reversible reaction in which a liquid and solid phase of fixed proportions react to form a single, different, solid phase upon cooling. Examples of peritectic reactions in the TiAl system are the $\beta+L \rightarrow \alpha$ and the $\alpha+L \rightarrow \gamma$ transformations. The primary solidification path shifts from $L \rightarrow \beta$ to $L \rightarrow \alpha$ and $L \rightarrow \gamma$ with increasing Al content, with the compounds containing less than about $49 \% \mathrm{Al}$ showing four-fold symmetry dendritic structures, and those containing more than about $49 \% \mathrm{Al}$ showing six-fold symmetry dendritic structures. The peritectic reaction of the $\alpha$ phase occurs at dendrite edges of the primary $\beta$ phase. However, both the dendrite core and dendrite edges transform into the lamellar structure with alternating $\alpha$ and $\gamma$ plates in the course of cooling through the $(\alpha+\gamma)$ two-phase field. This appears to make it difficult to distinguish the peritectic reaction. The peritectic compositions of $\alpha_{p}$ and $\gamma_{p}$ are at about $47(46.7$ at.\% Al) and 54 at\% Al respectively [13]. For example, for alloys near the $\beta+L \rightarrow \alpha$ peritectic (near Ti-46.7Al compositions), non equilibrium solidification is impacted by this peritectic. Near Ti-54Al, the $\alpha+L \rightarrow \gamma$ peritectic will also affect non equilibrium solidification. 

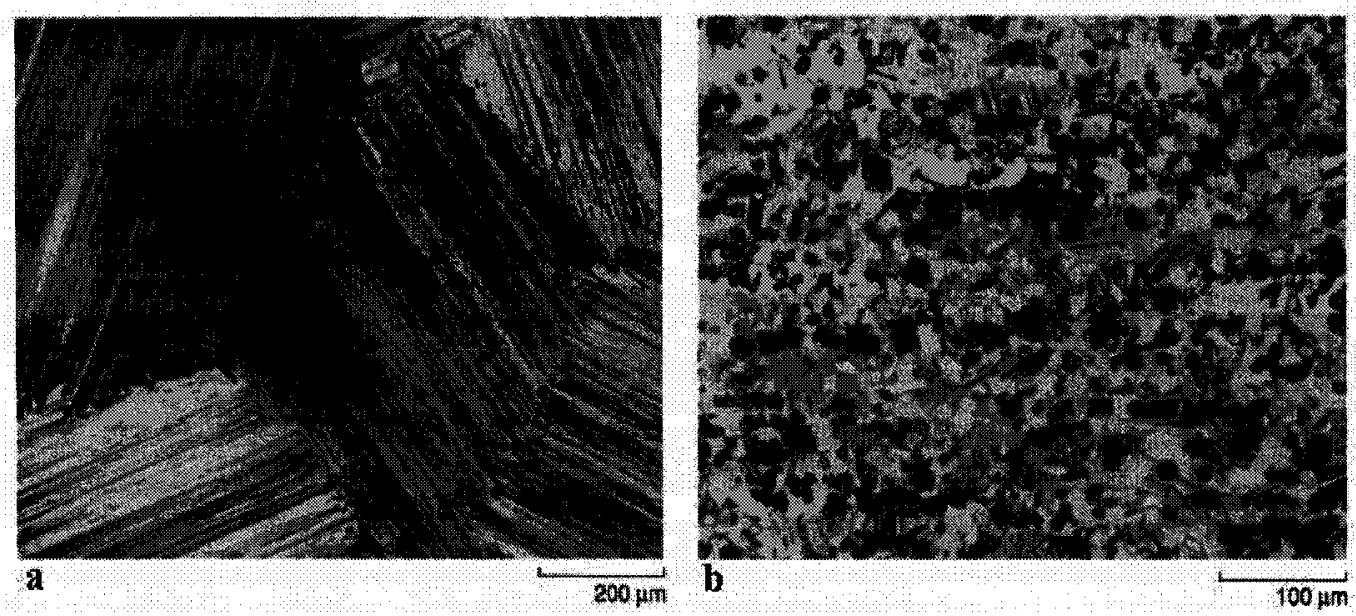

Figure 9: Two typical $\gamma$-TiAl microstructures: (a) fully lamellar and (b) duplex [12].
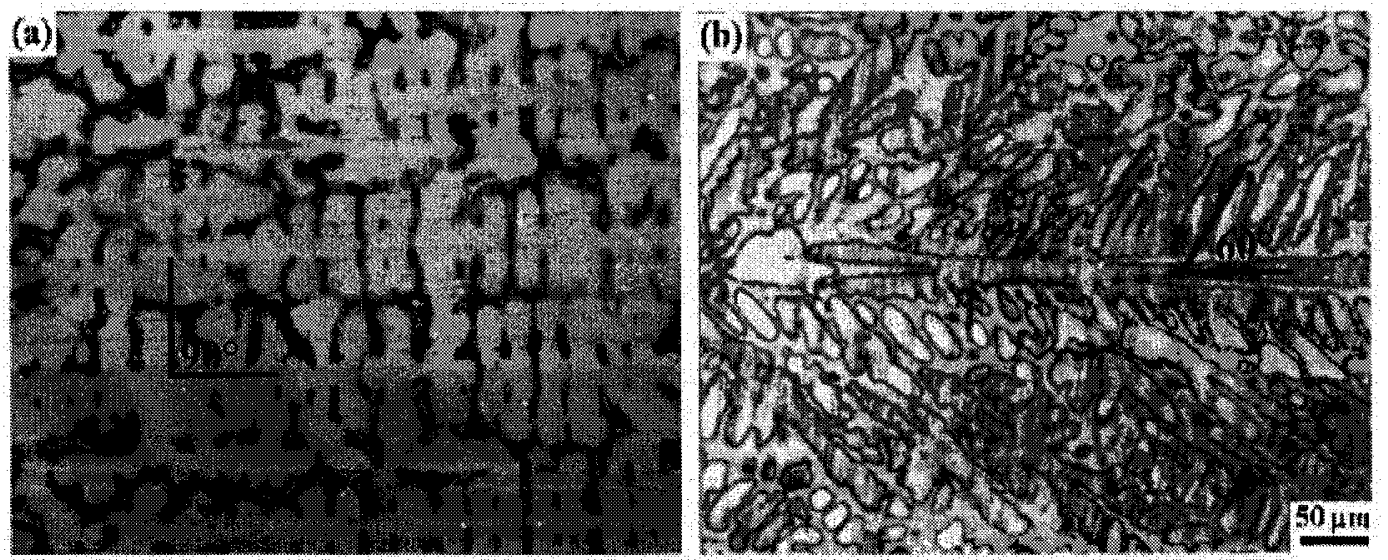

Figure 10: Optical micrographs showing the growth morphology of (a) cubic dendrites (Ti-44Al) and (b) hexagonal dendrites (Ti-52Al) [14].

\subsubsection{Crystallography and Mechanisms of Formation}

As mentioned previously, the dominant phases present of TiAl temperature are the ordered face centred tetragonal $\left(L 1_{0}\right) \gamma$ phase (Figure $8(\mathrm{a})$ ) and the ordered hexagonal close packed $\left(D 0_{19}\right) \alpha_{2}$ phase (Figure $\left.8(\mathrm{~b})\right)$. The $\gamma$ phase has lattice parameters varying with composition in the ranges $a=0.4015-0.3975 \mathrm{~nm}$ and $c=0.4062-0.4097 \mathrm{~nm}$. This slight tetragonality in the $\gamma$ structure is important to note for the discussion to come. The $\alpha_{2}$ phase has lattice parameters varying with composition in the ranges $a=0.5783-0.5640 \mathrm{~nm}$ and $c=0.476-0.4691 \mathrm{~nm}$. 
While it is common for metallic systems to transform from fcc $\rightarrow$ hep on cooling, the reverse transformation from hcp based structures $(\alpha)$ to fcc based structures $(\gamma)$ is rare [11]. Precipitation of $\gamma$ in both $\alpha$ and $\alpha_{2}$ follows the Shoji-Nishiyama orientation relationship which means that $\{111\}_{\gamma} \|(0001)_{\alpha_{2}}$, and $\langle 1 \overline{1} 0\rangle_{\gamma} \|\langle 11 \overline{2} 0\rangle_{\alpha_{2}}$. This was shown by Blackburn in 1970 [15]. The lamellar structure results because the close packed planes and directions, as well as the precipitating $\gamma$ plates, are all parallel to one another. As shown in Figure 11, the $\alpha$ hcp structure forms with the (0001) planes perpendicular to the direction of growth. The (111) planes of the fet $\gamma$ phase then form on the (0001) hcp planes. This produces parallel $\alpha$ and $\gamma$ lamellae. However, because of the tetragonal nature of the $\gamma$ phase, as illustrated in Figure 12, the [110] direction is not equivalent to the [011] and the [101] directions. Because of this, there are six possible orientations for the [110] direction of $\gamma$ with respect to the $\langle 11 \overline{2} 0\rangle$ directions in $\alpha$. Thus, six different types of ordered domain are formed corresponding to the six possible orientations of $\langle 011]$ on (111) in the $\gamma$ phase with respect to $\langle 0211\rangle$ on (0001) in the $\alpha$ phase $[15,11]$. In addition to the $\alpha / \gamma$ lamellar boundaries, $\gamma / \gamma$ lamellar domain boundaries form when $\gamma$ lamellae impinge on other $\gamma$ lamellae. This creates an ordered domain structure with various orientation relationships between the neighbouring $\gamma$ domains. Depending on the atomic stacking sequence in these adjacent $\gamma$ lamellae, there are three possible types of invariant boundaries that may form:

- $\gamma / \gamma$ true-twin domain boundaries (twin variant)

- $\gamma / \gamma$ pseudo-twin domain boundaries (twin variant)

- $\gamma / \gamma 120^{\circ}$ rotational order-fault domain boundaries (twin variant)

Ordered domains also coexist within each of the $\gamma$ lamellae but these are only of the $\gamma / \gamma 120^{\circ}$ rotational order-fault type. As shown in the TEM micrograph of the lamellar microstructure (Figure 13), the $\gamma / \gamma$ lamellar domain boundaries are flat and parallel, while the domain boundaries within the $\gamma$ lamellae do not have any preference for certain crystallographic plains [15]. A schematic microstructure is shown in Figure 14. 


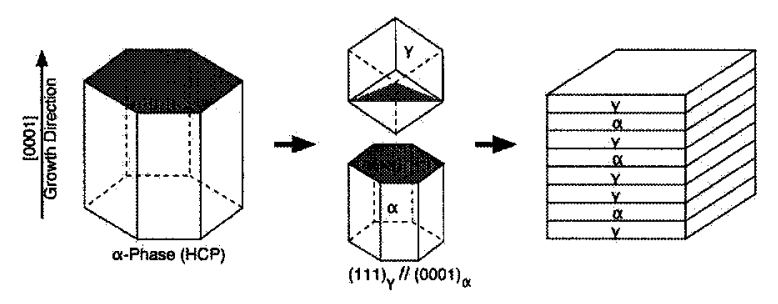

Figure 11: Lamellar orientation formation of $\gamma$ phase on $\alpha$ phase, adapted from [15].
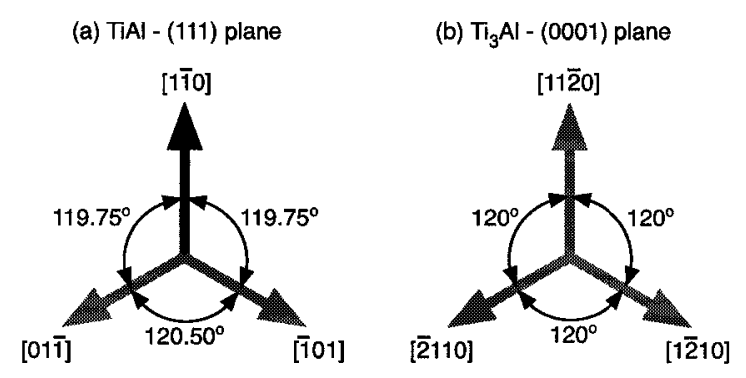

Figure 12: The fct nature of $\gamma$ phase means that the [110] direction is not

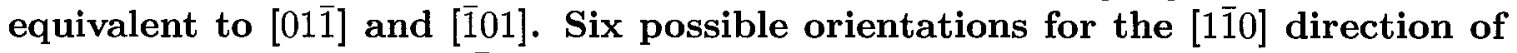
$\gamma$ with respect to the $\langle 11 \overline{2} 0\rangle$ directions in $\alpha$ are possible, adapted from [15].

\subsubsection{Lamellar Microstructure and Mechanical Properties}

As previously discussed, the fully lamellar microstructures have poor ductility but better fracture toughness, fatigue resistance, and high-temperature creep strength than duplex structures. For this reason, this microstructure is more suitable for high temperature service, and has attracted more interest in the gas turbine industry. Extensive research has been directed at characterizing the microstructural features of the fully lamellar microstructure and its fundamental mechanical properties. Specifically, much research has been carried out using polysynthetically twinned (PST) crystals. PST crystals consist of a single columnar grain with a unique lamellar orientation. These studies have demonstrated that mechanical properties are determined by the lamellar orientation with respect to the loading axis and microstructural variables such as grain size, thickness and spacing of the $\gamma$ and $\alpha_{2}$ lamellae, and $\gamma$ domain size. However, the single largest influence is from the angle, $\phi$, between the lamellar orientation and the loading axis, as shown in Figure 15 [10]. 


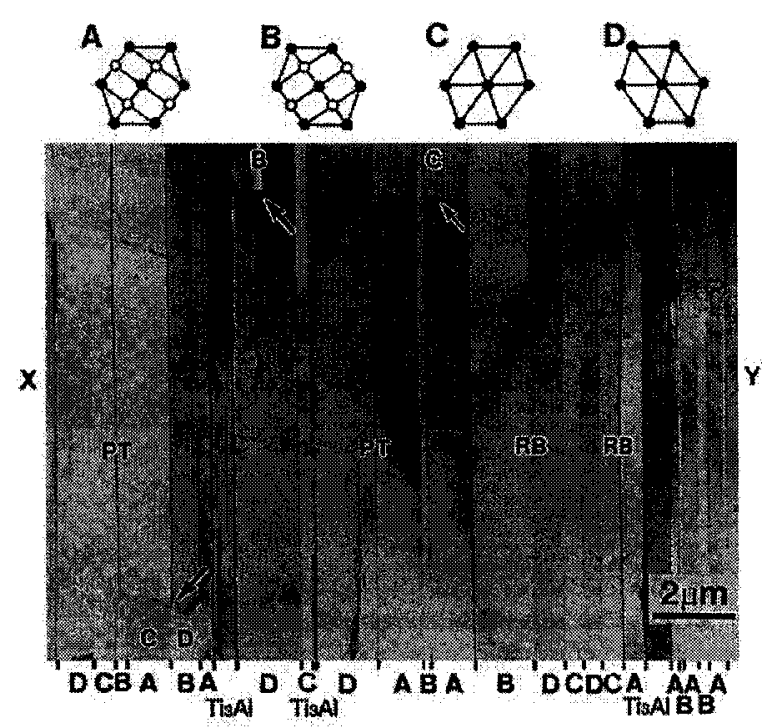

Figure 13: A TEM micrograph showing lamellar microstructure of a $\gamma$-TiAl PST crystal [16].

The dependence of yield strength and ductility on $\phi$ is shown in Figure 16. This plot shows that a good balance of strength and ductility occurs when $\phi=0^{\circ}$ (parallel orientation), and the highest strength and lowest ductility occurs when $\phi=90^{\circ}$ (normal orientation). These two orientations are said to give "hard mode" deformation. Intermediate values of $\phi$ (30 to $60^{\circ}$, angle orientation) give low strength and high ductility, or "soft mode" deformation. This dependence of strength on $\phi$ is due to the dislocation interaction between the various inter-phase boundaries in the lamellar structure. The soft mode is mainly shear deformation in the $\gamma$ phase parallel to the lamellar boundaries and only the $\gamma / \gamma 120^{\circ}$ rotational order-fault domain boundaries can resist deformation. The hard mode is mainly shear deformation on planes that intersect the lamellar boundaries so $\alpha / \gamma$ lamellar boundaries and all three types of domain boundaries can resist deformation. Thus, both modes of deformation can be explained in terms of the Hall-Petch relationship $[10,15,17]$ in that the mean free path of dislocations is much shorter in the hard mode than in the soft mode.

Other mechanical properties (fracture toughness, fatigue resistance, and hightemperature creep strength) also depend on the morphology and orientation of the lamellar 


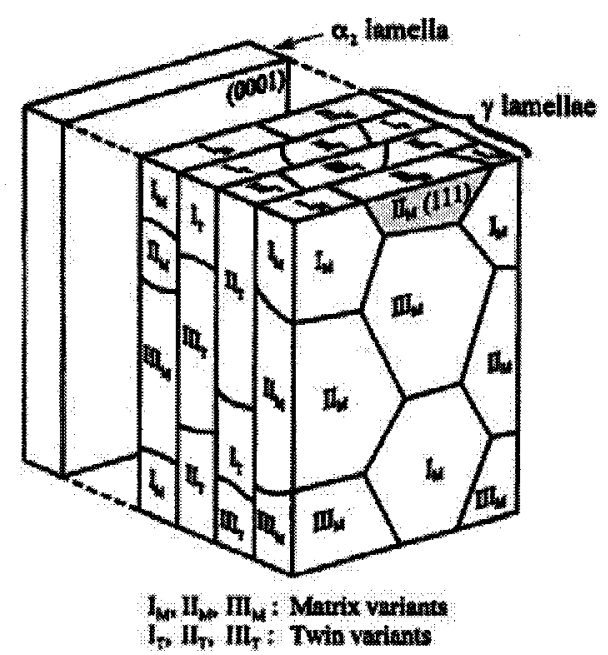

Figure 14: A schematic illustration of the two-phase $\gamma / \alpha_{2}$ lamellar microstructure of the $\gamma$-TiAl alloys showing the relationships between different matrix and twin variants $[15]$.

boundaries. Fracture toughness is dependent on lamellar grain size, spacing, and the orientation between the crack growth plane and the lamellar boundaries [15,18]. With regards to lamellar grain size, it is possible to increase toughness by increasing grain size, but this also leads to a decrease in ductility. However, toughness and ductility could be balanced in a lamellar structure of refined lamellar grains, since even an order of magnitude decrease in grain size causes a relatively small decrease in fracture toughness. A finer lamellar spacing increases toughness because the lamellar boundaries act as barriers to crack propagation, but it is important to consider the orientation of the crack with respect to the lamellar boundaries. Figure 17 shows three crack orientations. In the crack delamination orientation, Figure 17(a), failure occurs in a cleavage-like mode along planes parallel to the lamellar boundaries and thus this orientation has low fracture toughness. In the crack divider (Figure 17(b)) and the crack arrester (Figure 17(c)) orientations, the fracture surfaces are much rougher and the fracture toughness is higher due to toughening mechanisms like crack tip branching. Fatigue resistance and high temperature creep strength are dependent on $\phi$ in a manner similar to the yield strength. For fatigue, specimens with $\phi=0^{\circ}$ have higher fatigue strength than specimens with $\phi=45^{\circ}$, and finer lamellar spacing leads to longer fatigue life $[19,20,21]$. Similarly for creep, specimens with $\phi=0^{\circ}$ are considered stronger 
than specimens with $\phi=45^{\circ}$, and finer lamellar spacing leads to a decrease in both primary and secondary creep rate $[22,23,24,25,26]$. Grain size can also be decreased to increase ductility, down to $100 \mu \mathrm{m}$, without adversely affecting the creep strength [4].

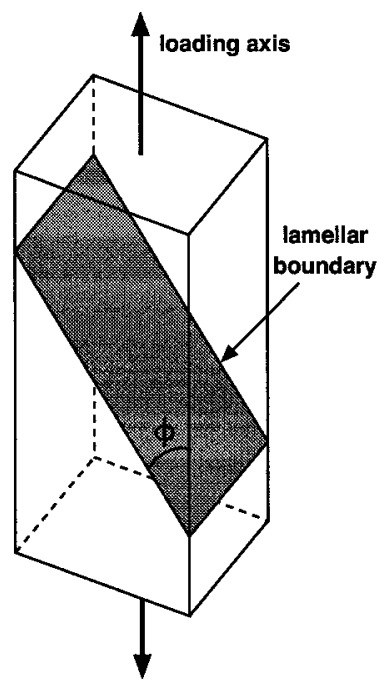

Figure 15: Schematic illustrating the angle, $\phi$, between the lamellar orientation and the loading axis, adapted from [10].

\subsection{Why DS Processing}

From the review in the previous section of the mechanical properties of fully lamellar microstructutres (from research that has been carried out on PST crystals), it can be seen that a good balance of mechanical properties requires a relatively fine-grained structure with fine lamellar spacing and lamellae oriented parallel to the loading axis. This type of microstructure can be expected to give a good combination of room temperature strength and ductility, fracture toughness, fatigue resistance, and high-temperature creep strength. From these requirements, a target microstructure has been proposed, see Figure 18, which is expected to exhibit a good balance of mechanical properties. This microstructure is characterized by $[27,28]$ :

- Columnar grains, with each grain having a fully lamellar microstructure

- $\gamma / \alpha_{2}$ and $\gamma / \gamma$ lamellar boundaries parallel to the main stress axis $\left(\phi=0^{\circ}\right)$ 


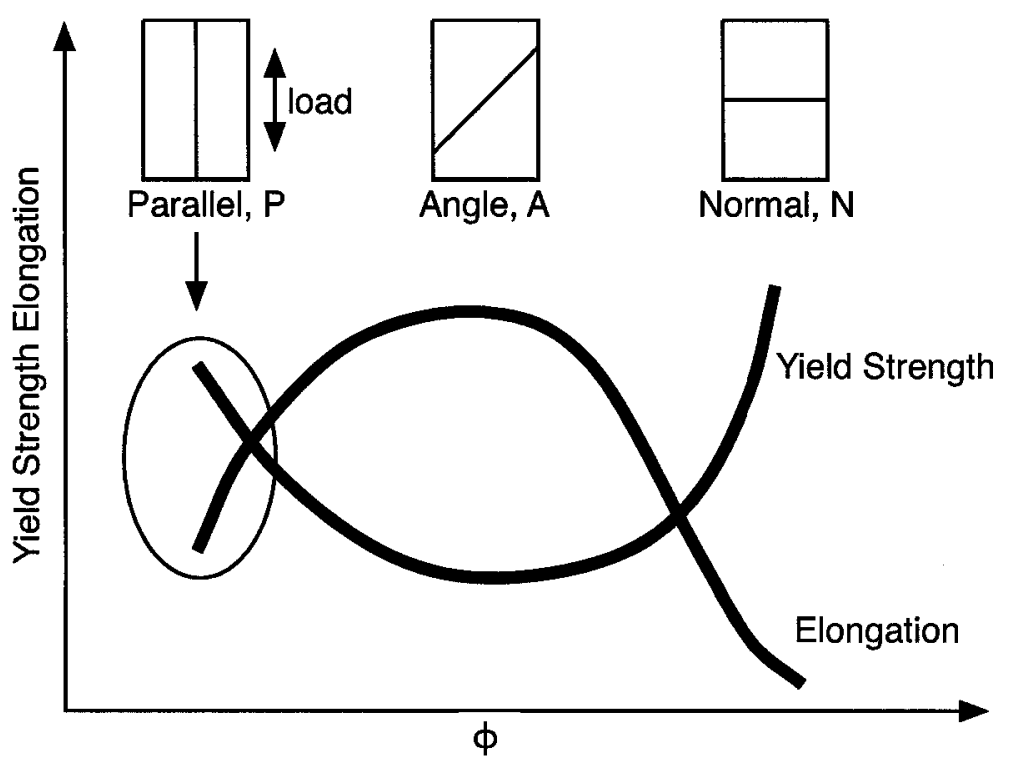

Figure 16: Yield strength and ductility plotted as a function of the angle $\phi$ between lamellar boundaries and the loading axis for binary PST crystals, adapted from $[17]$.

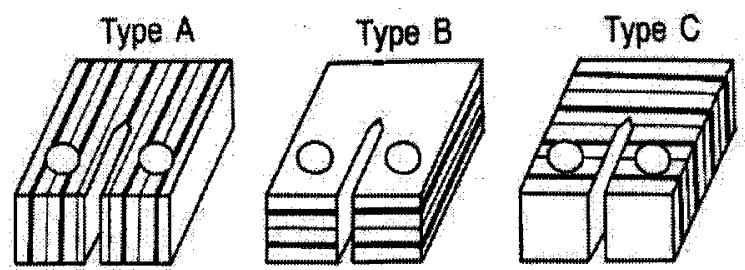

Figure 17: Schematic representation of three possible orientations of a crack with respect to the lamellar boundary orientation: (a) crack delamination, (b) crack divider, and (c) crack arrester [18].

- Individual grains slightly rotated about their longitudinal axes to provide off-axis fracture toughness

The DS casting technique is an obvious choice for producing this type of columnar microstructure, particularly for turbine blade applications. Thus far, DS processing of $\gamma$-TiAl alloys has produced structures with fully lamellar columnar grains oriented in the growth direction. The more difficult task has been aligning the lamellar orientation within each grain to the growth direction, since the fully lamellar microstructure forms during solidstate transformations on cooling, and not directly from the liquid phase during solidification. 
However, some promising research demonstrates that aligning the lamellar microstructure to the growth direction may be possible [4].

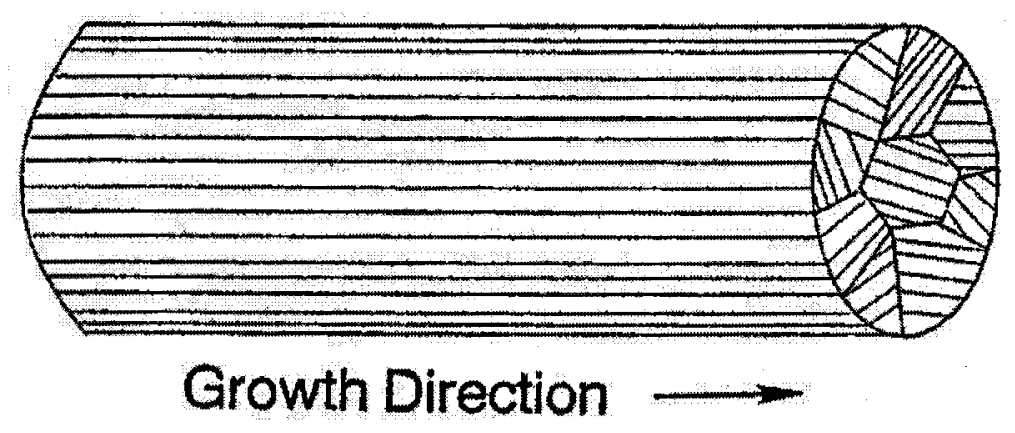

Figure 18: The target microstructure for $\gamma$-TiAl alloys for turbine blade applications. This microstructure should exhibit a good balance of mechanical properties [27].

\subsubsection{DS $\gamma$-TiAl Solidification Microstructures}

The quality of the DS casting is dependent on lamellar orientation and also on the microstructures and defects that form during solidification. However, since the technology associated with the $\gamma$-TiAl alloys is relatively new, the metrics used to quantify as-cast microstructure and defects are not fully developed. Because of the solid-state phase transformations that form the lamellar microstructure, cooling conditions also have a significant role in determining the final as cast microstructure. For this reason, the production of quality DS $\gamma$-TiAl castings requires detailed knowledge of the relationships between microstructure and defect formations and the pertinent solidification conditions: temperature gradient at the solidification interface, solidification rate, solidification interface morphology, and subsequent cooling conditions.

\subsubsection{The Importance of Process Modelling}

The DS casting process is very complex, involving coupled physical phenomena such as heat transfer, fluid flow, thermal stress, and the phase transformation kinetics of nucleation and growth. Additionally, as discussed above, the microstructures and defects that form during casting are controlled by the solidification conditions such as temperature gradient, 
solidification rate, and solidification interface shape. These solidification conditions are themselves dependent on numerous process parameters (including mold design, metal and mold temperatures, furnace temperature, and withdrawal rate) [4]. Due to this complexity in casting, process modelling techniques are often employed to simulate the heat transfer in castings to relate process parameters, solidification conditions and casting quality.

The advantage of process modelling, which simulates heat transfer features including temperature gradients, solidification rates, and isotherm shapes, is that it allows the evaluation of the effects of process parameters on the quality of castings without having to physically make the castings. Thus, process parameters can be modified until a suitable set is found. This analysis can be carried out using either analytical or numerical techniques, although complex processes such as DS casting of turbine blades require the use of numerical techniques such as the finite difference method (FDM) or the finite element method (FEM).

It is outside the scope of this thesis to discuss process modelling in more detail, except to note the importance of thermophysical properties in process modelling.

\subsubsection{Thermophysical Property Requirements for Process Modelling}

To correctly solve the heat transfer equation, accurate knowledge of a number of thermophysical properties is required. These properties include: thermal conductivity, density, specific heat, solidus and liquidus temperatures, latent heat of fusion, and fraction of solid. Computer models are now at the stage where one of the prime requirements for producing reliable models is accurate and reliable data.

For newer alloys like $\gamma$-TiAl intermetallics, these thermophysical properties are not available. This lack of reliable data reflects the complications that arise when working with reactive alloys at high temperatures. When working with these alloys, the only information available is often the alloy composition and its melting range. When this is the case, it is possible to make estimates from the available data for the parent metal of the alloy or 
for similar alloys, as is often done when modelling superalloys. It is fairly common to use this method, and many of the models published in literature use this approach [4]. Of course, it would be more appropriate and accurate to measure these properties directly for each alloy using thermal analysis techniques such as differential thermal analysis (DTA) or differential scanning calorimetry (DSC) $[29,30]$. These techniques are discussed in more detail in the next chapter. In addition to accurately measuring these properties, it is also important to take into account their temperature dependence, since using constant values can lead to erroneous results.

In previous research carried out at Carleton University, a ProCAST ${ }^{\circledR}$ model was developed that is capable of accurately simulating the thermal conditions that occur during Bridgman processing of high temperature alloys, specifically $\gamma$-TiAl intermetallics [4]. During validation of the model, sensitivity studies were carried out by varying certain key model parameters to determine the effects on simulation results. The parameters studied included interface heat transfer coefficients as well as some thermophysical properties. It was found that varying the thermophysical properties had a significantly larger effect on the simulation results than did varying the interface heat transfer coefficients. Based on the results of these sensitivity studies it was determined, for this model at least, that it is more critical to ensure that accurate thermophysical properties are employed, rather than focusing on interface heat transfer coefficients. This research illustrates the importance of reliable, accurate thermophysical property data on simulation results. Thus, to ensure the accuracy and value of casting simulation results, reliable temperature dependent thermophysical property data is required.

\subsection{Summary}

The efficiency and power output of gas turbine engines increase with operating temperature. Thus, there is a continuing push for high temperature light-weight materials to improve gas turbines, particularly for aerospace engine applications. For applications such as gas 
turbine blades, which must withstand an extremely arduous environment - with high temperatures, stresses, creep, thermal and high-cycle fatigue, oxidation and corrosion directionally solidified and single crystal nickel based superalloys are the only materials that can be used. However, there is a large weight penalty associated with these high temperature materials. For this reason, lighter materials such as $\gamma$-TiAl intermetallics are of interest to replace superalloys some engine applications, such as low pressure gas turbine blades.

$\gamma$-TiAl intermetallics have good high temperature strength, stiffness, and environmental resistance, with their main advantage being that they are about half the density of traditional nickel based superalloys. However, two main problems must be overcome before these materials can be used in large scale production: a microstructure must be developed to give a good balance of mechanical properties to overcome problems with low room temperature ductility, and a well developed processing procedure must be developed that makes it economical to produce large numbers of $\gamma$-TiAl parts. Based on previous research, it is thought that both of these problems can be solved using directional solidification (DS) casting. Previous research at Carleton University looked at developing a pilot scale industrial process to cast DS TiAl. Numerical process modelling is important to this process since it helps to better understand relationships between casting parameters, solidification conditions, and microstructure formation. However, reliable thermophysical properties are essential for interpretation and modelling of high temperature alloy solidification behaviour; errors in thermophysical properties can lead to significant errors in simulation results. Thus, to ensure the accuracy and value of casting simulations, reliable thermophysical property data is required. However, this information not available for new alloys such as $\gamma$-TiAl intermetallics. Thus, thermal analysis, in this case DSC, was used to measure the properties of interest directly for each alloy as well as detecting the phase transformations which occur.

In the next chapter, the thermal analysis methods for measuring the required thermophysical property data are discussed in more detail. 


\section{Chapter 3}

\section{Thermophysical Property Determination}

As discussed in Chapter 2, reliable knowledge of certain thermophysical properties is required for the interpretation and modelling of alloy solidification behaviour. When computer models are used to predict casting behaviour it is important that the thermophysical data being used is accurate and reliable since errors in this data can lead to significant errors in simulation results $[4,31]$. For commonly used materials this data is available in the open literature: handbooks, reference books, journals, conference proceedings, and online/commercial databases. However, for newer alloys like the titanium aluminide intermetallics these thermophysical properties are not readily available. Often the only data available is the alloy composition and its melting range. One option is to estimate the required values from the data available for the parent metal of the alloy or from similar alloys. A second, more accurate option is to measure the required thermophysical properties for each alloys directly using available thermal analysis techniques such as differential thermal analysis (DTA) or differential scanning calorimetry (DSC).

This chapter of the literature review describes the process of thermophysical property determination using thermal analysis techniques, specifically differential scanning calorimetry as carried out on high temperature materials. To begin, the fundamentals of thermal analysis are discussed in general terms, including a brief history of the development of DTA and DSC, the types of thermal analysis instruments and the types of thermal analysis measurements. Next the thermal analysis techniques which can be used to determine the 
properties of interest for TiAl, specifically DTA and DSC, are examined in more detail. Various high temperature calorimetry methods are also outlined. Some thermal analysis experimental factors are detailed next, as well as methods of interpretation of DTA and DSC curves. Finally, thermal analysis of Ti-Al alloys is examined, and an overview of some of the thermal analysis and thermophysical property studies of Ti-Al intermetallics that have been reported in the literature is given.

\subsection{Thermal Analysis Fundamentals}

Thermal analysis is the study of the effect of heat on materials. When a material undergoes a physical change in state, such as melting or transition from one crystalline form to another, or when it reacts chemically, heat is either absorbed or liberated [32]. Many of these processes can be initiated simply by raising the temperature of the material. During thermal analysis these thermal events are measured while the sample is heated or cooled using a controlled temperature program.

\subsubsection{The History of DTA and DSC}

The oldest thermal analysis arrangement was devised by H. Le Châtelier in 1887 and was used to classify different kinds of clay according to their heating pattern when subjected to a controlled temperature program. However, his method was not strictly differential, and thus lacked sensitivity. For this reason, the development of DTA is co-credited to Sir W.C. Roberts-Austen who published a description of the apparatus which forms the essential basis of all modern differential thermal analyzers in 1899 [29]. This classical DTA arrangement is further examined in Section 3.2.1.

In a paper published in 1955, S.L. Boersma suggested placing the samples in crucibles which make contact with the thermocouple junctions instead of placing the thermocouples inside the materials being analyzed [29]. This incorporation of a defined thermal resistance outside the sample, which paved the way for heat flux DSC [33], is further discussed in 
Section 3.2.2. From these beginnings, thermal analysis techniques have evolved. There are now a number of different thermal processes which can be measured, and many different types of thermal analysis instruments which can be used, as is discussed in more detail in the next section.

\subsubsection{Thermal Analysis Instruments}

Thermal analysis instruments are used to measure different aspects of thermal processes. All thermal analysis instruments have features in common, and a generalized thermal analysis instrument is shown in Figure 19. These types of instruments function by applying a controlled temperature program to the sample, and measuring the resulting signal using some type of thermal analysis transducer; the type of transducer will determine the type of measurement that is obtained. Thus, from this generalized instrument a variety of thermal analysis techniques are available. This variety stems from the variety of physical properties that can be measured and the variety of transducers that can be used to convert these properties into electrical signals. Table 2 shows a summary of the main thermal analysis techniques, which are based on the measurement of the different thermal properties. Note that it is often possible to carry out simultaneous measurements of more than one property.

\subsubsection{Thermal Analysis Measurements and Data}

When measuring thermal analysis data, three different types of measurement are possible:

1. The absolute values of the sample property may be recorded (absolute measurement).

2. The difference in the property of the sample compared to the same property of a reference material may be recorded (differential measurement).

3. The rate of change of the sample property with temperature may be recorded (derivative measurement).

Irrespective of the type used, thermal analysis measurements are usually continuous and the heating rate is often, though not necessarily, linear with time. These measurements 


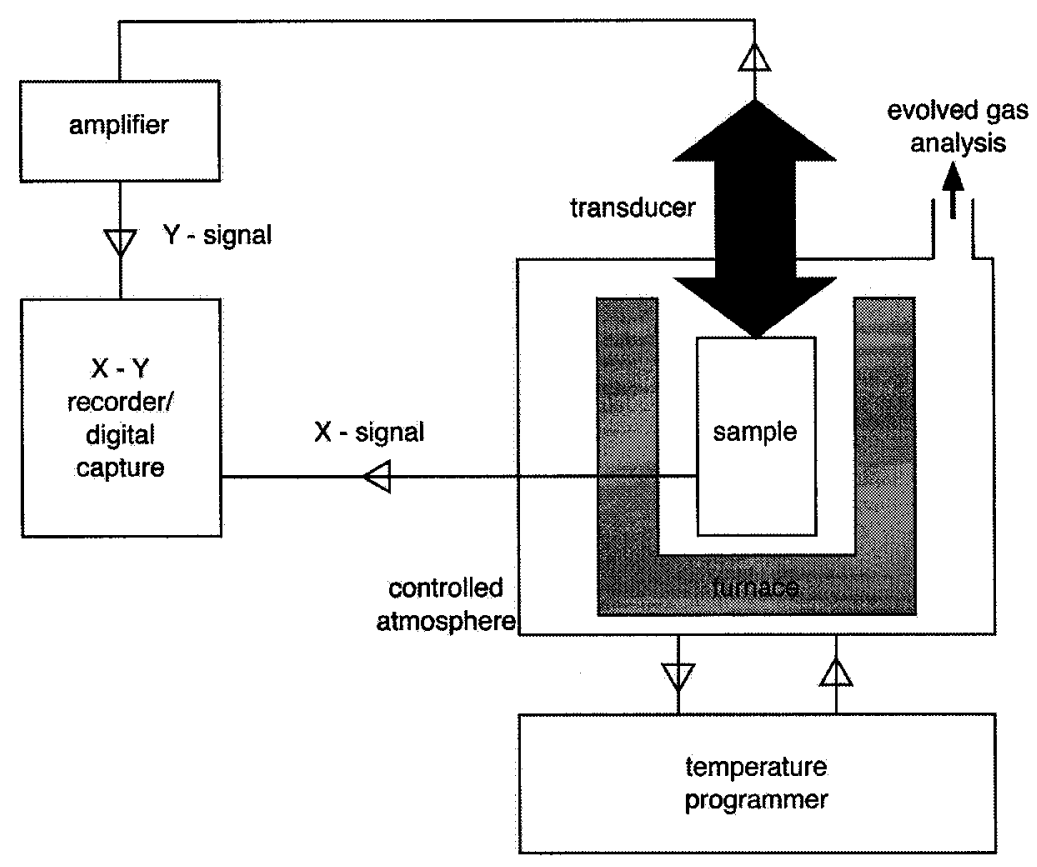

Figure 19: A generalized thermal analysis instrument, adapted from [30].

are usually displayed in the form of a thermal analysis curve. Figure 20 illustrates a generalized thermal analysis curve, with the instrument signal $(y)$ plotted against the sample temperature $\left(T_{s}\right)$. The various curve features (peaks, changes of slope, etc.) can then related to thermal events in the sample. Interpretation of thermal analysis curves is discussed more in Section 3.4.

Some of the thermal analysis techniques, DTA and DSC in particular, will now be discussed in more detail.

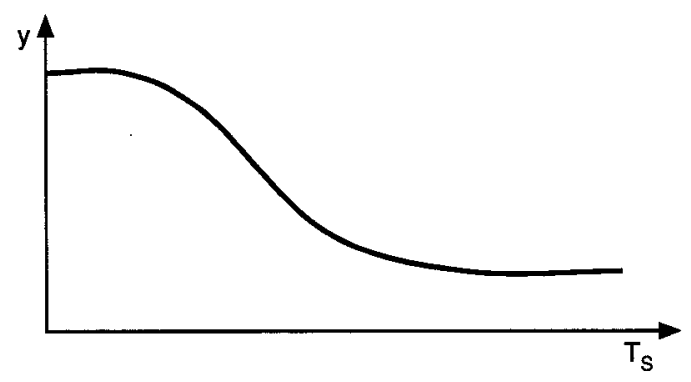

Figure 20: A generalized thermal analysis curve [30]. 


\begin{tabular}{llc}
\hline Property & Technique & Abbreviation \\
\hline Mass & Thermogravity & TG \\
& Derivative thermogravity & DTG \\
Temperature & Differential thermal analysis & DTA \\
Enthalpy & Differential scanning calorimetry & DSC \\
Dimensions & Thermodilatometry & \\
Mechanical properties & Thermomechanical analysis & TMA \\
& (Thermomechanometry) & \\
& Dynamic mechanical analysis & DMA \\
Optical properties & Thermoptometry or thermomicroscopy & \\
Magnetic properties & Thermomagnetometry & TM \\
Electrical properties & Thermoelectrometry & \\
Acoustic properties & Thermosonimetry and thermoacoustimetry & TS \\
Evolution of radioactive gas & Emanation thermal analysis & ETA \\
Evolution of particles & Thermoparticulate analysis & TPA \\
\hline
\end{tabular}

Table 2: The main thermal analysis techniques [30].

\subsection{Thermal Analysis Techniques}

There are several thermal analysis techniques which can be used to measure the thermophysical properties of interest for this thesis. The two main types of thermal analysis available are differential thermal analysis (DTA) and differential scanning calorimetry (DSC). DTA allows the recognition of thermal effects including melting and solidification and other phase transformations, and can be used to obtain solidus and liquidus temperatures. Differential scanning calorimetry (DSC) is useful for determining transformation energetics, such as the latent heat of fusion and fraction of solid, and thermophysical properties, such as specific heat. Phase transformation temperatures, such as liquidus and solidus can also be determined [29].

In this section, DTA and the two types of DSC (heat flux and power compensated) are described in terms of measurement type and instrument setup. The differences are explained, and a mathematical explanation of the principles of these analysis methods is 
given. Finally, Section 3.2.4 examines the issues of high temperature calorimetry and the techniques available for obtaining high temperature thermophysical data.

\subsubsection{Differential Thermal Analysis (DTA)}

DTA is the simplest and most widely used thermal analysis technique. The ASTM definition of DTA is "a technique in which the temperature difference between a substance and a reference material is measured as a function of temperature while the substance and the reference material are subjected to a controllecd temperature program [34]."

In classical DTA instruments a block containing symmetrical cavities for the sample and reference is heated in a furnace. A simplified illustration of a DTA setup is shown in Figure 21. The temperature difference between the sample and reference is measured by two thermocouples connected back to back and inserted in the sample or reference material. If an endothermic reaction takes place in the sample ( $\Delta H$ positive, such as melting) leading to a lag in the sample temperature, $T_{S}$, compared with the reference temperature, $T_{R}$, a corresponding temperature difference is measured. The opposite temperature difference appears with exothermic events. This classical DTA arrangement allows for the recording of thermal effects, but not, however, the quantitative determination of the enthalpy change. This is because the measured temperature difference depends on the thermal resistance of the sample itself [33].

Experimental data obtained is expressed in the form of a DTA curve. The temperature difference $(\Delta T)$ between the sample and the reference is plotted on the ordinate, with endothermic processes usually shown as a downward peak (by convention). Either time or temperature, ( $t$ or $T$ ) increasing from left to right, may be plotted on the abscissa. DTA curves normally consist of one or more exothermic and/or endothermic peaks, some of which may be superimposed upon one another, with the area under any given curve indicating qualitatively the amount of heat evolved or absorbed by the physical or chemical change which has occurred. 


\subsubsection{Differential Scanning Calorimetry (DSC)}

In DSC, the heat flux into the sample is measured. The ASTM definition of DSC is "a technique in which the difference in energy inputs into a substance and a reference material is measured as a function of temperature while the substance and the reference material are subjected to a controllecd temperature program [35]." The heat flux, the transmitted thermal power (in watts, $W$, or milliwatts, $m W$ ), can be integrated over time to give the heat consumption or the enthalpy change of a sample (in millijoules, $m J$ ). The main applications for DSC is in the determination of specific heat, thermal effects, purity, physical and chemical reactions, reaction kinetics, and melting and solidification behaviour.

In general, there are two main types of DSC based on two main principles for measuring heat flux: power compensated DSC and heat flux DSC. These two methods are explained below. In practice there are actually a number of different types of high-temperature calorimetry available; Section 3.2.4 contains a discussion of high-temperature calorimetry and the techniques available.

\section{Power Compensated DSC}

In power-compensated DSC, the sample and a reference material are maintained at the same temperature $\left(\Delta T=T_{S}-T_{R}=0\right)$ throughout the controlled temperature program. The difference in energy supplied to the sample and reference materials is then recorded against the applied temperature program.

The apparatus, see Figure 22, is usually set up so that the sample measuring station and the reference measuring station each have a temperature sensor and a heating device. The two sides are then provided with heating by separate controllers, which regulate the temperature of each such that they follow the desired temperature program. The power consumption or heat output of the sample is compensated by an equivalent increase or decrease in the heating power of a differential heating circuit. Thermal events in the 
sample appear as deviations from the DSC baseline, in either an endothermic or exothermic direction, depending on whether more or less energy has been supplied to the sample relative to the reference material.

This type of DSC is capable of directly measuring the enthalpy changes associated with thermal events such as melting, solid state phase transitions and chemical reactions. However, the operating temperature range of this type of DSC instrument is generally more restricted, since heat losses to the surroundings by radiation increase considerably with increasing temperature. Losses at temperatures above $650^{\circ} \mathrm{C}$ make the stability and repeatability of measurement signals increasingly unreliable. Thus, this type of DSC is not suitable for hight temperature inorganic materials such at $\gamma$-TiAl $[30,33,36]$.

\section{Heat Flux DSC (Calorimetric DTA)}

In heat flux DSC (also known as calorimetric DTA, Boersma DTA, differential dynamic calorimetry, or more recently high-temperature DSC), the sample and reference are placed in similar holders (crucibles) which are then placed on individual thermally conducting bases in a single furnace. The thermocouple junctions are attached to these bases, and are thus not in direct contact with the sample or reference materials. A schematic of a heat-flux DSC apparatus is shown in Figure 23. The advantage of this type of configuration is that the output signal is less dependent on the thermal properties of the sample. The disadvantage is a slower signal response, since the thermocouples do not directly contact the materials.

The temperature range of this type of DSC depends on the materials used for the furnace and the thermocouples, and is not as limited as power compensated DSC. The Carleton University facility is a heat-flux DSC. 


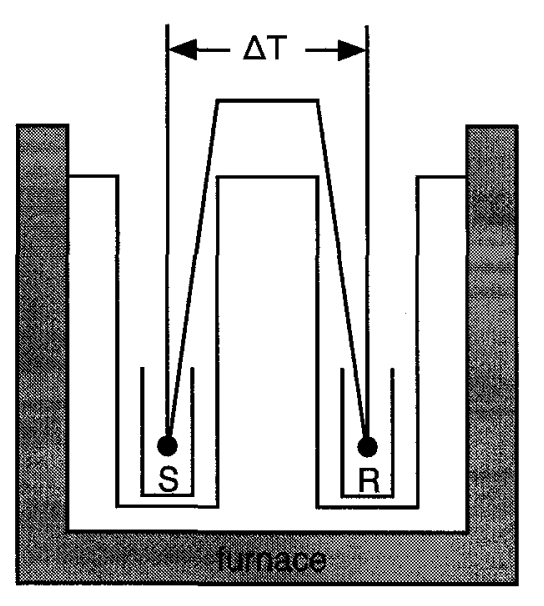

Figure 21: A typical classical DTA apparatus ( $\mathrm{S}=$ sample, $\mathrm{R}=$ reference), adapted from [30].

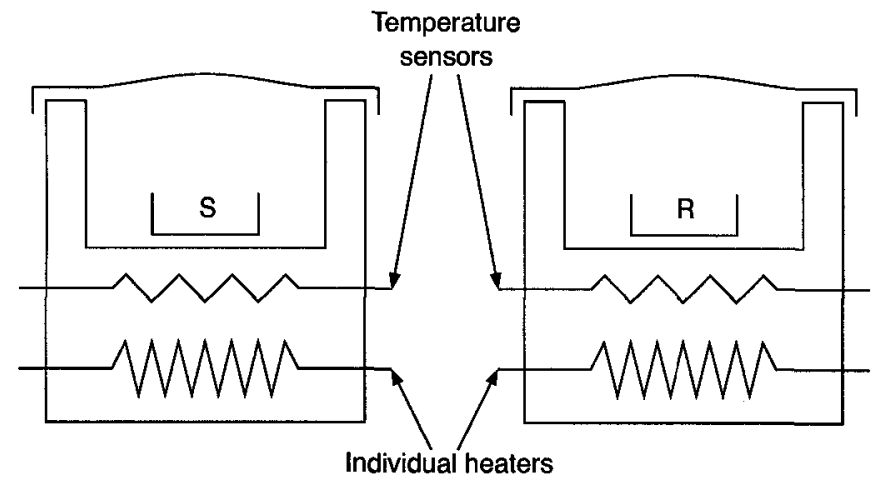

Figure 22: A typical power compensated DSC apparatus ( $\mathbf{S}=$ sample, $\mathbf{R}=$ reference), adapted from $[29,30]$.

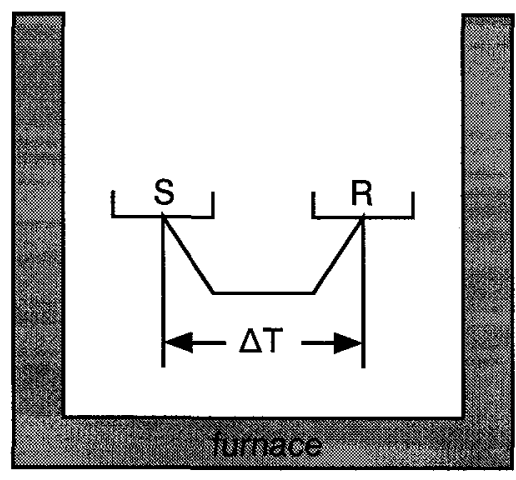

Figure 23: A typical heat flux DSC apparatus ( $S=$ sample, $R=$ reference), adapted from [30]. 


\subsubsection{Comparison of the Principles of DTA and DSC}

The principles of DTA, heat flux DSC and power compensated DSC are explained here with reference to Figure 24 [30], and all variables used in this section are defined with reference to the figure.

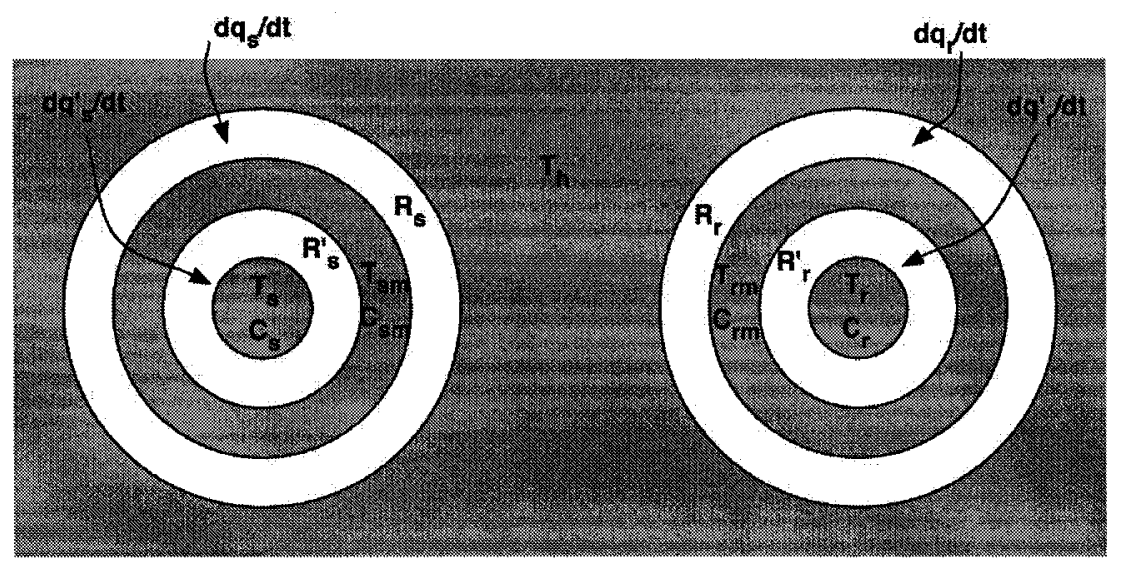

$$
T_{h}=\text { temperature of heat source }
$$

$T_{s}=$ actual sample temperature

$T_{s m}=$ measured sample temperature

$C_{s}=$ heat capacity of sample + pan

$C_{s m}=$ heat capacity of monitoring station

$R_{s}^{\prime}, R_{s}, R_{r}^{\prime}$, and $R_{r}$ are thermal resistances
$T_{r}=$ actual reference temperature

$T_{r m}=$ measured reference temperature

$C_{r}=$ heat capacity of reference + pan

$C_{r m}=$ heat capacity of monitoring station

$d q / d t$ terms are heat flows

Figure 24: Schematic diagram of a differential thermal apparatus, adapted from [30].

For an ideal instrument it can be assumed that the heat capacities and thermal resistances are matched, ie. $C_{r m}=C_{s m}, R_{r}=R_{s}=R$ and $R_{r}^{\prime}=R_{s}^{\prime}=R^{\prime}$. Note that $R \neq R^{\prime}$ and $C_{s} \neq C_{r}$. It can also be assumed that $C_{s}>C_{r}$ and that the heat flow is governed by Newtons's law of cooling (which states that heat flow from a body is proportional to the temperature difference between the body and its surroundings):

$$
d q / d t=(1 / R) \Delta T
$$

The sample side will be examined first. Heat flow to the sample side heats both the sample 
monitoring station and the sample, so that

$$
d q_{s} / d t=C_{s m}\left(d T_{s m} / d t\right)+C_{s}\left(d T_{s} / d t\right)
$$

and

$$
d q_{s}^{\prime} / d t=C_{s}\left(d T_{s} / d t\right)
$$

thus

$$
d q_{s} / d t=C_{s m}\left(d T_{s m} / d t\right)+d q_{s}^{\prime} / d t
$$

Applying Newton's law, Equation 1 from above, gives the heat flow terms:

$$
\begin{gathered}
d q_{s} / d t=(1 / R)\left(T_{h}-T_{s m}\right) \\
d q_{s}^{\prime} / d t=\left(1 / R^{\prime}\right)\left(T_{s m}-T_{s}\right)
\end{gathered}
$$

Similar expressions can be obtain for the reference side.

In classical DTA the thermocouples are embedded in the sample and reference material so that $T_{s m}=T_{s}$ and $T_{r m}=T_{r}$, ie. $R^{\prime}=0$. The signal obtained is then

$$
\Delta T=R(d T / d t)\left(C_{s}-C_{r}\right)
$$

and it depends on the difference in heat capacities between the sample and reference, the heating rate, and the thermal resistance $R$. However $R$ is difficult to determine since it depends on both the instrument and the properties of the sample and the reference.

In power compensated DSC the power is varied to make $T_{s m}=T_{r m}$. This means that $T_{h}=T_{s m}=T_{r m}, R=0$, and there is no thermal resistance. The signal is then

$$
\Delta(d q / d t)=(d T / d t)\left(C_{s}-C_{r}\right)
$$

In heat flux DSC conditions are such that $T_{h} \neq T_{s m} \neq T_{r m}$ and $R \neq R^{\prime} \neq 0$. The signal is

$$
\Delta T=T_{r m}-T_{s m}=R(d T / d t)\left(C_{s}-C_{r}\right)
$$


which is similar to the signal expression for classical DTA, Equation 7, except that $R$ depends on the instrument only and not on the sample characteristics.

This brief comparison shows the difference between the signals obtained by DTA and the two main types of DSC. The resistance, $R$, is a function of temperature and the relationship between $R$ and $T$ must be determined by instrument calibration at several different temperatures.

\subsubsection{A Discussion of High-Temperature Calorimetry and the Techniques Available}

As higher temperature materials are produced, and as the temperatures at which materials are used continue to increase, the need for improved high-temperature thermodynamic data increases. Equipment improvements have been part of the response to this need for improved data, and the development of many high temperature calorimeters has been particularly important.

The requirements for a good high-temperature calorimeter are as follows. The calorimeter should:

- Operate at as high a temperature as possible.

- Make measurements quickly, accurately, and reproducibly.

- Minimize interactions between the material being tested and the environment in which the testing takes place.

- Be usable for a variety of thermodynamic measurements, including heat capacity, enthalpies of transitions (phase changes, melting), and enthalpies of reaction.

Several types of high-temperature calorimeter have been used for these purposes. They include: drop calorimetry, adiabatic calorimetry, pulse calorimetry, power-compensated DSC, and high-temperature or heat-flux DSC. These different methods are briefly described below. 


\section{Drop Calorimetry}

In drop calorimetry, a small sample heated to a known temperature outside the calorimeter is rapidly dropped into the cavity of a well-insulated calorimeter block. The calorimeter block is much larger than the sample, and it is also at a known initial temperature. The increase in the calorimeter block temperature once equilibrium is regained after the drop indicates the sensible heat of the sample relative to the final temperature. Repeated drops with varied sample temperature gives a curve showing sensible heat vs. sample temperature. The derivative of this curve with respect to temperature gives sample heat capacity at a given temperature. This type of calorimetry has few temperature limitations and it is usable for a wide range of sample materials. However, the measurement process is extremely slow, and it does not have the best reproducibility. Accuracy is reduced as heat capacity is determined as the derivative of the sensible heat curve. Enthalpies of transition can only be measured if the sample goes through the required phase change in the calorimeter block.

\section{Adiabatic Calorimetry}

In adiabatic calorimetry, a measured amount of energy is input to a sample and container and the resulting temperature increase is measured. If the energy increments are small enough, the temperature rise can give a direct calculation of heat capacity at a given temperature. This method is faster than drop calorimetry, since numerous measurements can be made in each experiment. It can be used to measure enthalpies of reaction or mixing, if the enthalpy changes are small enough. It also has good accuracy at high temperature (up to about $1500^{\circ} \mathrm{C}$ ). However, the construction of the apparatus is complicated, increasingly so at high temperatures, and because each energy input requires some time to reach equilibrium radiation losses become an increasing concern at higher temperatures. Also, as each adiabatic calorimeter is different, reproducibility becomes a concern. Finally, although these instruments are faster than drop calorimeters, they are still relatively slow for making exact measurements. 


\section{Pulse Calorimetry}

In pulse calorimetry an electric current is used to heat the sample using the sample's electric resistance. The temperature increase in the sample is then measured, along with the voltage drop across the sample. If the heat loss from the sample is known, or if it is estimated through calibration using a sample of known heat capacity, then dividing the energy input by the temperature increase give the sensible heat change. If this measurement is done over short temperature intervals then the value approaches the true heat capacity of the sample. Pulse calorimetry eliminates many of the drawbacks of drop calorimetry, since it is fast, reproducible and accurate with proper calibration. However, its use is limited to conductive materials, and it's usefulness for measuring thermodynamic properties other than heat capacity is less certain.

\section{Power-Compensated DSC}

As previously discussed, power-compensated DSC involves using individual heaters to heat separate pans containing the sample and reference at the same rate. The difference in the electrical power required to keep the two pans at the same temperature is proportional to the difference in the heat capacities of the two samples. The use of an internal reference standard improves the reliability of this type of DSC measurement. Also, the use of small samples and highly accurate power measurements makes it possible to directly measure the enthalpy changes associated with other thermal events (melting, solid-state phase transitions, and chemical reactions). However, since radiation heat losses at temperatures above $650^{\circ} \mathrm{C}$ make the stability and repeatability of the baseline signals increasingly unreliable, powercompensated DSC is not recommended above this temperature.

\section{High-temperature or Heat-flux DSC}

High-temperature DSC, introduced about 15 years ago, is the newest type of calorimetry instrument. As previously discussed, it is similar to power-compensated DSC in that it also involves heating a small sample and reference material at the same time. However, since 
it is a heat flux DSC rather than a power compensated DSC, a single heater is used to heat the block (or furnace) containing both the sample and reference pans. Thermocouples mounted under the pans measure the temperature of each pan, and the difference in temperature between the two pans is related to the difference in their heat capacities. This type of DSC potentially solves most of the difficulties associated with other high temperature calorimeters. It can be used for any type of material, it is fast, easily standardized, and can operate at very high temperatures (up to and above $1500^{\circ} \mathrm{C}$, depending on the model). However, several factors affect the accuracy and reproducibility of high-temperature DSC. These include:

- Heating rate - in general the lower the heating rate the greater the precision, but higher heating rates may be recommended for testing metastable materials.

- Sample mass (or the ratio of sample mass to reference material mass) - higher sample masses improve the precision of the instrument by minimizing the effect of the crucible, but too high a sample mass creates concern over thermal lag between the instrument and sample temperatures.

- Sample form (powdered vs. single piece) - since materials may not always be available in solid form, measurements should not be overly dependent on material form.

- Cover gas flow rate - the rate the cover gas (eg. argon) flows over the sample and reference should be maintained at a constant rate.

- Measurement technique - high-temperature DSC can be operated using a scanning technique, which operates continuously over a preset temperature range, or an enthalpic technique, which attempts to simulate an adiabatic calorimeter. There is some evidence that the enthalpic technique is more accurate, but the scanning technique is faster and the degree to which the results of the two differ has not been determined.

Much research performed using high-temperature DSC has focused on their use for measuring heat capacities, however, they are also useful for measuring enthalpy changes for 
changes of state (melting, etc.) and possibly for chemical reactions as well. Results from earlier models of this type of instrument show good agreement with literature values. To summarize, high-temperature (heat-flux) DSC shows potential for making thermodynamic measurements at temperatures above $1000^{\circ} \mathrm{C}[36]$.

As noted previously, the Carleton University DSC facility is a high-temperature (heatflux) DSC. The instrument is discussed in further detail in Chapter 5. Some of the experimental factors which must be considered when carrying out DSC thermal analysis experiments are now examined.

\subsection{Thermal Analysis Experimental Factors}

There are some important experimental factors which must be considered when carrying out thermal analysis measurements. These factors, which include instrument calibration, reference material selection, and crucible material selection, are briefly described below. More specific experimental factors which relate directly to the DSC used for the research for this thesis are outlined and discussed in Chapter 5.

\subsubsection{Instrument Calibration}

For all thermal analysis techniques careful calibration is essential to correct for possible instrumental effects and to provide a basis for reliable thermal analysis. As discussed in Section 3.2.3, the resistance, $R$, of the instrument is a function of temperature and the relationship between $R$ and $T$ must be determined by instrument calibration at several different temperatures. This is generally done by testing samples of pure metals with known melting temperatures $(\mathrm{Zn}, \mathrm{Al}, \mathrm{Ag}, \mathrm{Au}, \mathrm{Ni}, \mathrm{Co}$, etc.) to obtain a calibration curve which corrects the temperatures measured by the instrument as a function of instrument temperature. 


\subsubsection{Reference Materials}

In DTA and DSC, the differential measurement is made by comparing the measured property in the sample and a reference material. The reference material should have the following characteristics:

- It should not undergo any thermal events over the operating temperature range.

- It should not react with the sample holder (crucible) or thermocouple.

- Both the thermal conductivity and the heat capacity of the reference should be similar to those of the sample.

Alumina is often used as a reference material for inorganic samples [30].

\subsubsection{Crucibles}

At temperatures below $500^{\circ} \mathrm{C}$ samples are usually contained in aluminum crucibles. For moderate temperatures (above $500^{\circ} \mathrm{C}$ ), or for samples which react with the Al crucibles, gold or graphite crucibles can be used. For high-temperature tests, platinum or ceramic crucibles are be used. The most common ceramic crucibles are made from alumina $\left(\mathrm{Al}_{2} \mathrm{O}_{3}\right)$. However for testing $\gamma$-TiAl intermetallics, which react with alumina crucibles, alumina crucibles can be coated with a yttria spray to avoid reactions between the sample and the crucible [37] or yttria $\left(\mathrm{Y}_{2} \mathrm{O}_{3}\right)$ crucibles can be used [4]. The only disadvantage of using yttria crucibles is that they are much more expensive than alumina crucibles. To further avoid reactions between the sample and the crucible for high temperature thermal analysis, the sample can be embedded in a ceramic powder (alumina or yttria powder for example). This powder protects the crucible, as well as improving the thermal contact between the sample and the crucible.

\subsubsection{Testing Atmosphere}

Thermal analysis tests can be carried out in inert, oxidizing, reducing or corrosive gas atmospheres, depending on the goals of the analysis [30]. For thermophysical property 
determination, where it is undesirable to have reactions between the sample and the atmosphere, an inert gas atmosphere (usually argon or nitrogen) is used. Alternately tests may be carried out in vacuum, but this is often damaging to the thermocouples, and it can cause heat transfer problems within the instrument furnace. Usually a vacuum pump is used to evacuate the instrument furnace, and then the furnace is back filled with the desired gas. Tests are usually carried out under flowing gas, so the test can be conducted at ambient pressure.

\subsection{Interpretation of DTA and DSC Curves}

After carrying out a thermal analysis experiment, the features recorded in the thermal analysis curve must be correlated to the thermal events taking place in the sample. To illustrate this process, part of a simple and idealized DTA curve is shown in Figure 25.

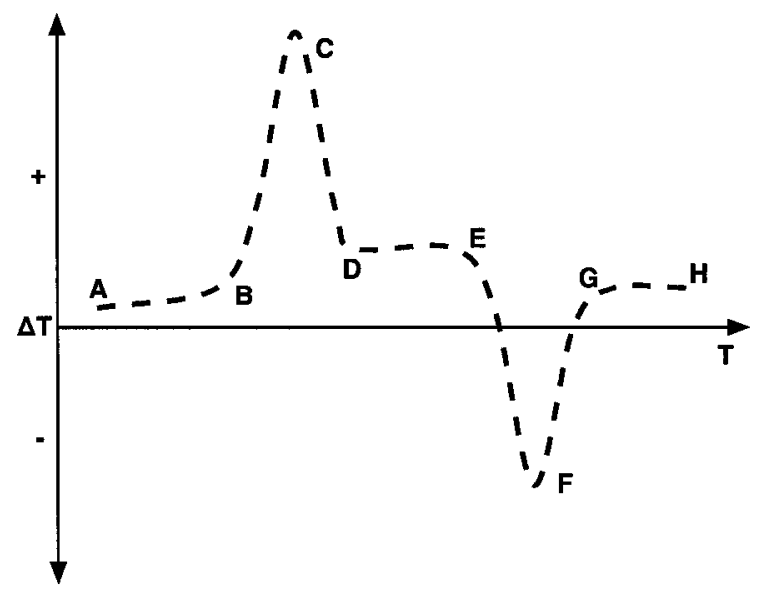

Figure 25: A hypothetical DTA curve, showing an exothermic peak (BCD), an endothermic peak (EFG), and the change in off-set temperature of the baseline resulting from these process, adapted from [29].

When the furnace temperature is raised, a small but steady temperature difference develops between the sample and reference materials. Although the temperature at the centre of both materials lags behind the furnace temperature, the magnitude of the lag between the sample and reference depends primarily on the thermal conductivity and heat capacity of each substance. The DTA curve will thus continue in an approximately 
rectilinear manner until some physical or chemical change occurs in the sample $(\mathrm{AB}$ in Figure 25). At $\mathrm{B}$ the curve begins to deviate from the baseline, due to an exothermic process in the sample. $\mathrm{B}$ is thus referred to as the onset temperature of the reaction, or phase transition, since it represents the temperature at which the process first became detectable by the DTA instrument. The exothermic peak temperature, C, corresponds to the maximum rate of heat evolution detected by the differential thermocouples, and does not necessarily correspond to the maximum rate of reaction or to the completion of the exothermic process. In general terms, the peak temperature shows a much greater variation due to experimental factors such as heating rate than the onset temperature, but it does tend to be more easily measured; the peak temperature is more easily detected but is subject to more variability than other temperatures on the curve. The exothermic process that gave rise to the peak $\mathrm{BCD}$ is complete at some temperature between the points $\mathrm{C}$ and $\mathrm{D}$.

When the process is finished, and no further heat is evolved, the curve returns to a new baseline, DE. The heights of the baselines $\mathrm{AB}$ and DE above the abscissa normally differ, and this difference in height reflects the change in heat capacity of the sample that results from the exothermic process which has occurred.

The downward deflection of the baseline at $\mathrm{E}$ indicates the onset of an endothermic process, peak EFG. Completion of the process and the formation of a new thermally stable phase is indicated by the horizontal portion of the curve, GH. In this hypothetical example, the DTA peaks are reasonably sharp and well separated. In practice, this is not typically the case, and superimposed and overlapping peaks often make the interpretation of results difficult. It is also important to remember that the peaks on a DTA curve arise from both physical and chemical changes. Physical changes include melting, boiling, and solid-solid structural transitions. Chemical changes result from reactions of the sample itself, as well as secondary reaction of evolved decomposition products. The thermal analysis curves for this thesis involve only physical changes. Chemical changes can be detected by changes in the mass of the sample. For this reason, all samples were weighted before and after each 
test.

\subsection{Determining Fraction of Solid}

The fraction of solid as a function of temperature can be determined from the area under the melting endotherm [29]. The fraction melted, that is $1-\mathrm{f}_{S}$ at a temperature, $\mathrm{T}$, is the ratio of the area under the melting endotherm up to that temperature to the total area under the melting endotherm. This can be explained with reference to Figure 26, where $A_{T}$ is the total peak area from onset to end, $T_{1}$ is the peak temperature and $A_{1}$ is the area under the peak from the onset up to $T_{1}$. The equation is thus:

$$
A_{1} / A_{T}=1-f_{s}\left(T_{1}\right)
$$

This value is one of the inputs needed for the ProCAST model for simulating the casting of TiAl parts.

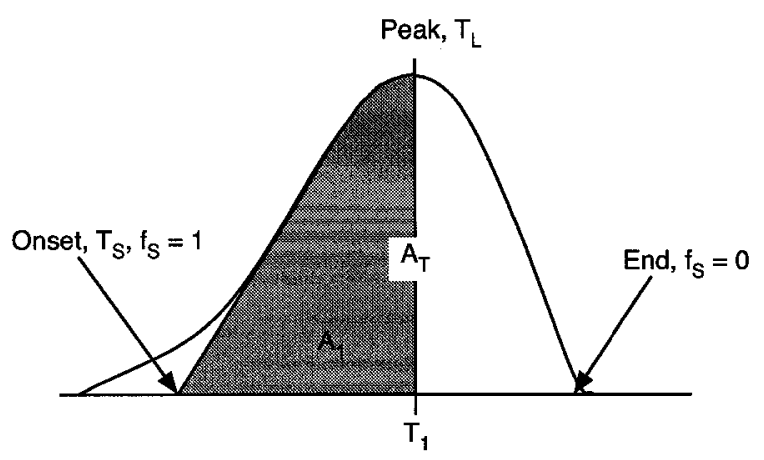

Figure 26: Diagram showing area method to determine fraction solid $\left(\mathrm{f}_{S}\right)$.

\subsection{Undercooling and Alloy Solidification Behaviour}

DSC is frequently used to determine the melting and solidification characteristics of metal alloys, for example melting temperature, enthalpy of fusion and onset temperatures of phase transformations. While various methods have been suggested in the literature $[29,30]$ for determining melting curves of alloys systems using thermal analysis, relatively few studies 
have been reported for the determination of solidification data during cooling. This is most likely due to problems in calibrating DSC equipment for cooling conditions because of the nucleation effect prior to solidification. To some extent, any liquid is undercooled before nucleation initiates solidification, so nucleation is a significant theoretical and practical problem. The magnitude of undercooling is thus an important parameter in microstructural development as well as the mechanical properties of the resulting material [38].

\subsection{DTA/DSC of TiAl in the Literature}

This section of Chapter 3 outlines a selection of the studies of $\mathrm{TiAl}$ that have been reported in the literature and which used DTA/DSC or reported thermophysical properties in other ways. A summary is given, including the goals of the study, the thermal analysis techniques used, and the relevant thermophysical properties found (if applicable). The research for this thesis examined $18 \mathrm{Ti}-\mathrm{Al}$ alloys; these alloys are listed in Chapter 5 . Some of the studies outlined below examined alloys with high or lower $\mathrm{Al}$ content than the alloys researched for this thesis, and some of the studies examined a few of the same alloys that were researched for this thesis. The studies that looked at the same alloys are directly relevant to this thesis. The other studies are included because the thermal analysis, phase transformation, or thermophysical property determination information is relevant.

\section{Thermal analysis of Ti-(45.5-48)Al-2Nb-2Cr}

Ahmed et al. [8] studied the high temperature phase stability of Ti-(45.5-48)Al-2Nb-2Cr using calorimetric differential thermal analysis (CDTA) to determine phase transformation temperatures. High temperature x-ray diffraction (HTXRD) was then used to determine the phases present at selected elevated temperatures. Both of the alloys studied are three phase $\alpha_{2}+\gamma+\beta$ at room temperature and have increased $\beta$ with increased Al content. CDTA and HTXRD indicated that the $\alpha_{2}+\gamma+\beta$ three phase structure persists to approximately $1200^{\circ} \mathrm{C}(1473 \mathrm{~K})$ for $\mathrm{Ti}-48 \mathrm{Al}-2 \mathrm{Nb}-2 \mathrm{Cr}$. The following transformation paths are proposed:

- Ti-45.5Al-2Nb-2Cr: $\gamma+\alpha_{2}+\beta \rightarrow \gamma+\alpha_{2}+\alpha+\beta \rightarrow \beta+\gamma+\alpha \rightarrow \beta+\gamma$ 
- Ti-48Al-2Nb-2Cr: $\gamma+\beta+\alpha_{2} \rightarrow \beta+\gamma+\alpha \rightarrow \beta+\gamma$

CDTA indicated that four reversible reactions occurred during heating/cooling of Ti-45.5Al$2 \mathrm{Nb}-2 \mathrm{Cr}$ while only three were observed for Ti-48Al-2Nb-2Cr. These transformation paths were suggested on the basis of CDTA and HTXRD results. Note the three and four phase regions in these transformation paths. For the binary compositions only two phases are present at a time. For example, for Ti-45.5Al the path is $\gamma+\alpha_{2} \rightarrow \gamma+\alpha \rightarrow \alpha \rightarrow \alpha+\beta \rightarrow$ $\beta+L \rightarrow L$, and for Ti-48Al the path is $\gamma+\alpha_{2} \rightarrow \gamma+\alpha \rightarrow \alpha \rightarrow \alpha+L \rightarrow \beta+L \rightarrow L$. Thus, additional alloying elements, especially beta stabilizers, make the transformation pathways much more complex.

\section{DSC analysis of $\gamma-\mathrm{TAB}, \mathrm{Ti}-47 \mathrm{Al}$ and $\mathrm{Ti}-45 \mathrm{Al}$}

While examining the microstructure and mechanical properties of a boron containing $\gamma$-TiAl alloy in different hot working stages, with the goal of limiting the lamellar colony size in hot worked high-pressure compressor blades, Oehring et al. carried out DSC analysis of several TiAl alloys [39]. The material of interest, called $\gamma-\mathrm{TAB}$, has a nominal composition Ti-47Al-3.7(Cr,Nb,Mn,Si)-0.5B. The binary compositions Ti-47Al and Ti-45Al were also examined for comparison. By DSC analysis the $\alpha$ transus temperature of the multicomponent alloy was found to be $1360{ }^{\circ} \mathrm{C}$ at heating rates of 10 and $20 \mathrm{~K} / \mathrm{min}$. Inspection of the binary phase diagram revealed that equal volume fractions of the $\alpha$ and $\gamma$ phase are present at $1300^{\circ} \mathrm{C}$ in a binary alloy with Ti-47Al. The DSC traces in Figure 27 show that the transformation of the $\gamma$ to the $\alpha$ phase starts at around $1250^{\circ} \mathrm{C}$ for a binary $\mathrm{Ti}-47 \mathrm{Al}$ as well as for the $\gamma$-TAB alloy. In contrast, a Ti-45Al under identical conditions exhibits a disordering transformation at the eutectoid temperature and, beginning from this temperature, a continuous transformation into the $\alpha$ phase. The DSC cooling curve comparing Ti-47Al to $\gamma$-TAB show that the undercooling of the lamellar reaction is by $60 \mathrm{~K}$ lower for the $\gamma$-TAB alloy than for the binary alloy. This indicates that drastically reduced cooling rates are required to decrease the lamellar spacing of the $\gamma$-TAB alloys. Thus, general transformation behaviour was determined for the material of interest using 
DSC analysis.

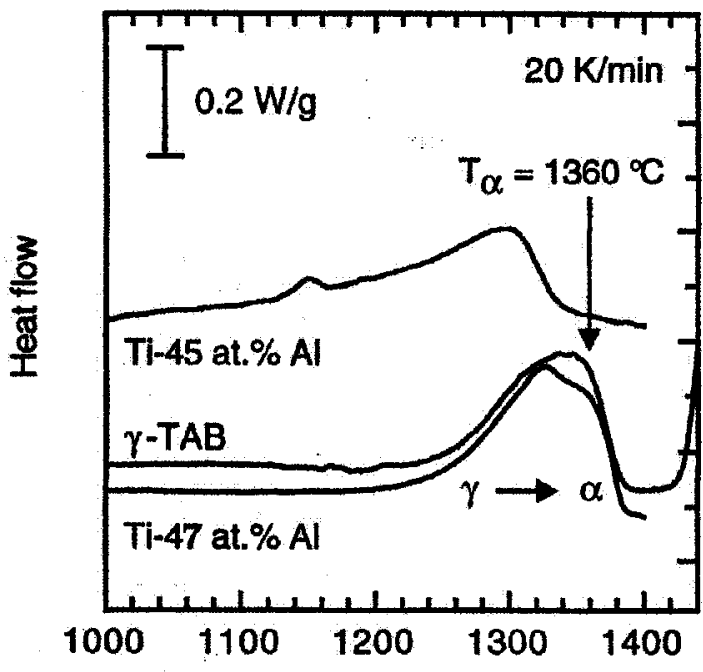

(a)

Temperature $\left({ }^{\circ} \mathrm{C}\right)$

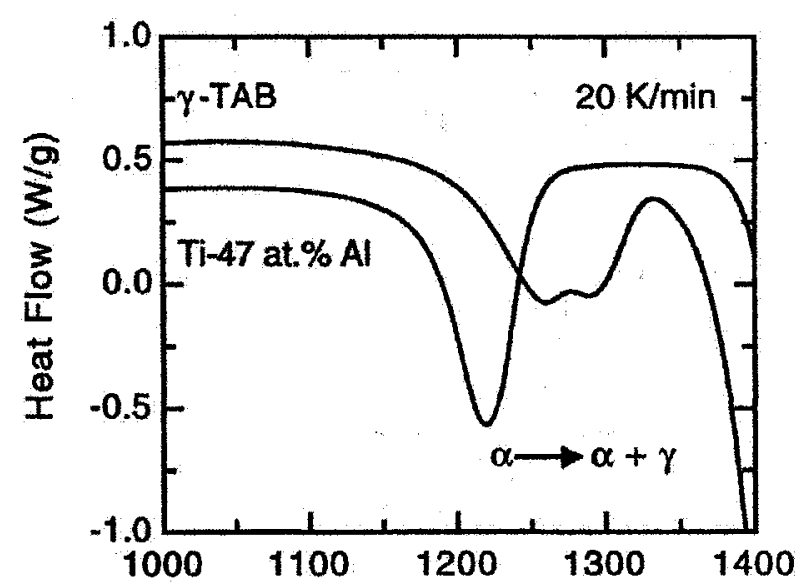

(b)

Temperature $\left({ }^{\circ} \mathrm{C}\right)$

Figure 27: DSC traces reported by Oehring et al., (a) heating at $20 \mathrm{~K} / \mathrm{min}$, (b) cooling at $20 \mathrm{~K} / \mathrm{min}[39]$.

\section{DSC analysis of Ti-(30.1-41.4)Al}

Ohnuma et al. presented experimental results on the phase equilibria in the binary Ti-Al system [40]. The presence of the $\beta$-Ti (A2) $/ \beta_{2}$-TiAl (B2) order-disorder transition in the $\beta$ phase is confirmed by a combination of DSC analysis and extrapolation of the ordering phase boundaries from the $\mathrm{Ti}-\mathrm{Al}-\mathrm{X}(\mathrm{X}=\mathrm{Cr}, \mathrm{Fe})$ ternary systems. $\mathrm{DSC}$ analysis was carried out in a Netzsch DSC404 calorimeter to determine the $\alpha_{2} / \alpha_{2}+\alpha$ and $\alpha / \alpha+\beta_{2}$ transus and the A2/B2 order-disorder transition temperatures. DSC measurements were performed under high purity argon flow, using Pt-Rh crucibles with the specimen placed in the crucible on a thin tungsten foil to prevent any chemical reaction between the crucible and the specimen. A heating rate of $5 \mathrm{~K} / \mathrm{min}$ was used. DSC runs were found to be consistent with SEM-EDS analysis of the specimens, and contamination with oxygen during DSC measurements was found to be negligibly small. The Ti-Al alloys examined had Al content ranging from 30.1 to 41.4 at.\%, and an example DSC trace, for Ti-32.6Al, is shown in Figure 28. For this 


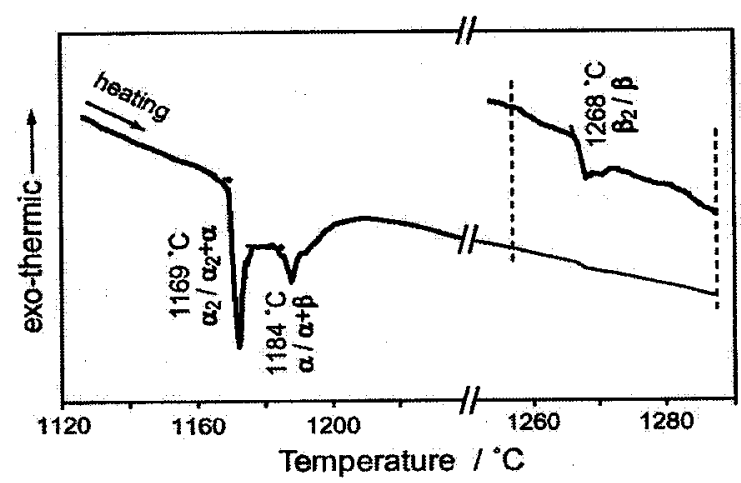

Figure 28: DSC heating trace reported by Ohnuma et al. for Ti-32.6Al [40].

study, DSC analysis data was used to confirm the thermodynamic data used for a calculated $\mathrm{Ti}-\mathrm{Al}$ phase diagram.

\section{DTA analysis of near Ti-50Al}

Jung et al. [14] studied the high temperature phase equilibria of near Ti-50Al by directional solidification. Direct temperature measurement were taken of the liquid, liquid/solid interface, and solid phase during the DS process, and liquidus temperatures of selected compositions were inspected. Liquidus temperatures were verified using DTA. A high temperature phase diagram for $\mathrm{Ti}-44,46,48,50,52 \mathrm{Al}$ alloy compositions was established, and is shown in Figure 29. Temperature gradient measurements provided important information about the liquid-solid phase transformations - the tip of a B-type thermocouple enclosed by a $2 \mathrm{~mm}$ alumina protective tube was lowered to a position $20 \mathrm{~mm}$ above the advancing solid/liquid interface to measure the temperature gradient along the growth direction. The liquidus temperatures for each composition measured by temperature gradient methods were inspected and verified again by DTA. Estimated phase transformation temperatures, based on DTA and DS experimental results, are shown in Table 3.

\section{Calculated phase equilibria in multi-component TiAl alloys}

Phase equilibria in multi-component $\gamma$-TiAl based alloys was examined by Saunders [41]. This study does not include thermal analysis, but it does report on transformation behaviour 


\begin{tabular}{llccc}
\hline Composition (at \%) & & By DTA $\left({ }^{\circ} \mathrm{C}\right)$ & By DS $\left({ }^{\circ} \mathrm{C}\right)$ & Estimated Temperature $\left({ }^{\circ} \mathrm{C}\right)$ \\
\hline Ti-44Al & Liquidus & 1558 & 1557 & 1557 \\
& Solidus & 1524 & - & 1524 \\
Ti-46Al & Liquidus & 1534 & 1532 & 1532 \\
& $\mathrm{~T}_{\text {peritectic }}$ & 1493 & - & 1492 \\
& $\mathrm{~T}_{(\alpha+\beta) / \alpha}$ & 1446 & - & 1446 \\
Ti-48Al & Solidus & 1506 & 1504 & 1504 \\
& $\mathrm{~T}_{\text {peritectic }}$ & 1492 & - & 1492 \\
& $\mathrm{~T}_{(\alpha+\beta) / \alpha}$ & 1447 & - & 1447 \\
\hline
\end{tabular}

Table 3: Estimated phase transformation temperatures [14].

using thermodynamic calculations. So, while there is no thermal analysis there is useful data showing the relative proportions of the various phases present vs. temperature for several alloys the same as or similar to the ones examined in this thesis. Figure 30 shows the binary phase diagram reported by Saunders, which was determined using thermodynamic calculations. Figures 31, 32 and 33 are plots showing the results for Ti-47Al-2Mn-2Nb, Ti-47Al-2Cr-2Nb-0.5W and Ti-47Al-2Nb-1Mn-0.5W-0.5Mo-0.2Si respectively. According to these diagrams, the transformation sequences for these alloys are as follows:

- Ti-47Al-2Mn-2Nb-2Cr: $\gamma+\alpha_{2} \rightarrow \gamma+\alpha \rightarrow \alpha \rightarrow \alpha+\beta \rightarrow \beta+L \rightarrow L$

- Ti-47Al-2Nb-1Mn-0.5W-0.5Mo-0.2Si: $\gamma+\alpha_{2}(+\alpha C r+\alpha W+B 2) \rightarrow \gamma+\alpha+B 2 \rightarrow$ $\alpha \rightarrow \alpha+\beta \rightarrow \beta+L \rightarrow L$

- Ti-47Al-2Cr-2Nb-0.5W: $\gamma+\alpha_{2}(+\alpha W+B 2) \rightarrow \gamma+\alpha+B 2 \rightarrow \alpha \rightarrow \alpha+\beta \rightarrow \beta+L \rightarrow L$

\section{DTA determination of $\mathbf{T}_{\alpha}$ for various Ti-Al alloys}

The effect of boron addition on grain refinement and lamellar formation in wrought processed $\gamma$ TiAl alloys is reported by Kim et al. [42]. DTA experiments show that the borides on grain boundaries help the $\gamma$ phase nucleate to raise the lamellar formation temperatures, which leads to the formation of lath structures more coarse and more inhomogeneous than in alloys containing no boron. Boron is added for grain refinement, with large amounts of 


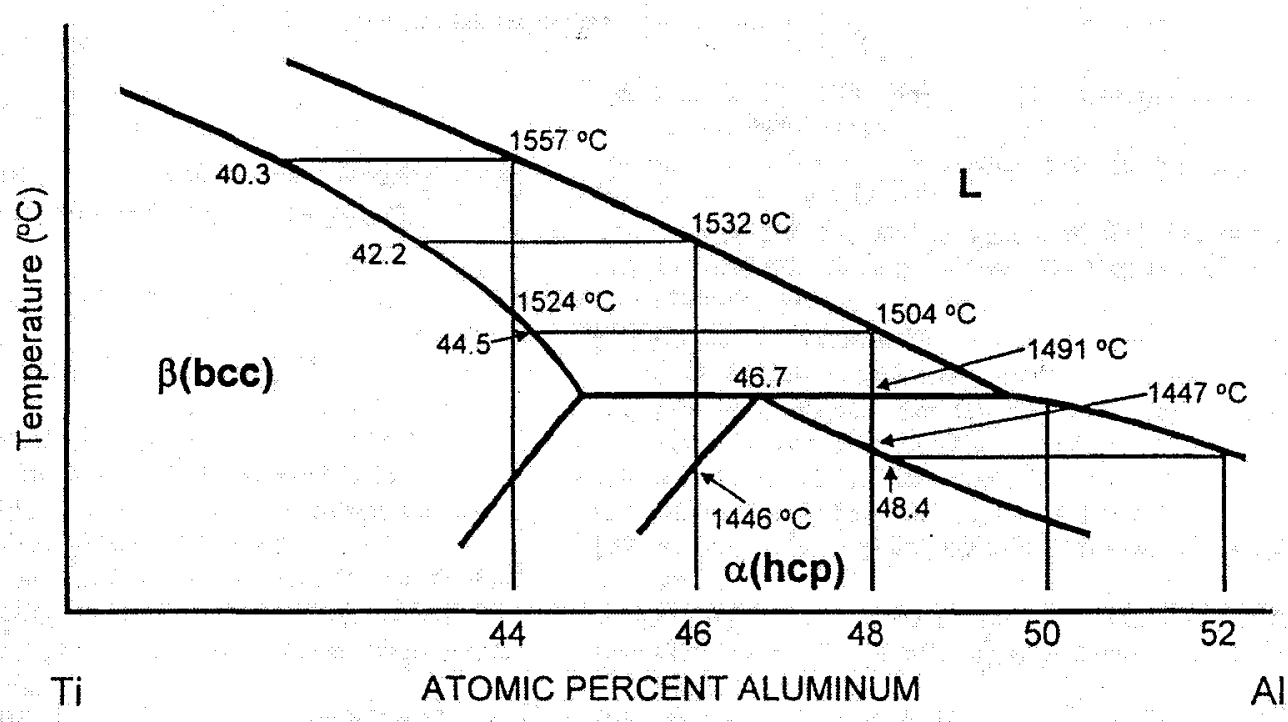

Figure 29: Binary Ti-Al phase diagram reported by Jung et al. showing transformation temperatures for the $\gamma$-TiAl compositions used in this study [14].

boron (typically greater than $0.5 \%$ ) being needed to refine cast lamellar microstructures, and smaller amounts (as small as $0.05 \%$ ) being sufficient for refining wrought lamellar grains. The mechanisms in both cases differ, but are related to constitutional supercooling for casting, and grain boundary pinning for wrought materials. Careful DTA measurements were used to monitor variations of lamellar formation temperature. The $\alpha$ transus temperatures as determined through DTA are listed in Table 4 for several Ti-Al alloy compositions with varying amounts of added boron. $\mathrm{T}_{\alpha}$ varied from 1242 to $1388^{\circ} \mathrm{C}$. DTA measurements were conducted through two heating cycles to remove stress effects on the exothermic reactions. Various cooling rates were also used to investigate the undercooling behaviour of endothermic reactions.

\begin{tabular}{|c|c|c|}
\hline Alloy & $\mathrm{B}$ & $T_{\alpha}$ \\
\hline Ti-43Al & 0 & 1242 \\
Ti-44Al & $0,0.05,0.1,0.2,0.3,0.4$ & 1280 \\
Ti-47Al & $0,0.05,0.1,0.2,0.3,0.5$ & 1358 \\
Ti-48Al & $0,0.03,0.1,0.2,0.4$ & 1388 \\
\hline
\end{tabular}

Table 4: Alpha transus temperatures $\left(T_{\alpha}\right)$ determined by DTA for various Ti-Al alloys, adapted from [42]. 


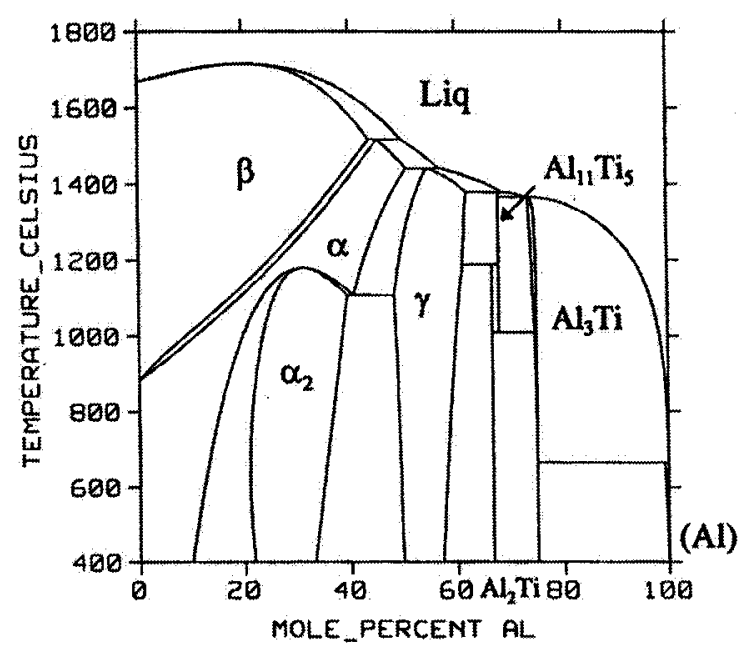

Figure 30: Binary Ti-Al phase diagram reported by Saunders [41].

\section{DTA analysis of Ti-(58-73)Al}

Stein et al. investigated Al-rich titanium aluminide alloys with 58-73at\% Al using several methods, including DTA [43]. The combination of different experimental methods allowed the determination of stability ranges of the different phases as a function of composition, temperature and time. The DTA measurements were carried out using a Setaram SETSYS18 DTA at different heating rates between 2 and $30 \mathrm{~K} / \mathrm{min}$. Alumina crucibles were used and tests were done under a flowing argon atmosphere. A DTA heat flow curve for the alloys examined is shown in Figure 34. Besides the large effects of melting and the peritectic dissolusion of $\mathrm{TiAl}_{3}$, no other effects were observed.

\section{DTA of Ti-Al alloys in support of alloy design of $\gamma$-TiAl based on phase diagrams}

Hashimoto et al. [44] examined the alloy design of $\gamma$-TiAl based on phase diagrams. Their study investigates phase stability in the Ti-Al-X $(\mathrm{X}=\mathrm{Cr}$, Mo and $\mathrm{W})$ system at $1200^{\circ} \mathrm{C}$ $(1473 \mathrm{~K})$ and $1300^{\circ} \mathrm{C}(1573 \mathrm{~K})$ by several methods including DTA. $\mathrm{Cr}$ and $\mathrm{Nb}$ are added as alloying elements because they are both $\beta$ stabilizing elements in Ti. For additions of third elements in $\gamma \mathrm{TiAl}$, it is necessary to consider that the Ti-Al-X ternary systems, phase stability and microstructure of TiAl change throughout depending on composition and 


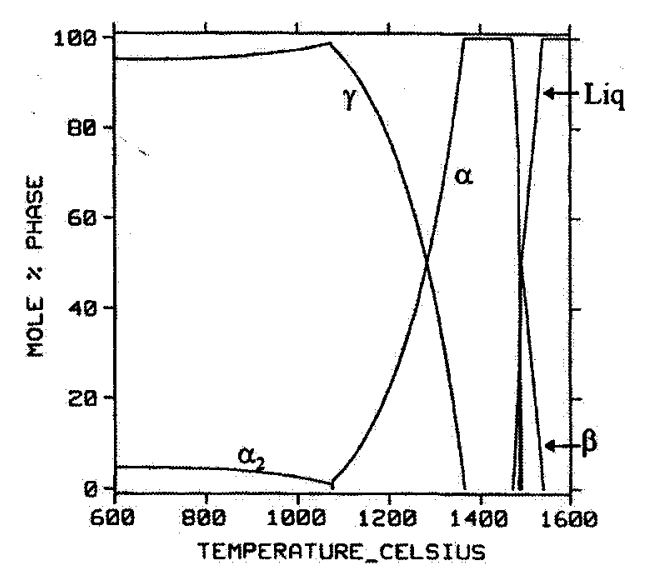

Figure 31: Calculated mole \% vs. temperature plot for Ti-47Al-2Mn-2Nb, reported by Saunders [41].

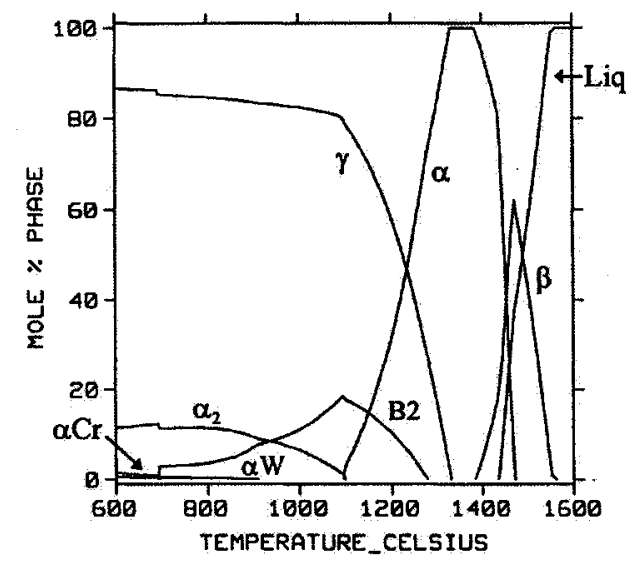

Figure 32: Calculated mole \% vs. temperature plot for Ti-47Al-2Nb-1Mn-0.5W0.5Mo-0.2Si, reported by Saunders [41].

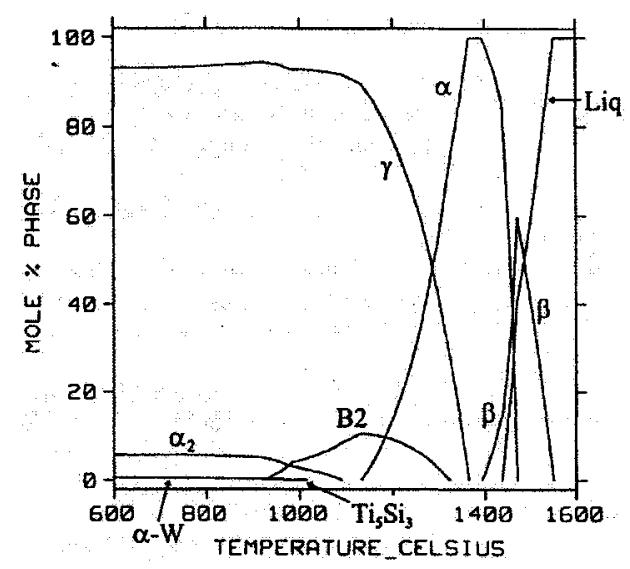

Figure 33: Calculated mole \% vs. temperature plot for Ti-47Al-2Cr-2Nb-0.5W, reported by Saunders [41]. 
temperature. Among other experiments, DTA measurements were carried out at a heating rate of $20 \mathrm{~K} / \mathrm{min}$ with tungsten powder used as reference. These measurements were used in conjunction with HTXRD to determine the equilibrium phase at specific temperatures using composition fixed specimens. Figure 35 shows the DTA measurements and calculated phase fractional change in Ti-47Al-3Cr. Since the DTA peak indicates phase transformation, the calculated phase fractions agree with the DTA peak temperatures. Although the $\alpha+\gamma$ two phases reach an equilibrium state at $1200^{\circ} \mathrm{C}(1473 \mathrm{~K})$, the volume fraction of $\alpha$ phase increases with temperature up to $1327^{\circ} \mathrm{C}(1600 \mathrm{~K})$ and decreases rapidly from $1407^{\circ} \mathrm{C}(1680$ $\mathrm{K})$. Instead of the $\alpha$ phase, the volume fraction of liquid and the $\beta$ phases increase with temperature. Thus, DTA measurements were used to help confirm the proposed ternary phase diagrams in this study.

\section{Long time heat treatments to determine $\alpha$ transus temperature}

In contrast to the work done by Hashimoto, Dudzinski et al. found slightly different $\alpha$ transus temperatures while examining the microstructural evoltion of near- $\gamma$ TiAl alloys during long-time heat treatments [45]. Three TiAl alloys were examined: Ti-48Al, Ti47.5Al-3Cr, and Ti-48Al-2W. By examining the dissolution of $\gamma$ grains after long term heat treatments, $\mathrm{T}_{\alpha}$ were found as follows. For $\mathrm{Ti}-48 \mathrm{Al}, \mathrm{T}_{\alpha}$ was estimated to be $1370 \pm 5^{\circ} \mathrm{C}$. For Ti-47.5Al-3Cr and Ti-48Al-2W, $\mathrm{T}_{\alpha}$ was estimated to be $1340 \pm 5^{\circ} \mathrm{C}$ and $1370 \pm 5^{\circ} \mathrm{C}$ respectively. These results were considered to be more accurate than the $T_{\alpha}$ temperatures found by DTA $\left(1363,1308\right.$ and $1342^{\circ} \mathrm{C}$ for the three alloys respectively.) The lower values for the ternary alloys, as determined using DTA, is suggested to be the result of dendritic segregation in the samples.

\section{DTA to study transformation kinetics of TiAl}

McQuay et al. report on their investigation into the decomposition of alpha phase during continuous cooling and isothermal transformation in gamma TiAl [46]. A typical DTA curve for Ti-48Al-2Mn-2Nb at $30 \mathrm{~K} / \mathrm{min}$ is shown in Figure 36 . The heating curve shows a broad endothermic reaction or transformation typical of a dissolution reaction which occurs 


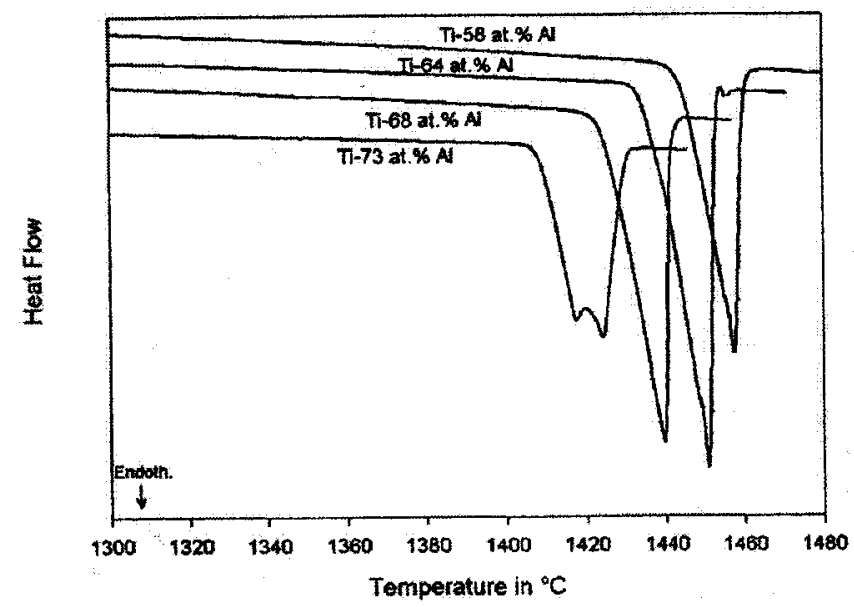

Figure 34: DTA heat flow curves at high temperature reported by Oehring et al. $[43]$.

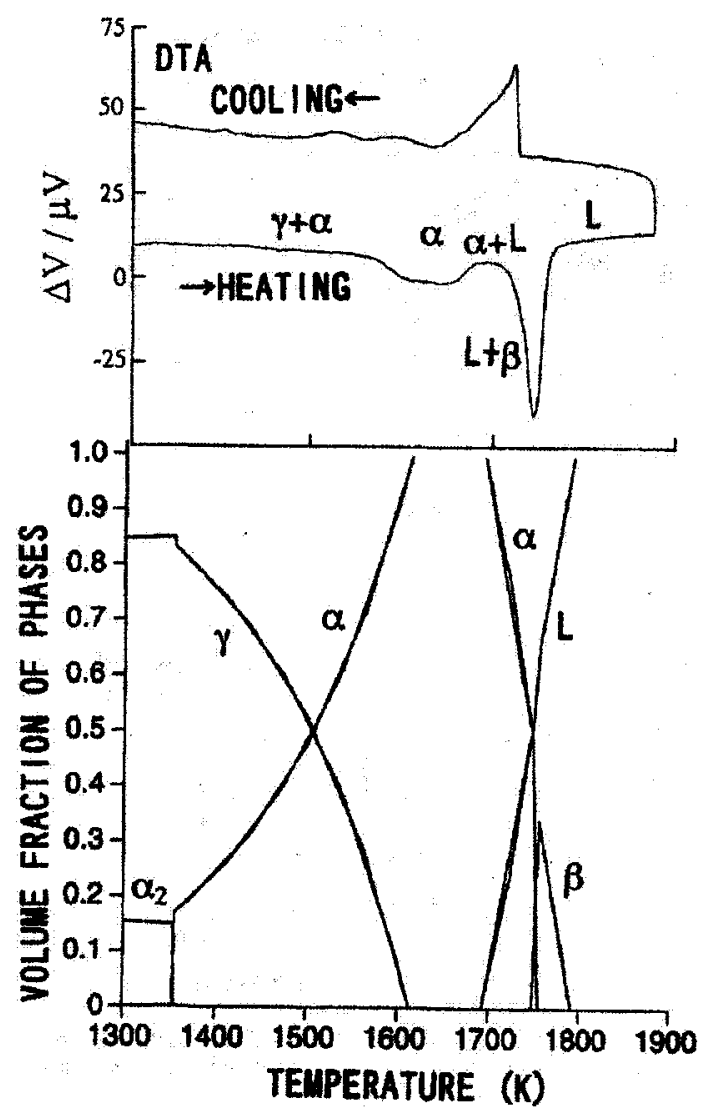

Figure 35: DTA measurements and the calculated phase fractional change in Ti-47Al-3Cr reported by Hashimoto et al. [44]. 
over a wide temperature range. The cooling curve indicates a very sharp exothermic reaction typical of a decomposition reaction. In order to better estimate $T_{\alpha}$ from the heating curve the sample was also run at $10 \mathrm{~K} / \mathrm{min}$ heating/cooling rates in order to extrapolate the transformation temperatures to near equilibrium conditions. The transus temperature determined metallographically is between 1360 and $1370{ }^{\circ} \mathrm{C}$, compared to $1369^{\circ} \mathrm{C}$ extrapolated from the DTA data. When this extrapolation technique is used, the DTA data compare very well with heat treatment and metallographic data. The dissolution reaction on heating, $\alpha+\gamma \rightarrow \alpha$, is sluggish and occurs over a wide temperature range (from $T_{E}$ to $T_{\alpha}$ ) and $T_{f}$, the final temperature of the endothermic peak is at best an estimate. Also, the endothermic peak temperature is taken as an estimate of the alpha transus temperature for each of the compositions, from the dissolution reaction on heating $(\alpha+\gamma \rightarrow \alpha)$, and the exothermic onset temperature is taken as the decomposition reaction temperature below the alpha transus for a given cooling rate, associated with the reverse of the above reaction $\left(\alpha^{s s} \rightarrow \alpha+\gamma\right)$. The amount of undercooling for the reaction is sensitive to $\mathrm{Al}$ content (ranging from $\Delta T_{48 A l}=50^{\circ} C$ to $\Delta T_{45 A l}=125^{\circ} C$ ). This is expected since the driving force for nucleation and growth of proeutectoid gamma decreases with decreasing $\mathrm{Al}$, as does the equlibrium volume fraction of gamma from the lever rule, resulting in larger undercooling. The decomposition reaction temperature from the cooling cycle is well above the reported eutectoid temperature $T_{E}=1125^{\circ} \mathrm{C}$. This data also indicates the reaction temperature decreases with decreasing $\mathrm{Al}$ content. This indicates the exothermic reaction is not the eutectoid, or an invariant reaction, but is the proeutectoid decomposition of disordered alpha. Since only lamellar gamma is found in the transformed alpha microstructure (optical and BSE examination), this implies that the reaction observed by DTA is the nucleation and growth of the gamma plates within the disordered alpha, ie. the formation of the lamellar structure. Additionally, the formation of the lamellar structure is very sensitive to cooling rate, and will not form when quenched from the alpha phase. To summarize, DTA was used in this study to examine the transformation paths and the kinetics of the transformations in several TiAl alloys. 


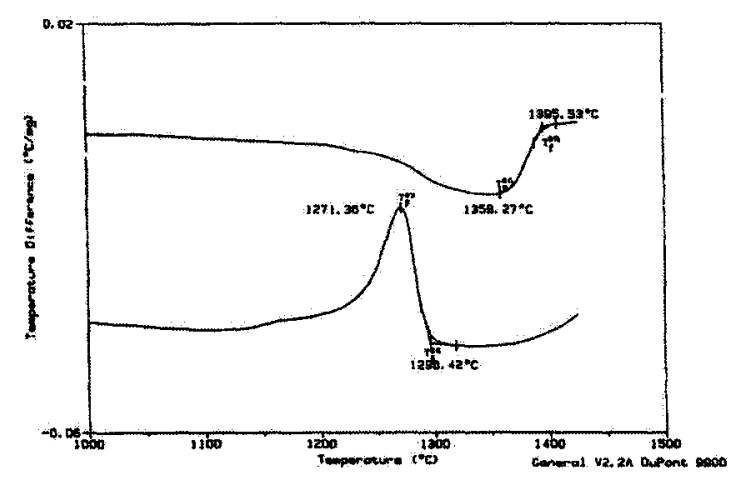

Figure 36: DTA curve for Ti-48Al-2Mn-2Nb, $30^{\circ} \mathrm{C} / \mathrm{min}$ reported by McQuay et al. [46].

\section{DSC for thermophysical property determination of TiAl alloys}

In the work reported by Saari $[4,37]$, several TiAl alloys (TAWS and TAMN) were analyzed using DSC. Note that these alloys were also studied for this thesis, and their compositions are given in Chapter 5. For some runs, platinum crucibles with alumina liners and lids were used and the inner surface of the crucibles was coated with an yttria spray to avoid reaction between the sample and the alumina liner. For other runs, yttria crucibles with the samples embedded in yttria powder were used. Tests were carried out at $20^{\circ} \mathrm{C} / \mathrm{min}$. Some typical DSC results for the TAWS and TAMN alloys are shown in Figure 37 and Figure 38 .

On heating, the solidus temperature for TAWS is $1453^{\circ} \mathrm{C}$ (extrapolated onset) and the liquidus temperature is $1522^{\circ} \mathrm{C}$ (extrapolated finish). For TAMN, the solidus and liquidus temperatures are $1479^{\circ} \mathrm{C}$ and $1561^{\circ} \mathrm{C}$. The effects of undercooling are evident in the cooling curves or both alloys. These results are consistent with the binary Ti-Al diagram, Figure 39, where liquidus temperature increases with decreasing $\mathrm{Al}$ content (TAWS $47.5 \mathrm{Al}$ and TAMN 46Al). The solidification paths, as evidenced by the cooling curves, are somewhat different for the two alloys. The TAWS alloy shows a pronounced terminal solidification event that is likely the peritectic reaction $\beta+L \rightarrow \alpha$. The TAMN alloy does not go through a terminal solidification event. This behaviour can be explained with reference to the phase 
diagram, Figure 39, which shows that the TAWS alloy, with its higher Al content, "passes through" the peritectic tie line during solidification. On the other hand, the TAMN alloy with its lower Al content "misses" the peritectic tie line. DSC was used in this case to provide some of the thermophysical data needed to simulate the solidification behaviour of these alloys. This thesis is the continuation of this research.

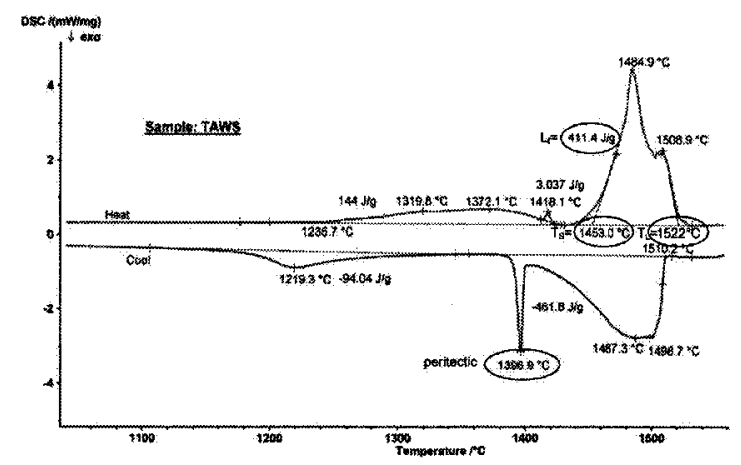

Figure 37: DSC heating (top line) and cooling results for TAWS, $20^{\circ} \mathrm{C} / \mathrm{min}$, reported by Saari et al. [37].

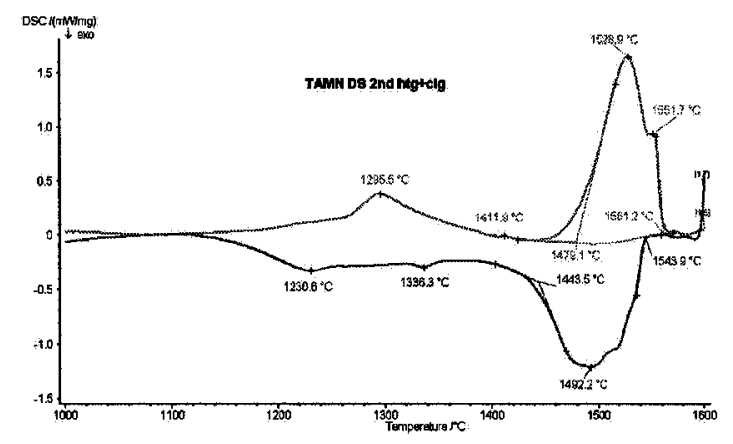

Figure 38: DSC heating (top line) and cooling results for TAMN, $20^{\circ} \mathrm{C} / \mathrm{min}$, reported by Saari et al. [37].

\subsection{The Importance of Understanding Phase Transforma- tions}

In addition to the need for accurate thermophysical properties, it is also important to understand the phase transformations that are occurring in the TiAl alloys being studied. In the work reported by Saari, of which the DSC portion is reported in Section 3.7 above, 


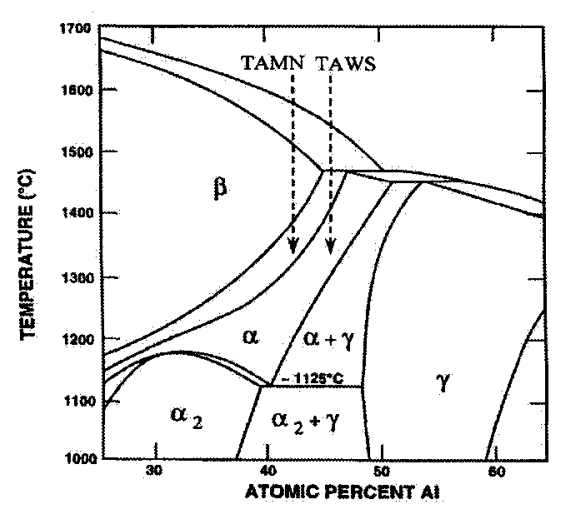

Figure 39: Binary Ti-Al phase diagram with the solidification paths for TAWS and TAMN indicated [4].

the TAWS and TAMN alloys were chosen to solidify completely as primary $\beta$, and thus avoid the normal lamellar orientation in solidification during casting. The presence of the peritectic reaction in the DSC results for the TAWS alloy indicates that the Al content was too high and/or that insufficient additions of $\mathrm{W}$ (a $\beta$ stabilizer) were added to guarantee complete $\beta$ solidification. Because of this, the alloy "passed through" the peritectic tie line during cooling, causing the $\alpha$ phase to form directly from the liquid. This peritectic $\alpha$ phase may then have influenced the lamellar orientation, resulting in grains with the normal orientation of lamellae. This would explain the presence of grains with the normal orientation in the TAWS castings. From the DSC results, the TAMN alloy seems to "miss" the peritectic reaction. If this were the situation, one would instead expect to see only parallel and angled orientations in the final as-cast microstructure. However, that is not the case as the TAMN castings also contain grains with the normal orientation of lamellae. A possible explanation for this is that dendrites of the $\beta$ phase form first, with the composition that solidifies gradually increasing. At the peritectic temperature, the $\alpha$ phase begins to form in the interdendritic regions. This $\alpha$ phase surrounds the primary $\beta$ phase, and prevent the peritectic reaction from occurring. As the temperature decreases further, the $\alpha$ phase continues to grow. Because the $\alpha$ phase forms directly from the liquid, its preferred growth direction combined with the subsequent orientation relationships governing the solid-state transformations results in lamellae normal to the growth direction. This could then control 
the orientation of the lamellae in the $\beta$ phase as well. If this were, indeed, the case, it would mean that the formation of the normal orientation of lamellae could not be ruled out for alloys with nominal compositions that "miss" the peritectic tie line [4].

\subsection{Summary}

Reliable thermophysical properties, such as liquidus $\left(\mathrm{T}_{L}\right)$ and solidus $\left(T_{S}\right)$ temperatures and fraction of solid $\left(f_{S}\right)$, are required for the simulation of casting of $\gamma$-TiAl parts. These properties can be found by using thermal analysis techniques. There are a number of high temperature thermal analysis techniques that are suitable for measuring the properties of interest. However, for the purposes of this thesis, high-temperature heat-flux DSC was used since Carleton University has a very high quality high-temperature DSC facility. For this reason, an emphasis was placed on explaining the DSC technique of thermal analysis. Various considerations for high-temperature calorimetry were discussed, as were general considerations for high-temperature thermal analysis experiments. Some of the aspects of thermal analysis of $\gamma$-TiAl alloys were also examined, and an overview of some of the thermal analysis experiments of $\mathrm{TiAl}$ that have been reported in the literature was given.

This ends the literature review portion of this thesis. In the next chapter the thesis objectives and scope are outlined. 


\section{Chapter 4}

\section{Thesis Objectives and Scope}

This thesis is continuing work that was begun as a research partnership program between Carleton University, the Structures and Materials Performance Laboratory (SMPL) of the National Research Council of Canada, and Pratt and Whitney Canada. The ultimate goal of the initial project was to develop a pilot-scale industrial process capable of producing DS $\gamma$-TiAl airfoil-shaped structures. While carrying out casting trials and simulations on TiAl materials, it was determined that more detailed thermophysical property data is required for TiAl intermetallics if accurate casting models are to be produced. The specific objectives of this thesis, within the scope of the original project, are as follows:

1. Determine the transformation paths for the various alloys tested.

2. Determine the transformation temperatures from the DSC analysis of the alloys.

3. Determine thermophysical properties as a function of composition $\left(T_{S}, T_{L}, f_{s}\right)$.

To meet these objectives, several major tasks were identified:

1. Review the literature to determine reported phase transformations and transformation temperatures for TiAl alloys.

2. Examine the binary TiAl compositions, determine the phase transformation sequence and the corresponding temperatures on the DSC plots.

3. Examine the ternary TiAl compositions and compare the results to those obtained for the binary compositions. 
4. Examine more complex TiAl compositions.

The DSC testing and analysis that was carried out to meet these tasks is outlined in the following chapter. 


\section{Chapter 5}

\section{Thermal Analysis of TiAl using DSC}

This chapter presents the thermal analysis of the $\gamma$-TiAl alloys carried out for this thesis. The following sections describe the experimental procedure followed and the results obtained. To begin, the materials analyzed are listed and discussed. Details of the Carleton University DSC facility are given, including the preparation of samples, the crucibles and reference material used for testing, the details of crucible and sample cleaning, the use of yttria powder in the sample crucible, and the procedure for weighing the test components. Other instrument factors are discussed next, including instrument calibration, baseline correction, heating programs, and heating rate effects. After this overview of the experimental procedure, the results of the DSC testing are presented. Results are divided into three sections: binary compositions, ternary compositions, and complex compositions. The transformation path, transformation temperatures (including $\mathrm{T}_{S}$ and $\mathrm{T}_{L}$ ), and the fraction of solid $\left(f_{s}\right)$ are presented for each alloy. The chapter ends with a discussion of these results.

\subsection{Experimental Procedure}

Thermal analysis of $18 \mathrm{TiAl}$ alloys was carried out using high-temperature heat flux DSC. The materials analyzed, the DSC equipment and the experimental details are discussed in the sections below. 


\subsubsection{TiAl Compositions Tested}

DSC analysis of eighteen (18) $\gamma$-TiAl alloys was carried out. The alloys used are listed in Table 5. The TiAl samples were supplied in one of three forms: investment cast bars, consolidated powder metallurgy, or loose powder metallurgy bars. Some of the samples were already available from previous research at Carleton University, and the rest of the samples were supplied by the Structures and Materials Performance Laboratory of the National Research Council of Canada. Binary, ternary, and more complex compositions with up to seven component elements were examined. The two binary compositions, Ti-48Al and Ti-54Al, were used to determine the transformation reactions on the DSC plots and to correlate the information obtained to the binary phase diagram predicted transformations and temperatures. The rest of the alloys varied in composition from 45 to 52 at. $\% \mathrm{Al}$, with various alloying additions including $\mathrm{Cr}, \mathrm{W}, \mathrm{Nb}, \mathrm{Mn}, \mathrm{Mo}, \mathrm{Si}$, and $\mathrm{TiB}_{2}$. The function of these alloying additions for TiAl are as follows:

- $\mathrm{W}$ is a $\beta$ stabilizer, also enhances oxidation and creep resistance

- Mo is a $\beta$ stabilizer, also increases ductility, strength and oxidation resistance

- $\mathrm{Nb}$ is a $\beta$ stabilizer, also increases oxidation and creep resistance

- $\mathrm{Cr}$ is a $\beta$ stabilizer and enhances ductility

- Mn enhances ductility

- Si increases creep resistance

- $\mathrm{TiB}_{2}$ is added as a grain refiner and exists as small particles with a very high melting temperature (should have little or no effect on the DSC results)

The preparation of samples is discussed in the next section.

\subsubsection{Preparation of Samples for DSC}

The samples used weighed approximately $30 \mathrm{mg}$. Two types of sample were used: solid (cast and consolidated powder metallurgy) and loose powder. Solid samples were prepared 


\begin{tabular}{|c|c|c|c|}
\hline Complexity & Condition & Name/Composition & Exact Composition \\
\hline \multirow{2}{*}{ Binary } & PM-L,C & $\mathrm{Ti}-48 \mathrm{Al}$ & $\mathrm{Ti}-48.1 \mathrm{Al}(530$ wppm O) \\
\hline & PM-L & Ti-54Al & $\mathrm{Ti}-53.1 \mathrm{Al}(680$ wppm O) \\
\hline \multirow{4}{*}{ Ternary } & PM-L & $\mathrm{Ti}-47 \mathrm{Al}-2 \mathrm{Cr}$ & - \\
\hline & PM-L & $\mathrm{Ti}-47.5 \mathrm{Al}-3 \mathrm{Cr}$ & - \\
\hline & PM-L & $\mathrm{Ti}-48 \mathrm{Al}-2 \mathrm{Cr}$ & - \\
\hline & $\mathrm{PM}-\mathrm{C}$ & Ti-48Al-2W & Ti-48.4Al-1.9W (830 wppm O) \\
\hline \multirow{7}{*}{ Quaternary } & Cast & Ti-45Al-2W-0.1Si & $\mathrm{Ti}-45 \mathrm{Al}-2.02 \mathrm{~W}-0.103 \mathrm{Si}$ \\
\hline & Cast & Ti-45Al-2W-0.5Si & Ti-45.7Al-2.2W-0.5Si \\
\hline & Cast & TAMN: Ti-46Al-2Mo-2Nb & - \\
\hline & Cast & ABB-2: Ti-47Al-2W-0.5Si & - \\
\hline & Cast & TAWS: Ti-47.5Al-2W-0.5Si & $\mathrm{Ti}-47.45 \mathrm{Al}-2.03 \mathrm{~W}-0.46 \mathrm{Si}$ \\
\hline & PM-L & $\mathrm{Ti}-48 \mathrm{Al}-2 \mathrm{Cr}-2 \mathrm{Nb}$ & $\mathrm{Ti}-47.7 \mathrm{Al}-1.97 \mathrm{Cr}-2.03 \mathrm{Nb}(660 \mathrm{wppm} \mathrm{O})$ \\
\hline & Cast & Ti-52Al-2W-0.5Si & - \\
\hline \multirow{7}{*}{ Complex } & PM-L & Ti-48Al-2Nb-2Cr-0.5W & - \\
\hline & PM-L & Ti-48Al-2Nb-2Cr-1W & - \\
\hline & $\mathrm{Coct}$ & 45XD: Ti-45Al-2Nb-2Mn & - \\
\hline & & $+0.8 \mathrm{TiB}_{2}$ & \\
\hline & Cast & 47XD: Ti-47Al-2Nb-2Mn & - \\
\hline & & $+0.8 \mathrm{TiB}_{2}$ & \\
\hline & Cast & $\begin{array}{c}\text { TiAlWMoSi: Ti-47Al-2Nb- } \\
2 \mathrm{Mn}-0.5 \mathrm{~W}-0.5 \mathrm{Mo}-0.2 \mathrm{Si}\end{array}$ & $\begin{array}{c}\mathrm{Ti}-47.02 \mathrm{Al}-1.98 \mathrm{Nb}-0.95 \mathrm{Mn}- \\
0.5 \mathrm{~W}-0.5 \mathrm{Mo}-0.21 \mathrm{Si}\end{array}$ \\
\hline
\end{tabular}

Table 5: The $18 \gamma$-TiAl alloys that were analyzed using DSC. All values are given in at. \%. Condition referes to the initial condition of the alloys, investment cast or powder metallurgy (PM). The PM alloys were either consolidated (PM-C) or in loose powder (PM-L) form. The binary Ti-48Al was available in both consolidated and loose powder form. Note that exact chemical compositions were only available for some of the alloys tested. 
from slices cut from the supplied bar stock or consolidated powder metallurgy. The samples were prepared as small disks approximately $0.5-1 \mathrm{~mm}$ thick and $3 \mathrm{~mm}$ in diameter. These disks were cleaned in an ultrasonic cleaner in a methanol bath, and rinsed with acetone, methanol and distilled water, and dried with clean compressed air before being weighed and tested in the DSC. Loose powder metallurgy samples were simply weighed and place in the crucible. Approximately $30 \mathrm{mg}$ of powder was used. Both solid and powder samples were tested in yttria crucibles, and the samples were surrounded by yttria powder. A new sample crucible was used for each of the 18 samples to ensure that no crucible contamination occurred between samples. The crucibles and yttria powder are discussed in more detail below.

\subsubsection{Crucibles and Reference Material}

For the DSC experiments the sample and reference materials were contained in high purity yttria $\left(\mathrm{Y}_{2} \mathrm{O}_{3}\right)$ crucibles. Yttria was used instead of the normal alumina $\left(\mathrm{Al}_{2} \mathrm{O}_{3}\right)$ crucibles, because of the reactivity of $\gamma$-TiAl at high temperatures. The crucibles, from Custom Technical Ceramics ${ }^{3}$, had a maximum outer diameter of $6.7 \mathrm{~mm}$, a maximum wall thickness of $0.7 \mathrm{~mm}$ and a height of $4.0 \mathrm{~mm}$, as illustrated in Figure 40. An alumina disk, with a mass of $41.2 \mathrm{mg}$, was used as the reference material for all of the DSC tests. The samples were embedded in yttria powder inside the crucibles to improve the thermal contact between the sample and the crucible, and to further reduce reactions between the sample and crucible. Even with yttria crucibles, and with the sample embedded in yttria powder, some reaction between the samples and crucibles took place. For this reason, a new crucible was used for each TiAl alloy tested. This eliminated cross contamination of crucibles between samples. A cleaning run was carried out for each new crucible, from room temperature up to $1600^{\circ} \mathrm{C}$ at $20 \mathrm{~K} / \mathrm{min}$, to ensure that any contaminants on the crucible were removed before sample runs were carried out. Between tests the crucibles were cleaned in methanol in an ultrasonic cleaner, then rinsed with acetone, methanol and distilled water, and finally dried with clean compressed air.

\footnotetext{
${ }^{3}$ http://www.customtechceramics.com/
} 


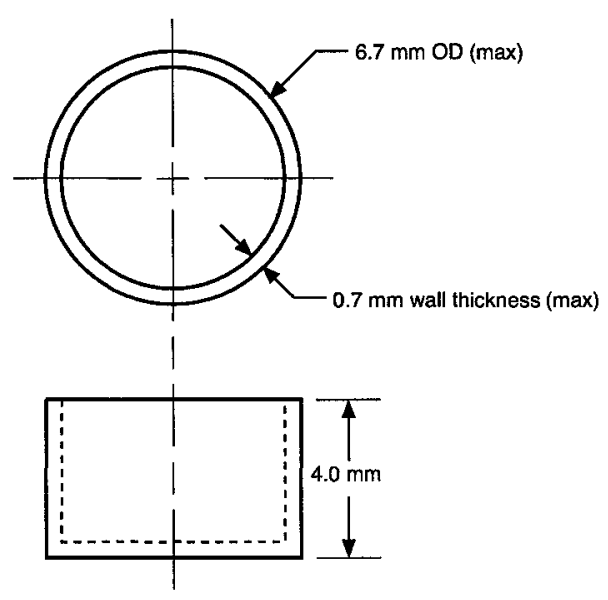

Figure 40: Schematic of DSC crucible, material: yttria.

\subsubsection{Crucible and Sample Cleaning}

Samples and sample crucibles were cleaned thoroughly before each test. As mentioned previously, solid samples were cleaned in a methanol bath in an ultrasonic cleaner, rinsed with acetone, methanol and distilled water, and then dried with clean compressed air to ensure that all moisture was removed prior to weighing and placing in the yttria powder in the crucible. A new sample crucible was cleaned for each different TiAl alloy by baking it out in the DSC. Crucibles were also cleaned between tests in the ultrasonic cleaner and were rinsed and dried in the same way as samples before being weighed and reused for the next test. Tweezers and clean gloves were used to handle all of the materials used for the DSC tests; clean samples, crucibles, reference, and powder were never touched with bare hands.

\subsubsection{Yttria Powder}

Samples were embedded in yttrium oxide powder $\left(\mathrm{Y}_{2} \mathrm{O}_{3}, 99.99 \%\right.$ pure, $<10$ micron particle size) for all DSC tests. The powder provides good thermal contact between the sample and the crucible. It also protects the crucible from damage if reactions with the sample occur. The amount of powder used was dependant on the sample size, but in general approximately $50 \mathrm{mg}$ of powder was used for each test. The procedure was as follows: the bottom of the 
crucible was covered with a layer of powder, the sample was placed in the centre of the crucible on top of the powder (for powder metallurgy samples a small well was made in the yttria powder in the crucible and then the TiAl powder was poured into this hole), and finally yttria powder was used to completely cover the sample in the crucible. The bottom of the sample crucible was wiped off on a clean piece of paper before each test to ensure that no yttria powder was adhering to it.

\subsubsection{Weights}

All experimental components (crucibles, sample, reference, powder) were weighed with a precision scale, shown in Figure 41, before and after each test. All masses were recorded in $\mathrm{mg}$, and the scale used has a precision of $\pm 0.005 \mathrm{mg}$. Initial weights were required as input for the DSC software. Final weights were recorded after each test to ensure that no significant change in weight occurred during testing. Changes in weight during a DSC test can indicate problems that occured during the test such as undesirable chemical reactions.

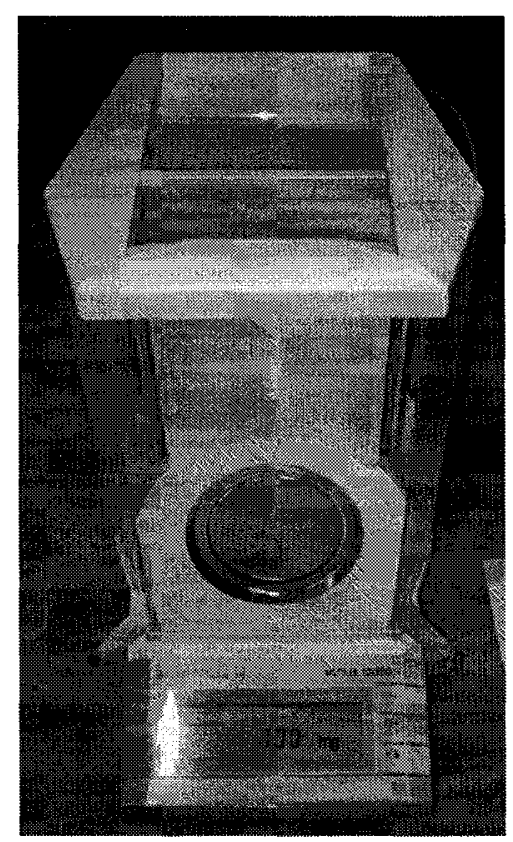

Figure 41: Photo of the scale used to weigh samples for DSC tests. 


\subsubsection{Carleton University DSC Facility}

Tests were carried out using the differential scanning calorimetry equipment at Carleton University: a Netzsch DSC 404C Pegasus. It is capable of measurements from room temperature up to $1650^{\circ} \mathrm{C}$ at heating rates of 0.1 to $20 \mathrm{~K} / \mathrm{min}$. The sample carrier used has a DSC - Cp high-accuracy measuring head with type S (Pt10\%/Pt-Rh) thermocouples that can measure from room-temperature to $1650^{\circ} \mathrm{C}$. The unit is capable of running tests with several types of atmosphere in the sample chamber: static or dynamic oxidizing, reducing, inert or vacuum [47]. Tests for this thesis used a dynamic (flowing) inert ultra high purity argon atmosphere, with a flow rate of approximately $60 \mathrm{~mL} / \mathrm{min}$. To ensure that no oxygen was present during the experimental runs, three cycles of furnace evacuation and back-filling with argon were carried out before the final flowing argon atmosphere was introduced. Vacuum levels obtained during the evacuation process were approximately 1 mbar.

A photo of the DSC equipment is shown in Figure 42. Details of the measuring unit are shown in Figure 43, which labels the main components of the measuring unit. Figure 44 also shows a side detail cutaway of the measuring unit. The furnace is lowered over the sample carrier system using the hoisting device. As indicated by the small arrows in Figure 44, argon gas flows up around the bottom of the sample carrier, through the furnace, and out through the valve at the top. The furnace is heated by circumferential elements in its walls, and protective argon gas flows through the outer wall of the furnace for cooling to ensure the outside of the furnace remains cool. A close up detail of the sample carrier system is shown in Figure 45. The sample and reference crucibles are placed on the measuring head and the thermocouples are attached to the bottom of the crucible holders. The thermocouple wires pass down through the hollow capillary tube to the plug at the bottom of the carrier. Radiation shields protect the lower portions of the sample carrier and furnace from the high temperatures around the measuring head. The carrier is screwed in place once the plug is set, and adjusting micrometers attached to the base 
can be used to centre it in the furnace. Purge gas flow is controlled using the front panel of the measuring unit and the needle valve adjusting knobs on the top of the measuring unit.

Appendix B contains an illustrated guide of the setup procedures for carrying out DSC testing using the Carleton University equipment.

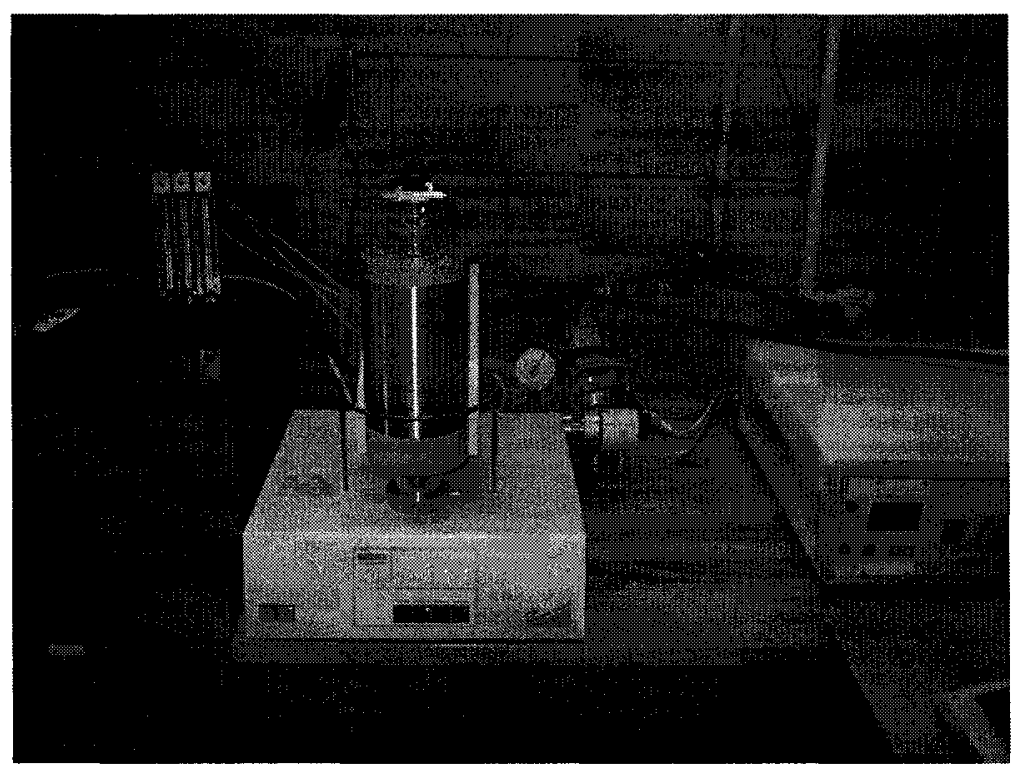

Figure 42: Photo of the DSC equipment.

\subsubsection{Baseline Correction}

Baseline corrections, carried out with empty sample and reference crucibles, were also used for each heating program to ensure that any drift in the instrument baseline was removed for the sample runs. The baselines used the same heating program as the sample runs. The effect on the baseline of empty crucibles vs. crucible with yttria powder and alumina reference was examined and was found to be negligible.

\subsubsection{Heating Programs}

Two heating and cooling cycles were used for each test. The heating program for the 20 $\mathrm{K} / \mathrm{min}$ tests is shown in Figure 46 . The program has several distinct phases, beginning 


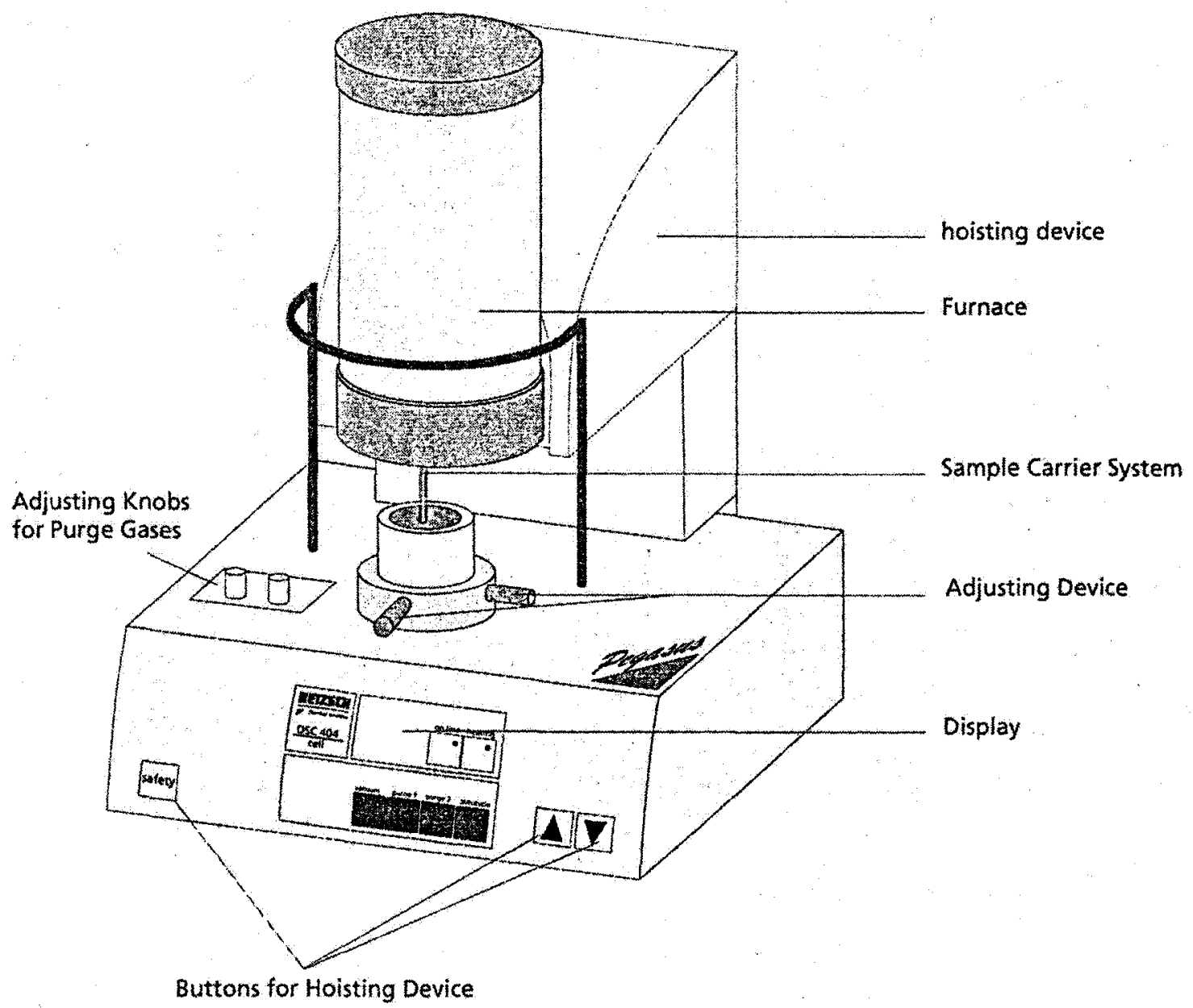

Figure 43: Measuring unit of the DSC 404 Pegasus [47]. 


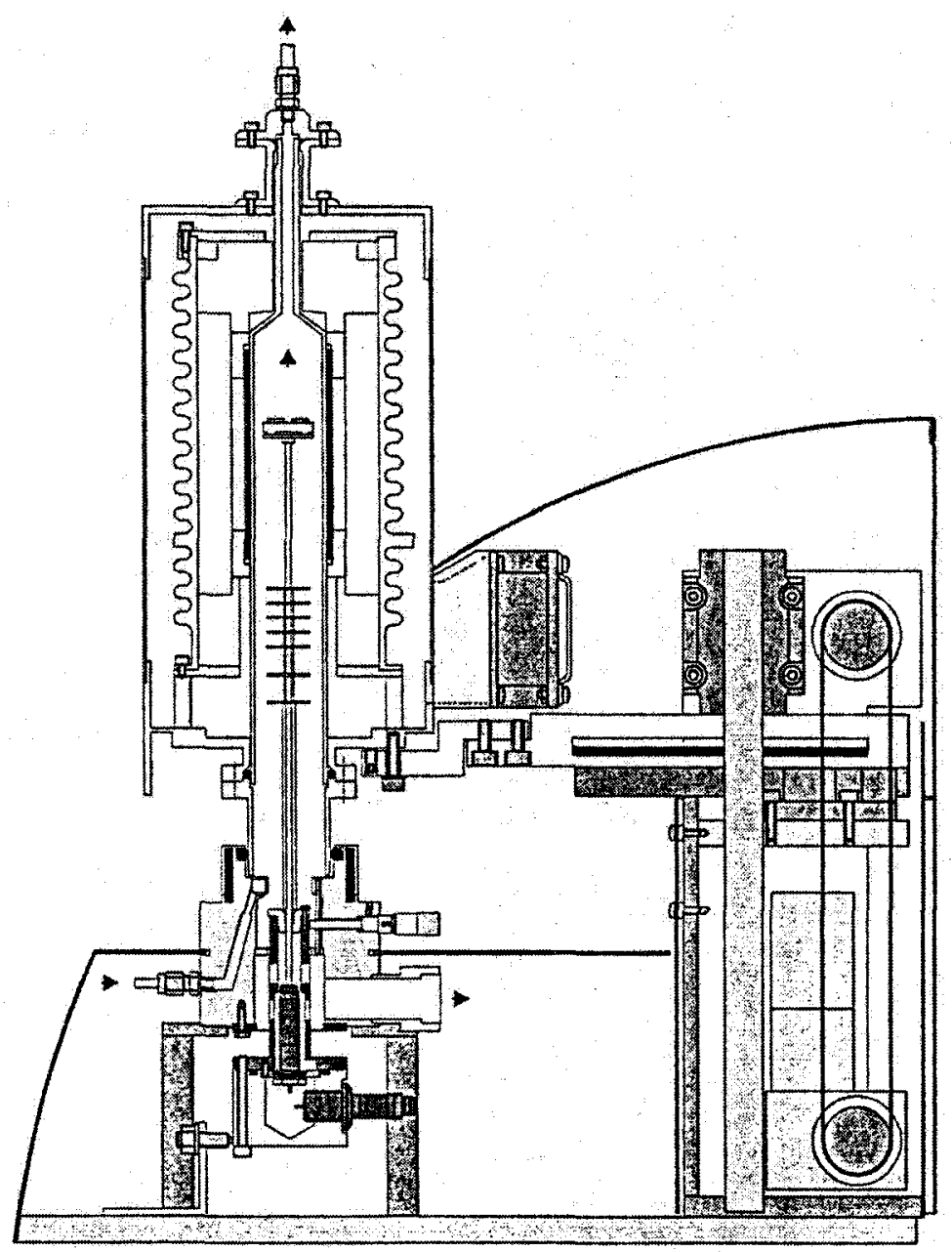

Figure 44: Side detail cutaway of the DSC 404 Pegasus measuring unit [47]. 


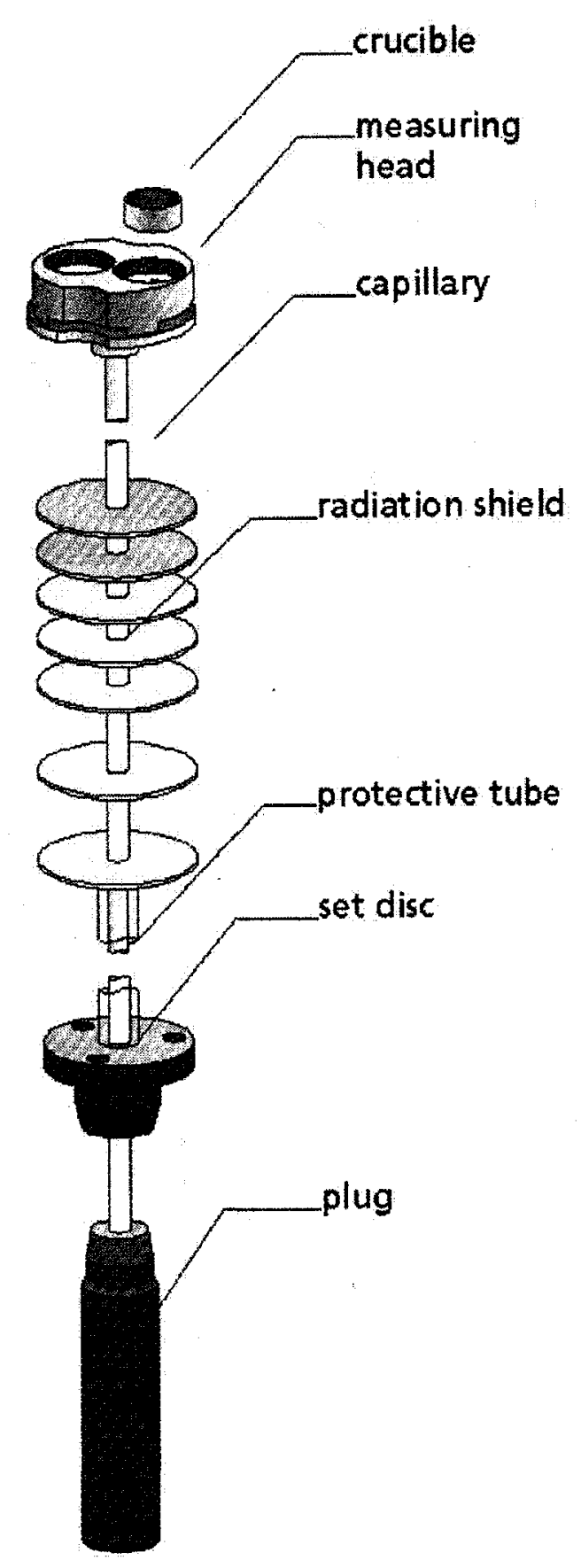

Figure 45: Detail of sample carrier system and DSC high-accuracy measuring head, adapted from [47]. 
with the initial standby from room temperature (RT) up to $100^{\circ} \mathrm{C}$ at $10 \mathrm{~K} / \mathrm{min}$. This initial standby portion of the run ensured that all tests began in the same way. The next phase is the first dynamic portion, from $100^{\circ} \mathrm{C}$ to $1600^{\circ} \mathrm{C}$ at $20 \mathrm{~K} / \mathrm{min}$. Each heating and cooling phase was followed by an isothermal time of 5 minutes, so that all temperatures in the furnace could reach equilibrium before the next dynamic portion began. The second dynamic portion, the first cooling, cools the sample from $1600^{\circ} \mathrm{C}$ down to $700^{\circ} \mathrm{C}$. The cooling is not continued all the way to room temperature to save time in testing, and since all of the reactions of interest are finished by the time the sample reaches $700^{\circ} \mathrm{C}$. The heating and cooling cycles are then repeated to see what the transformation temperatures of the sample are with the initial solidification conditions removed. This also provides twice as much thermal data from each test. For each test an external reset temperature $\left(T_{\text {reset }}\right)$ is used. It is typically 10 degrees above the maximum temperature for the test, and is used to protect the sample and furnace from damage. For the TiAl tests, with a maximum sample temperature of $1600^{\circ} \mathrm{C}, T_{\text {reset }}$ was set to $1610^{\circ} \mathrm{C}$. The maximum test temperature of $1600^{\circ} \mathrm{C}$, just below the maximum instrument temperature of $1650^{\circ} \mathrm{C}$, was chosen because it is high enough to capture all of the thermal events that should be occurring in the $\gamma$-TiAl samples while ensuring that no damage should occur to the DSC equipment due to overheating above the maximum allowable temperature.

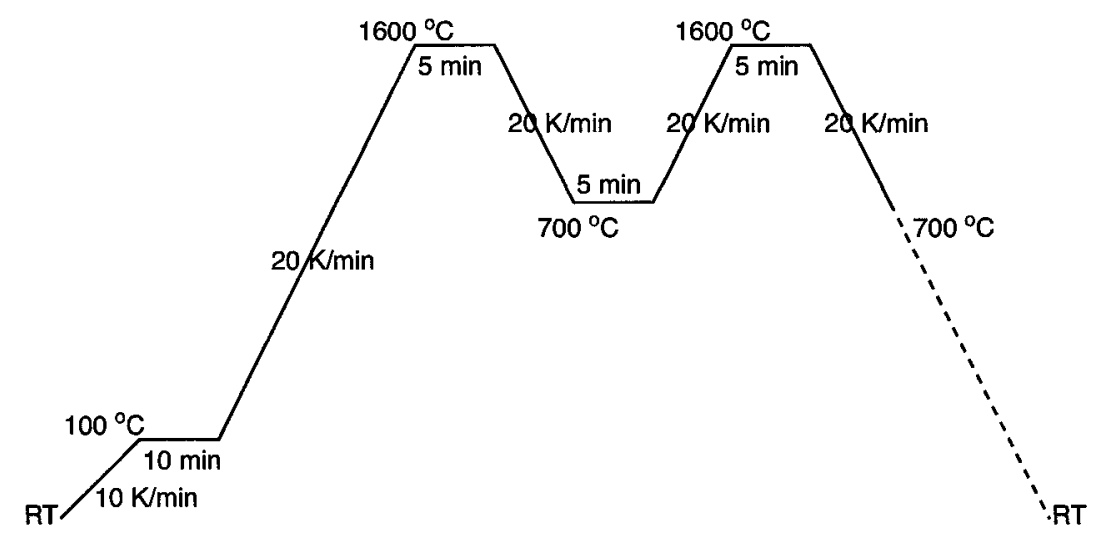

Figure 46: DSC heating program, $20 \mathrm{~K} / \mathrm{min}$. 


\subsubsection{DSC Calibration}

Calibration of the DSC was carried out at various heating rates using known standards to produce temperature and enthalpy calibration curves to ensure accurate readings in all temperature ranges. Six calibration standards ( $\mathrm{Zn}, \mathrm{Al}, \mathrm{Ag}, \mathrm{Au}, \mathrm{Ni}$ and $\mathrm{Co}$ ) were used to ensure a very wide range of accurate temperature readings. For each calibration standard, an appropriate heating program was chosen (heating to just above the melting temperature of the sample), and a baseline was run. The calibration run for each standard was then carried out using the previously run baseline for that material. Two heating and cooling cycles were used for each calibration run. The results of these two runs were averaged used as the input for the calibration file. A sample calibration curve, the temperature calibration for $20 \mathrm{~K} / \mathrm{min}$, is shown in Figure 47 .

Temperature calibration used the melting temperature of pure samples. The melting temperature of the samples was taken as the onset temperature from the DSC curve; the onset is the temperature at which melting begins. Onset temperatures tend to be less variable than peak temperatures with respect to experimental factors such as heating rate [29]. Another consideration for temperature calibration is that the measured temperature must be within $20 \mathrm{~K}$ of the theoretical temperature for the software to accept the experimental value and produce the calibration curve. Many of the peak temperatures, especially for the higher melting temperature materials, fell outside this $20 \mathrm{~K}$ range. There was some undercooling in all of the samples, so only the heating values were used for calibration purposes. The melting temperature for calibration was taken as the average of the first and second peak onset temperatures from the heating curves. The theoretical and measured temperature values for the $20 \mathrm{~K} / \mathrm{min}$ calibration run is shown in Table 6 . As an example, the DCS curve for Au is shown in Figure 48. The onset temperatures for the two heating curves are $T_{m, H 1}=1060.3^{\circ} \mathrm{C}$ and $T_{m, H 2}=1056.6^{\circ} \mathrm{C}$, as listed in Table 6. The average of these two temperatures gives $\bar{T}_{m, H 1+H 2}=1058.45^{\circ} \mathrm{C}$, which is the experimental melting temperature for $\mathrm{Au}$ input into the calibration curve. The theoretical melting temperature 
for gold is $T_{m}=1064.2^{\circ} \mathrm{C}$. Enthalpy calibration used the area under the melting peaks of the DSC curves (in $\mu \mathrm{V}^{*} \mathrm{~s} / \mathrm{mg}$ ), compared to the corresponding theoretical enthalpy of the sample (in $\mathrm{J} / \mathrm{g}$ ).

\begin{tabular}{|c|c|c|c|c|c|c|}
\hline Standard & Theoretical $\boldsymbol{T}_{\boldsymbol{m}}$ & $\boldsymbol{T}_{\boldsymbol{m}, \boldsymbol{H} \mathbf{1}}$ & $\boldsymbol{T}_{\boldsymbol{m}, \boldsymbol{H} \mathbf{2}}$ & $\overline{\boldsymbol{T}}_{\boldsymbol{m}, \boldsymbol{H 1}+\boldsymbol{H 2}}$ & Tolerance & \% Diff. \\
\hline $\mathrm{Zn}$ & 419.6 & 420.6 & 421.0 & 420.80 & $+/-3 \mathrm{~K}$ & -0.29 \\
$\mathrm{Al}$ & 660.3 & 662.2 & 662.1 & 662.15 & $+/-3 \mathrm{~K}$ & -0.28 \\
$\mathrm{Ag}$ & 961.8 & 960.7 & 961.5 & 961.10 & $+/-3 \mathrm{~K}$ & -0.07 \\
$\mathrm{Au}$ & 1064.2 & 1060.3 & 1056.6 & 1058.45 & $+/-3 \mathrm{~K}$ & 0.54 \\
$\mathrm{Ni}$ & 1455.0 & 1440.2 & 1439.5 & 1439.85 & $+/-5 \mathrm{~K}$ & 1.04 \\
$\mathrm{Co}$ & 1495.0 & 1485.8 & 1484.8 & 1485.30 & - & 0.65 \\
\hline
\end{tabular}

Table 6: Temperature calibration table (for $20 \mathrm{~K} / \mathrm{min}$ ) showing the calibration standards used, their theoretical melting temperature, the measured melting temperatures on the first and second heading during the DSC measurement, the average of the two heatings, the tolerance for the sample, and the \% difference between the theoretical and measure values. All temperatures are given in ${ }^{\circ} \mathrm{C}$.

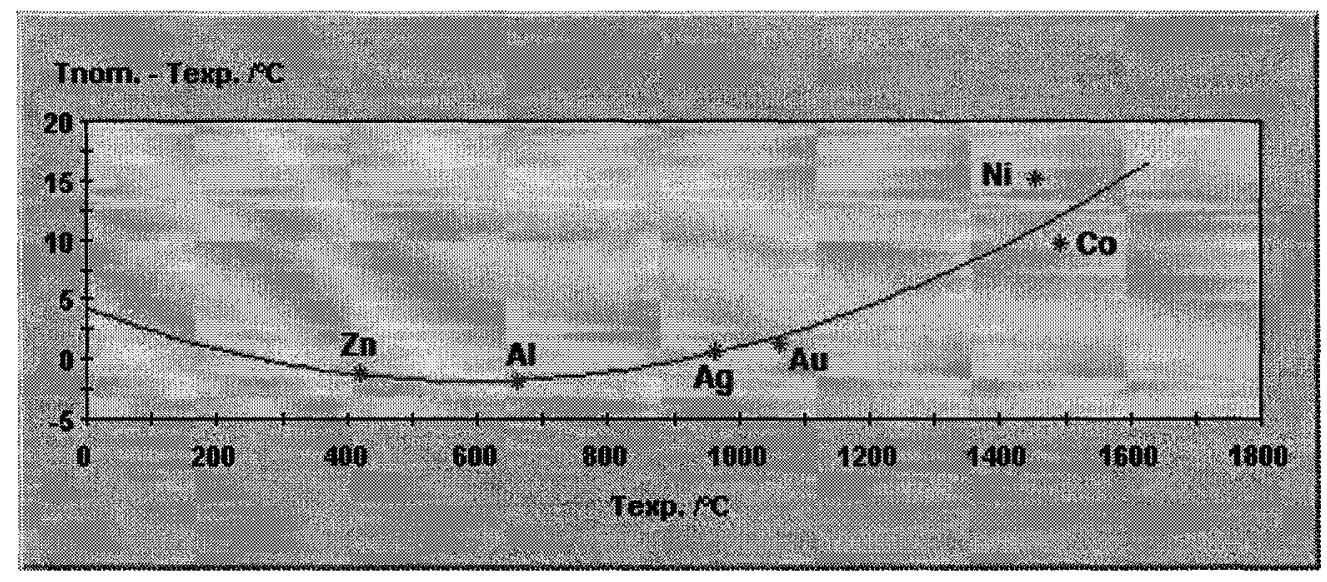

Figure 47: DSC temperature calibration curve, $20 \mathrm{~K} / \mathrm{min}$.

\subsubsection{Heating Rate Effects}

To examine the heating rate effect, tests were carried out at various heating rates. Sample runs were carried out at 20 and $5 \mathrm{~K} / \mathrm{min}$. Some calibration runs were also carried out at $10 \mathrm{~K} / \mathrm{min}$ so that comparisons of the various heating rates, as well as extrapolation to 


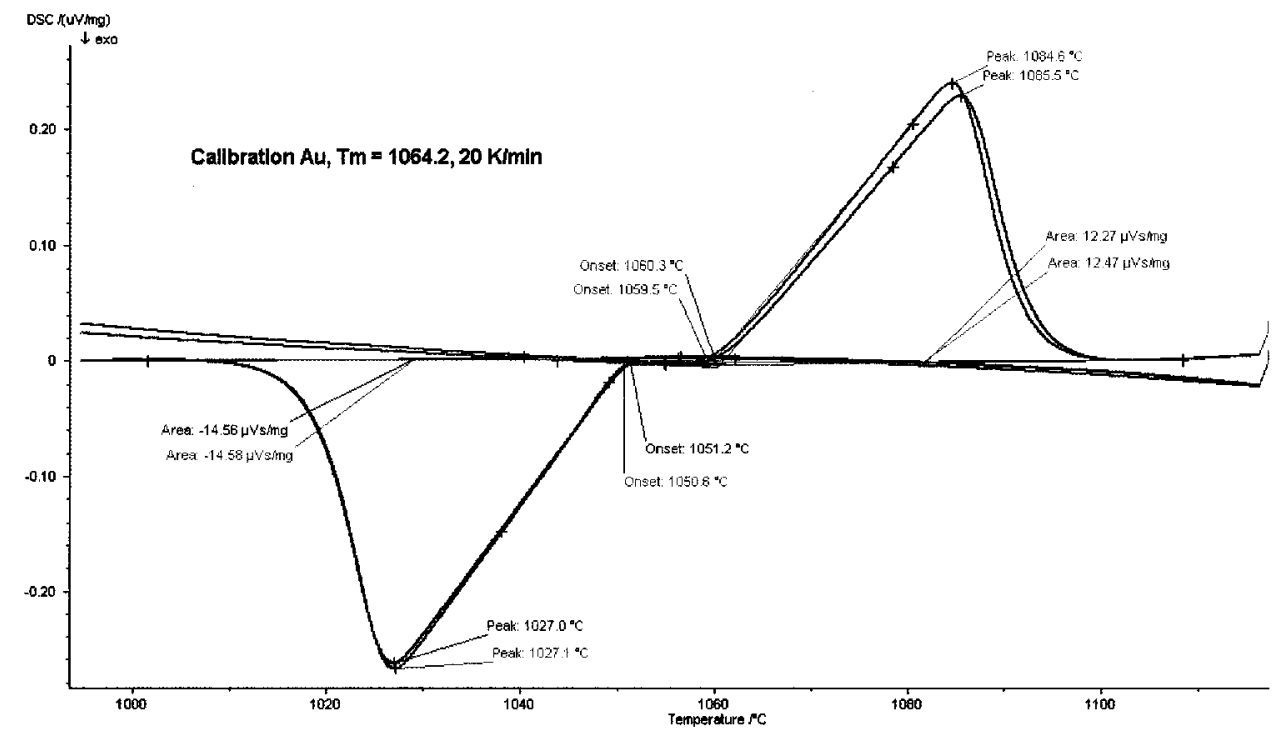

Figure 48: Sample DSC plot for one of the calibration samples, Au, showing heating and cooling curves. Heating rate is $20 \mathrm{~K} / \mathrm{min}$. The peak onset temperatures on the heating curves were used for calibration purposes.

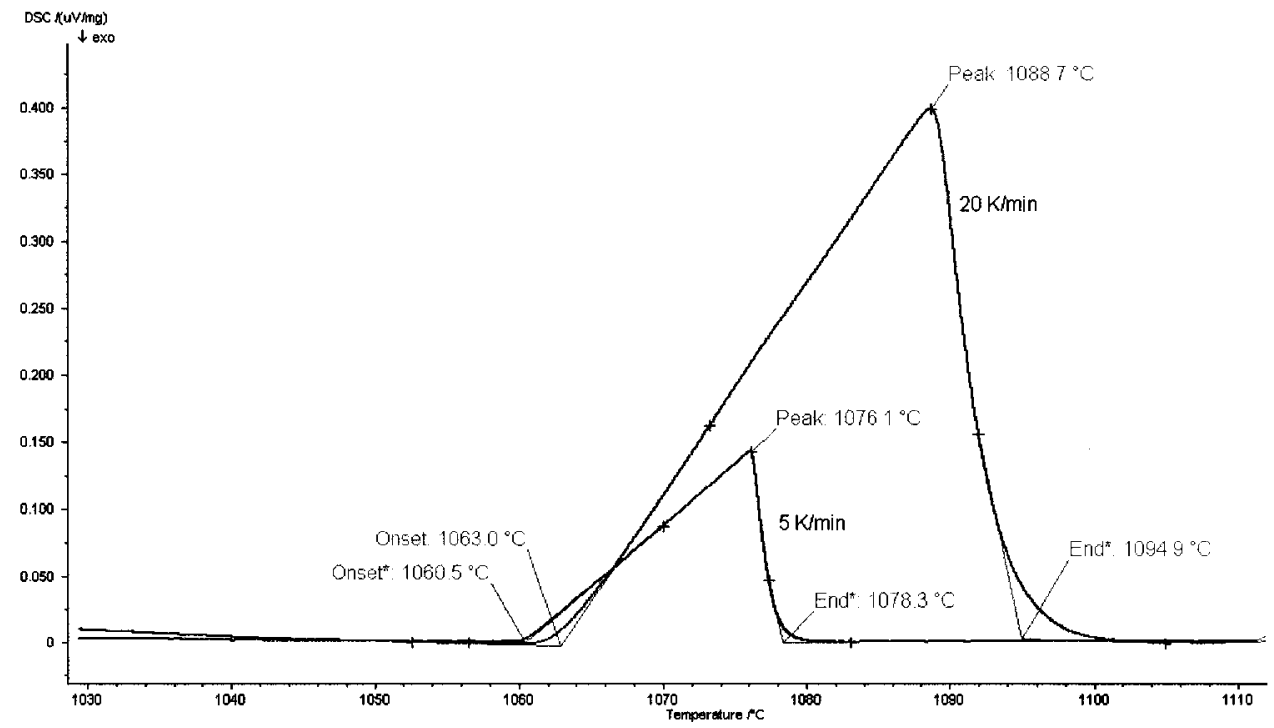

Figure 49: DSC plots illustrating the heating rate effect on the melting temperature of $\mathrm{Au}$ at 5 and $20 \mathrm{~K} / \mathrm{min}$. 
equilibrium values, could be carried out. Heating rate tends to have more of an effect on the peak temperature than on the onset temperature of a thermal event [29]. This can be seen in Figure 49 where there is a small difference $\left(2.5^{\circ} \mathrm{C}\right)$ in the onset temperatures between 5 and $20 \mathrm{~K} / \mathrm{min}$, and a much larger difference $\left(11.8^{\circ} \mathrm{C}\right)$ between the peak temperatures.

\subsubsection{Other Considerations}

Several runs were carried out with no sample in the DSC to examine crucible, powder and instrument effects on the test results. Runs were carried out using the sample heating program with no crucibles, crucibles with no powder, and crucible with powder. It was found that no thermal effects are introduced by the crucibles or powder. There was no difference between tests run with empty crucibles vs. tests run with crucibles containing only the reference and powder. By carrying out sample plus correction runs (ie. by including a baseline in each sample run) instrument and crucible effects are negated.

\subsubsection{Analysis of DSC Curves}

The analysis of the DSC data obtained was carried out using the Netzsch Thermal Analysis Software. For each test the onset, peak, end and inflection temperatures were marked on the DSC curve using the Netzsch analysis software. This data is compiled and discussed in the Results Section below.

\subsection{Results}

The results of the DSC analysis are presented and discussed in this section. First the results for the binary compositions will be discussed, then the ternary compositions, and finally the more complex alloys. Results are presented in the form of DSC curves as well as temperature data obtained from the curves. The transformation path that the alloy goes through, the liquidus $\left(\mathrm{T}_{L}\right)$ and solidus $\left(\mathrm{T}_{S}\right)$ temperatures, and the fraction of solid $\left(\mathrm{f}_{S}\right)$ as a function of temperature are given. A sample DSC curve is shown for each alloy discussed to illustrate the general curve trends for that alloy; including the curves for all of the tests 
that were carried out would be redundant. DSC results for all compositions are compiled in Appendix C.

\subsubsection{Binary Compositions}

Two binary compositions, Ti-48Al and Ti-54Al, were available for testing. Figures 50 and 51 show the DSC curves for the two binary compositions of TiAl that were studied. The results for each are summarized below.

\section{Ti-48Al}

With reference to the binary phase diagram, Figure 7, it can be seen that the transformation sequence on heating for Ti-48Al is: $\alpha_{2}+\gamma \rightarrow \alpha+\gamma \rightarrow \alpha \rightarrow \alpha+L \rightarrow \beta+L \rightarrow L$. The equilibrium phase transformation temperatures can be picked off the binary phase diagram and are listed in Table 7. These transformations are marked on the DSC curve, Figure 50. The second heating curve is shown because the transformations seem to show up more clearly on this curve than for the first heating. This may be due to the non-homogeneous nature of the powder metallurgy sample. In interpreting the DSC curve, the following transformations and curve features were matched up. Starting with the most prominent feature, the largest peak on the curve corresponds to the $\alpha+L \rightarrow \beta+L \rightarrow L$ transformation. The onset of the large peak corresponds to the $\alpha+L \rightarrow \beta+L$ transformation. While it is not evident on the $20 \mathrm{~K} / \mathrm{min}$ curve, on the $5 \mathrm{~K} / \mathrm{min}$ curve the main melting peak can clearly be seen as two distinct peaks; these two peaks are merged into the single large peak on the $20 \mathrm{~K} / \mathrm{min}$ curve. This double peak on the $5 \mathrm{~K} / \mathrm{min}$ curve can be seen in the inset portion of Figure 50. This first peak corresponds to the $\alpha+L \rightarrow \beta+L$ transformation (the main peak on the $20 \mathrm{~K} / \mathrm{min}$ curve) and the second peak corresponds to the $\beta+L \rightarrow L$ transformation (the inflection point on the $20 \mathrm{~K} / \mathrm{min}$ curve). The end temperature of the peak is the end of the $\beta+L \rightarrow L$ transformation, and only liquid phase is present above that temperature. The broad endotherm before the large peak indicates a dissolution which is occurring over a wide temperature range. This is the $\alpha+\gamma \rightarrow \alpha$ transformation, with the onset temperature indicating the end of the $\alpha_{2}+\gamma \rightarrow \alpha+\gamma$ transformation, and the end 


\begin{tabular}{|l|c|c|c|c|c|c|}
\hline Transformaion & DSC Curve & Theoretical & Literature & $\mathbf{2 0} \mathbf{~ K} / \mathbf{m i n}$ & $\mathbf{5 ~ K} / \mathbf{m i n}$ & $\boldsymbol{f}_{\boldsymbol{S}}$ \\
\hline$\alpha_{2}+\gamma \rightarrow \alpha+\gamma$ & & 1125 & - & 1191 & - & 1 \\
$\alpha+\gamma \rightarrow \alpha$ & & 1370 & $1370[45]$ & 1348 & - & 1 \\
$\alpha \rightarrow \alpha+L\left(\mathrm{~T}_{S}\right)$ & onset & 1460 & $1447[14]$ & 1463 & 1481 & 1 \\
$\alpha+L \rightarrow \beta+L$ & peak & 1470 & $1491[14]$ & 1529 & 1512 & 0.44 \\
$\beta+L \rightarrow L\left(\mathrm{~T}_{L}\right)$ & inflection & 1510 & $1504[14]$ & 1545 & 1559 & 0.18 \\
$L$ & end & - & - & 1564 & 1567 & 0 \\
\hline
\end{tabular}

Table 7: Transformation temperatures for Ti-48Al, all temperatures given in ${ }^{\circ} \mathrm{C}$. Temperatures from the $5 \mathrm{~K} / \mathrm{min} \mathrm{DSC}$ run are included for comparison. The $f_{S}$ values listed correspond to the $20 \mathrm{~K} / \mathrm{min}$ curve.

temperature indicating that all of the $\gamma$ has been transformed to $\alpha$. The phases present have been marked on the DSC curve. To determine the fraction of solid present as a function of temperature, the areas under the curve at several temperatures must be examined. The onset of the large peak, $T_{\alpha \rightarrow \alpha+L}$, is the solidus temperature because only solid exists up to that point. The peak temperature, $T_{\alpha+L \rightarrow \beta+L}$, and the inflection point, $T_{\beta+L \rightarrow L}$, are the points at which $f_{S}$ is calculated from the areas shown in Figure 50 using the area equation given in Section 3.5. The fraction solid values, $f_{S}$, are listed in Table 7, and they correspond to the areas from the $20 \mathrm{~K} / \mathrm{min}$ run.

\section{Ti-54Al}

There were problems with reactions between the Ti-54Al binary alloy and the yttria crucibles. The first sample that was tested was fine. However with subsequent samples tested under the same conditions there were problems with reactions between the sample and the yttria powder and crucible. The second sample had significant weight gain during the test (31.14 $\mathrm{mg}$ before to $56.63 \mathrm{mg}$ after testing). The third sample reacted through the yttria powder and damaged the bottom of the crucible. The reaction caused a portion of the bottom of the crucible to adhered to the measurement head. The crucible cracked while trying to remove the powder and the sample. No final measurement of the sample was obtained for the third sample because so much of the yttria powder was attached to the Ti-54Al. Thus, because of problems with sample reactivity, only one accurate 20 


\begin{tabular}{|l|c|c|c|c|}
\hline Transformaion & DSC Curve & Theoreical & DSC 20 K/min & $\boldsymbol{f}_{\boldsymbol{S}}$ \\
\hline$\gamma \rightarrow \alpha+L\left(\mathrm{~T}_{S}\right)$ & onset & 1445 & 1446 & 1 \\
$\alpha+L \rightarrow L\left(\mathrm{~T}_{L}\right)$ & inflection & 1460 & 1490 & 0.16 \\
$L$ & end & - & 1506 & 0 \\
\hline
\end{tabular}

Table 8: Transformation temperatures for Ti-54Al, all temperatures given in ${ }^{\circ} \mathbf{C}$.

$\mathrm{K} / \mathrm{min}$ DSC test was obtained for this sample and no $5 \mathrm{~K} / \mathrm{min}$ test were run. For this reason, only the results for the first $20 \mathrm{~K} / \mathrm{min}$ test are included here.

From the binary phase diagram, Figure 7, and as reported in the literature [13], Ti-54Al is a peritectic composition. The transformation sequence on heating is thus: $\gamma \rightarrow \alpha+L \rightarrow L$. However, the powder used had a reported exact chemical composition of Ti-53.1Al which falls just to the left of the peritectic composition on the phase diagram. The transformation sequence for this composition is: $\gamma \rightarrow \alpha+\gamma \rightarrow \alpha+L \rightarrow L$. However, at $20 \mathrm{~K} / \mathrm{min}$ the small volume of the $\alpha+\gamma$ transformation does not show up on the DSC curve. The DSC curve for this sample is shown in Figure 51. Note the large difference between the first and second heating curves; this difference is most likely due to the nature of the powder sample and the consolidation process. The first heating has one large peak corresponding to the consolidation of the powder sample, and is probably also affected by the change in surface energy of the sample. The second heating has a peak and an inflection point, which matches general shape of the cooling curve. Thus, the second heating curve better represents the transformations that occurred in the sample. Examining the cooling curve for $\mathrm{Ti}-54 \mathrm{Al}$ with reference to the binary phase diagram, on cooling the sample goes from liquid to the broad peak which corresponds to $\alpha+L$. The large peak is then the peritectic transformation from $\alpha+L$ to $\gamma$. Thus, for the heating curve, the large peak is the peritectic reaction, so the onset corresponds to the $\gamma \rightarrow \alpha+L$ transformation. The inflection point is then the $\alpha+L \rightarrow L$ transformation. Table 8 summarizes the results for $\mathrm{Ti}-54 \mathrm{Al}$, with the theoretical transformation temperatures that were taken from the equilibrium phase diagram. The fraction of solid values are listed in Table 8. 


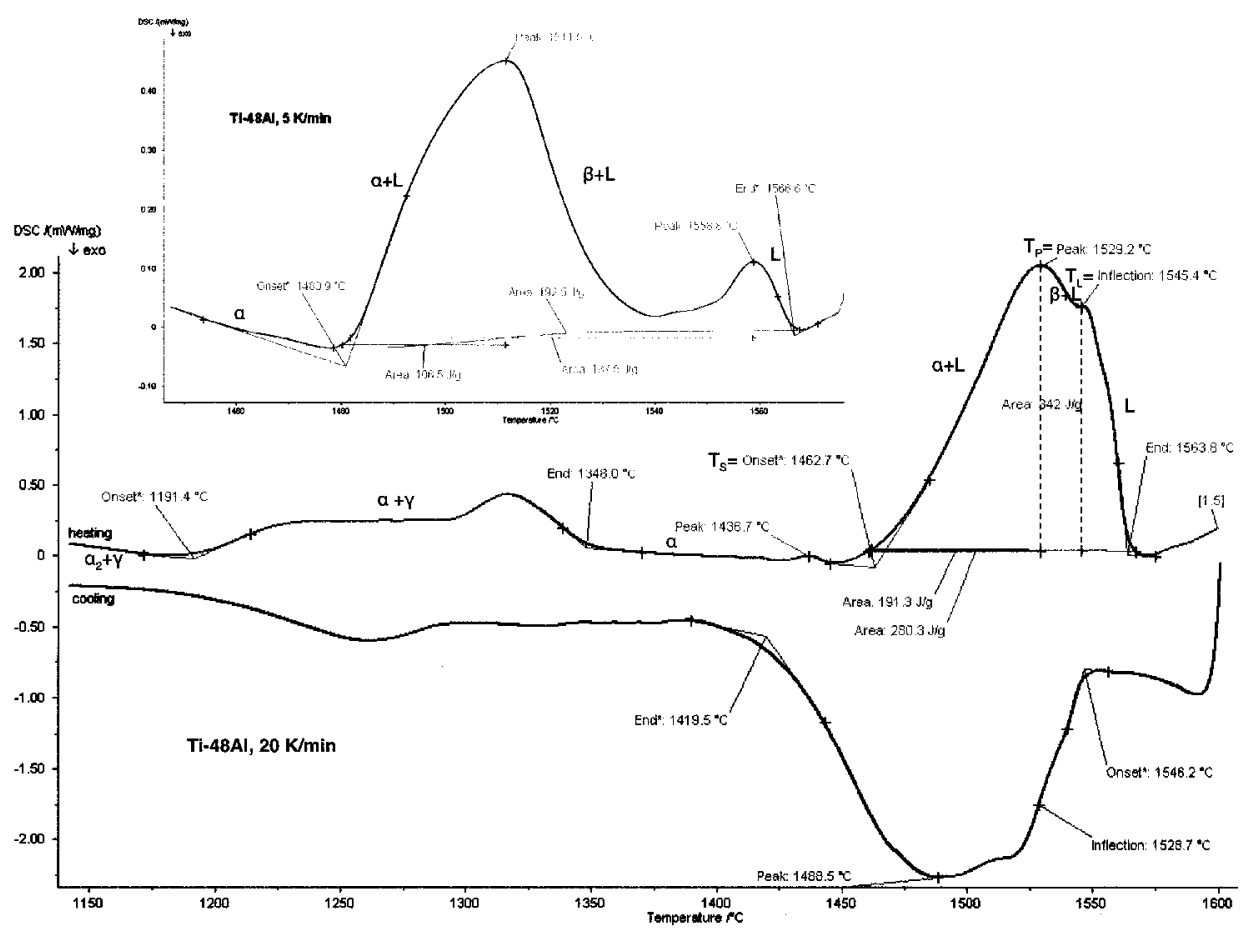

Figure 50: DSC curve for the binary Ti-48Al, run at $20 \mathrm{~K} / \mathrm{min}$. Inset graph shows a portion the $5 \mathrm{~K} / \mathrm{min}$ run for this alloy.

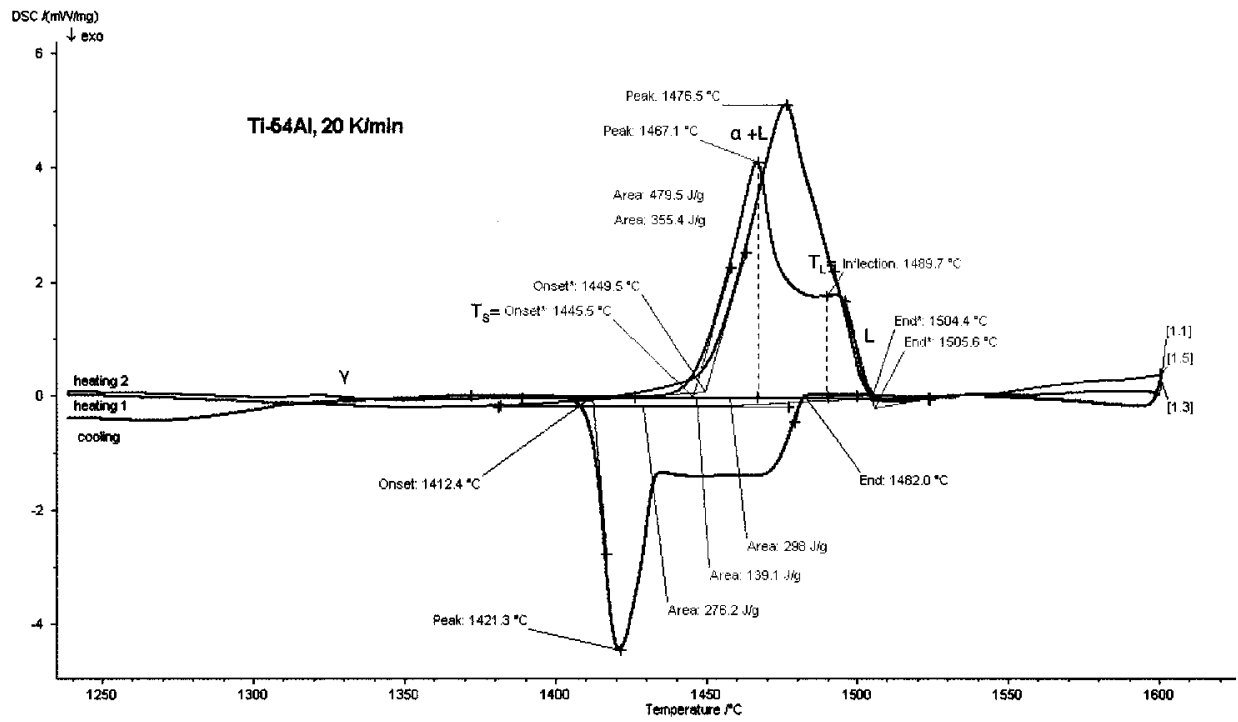

Figure 51: DSC curve for the binary Ti-54Al, run at $20 \mathrm{~K} / \mathrm{min}$. Note the difference between the first (red) and second (magenta) heating curves, due to powder consolidation on the first heating. 


\subsubsection{Ternary Alloys}

Four ternary compositions were available for testing: Ti-47Al-2Cr, Ti-47.5Al-3Cr, Ti-48Al$2 \mathrm{Cr}$, and Ti-48Al-2W. The $\alpha \rightarrow \beta+L$ peritectic lies in this range of $\mathrm{Al}$ (just below 47 at. $\%$ Al) [13]. Thermal analysis for a similar alloy, Ti-47Al-3Cr, is reported in the literature [44]. The transformation sequence for this alloy is given as $\alpha_{2}+\gamma \rightarrow \alpha+\gamma \rightarrow \alpha \rightarrow \alpha+L \rightarrow$ $L+\beta \rightarrow L$. The alloying elements $\mathrm{Cr}$ and $\mathrm{W}$ are $\beta$ stabilizers, but it generally requires material processing such as heat treatments to obtain $\beta$ phase in the final room temperature solid. DSC does not seem to pick up stabilized $\beta$ phase formation for the Cr containing alloys. For these alloys the transformation sequence is considered to be the same as for the binary Ti-48Al alloy, with slightly different transformation temperatures. Any stabilized $\beta$ phase that does form in these alloys has too small a volume fraction to be detected using DSC. The $\mathrm{W}$ containing alloy has a small initial peak before the main melting peak, which may be related to $\beta$ phase formation. From the literature, for a similar ternary alloy, $\mathrm{Ti}-47 \mathrm{Al}-3 \mathrm{Cr}$, the following transformation temperatures are reported: $\mathrm{T}_{\gamma+\alpha \rightarrow \alpha}=1327^{\circ} \mathrm{C}$, $\mathrm{T}_{\alpha \rightarrow \alpha+L}=1407^{\circ} \mathrm{C}[44]$. For the alloys tested, the following $\alpha$ transus temperatures are reported in the literature: for $\mathrm{Ti}-47.5 \mathrm{Al}-3 \mathrm{Cr} \mathrm{T}_{\alpha}=1370 \pm 5^{\circ} \mathrm{C}$ and for $\mathrm{Ti}-48 \mathrm{Al}-2 \mathrm{~W} \mathrm{~T}_{\alpha}=$ $1340 \pm 5^{\circ} \mathrm{C}[45]$.

\section{$\mathrm{Ti}-47 \mathrm{Al}-2 \mathrm{Cr}$}

The transformation path for Ti-47Al-2Cr is: $\alpha_{2}+\gamma \rightarrow \alpha+\gamma \rightarrow \alpha \rightarrow \alpha+L \rightarrow L+\beta \rightarrow L$. A portion of the DSC curve for this alloy is shown in Figure 52, and the transformation temperature results are summarized in Table 9. The theoretical transformation temperatures listed in the table are for the binary $\mathrm{Ti}-47 \mathrm{Al}$ from the equilibrium phase diagram. The binary equilibrium values are listed as a reference of what the transformation temperatures should theoretically be if the ternary alloying element were not present. The description of the breakdown of the DSC curve is similar to Ti-48Al. The fraction of solid values are listed in Table 9. 


\begin{tabular}{|l|c|c|c|c|c|}
\hline Transformaion & Curve & Theoretical & Literature* & DSC 20 K/min & $f_{\boldsymbol{S}}$ \\
\hline$\alpha_{2}+\gamma \rightarrow \alpha+\gamma$ & & 1125 & - & 1229 & 1 \\
$\alpha+\gamma \rightarrow \alpha$ & & 1340 & $1327[44]$ & 1368 & 1 \\
$\alpha \rightarrow \alpha+L\left(\mathrm{~T}_{S}\right)$ & onset & 1460 & $1407[44]$ & 1449 & 1 \\
$\alpha+L \rightarrow \beta+L$ & peak & 1470 & - & 1496 & 0.43 \\
$\beta+L \rightarrow L\left(\mathrm{~T}_{L}\right)$ & inflection & 1530 & - & 1518 & 0.07 \\
$L$ & end & - & - & 1532 & 0 \\
\hline
\end{tabular}

Table 9: Transformation temperatures for $\mathrm{Ti}-47 \mathrm{Al}-2 \mathrm{Cr}$, all values given in ${ }^{\circ} \mathrm{C}$. ${ }^{*}$ The transformation temperatures listed here from the literature are for Ti47Al-3Cr, a slightly different alloy.

\begin{tabular}{|l|c|c|c|c|c|}
\hline Transformaion & Curve & Theoretical & Literature & DSC 20 K/min & $\boldsymbol{f}_{\boldsymbol{S}}$ \\
\hline$\alpha_{2}+\gamma \rightarrow \alpha+\gamma$ & & 1125 & - & 1231 & 1 \\
$\alpha+\gamma \rightarrow \alpha$ & & 1355 & $1370[45]$ & 1367 & 1 \\
$\alpha \rightarrow \alpha+L\left(\mathrm{~T}_{S}\right)$ & onset & 1465 & - & 1448 & 1 \\
$\alpha+L \rightarrow \beta+L$ & peak & 1470 & - & 1497 & 0.42 \\
$\beta+L \rightarrow L\left(\mathrm{~T}_{L}\right)$ & inflection & 1520 & - & 1520 & 0.06 \\
$L$ & end & - & - & 1532 & 0 \\
\hline
\end{tabular}

Table 10: Transformation temperatures for $\mathrm{Ti}-47.5 \mathrm{Al}-3 \mathrm{Cr}$, all values given in ${ }^{o} \mathbf{C}$.

\section{Ti-47.5Al-3Cr}

The transformation path for Ti-47.5Al-3Cr is: $\alpha_{2}+\gamma \rightarrow \alpha+\gamma \rightarrow \alpha \rightarrow \alpha+L \rightarrow L+\beta \rightarrow L$. A portion of the DSC curve for this alloy is shown in Figure 53, and the transformation temperature results are summarized in Table 10. The theoretical transformation temperatures listed in the table are the equilibrium values from the Ti-Al phase diagram for Ti-47.5Al. The description of the breakdown of the DSC curve is similar to Ti-48Al. The fraction of solid values are listed in Table 10.

\section{Ti-48Al-2Cr}

The transformation path for $\mathrm{Ti}-48 \mathrm{Al}-2 \mathrm{Cr}$ is: $\alpha_{2}+\gamma \rightarrow \alpha+\gamma \rightarrow \alpha \rightarrow \alpha+L \rightarrow L+\beta \rightarrow L$. A portion of the DSC curve for this alloy is shown in Figure 54, and the transformation temperature results are summarized in Table 11. The theoretical transformation temperatures 


\begin{tabular}{|l|c|c|c|c|}
\hline Transformaion & Curve & Theoretical & DSC 20 K/min & $\boldsymbol{f}_{\boldsymbol{S}}$ \\
\hline$\alpha_{2}+\gamma \rightarrow \alpha+\gamma$ & & 1125 & 1228 & 1 \\
$\alpha+\gamma \rightarrow \alpha$ & & 1370 & 1370 & 1 \\
$\alpha \rightarrow \alpha+L\left(\mathrm{~T}_{S}\right)$ & onset & 1460 & 1448 & 1 \\
$\alpha+L \rightarrow \beta+L$ & peak & 1470 & 1491 & 0.50 \\
$\beta+L \rightarrow L\left(\mathrm{~T}_{L}\right)$ & inflection & 1510 & 1519 & 0.08 \\
$L$ & end & - & 1531 & 0 \\
\hline
\end{tabular}

Table 11: Transformation temperatures for $\mathrm{Ti}-48 \mathrm{Al}-2 \mathrm{Cr}$, all values given in ${ }^{\circ} \mathrm{C}$.

\begin{tabular}{|l|c|c|c|c|c|}
\hline Transformaion & Curve & Theoretical & Literature & DSC 20 K/min & $\boldsymbol{f}_{\boldsymbol{S}}$ \\
\hline$\alpha_{2}+\gamma \rightarrow \alpha+\gamma$ & & 1125 & - & - & 1 \\
$\alpha+\gamma \rightarrow \alpha$ & & 1370 & $1340[45]$ & - & 1 \\
$\alpha \rightarrow \alpha+\beta$ & small peak & - & - & 1457 & 1 \\
$\alpha+\beta \rightarrow \alpha+L\left(\mathrm{~T}_{S}\right)$ & onset & 1460 & - & 1474 & 1 \\
$\alpha+L \rightarrow \beta+L$ & peak & 1470 & - & 1538 & 0.34 \\
$\beta+L \rightarrow L\left(\mathrm{~T}_{L}\right)$ & inflection & 1510 & - & 1558 & 0.06 \\
$L$ & end & - & - & 1568 & 0 \\
\hline
\end{tabular}

Table 12: Transformation temperatures for Ti-48Al-2W, all values given in ${ }^{o} \mathrm{C}$.

listed in the Table are the equilibrium values from the Ti-Al phase diagram for Ti-48Al. The description of the breakdown of the DSC curve is similar to Ti-48Al. The fraction of solid values are listed in Table 11 .

\section{Ti-48Al-2W}

The proposed transformation path for Ti-48Al-2W is: $\alpha_{2}+\gamma \rightarrow \alpha+\gamma \rightarrow \alpha \rightarrow \alpha+\beta \rightarrow$ $\alpha+L \rightarrow L+\beta \rightarrow L$. A portion of the DSC curve for this alloy is shown in Figure 55, and the transformation temperature results are summarized in Table 12. The small peak, just before the main melting peak, may correspond to the solid $\alpha \rightarrow \alpha+\beta$ transformation, with the W addition acting as a $\beta$ stabilizer in this alloy. This small peak only shows up in the second heating curve, most likely due to the non-homogeneous nature of the $\mathrm{W}$ containing powder sample; the first heating curve shows consolidation and homogenization of the sample, and the second heating curve shows the transformations that occur more accurately. The 
theoretical transformation temperatures listed in the Table are the equilibrium values from the Ti-Al phase diagram for Ti-48Al. The fraction of solid values are listed in Table 12.

\section{Summary for the Ternary Compositions}

The transformation sequence for the ternary alloys tested was the same as for the Ti-48Al binary for the $\mathrm{Cr}$ containing alloys. Although small amounts of $\beta$ stabilizers were added to these alloys the effect on the transformations measured using DSC is not significant. That is, DSC was not able to detect the formation of stabilized $\beta$ phase for these alloys. For the W containing alloy, the DSC did seem to pick up stabilized $\beta$ formation in the form of a small peak just before the main melting peak. This small peak is seen in Section 5.2.3 in the more complex $\mathrm{W}$ containing alloys. In general for the ternary alloys, adding $\mathrm{W}$ increases the transformation temperatures and adding $\mathrm{Cr}$ decreases the transformation temperatures. The results for $\mathrm{Ti}-47 \mathrm{Al}-2 \mathrm{Cr}$ and $\mathrm{Ti}-48 \mathrm{Al}-2 \mathrm{Cr}$ are almost identical, with only a few degrees difference between the temperatures found on the DSC curves for each alloy. The results for the complex alloys will now be presented.

\subsubsection{Complex Alloys}

A number of complex compositions were available for testing. There were seven compositions with four alloying components (Ti-45Al-2W-0.1Si, Ti-45Al-2W-0.5Si, TAMN: Ti-46Al-2Mo-2Nb, ABB-2: Ti-47Al-2W-0.5Si, TAWS: Ti-47.5Al-2W-0.5Si, Ti-48Al-2Nb$2 \mathrm{Cr}$, and Ti-52Al-2W-0.5Si), four with five alloying components (Ti-48Al-2Nb-2Cr-0.5W, Ti-48Al-2Nb-2Cr-1W, 45XD: Ti-45Al-2Nb-2Mn + 0.8TiB 2 , and 47XD: Ti-47Al-2Nb-2Mn $+0.8 \mathrm{TiB}_{2}$ ), and one with seven alloying components (TiAlWMoSi: Ti-47Al-2Nb-2Mn$0.5 \mathrm{~W}-0.5 \mathrm{Mo}-0.2 \mathrm{Si}$ ). The results for these alloys are presented and discussed below.

However, some of the complex alloys did not produce coherent DSC results, particularly the 45 at.\% Al compositions (Ti-45Al-2W-0.1Si, Ti-45Al-2W-0.5Si, 45XD Ti-45Al-2Nb-2Mn $+0.8 \mathrm{TiB}_{2}$ ), and TiAlWMoSi (Ti-47Al-2Nb-2Mn-0.5W-0.5Mo-0.2Si). The transformation sequences and temperatures from the DSC curves for these alloys were very difficult to 


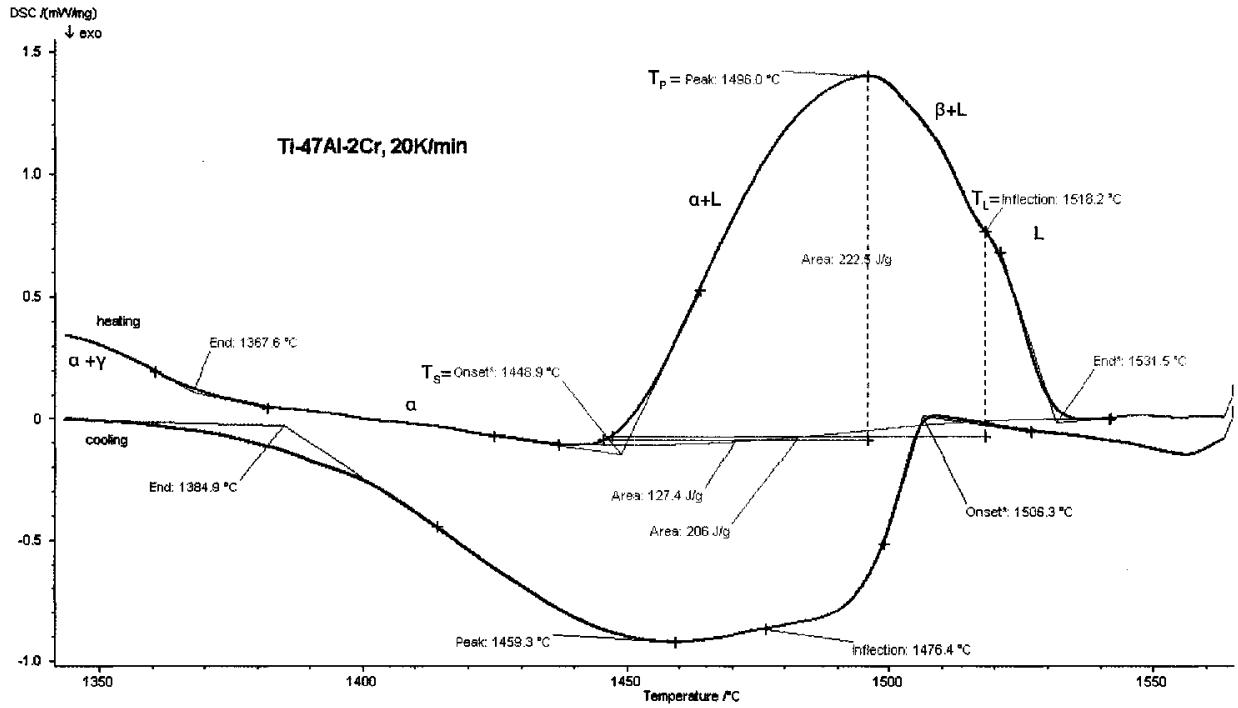

Figure 52: DSC curve for Ti-47Al-2Cr, $20 \mathrm{~K} / \mathrm{min}$.

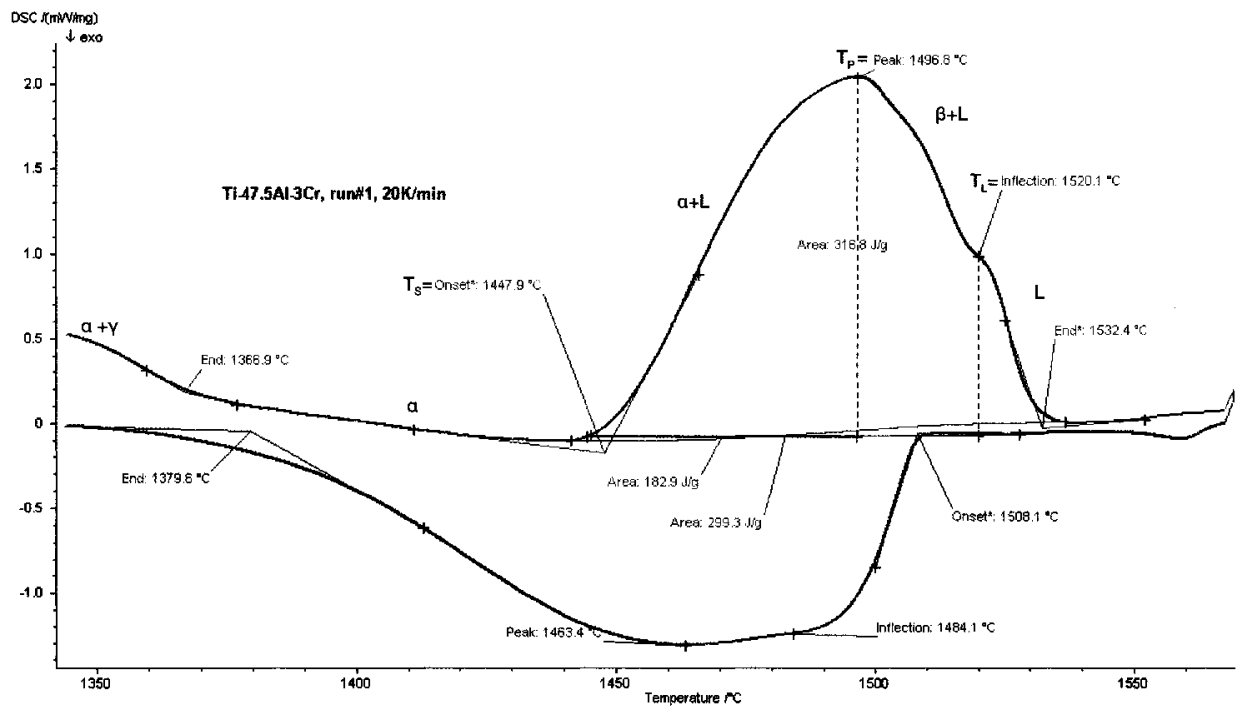

Figure 53: DSC curve for Ti-47.5Al-3Cr, $20 \mathrm{~K} / \mathrm{min}$. 


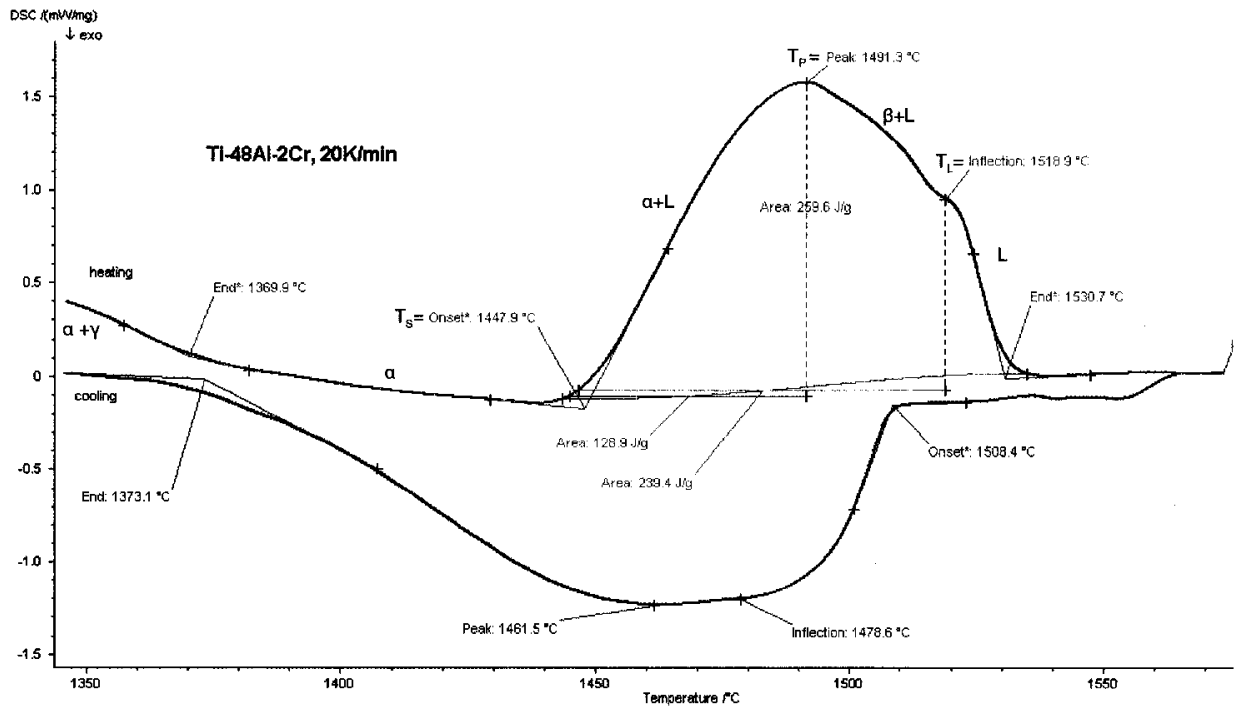

Figure 54: DSC curve for Ti-48Al-2Cr, $20 \mathrm{~K} / \mathrm{min}$.

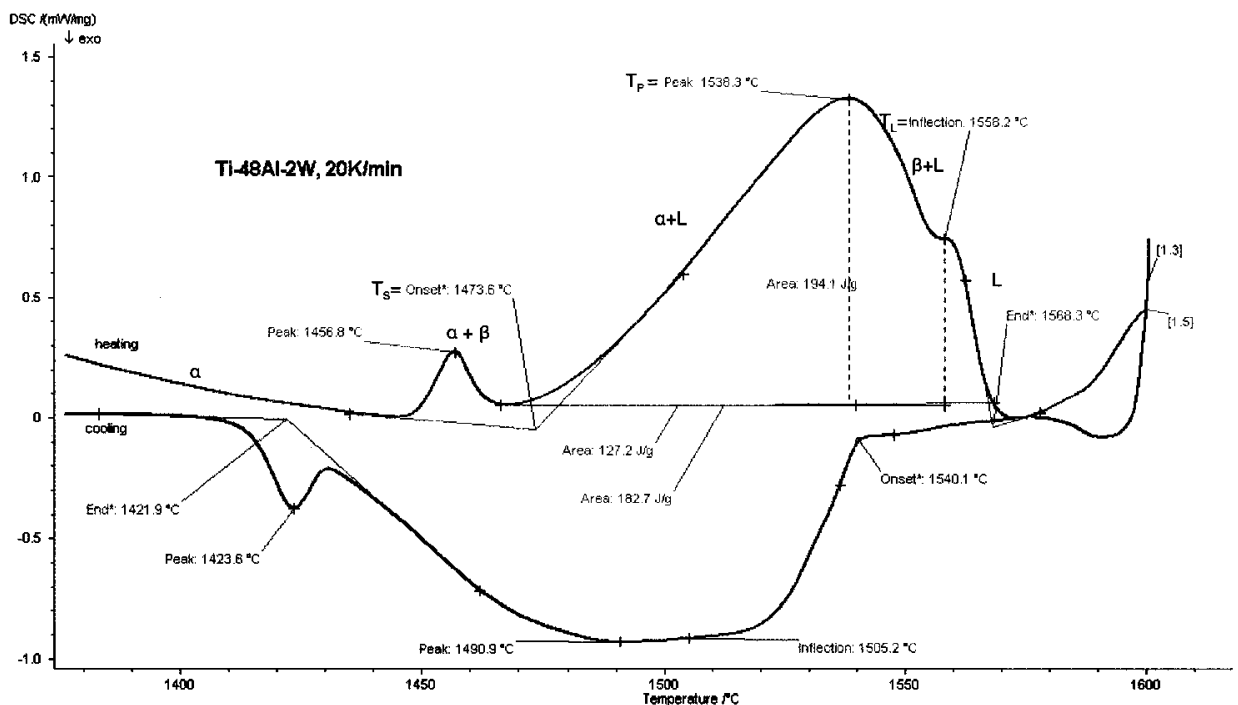

Figure 55: DSC curve for Ti-48Al-2W, $20 \mathrm{~K} / \mathrm{min}$. 
interpret. For these alloys it would be advisable to carry out more detailed metallographic analysis. In situ high-temperature x-ray diffraction (HTXRD) would be useful in determining the phases that are present at the various temperatures for these alloys. The DSC curves for these alloys are not included in this chapter, but can be seen in Appendix C.

The effect of the additional alloying elements can be the formation of addition phases. The inclusion of $\beta$ stabilizers tend to extend the region of $\beta$ phase at high temperatures, so that instead of $\alpha \rightarrow \alpha+L \rightarrow \beta+L \rightarrow L$ the transformation sequence can become $\alpha \rightarrow \alpha+L \rightarrow \alpha+L+\beta \rightarrow \beta+L \rightarrow L, \alpha \rightarrow \alpha+L+\beta \rightarrow \beta+L \rightarrow L$, or even $\alpha \rightarrow \alpha+\beta \rightarrow \alpha+\beta+L \rightarrow \beta+L \rightarrow L$ as the temperature range over which $\beta$ can exist is extended. The regions of overlap of these three phases should tend to be fairly small, and are thus difficult or impossible to distinguish by examining a DSC curve only. The body centred cubic (BCC) $\beta$ phase and the ordered BCC B2 phase can also be stabilized at lower temperatures. Additions of $\mathrm{Cr}$ can cause the B2 phase to appear at lower temperatures, in the $\alpha_{2}+\gamma$ temperature region. $\mathrm{W}$ also stabilizes the $\mathrm{BCC}$ based phases, and causes the formation of W-rich BCC phases at low temperatures, with the possibility of precipitate formation. The addition of $\mathrm{Si}$ can cause the formation of silicides like $\mathrm{Ti}_{5} \mathrm{Si}_{3}$, and the addition of $\mathrm{B}$ can cause the formation of borides such as $\mathrm{TiB}_{2}$ [41]. Note that in the case of the $\mathrm{XD}$ alloys, $\mathrm{TiB}_{2}$ was intentionally added as a grain refiner. It would be advisable to confirm the presence of these phases with additional testing of the complex TiAl alloys using methods other than DSC analysis.

\section{Ti-45Al-2W-0.1Si and Ti-45Al-2W-0.5Si}

No analysis was performed on the DSC curves for these alloys since the curves were difficult to interpret. Thus, no results are available for these alloys. More detailed analysis, such as heat treatment and HTXRD, is suggested to determine the phase transformations and temperatures for these alloys. 


\begin{tabular}{|l|c|c|c|}
\hline Transformaion & Curve & DSC 20 K/min & $\boldsymbol{f}_{\boldsymbol{S}}$ \\
\hline$\alpha \rightarrow \alpha+L+\beta\left(\mathrm{T}_{S}\right)$ & onset & 1481 & 1 \\
$\alpha+L+\beta \rightarrow \beta+L$ & peak & 1536 & 0.42 \\
$\beta+L \rightarrow L\left(\mathrm{~T}_{L}\right)$ & inflection & 1561 & 0.06 \\
$L$ & end & 1570 & 0 \\
\hline
\end{tabular}

Table 13: Transformation temperatures for TAMN, all values given in ${ }^{\circ} \mathrm{C}$.

\begin{tabular}{|l|c|c|c|}
\hline Transformaion & Curve & DSC 20 K/min & $f_{S}$ \\
\hline$\alpha \rightarrow \alpha+\beta$ & small peak & 1427 & 1 \\
$\alpha+\beta \rightarrow \alpha+L+\beta\left(\mathrm{T}_{S}\right)$ & onset & 1464 & 1 \\
$\alpha+L+\beta \rightarrow \beta+L$ & peak & 1536 & 0.40 \\
$\beta+L \rightarrow L\left(\mathrm{~T}_{L}\right)$ & inflection & 1560 & 0.06 \\
$L$ & end & 1570 & 0 \\
\hline
\end{tabular}

Table 14: Transformation temperatures for ABB-2, all values given in ${ }^{\circ} \mathrm{C}$.

\section{TAMN: Ti-46Al-2Mo-2Nb}

The suggested transformation path for TAMN is: $\alpha_{2}+\gamma \rightarrow \alpha+\gamma \rightarrow \alpha \rightarrow \alpha+L+\beta \rightarrow$ $\beta+L \rightarrow L$. A portion of the DSC curve for this alloy is shown in Figure 56, and the transformation temperature results are summarized in Table 13. The second heating curve seems to show the transformations in the sample more clearly, so it is the second heating shown in Figure 56. The fraction of solid values are listed in Table 13.

\section{ABB-2: Ti-47Al-2W-0.5Si}

The suggested transformation path for ABB-2 is: $\alpha_{2}+\gamma \rightarrow \alpha+\gamma \rightarrow \alpha \rightarrow \alpha+\beta \rightarrow$ $\alpha+L+\beta \rightarrow L+\beta \rightarrow L$. A portion of the DSC curve for this alloy is shown in Figure 57, and the transformation temperature results are summarized in Table 14. There is a small peak just before the main melting peak on the DSC curve for this alloy, which is similar to Ti-48Al-2W, and which only shows up in the second heating curve for this alloy. This small peak may indicate the $\alpha \rightarrow \alpha+\beta$ transformation. The fraction of solid values for this alloy are shown in Table 14. 


\begin{tabular}{|l|c|c|c|}
\hline Transformaion & Curve & DSC 20 K/min & $\boldsymbol{f}_{\boldsymbol{S}}$ \\
\hline$\alpha \rightarrow \alpha+\beta$ & small peak & 1433 & 1 \\
$\alpha+\beta \rightarrow \alpha+L+\beta\left(\mathrm{T}_{S}\right)$ & onset & 1454 & 1 \\
$\alpha+L+\beta \rightarrow \beta+L$ & peak & 1520 & 0.39 \\
$\beta+L \rightarrow L\left(\mathrm{~T}_{L}\right)$ & inflection & 1542 & 0.06 \\
$L$ & end & 1553 & 0 \\
\hline
\end{tabular}

Table 15: Transformation temperatures for TAWS, all values given in ${ }^{\circ} \mathrm{C}$.

\begin{tabular}{|l|c|c|c|}
\hline Transformaion & Curve & DSC 20 K/min & $\boldsymbol{f}_{\boldsymbol{S}}$ \\
\hline$\alpha_{2}+\gamma \rightarrow \alpha+\gamma$ & & 1243 & 1 \\
$\alpha+\gamma \rightarrow \alpha$ & & 1379 & 1 \\
$\alpha \rightarrow \alpha+L+\beta\left(\mathrm{T}_{S}\right)$ & onset & 1461 & 1 \\
$\alpha+L+\beta \rightarrow \beta+L$ & peak & 1518 & 0.41 \\
$\beta+L \rightarrow L\left(\mathrm{~T}_{L}\right)$ & inflection & 1539 & 0.09 \\
$L$ & end & 1552 & 0 \\
\hline
\end{tabular}

Table 16: Transformation temperatures for $\mathrm{Ti}-48 \mathrm{Al}-2 \mathrm{Nb}-2 \mathrm{Cr}$, all values given in ${ }^{\circ} \mathrm{C}$.

\section{TAWS Ti-47.5Al-2W-0.5Si}

The suggested transformation path for TAWS is: $\alpha_{2}+\gamma \rightarrow \alpha+\gamma \rightarrow \alpha \rightarrow \alpha+\beta \rightarrow$ $\alpha+L+\beta \rightarrow L+\beta \rightarrow L$. A portion of the DSC curve for this alloy is shown in Figure 58, and the transformation temperature results are summarized in Table 15. As for the other W containing alloys, there is a small peak just before the main melting peak, which may indicate the $\alpha \rightarrow \alpha+\beta$ transformation. This peak only shows up in the second heating for this alloy, as for the other $\mathrm{W}$ containing alloys discussed previously. The fraction of solid values are listed in Table 15.

\section{Ti-48Al-2Nb-2Cr}

The suggested transformation path for Ti-48Al-2Nb-2Cr is: $\alpha_{2}+\gamma \rightarrow \alpha+\gamma \rightarrow \alpha \rightarrow$ $\alpha+L+\beta \rightarrow L+\beta \rightarrow L$. A portion of the DSC curve for this alloy is shown in Figure 59, and the transformation temperature results are summarized in Table 16. The fraction of solid values are listed in Table 16. 


\begin{tabular}{|l|c|c|c|}
\hline Transformaion & Curve & DSC 20 K/min & $f_{S}$ \\
\hline$\gamma \rightarrow \alpha+\gamma$ & onset (small peak) & 1423 & 1 \\
$\alpha+\gamma \rightarrow \alpha+L\left(\mathrm{~T}_{S}\right)$ & onset (large peak) & 1434 & 1 \\
$\alpha+L \rightarrow L+\beta$ & peak & 1491 & 0.26 \\
$L+\beta \rightarrow L\left(\mathrm{~T}_{L}\right)$ & inflection & 1508 & 0.04 \\
$L$ & end & 1514 & 0 \\
\hline
\end{tabular}

Table 17: Transformation temperatures for Ti-52Al-2W-0.5Si, all values given in ${ }^{\circ} \mathrm{C}$.

\section{Ti-52Al-2W-0.5Si}

This alloy is similar to the Ti-54Al binary, with the $\beta$ stabilizer $\mathrm{W}$ added. The suggested transformation path for Ti-52Al-2W-0.5Si is: $\gamma \rightarrow \alpha+\gamma \rightarrow \alpha \rightarrow \alpha+L \rightarrow L+\beta \rightarrow L$. It is suggested that $\mathrm{W}$, a $\beta$ stabilizer, shifts the $\beta$ portion of the phase diagram to the right, so that this alloy passes through the $\beta+L$ phase field. A portion of the DSC curve for this alloy is shown in Figure 60, and the transformation temperature results are summarized in Table 17. The main peak is composed of three smaller peaks, corresponding to the various transformations. The first small peak is the $\alpha+\gamma$ transformation, so the onset of this peak is the $\gamma \rightarrow \alpha+\gamma$ transformation. The second larger peak is the $\alpha+L$ peritectic, so the onset of this peak corresponds to the $\alpha+\gamma \rightarrow \alpha+L$ peritectic transformation. The third large peak is the $\beta+L$ peritectic. The inflection point near the end of the peak is the $L$ transformation. For this alloy, unlike the other W containing alloys, the first and second heating produced similarly shaped curves with the same number of peaks. The fraction of solid values are listed in Table 17. Note that the area up to the $\alpha+\gamma \rightarrow \alpha+L$ transformation was subtracted from the areas used for the $f_{S}$ calculations, since no liquid is present before this point.

\section{Ti-48Al-2Cr-2Nb-0.5W}

The transformation path reported in the literature for Ti-47Al-2Cr-2Nb-0.5W is: $\alpha_{2}+\gamma+$ $(B 2+\alpha C r+\alpha W) \rightarrow \alpha+\gamma+(B 2) \rightarrow \alpha \rightarrow \alpha+\beta \rightarrow \alpha+L+\beta \rightarrow L+\beta \rightarrow L$ [41]. The transformation path for $\mathrm{Ti}-48 \mathrm{Al}-2 \mathrm{Nb}-2 \mathrm{Cr}-0.5 \mathrm{~W}$ should be similar. A portion of the DSC 


\begin{tabular}{|l|c|c|c|}
\hline Transformaion & Curve & DSC 20 K/min & $\boldsymbol{f}_{\boldsymbol{S}}$ \\
\hline$\alpha+\gamma \rightarrow \alpha$ & & 1387 & 1 \\
$\alpha \rightarrow \alpha+L+(\beta)\left(\mathrm{T}_{S}\right)$ & onset & 1464 & 1 \\
$\alpha+L+(\beta) \rightarrow(\alpha)+L+\beta$ & peak & 1512 & 0.48 \\
$(\alpha)+L+\beta \rightarrow L\left(\mathrm{~T}_{L}\right)$ & inflection & 1537 & 0.08 \\
$L$ & end & 1548 & 0 \\
\hline
\end{tabular}

Table 18: Transformation temperatures for Ti-48Al-2Cr-2Nb-0.5W, all values given in ${ }^{\circ} \mathrm{C}$.

curve for this alloy is shown in Figure 61, and the transformation temperature results are summarized in Table 18. The $\alpha \rightarrow \alpha+\beta \rightarrow \alpha+L+\beta \rightarrow L+\beta \rightarrow L$ transformations do not show up as distinct inflections or peaks on the main solid-liquid peak of the DSC curve. For this reason the region is marked as $\alpha \rightarrow \alpha+L+(\beta) \rightarrow(\alpha)+L+\beta \rightarrow L$. A more detailed analysis of this alloy should be undertaken to determine the presence of these phases and the temperatures at which they occur. The fraction of solid values are listed in Table 18.

\section{Ti-48Al-2Nb-2Cr-1W}

The transformation path for Ti- $48 \mathrm{Al}-2 \mathrm{Nb}-2 \mathrm{Cr}-1 \mathrm{~W}$ should be similar to Ti- $48 \mathrm{Al}-2 \mathrm{Nb}-2 \mathrm{Cr}-$ $0.5 \mathrm{~W}: \alpha_{2}+\gamma+(B 2+\alpha C r+\alpha W) \rightarrow \alpha+\gamma+(B 2) \rightarrow \alpha \rightarrow \alpha+\beta \rightarrow \alpha+L+\beta \rightarrow L+\beta \rightarrow L$ A portion of the DSC curve for this alloy is shown in Figure 62, and the transformation temperature results are summarized in Table 19. The $\alpha \rightarrow \alpha+\beta \rightarrow \alpha+L+\beta \rightarrow L+\beta \rightarrow L$ transformations do not show up as distinct inflections or peaks on the main solid-liquid peak of the DSC curve. For this reason the region is marked as $\alpha \rightarrow \alpha+L+(\beta) \rightarrow(\alpha)+L+\beta \rightarrow L$. A more detailed analysis of this alloy should be undertaken to determine the presence of these phases and the temperatures at which they occur. The fraction of solid values are listed in Table 19.

\section{XD: Ti-45Al-2Nb-2Mn $+0.8 \mathrm{TiB}_{2}$}

The DSC results for this alloy could not be analyzed. A more detailed study metallographic study, including heat treatment and HTXRD analysis, is suggested to determine the phase 


\begin{tabular}{|l|c|c|c|}
\hline Transformaion & Curve & DSC 20 K/min & $f_{\boldsymbol{S}}$ \\
\hline$\alpha+\gamma \rightarrow \alpha$ & & 1389 & 1 \\
$\alpha \rightarrow \alpha+L+(\beta)\left(\mathrm{T}_{S}\right)$ & onset & 1458 & 1 \\
$\alpha+L+(\beta) \rightarrow(\alpha)+L+\beta$ & peak & 1511 & 0.44 \\
$(\alpha)+L+\beta \rightarrow L\left(\mathrm{~T}_{L}\right)$ & inflection & 1532 & 0.09 \\
$L$ & end & 1544 & 0 \\
\hline
\end{tabular}

Table 19: Transformation temperatures for Ti-48Al-2Cr-2Nb-1W, all values given in ${ }^{\circ} \mathrm{C}$.

\begin{tabular}{|l|c|c|c|}
\hline Transformaion & Curve & DSC 20 K/min & $\boldsymbol{f}_{\boldsymbol{S}}$ \\
\hline$\alpha+\gamma \rightarrow \alpha$ & & 1386 & 1 \\
$\alpha \rightarrow \alpha+L+\beta\left(\mathrm{T}_{S}\right)$ & onset & 1443 & 1 \\
$\alpha+L+\beta \rightarrow L+\beta$ & peak & 1495 & 0.41 \\
$L+\beta \rightarrow L\left(\mathrm{~T}_{L}\right)$ & inflection & 1520 & 0.05 \\
$L$ & end & 1531 & 0 \\
\hline
\end{tabular}

Table 20: Transformation temperatures for $47 \mathrm{XD}$, all values given in ${ }^{\circ} \mathrm{C}$.

transformations and temperatures for this alloy.

47XD: Ti-47Al-2Nb-2Mn $+0.8 \mathrm{TiB}_{2}$

The transformation path reported in the literature for Ti-47Al-2Mn-2Nb is: $\alpha_{2}+\gamma \rightarrow$ $\alpha+\gamma \rightarrow \alpha \rightarrow \alpha+L+\beta \rightarrow L+\beta \rightarrow L$ [41]. 47XD should have a similar transformation path, since the only difference is the addition of $\mathrm{TiB}_{2}$. These borides should exist as small particles in the alloy, and since they have a very high melting temperature they should have little to no impact on the DSC results. A portion of the DSC curve for this alloy is shown in Figure 63, and the transformation temperature results are summarized in Table 20. The fraction of solid values are listed in Table 20.

\section{TiAlWMoSi: Ti-47Al-2Nb-1Mn-0.5W-0.5Mo-0.2Si}

Results published in the literature report the transformation path for this alloy, as determined using thermodynamic calculations, to be: $\alpha_{2}+\gamma(\alpha C r+\alpha W+B 2) \rightarrow \alpha+\gamma+B 2 \rightarrow$ $\alpha \rightarrow \alpha+L+\beta \rightarrow L+\beta \rightarrow L[41]$. However, since the DSC results for this alloy could not 
be analyzed, additional research is recommended to confirm these phase transformations and to determine transformation temperatures.

\section{Summary for the Complex Alloys}

Similarly to the ternary alloys, the formation of $\beta$ phase, due to the addition of $\beta$ stabilizing elements, was only detected for the complex alloys with $\mathrm{W}$ as the main alloying addition. For the other alloys, containing $\mathrm{Cr}, \mathrm{Nb}, \mathrm{Mo}$ and $\mathrm{Mn}$, even if some $\mathrm{W}$ was added to the alloy, the lower temperature $\beta$ phase formation could not be detected using DSC. It would be advisable to carry out additional testing to determine the exact phases present and the temperatures at which they occur.

\subsection{Discussion}

\section{Binary Results and the TiAl Phase Diagram}

The DSC results for the binary compositions can be compared to the binary phase diagram. The diagram reported by Jung et al., Figure 29 [14], was determined by DTA. The diagram has temperature and composition values listed on it, so it was reproduced to include the binary results found by DSC for $\mathrm{Ti}-48 \mathrm{Al}$ and $\mathrm{Ti}-54 \mathrm{Al}$. The modified phase diagram is shown in Figure 64. The solid lines are the results reported by Jung et al., and the dotted lines are the extrapolated results as determined using DSC. The solidus temperatures found using DSC, the peak onset temperatures, tend to be very close to the binary phase diagram results since calibration of the DSC was carried out using melting peak onset. Above the solidus, the DSC results tend to be shifted to higher temperatures since the peak temperatures are shifted higher at higher heating rates (test were run at $20 \mathrm{~K} / \mathrm{min}$ ); at slower heating rates the transformation temperatures as determined from the melting peak should be closer to equilibrium values. In addition, note that the phase diagram in Figure 64 does not look the same as the one shown in Figure 29, since a non uniform temperature scale was used in the latter. 


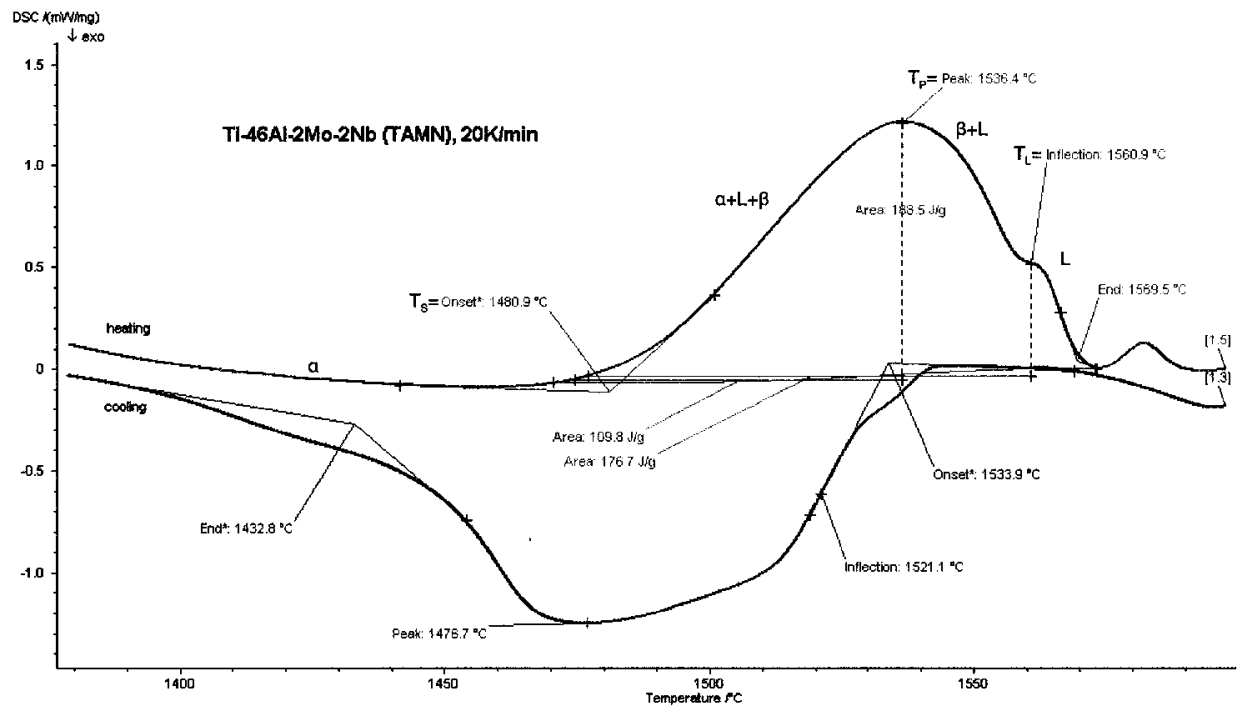

Figure 56: DSC curve for a TAMN, $20 \mathrm{~K} / \mathrm{min}$.

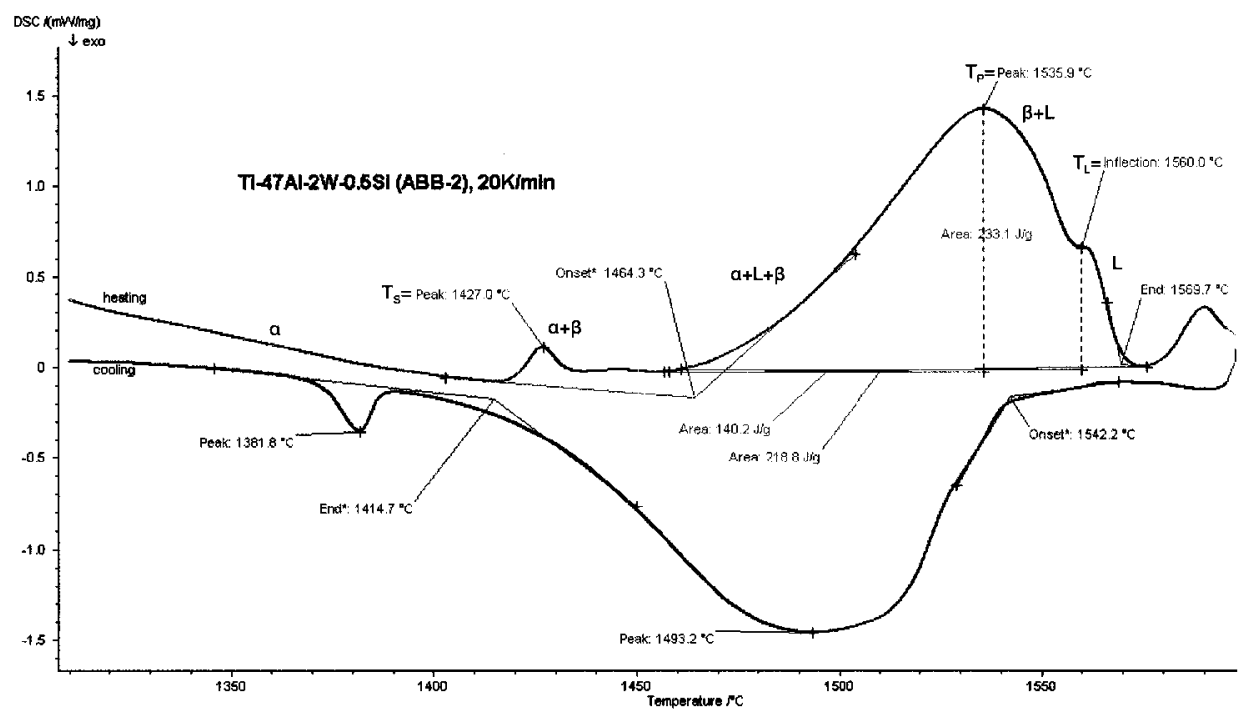

Figure 57: DSC curve for a ABB-2, $20 \mathrm{~K} / \mathrm{min}$. 


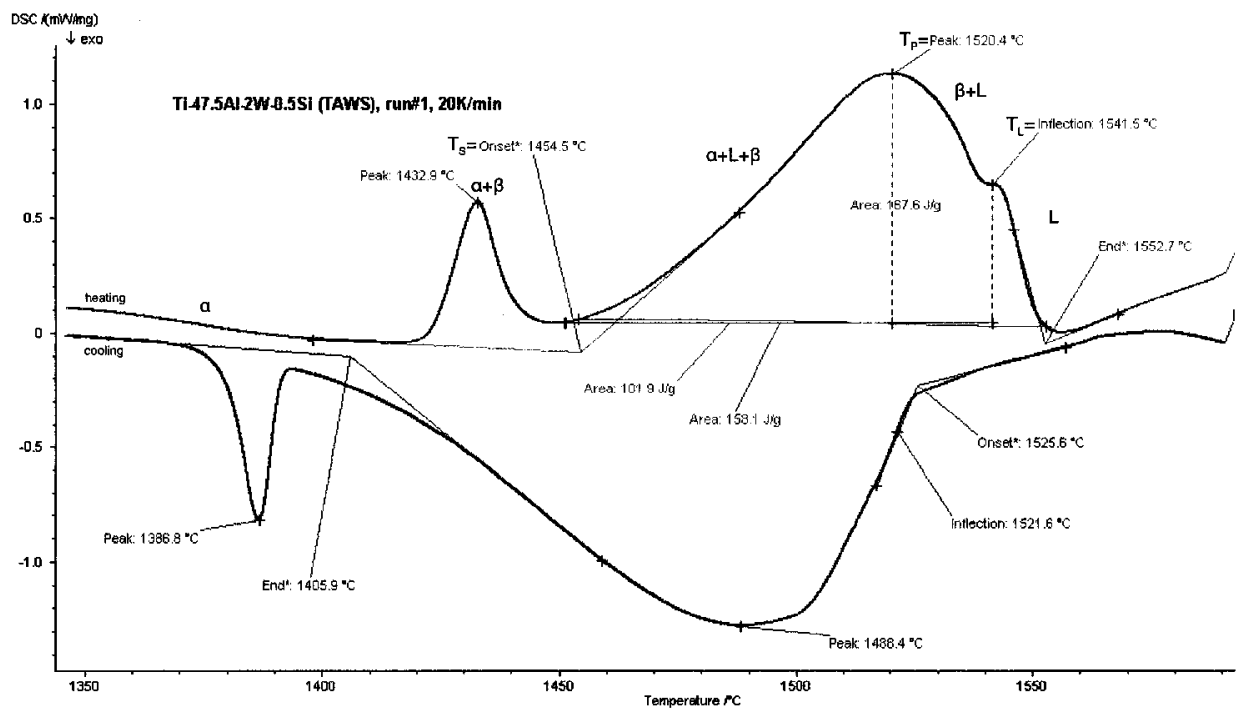

Figure 58: DSC curve for a TAWS, $20 \mathrm{~K} / \mathrm{min}$.

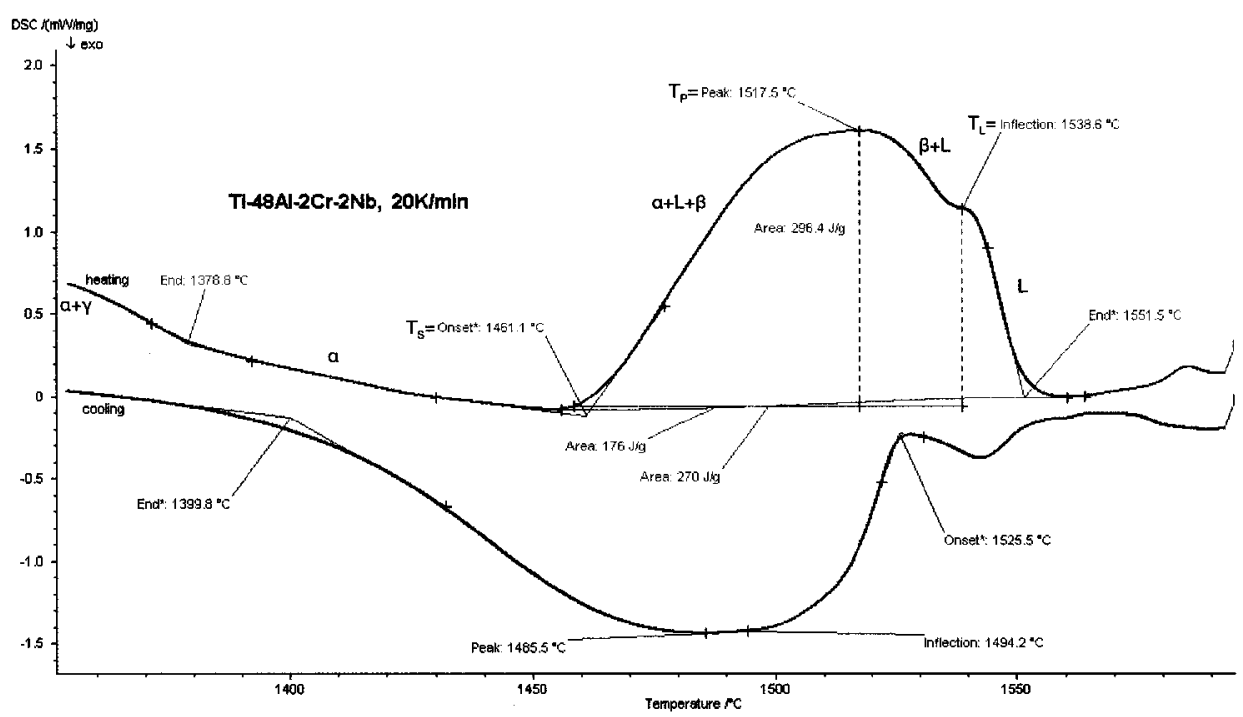

Figure 59: DSC curve for a Ti-48Al-2Nb-2Cr, $20 \mathrm{~K} / \mathrm{min}$. 


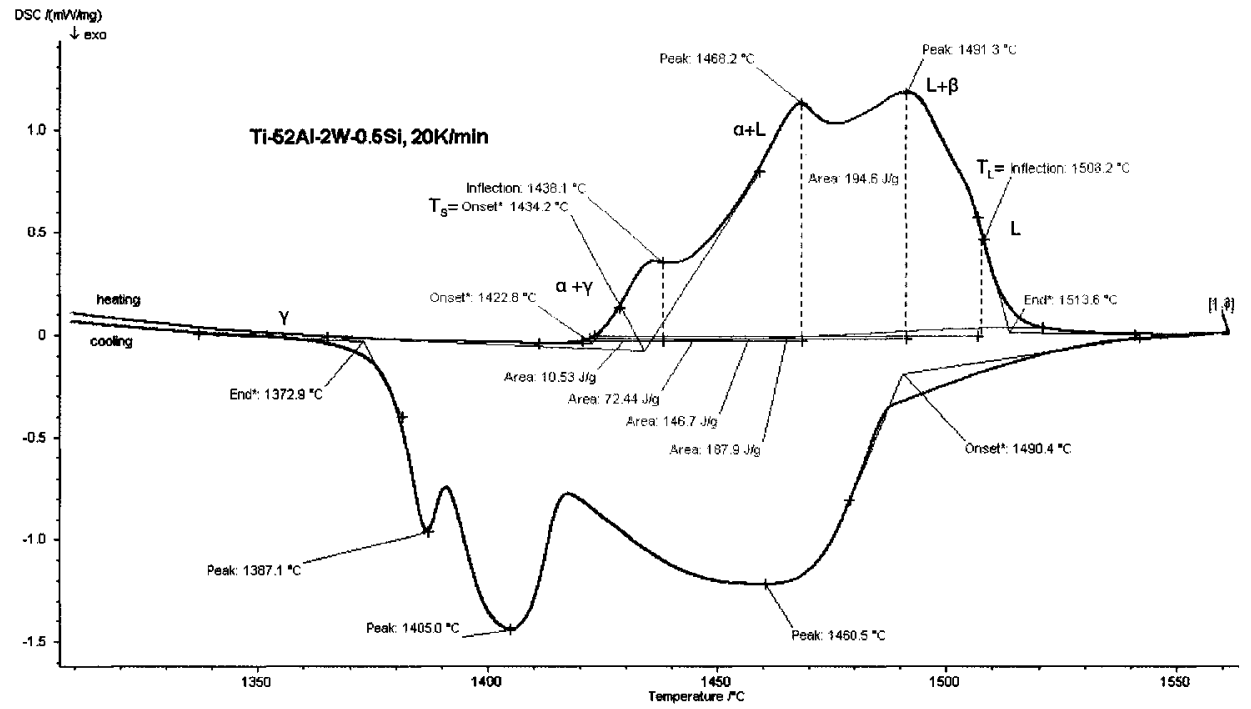

Figure 60: DSC curve for a Ti-52Al-2W-0.5Si, $20 \mathrm{~K} / \mathrm{min}$.

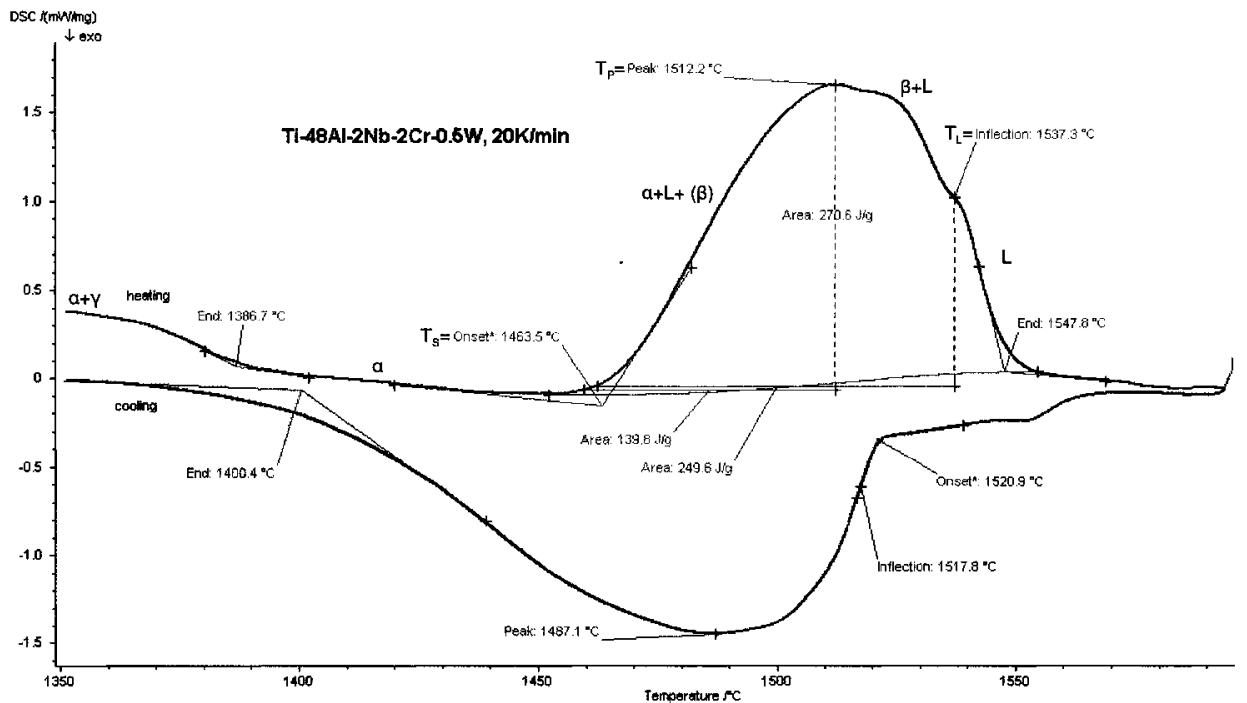

Figure 61: DSC curve for a Ti-48Al-2Cr-2Nb-0.5W, $20 \mathrm{~K} / \mathrm{min}$. 


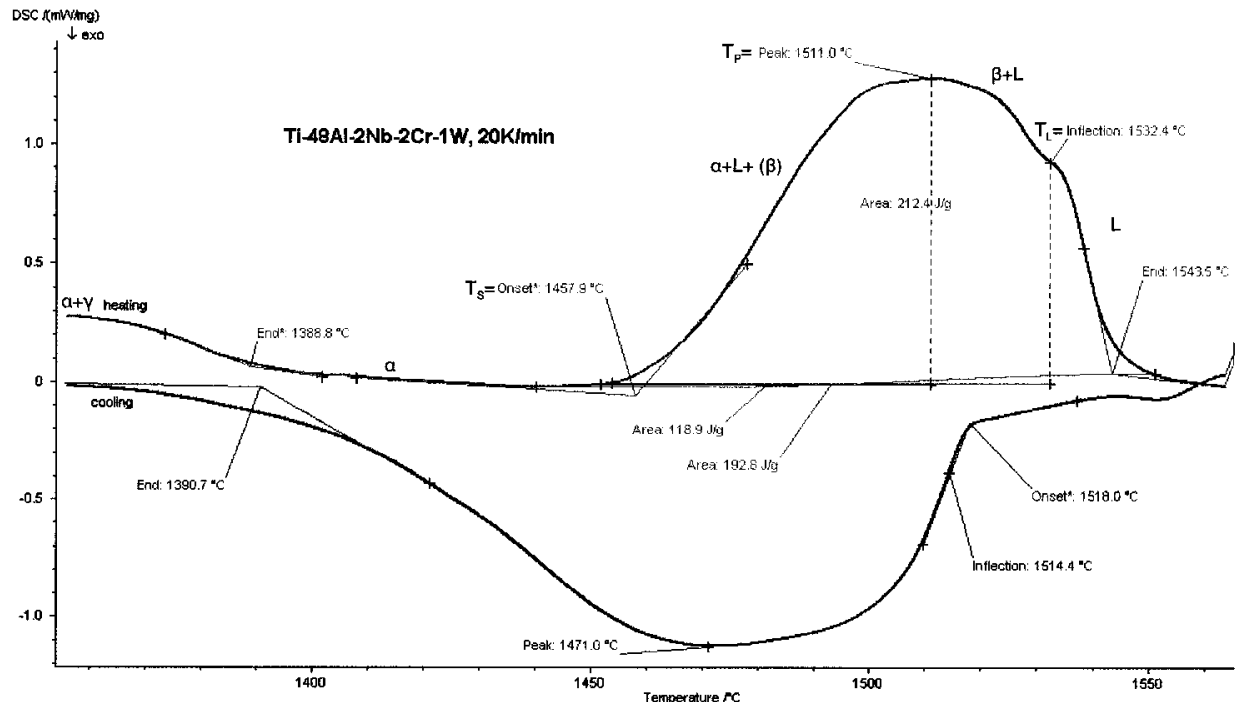

Figure 62: DSC curve for a Ti-48Al-2Cr-2Nb-1W, $20 \mathrm{~K} / \mathrm{min}$.

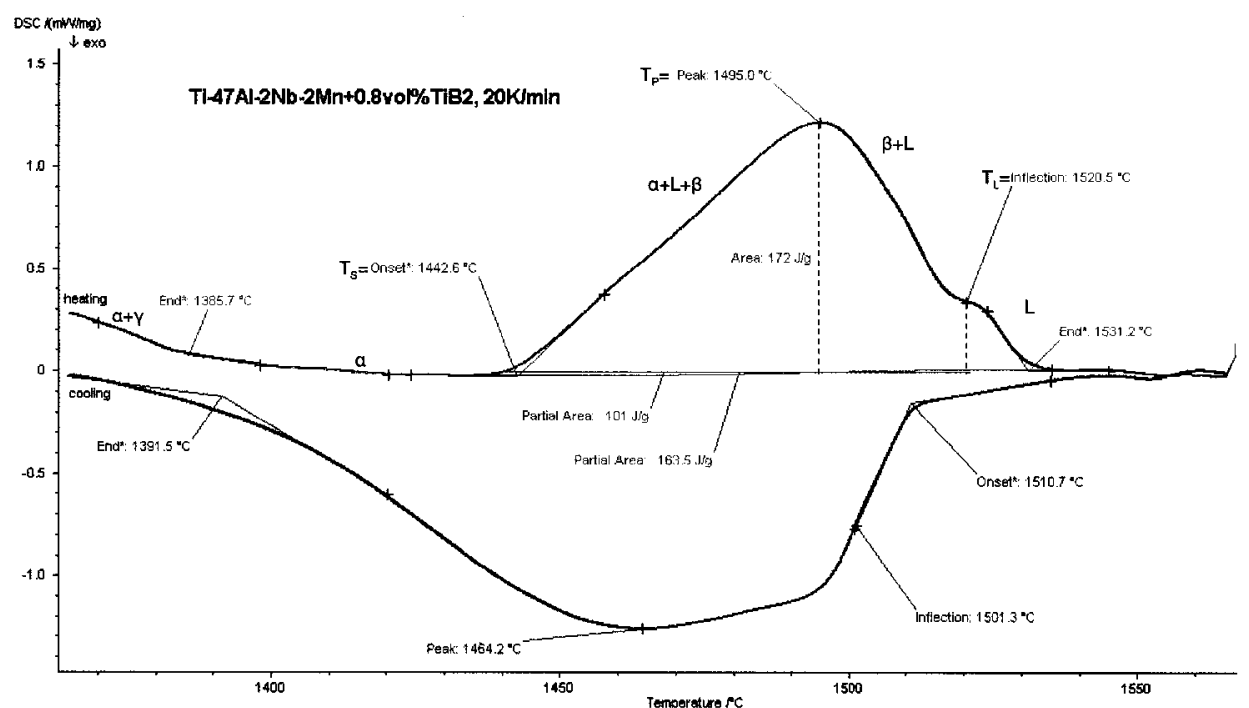

Figure 63: DSC curve for a $47 \mathrm{XD}, 20 \mathrm{~K} / \mathrm{min}$. 


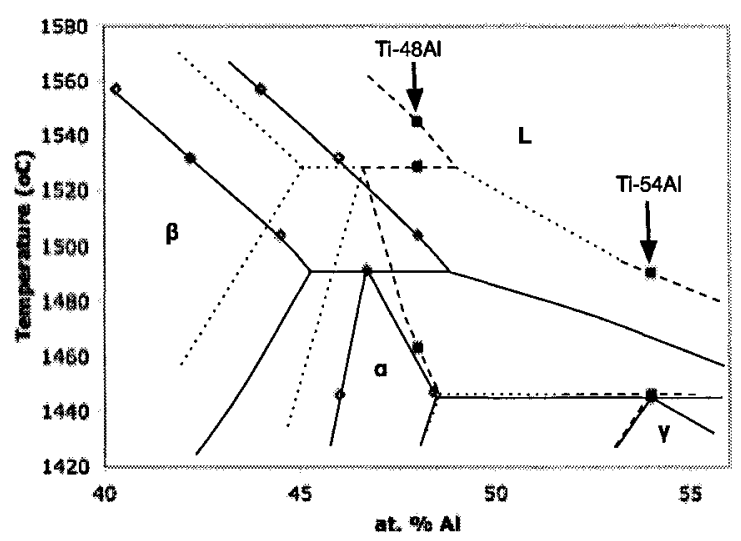

Figure 64: TiAl phase diagram including the DSC results for the Ti-48Al and Ti-54Al binary compositions, overlaid on the phase diagram reported by Jung et al. [14].

\section{The Effect of Initial Sample Condition}

Some of the samples tested showed differences between the shapes of the first and second heating curves. This was especially evident for the alloys with $\mathrm{W}$ as one of the main alloying elements. For these samples a small peak showed up just before the main peak, but not on the first heating curve; the small peak is evident on the second heating and both of the cooling curves for these alloys. For the W containing PM samples the reason for this difference between the first and second heating curves could be due to the non-homogeneous nature to the powder. Segregation in the powder may cause the second heating curve to be different from the first, with the first heating peak corresponding to powder consolidation, and the second heating showing the true transformations occurring in the sample. Also, the change in surface energy on consolidation of the PM samples could be affecting the DSC results.

\section{The Effect of Alloying Additions}

One of the goals of this thesis was to determine the effects of alloying additions on the transformation temperatures. Some of the alloys show a progression in the addition of alloying elements. For example: Ti-48Al, Ti-48Al-2Cr, Ti-48Al-2Cr-2Nb, Ti-48Al-2Cr-2Nb-0.5W, 
Ti-48Al-2Cr-2Nb-1W. The ternary composition Ti-48Al-2W can also be added to this list, to show the effect of adding $\mathrm{W}$ to the $\mathrm{Ti}-48 \mathrm{Al}$ binary. The transformation temperatures found for these alloys are summarized in Table 21. The temperatures reported are peak onset $\left(\mathrm{T}_{S}\right)$, the two temperatures in the peak, the peak and the inflection point $\left(\mathrm{T}_{L}\right)$, and the peak end temperature. Adding $\mathrm{Cr}$ to the binary alloy reduces the transformation temperatures. Adding $\mathrm{W}$ to the binary increases the transformation temperature. When $\mathrm{Nb}$ is added to the $\mathrm{Ti}-48 \mathrm{Al}-2 \mathrm{Cr}$ ternary, the temperatures all increase, so $\mathrm{Nb}$ seems to increase transformation temperatures. However, increasing the amount of $\mathrm{W}$ in the Ti-48Al-2Cr-2Nb-XW alloys tends to decrease the transformation temperatures. The trends in the effects of alloying additions are not very clear, and it would be advisable to carry out further heat treatment and metallographic testing to confirm the DSC results.

The binary Ti-54Al and Ti-52Al-2W-0.5Si have similar DSC curves, although the addition of $\mathrm{W}$ causes $\beta$ phase formation in the later which makes their transformation paths quite different. Ignoring the $\beta$ phase in the complex alloy, the transformation temperatures can be matched up, as shown in Table 22. The addition of $\mathrm{W}$ pushes the melting temperature of the complex alloy higher when compared to the binary.

Some of the alloys show very similar DSC curve shapes based on alloying additions. For example, the alloys with $\mathrm{W}$ as the main alloying element all showed a similar DSC curve. This can be seen in Figure 65, which includes the melting peaks for Ti-48Al, Ti-48Al-2W, Ti-47Al-2W-0.5Si and Ti-47.5Al-2W-0.5Si. Note that all of the curves show a small peak just before the main melting peak, which corresponds to the $\alpha+\beta$ transformation due to the $\beta$ stabilizing effects of the $\mathrm{W}$. The curves all have a main peak corresponding to the $\alpha+L \rightarrow \beta+L$ transformation, and then an inflection point showing the merging of the $L$ transformation peak in to the larger peak. 


\begin{tabular}{|l|c|c|c|c|}
\hline Alloy & peak onset $\left(\mathbf{T}_{S}\right)$ & peak $\mathbf{T}_{P}$ & inflection $\mathbf{T}_{L}$ & end \\
\hline Ti-48Al & 1463 & 1529 & 1545 & 1564 \\
Ti-48Al-2Cr & 1448 & 1491 & 1519 & 1531 \\
Ti-48Al-2W & 1474 & 1538 & 1558 & 1568 \\
Ti-48Al-2Cr-2Nb & 1461 & 1518 & 1539 & 1552 \\
Ti-48Al-2Cr-2Nb-0.5W & 1464 & 1512 & 1537 & 1548 \\
Ti-48Al-2Cr-2Nb-1W & 1458 & 1511 & 1532 & 1544 \\
\hline
\end{tabular}

Table 21: Summary of the effect of alloying additions to Ti-48Al on the DSC transformation temperatures, all temperatures given in ${ }^{\circ} \mathrm{C}$.

\begin{tabular}{|l|c|c|c|c|}
\hline Alloy & peak onset & peak $\mathbf{T}_{S}$ & inflection $\mathbf{T}_{L}$ & end \\
\hline Ti-54Al & 1446 & 1467 & 1490 & 1506 \\
Ti-52Al-2W-0.5Si & 1434 & 1468 & 1508 & 1513 \\
\hline
\end{tabular}

Table 22: Summary of the transformation temperatures in Ti-54Al and Ti-52Al$2 \mathrm{~W}-0.5 \mathrm{Si}$, all temperatures given in ${ }^{\circ} \mathrm{C}$.

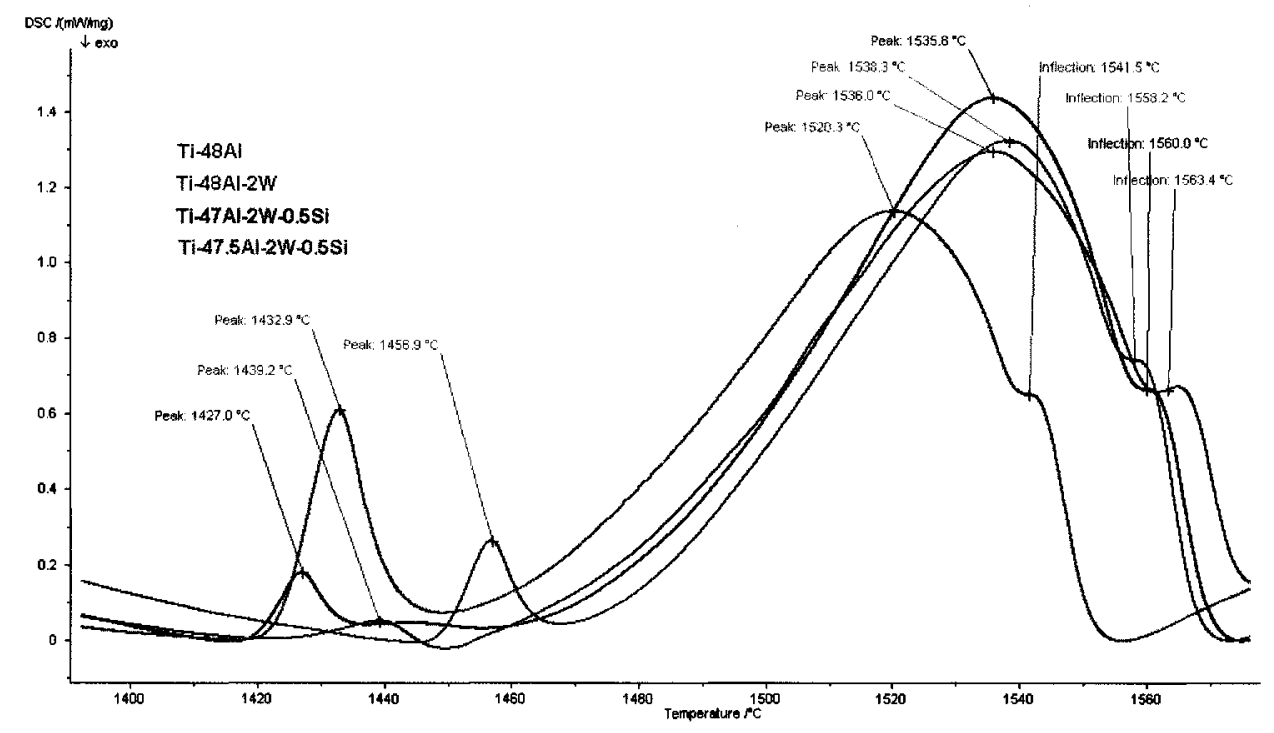

Figure 65: A comparison of the DSC curves for various Ti-Al-W alloys. Note the similarity in curve shape. 


\section{Chapter 6}

\section{Summary and Conclusions}

To summarize, the goal of this thesis was to examine a number of $\gamma$-TiAl alloys to determine the phase transformations that occur, and how these are effected by varying alloy composition.

1. Thermal analysis of $18 \gamma$-TiAl alloys was carried out. For each alloy, two tests were run at $20 \mathrm{~K} / \mathrm{min}$ and one at $5 \mathrm{~K} / \mathrm{min}$.

2. Analysis of DSC curves was correlated to the binary Ti-Al phase diagram and to transformation paths reported in literature to determine the phase transformations that were occurring in the various alloys tested.

3. The temperatures for these phase transformations were obtained from the DSC curves. The important temperatures for the ProCAST model, to simulate the DS casting of TiAl alloys for gas turbine engine applications, are the liquidus $\left(\mathrm{T}_{L}\right)$ and solidus $\left(\mathrm{T}_{S}\right)$ tempeartures.

4. The fraction of solid that exists in the alloy as a function of temperature was also determined for the various transformations in the solidus to liquid peak of the DSC curves. Fraction of solid $\left(\mathrm{f}_{S}\right)$ is another important thermophysical property required for the ProCAST model.

From this work, the significant conclusions are that: 
1. DSC can be used to detect the phase transformations which occur in most $\gamma$-TiAl intermetallics.

2. DSC can be used to find the approximate temperatures at which these transformations occur.

3. The area under the melting peak can give an indication of the fraction of solid values as a function of temperature.

4. DSC can be used to determine the effects of alloying additions on phase transformations and transformation temperatures. The different alloying additions produce distinct DSC curves.

\subsection{Future Research}

DSC analysis is a good initial tool for studying these alloys to determine phase transformations and temperatures. From the DSC curves obtained for each alloy the phase transformations that are occurring and the temperatures at which they occur indicate the temperatures that should be examined further. Subsequent studies can then use heat treatments above and below the temperatures of interest. Quenching can be used to determine the phases present microstructurally, and HTXRD can be used to determine the crystallography. Note that since HTXRD can not be used above the temperature of first liquid formation accurate determination of the solidus temperature is important for further studies using this method. Future work should focus on confirming the transformation paths and transformation temperature, especially for the alloys for which the DSC results were unclear.

One reason that the phase transformation that occur on cooling are of interest because the lamellar orientation is determined by the phases that form. That is, $\alpha$ will produce normal lamellae and $\beta$ will produce parallel or angled lamellae. The ideal case for DS casting is $\beta$ solidification to produce parallel lamellae. DS casting trials have shown that 
it is possible to produce $\beta$ solidification since the castings produced have the four fold dendritic structure characteristic of the $\beta$ phase. However, solidification produced normal rater than parallel or angled lamellae [4]. A question that has come out of this research is the effect of the peritectic on the solidification structures formed. This is why further research must be carried out to look at the solidification of these alloys in more detail. One option, for example, is to use electron probe microanalysis (EPMA) to examine the compositions of the phases present in the dendrite core vs. the interdendritic regions. This could also be compared to the results of DSC analysis to try to determine which phases are solidifying first (at the dendrite core), and which phases are solidifying last in the remaining liquid between the dendrites. Thus, it may be possible to use this method to determine the solidification sequence based on the phases that form. These results could then be compared to expected transformation paths predicted by the phase diagram.

Figure 66 shows several images of the microstructures formed by TAMN and TAWS using DS casting at different withdrawal rates. The dendrites formed can be seen in these images. As discussed above, the dendrites solidify following the transformation path, with the first solid phase to form at the dendrite core the last solid forming in the liquid remaining in the inter-dendritic regions. EPMA could be used to determine the composition of the dendrite, and could thus be used to help determine the solidification sequence followed on cooling.

Further development of knowledge regarding the phase transformations that occur on cooling must also be carried out, specifically the effects of undercooling as a function of cooling rate. At $20 \mathrm{~K} / \mathrm{min}$, the transformation temperatures on cooling lagged considerably behind those found on heating. DSC test were run for all of the alloys at $5 \mathrm{~K} / \mathrm{min}$, in the hopes that the cooling rate effects could be studied between different heating rates. Unfortunately, the $5 \mathrm{~K} / \mathrm{min}$ results were not helpful in this.

Finally, the thermophysical data that was found should be input into the ProCAST 
model to determine its effects on the model.
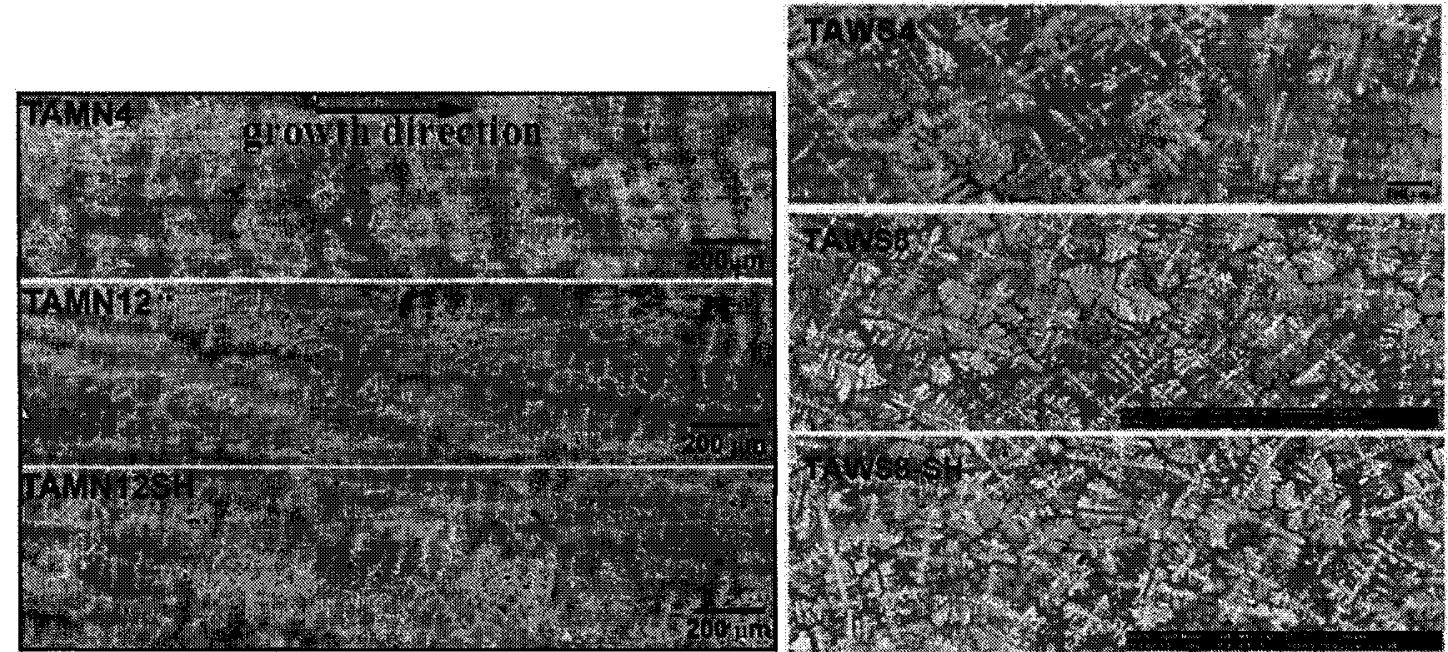

Figure 66: BSE images showing the microstructures of DS cast TAMN and TAWS solidified under different withdrawal rates [4]. 


\section{References}

[1] G. Meetham, The Development of Gas Turbine Materials. London: Applied Science Publishers Ltd., 1981.

[2] H. Saravanamuttoo, G. Rogers, and H. Cohen, Gas Turbine Theory. Essex: Prentice Hall, Pearson Education Limited, 5 ed., 2001.

[3] Rolls-Royce, "The jet engine," Derby, England, 1996.

[4] H. M. Saari, Process Modelling of the Directional Solidificationof Gas Turbine Materials. $\mathrm{PhD}$ thesis, Carleton University, February 2003.

[5] C. Austin and T. Kelly, "Gas turbine engine implementation of gamma titanium aluminide," in Superalloys 1996 (R. K. et al., ed.), pp. 539-543, 1996.

[6] A. Gilchrist and T. Pollock, "Cast gamma titanium aluminides for low pressure turbine blades: A design case study for intermetallics," in Structural Intermetallics 2001 (K. H. et al., ed.), pp. 3-12, 2001.

[7] D. Dimiduk, "Gamma titanium aluminide alloys - an assessment within the competition of aerospace structural materials," Materials Science and Engineering A263, pp. 281288,1999 .

[8] T. Ahmed, S. Guillard, H. Rack, V. Seetharaman, and J. Chestnutt, "High temperature phase stability of Ti-(45.5-48)Al-2Nb-2Cr," in Gamma Titanium Aluminides (Y.-W. Kim, R. Wagner, and M. Yamaguchi, eds.), pp. 203-210, The Minerals, Metals \& Materials Society, 1995.

[9] S. Semiatin, J. Chestnutt, C. Austin, and V. Seetharam, "Processing of intermetallic alloys," Structural Intermetallics, pp. 263-276, 1997.

[10] M. Yamaguchi, H. Inui, and K. Ito, "High-temperature structural intermetallics," Acta mater., no. 48, pp. 307-322, 2000.

[11] R. Ramanujan, "Phase transformations in $\gamma$ based titanium aluminides," International Materials Reviews, vol. 45, no. 6, pp. 217-240, 2000. 
[12] Y. Kim and D. Dimiduk, "Process in the understanding of gamma titanium aluminides," JOM, August 1991.

[13] J. Jung, J. Park, and C. Chun, "Influence of Al content on cast microstructures of ti-al intermetallic compounds," Intermetallics 7, pp. 1033-1041, 1999.

[14] I. Jung, M. Kim, J. Lee, M. Oh, and D. Wee, "High temperature phase equilibria near Ti-50 atsolidification," Intermetallics 7, pp. 1247-1253, 1999.

[15] H. Inui, M. Oh, A. Nakamura, and M. Yamaguchi, "Ordered domains in tial coexisting with $\mathrm{Ti}_{3} \mathrm{Al}$ in the lamellar structure of Ti-rich TiAl compounds," Philosophical Magazine A, vol. 66, no. 4, pp. 539-555, 1992.

[16] M. Yamaguchi and H. Inui, "TiAl compounds for structural applications," Structural Intermetallics, pp. 127-142, 1993.

[17] H. Inui, M. H. Oh, A. Nakamura, and M. Yamaguchi, "Room-temperature tensile deformation of polysynthetically twinned (PST) crystals of TiAl," Acta metallurgica et materialia, vol. 40, no. 11, pp. 3095-3104, 1992.

[18] T. Nakano, T. Kanawaka, H. Yasuda, and Y. Umakoshi, "Effect of lamellar structure on fracture behaviour of TiAl polysynthetically twinned crystals," Materials Science and Engineering A194, pp. 43-51, 1995.

[19] Y. Umakoshi, H. Yasuda, and T. Nakano, "Plastic anisotropy and fatigue of TiAl PST crystals: a review," Intermetallics 4, pp. S65-S75, 1996.

[20] T. Nakano, H. Yasuda, N. Higashitanaka, and Y. Umakoshi, "Anomalous behaviour of cyclic deformation and fatigue properties of TiAl PST crystals under constant applied stress," Acta materialia, vol. 45, no. 11, pp. 4807-4821, 1997.

[21] Y. Umakoshi, H. Yasuda, T. Nakano, and K. Ikeda, "Effect of deformation temperature on fatigue and fracture behaviour in TiAl polysynthetically twinned crystals," Metallurgical and Materials Transactions A, vol. 29A, pp. 943-950, 1998.

[22] T. Matsuo, T. Nozaki, T. Asai, S. Chang, and M. Takeyama, "Effect of lamellar plates on creep resistance in near gamma TiAl alloys," Intermetallics 6, pp. 695-698, 1998.

[23] T. Parthasarathy, P. Subramanian, M. Mendiratta, and D. Dimiduk, "Phenomenological observations of lamellar orientation effects on the creep behaviour of Ti-48at.\%Al PST crystals," Acta mater., vol. 48, pp. 541-551, 2000.

[24] C. Wen, K. Yasue, J. Lin, Y. Zhang, and C. Chen, "The effect of lamellar spacing on the creep behaviour of a fully lamellar TiAl alloy," Intermetallics 8, pp. 525-529, 2000. 
[25] D. Johnson, Y. Masuda, T. Yamanaka, H. Inui, and M. Yamaguchi, "Creep deformation of TiAl-si alloys with aligned $\gamma / \alpha_{2}$ lamellar microstructures," Metallurgical and Materials Transactions A, vol. 31A, pp. 2463-2473, 2000.

[26] K. Maruyama, H. Kim, and D. Luzzi, "Optimization of microstructural variable for creep resistance and yield strength in fuly-lamellar TiAl alloys," in Structural Intermetallics 2001 (K. H. et al., ed.), pp. 53-62, 2001.

[27] D. Johnson, H. Inui, and M. Yamaguchi, "Directional solidification and microstructural control of the TiAl/ $\mathrm{Ti}_{3} \mathrm{Al}$ lamellar microstructure in TiAl-Si alloys," Acta materialia, vol. 44, no. 6, pp. 2523-2535, 1996.

[28] K. Kishida, D. Johnson, Y. Shimada, H. Inui, Y. Shirai, and M. Yamaguchi, "Characteristics, benefits and applications of PST TiAl crystals," in Gamma Titanium Aluminides (Y. K. et al., ed.), pp. 219-229, 1995.

[29] M. Pope and M. Judd, Differential Thermal Analysis: A Guide to the Technique and Its Applications. London: Heyden \& Sons Ltd., 1977.

[30] M. E. Brown, Introduction to Thermal Analysis: Techniques and Applications. London: Chapman and Hall Ltd., 1988.

[31] R. Wu and J. Perepezko, "Liquidus temperature determination in multicomponent alloys by thermal analysis," Metallurgical and Materials Transactions A, vol. 31A, pp. 497-501, February 2000.

[32] J. McNaughton and C. Mortimer, "Differential scanning calorimetry," International Review of Science: Physical Chemistry Ser. 2, vol. 10, pp. 1-44, 1975.

[33] G. Widmann and R. Riesen, Thermal Analysis: Terms, Methods, Applications. Germany: Dr. Alfred Hüthig Verlag Heidelberg, 1987.

[34] Melting and Crystallization Temperatures ASTM E 794.

[35] Heat of Fusion and Crystallization ASTM E 793.

[36] M. E. Schlesinger and S. Jacob, "Advances in high-temperature calorimetry: A comparison," JOM, pp. 37-40, December 2004.

[37] H. Saari, D. Seo, J. Blumm, and J. Beddoes, "Thermophysical property determination of high temperature alloys by thermal analysis," Journal of Thermal Analysis and Calorimetry, vol. 71, pp. 381-388, 2003.

[38] A. Pedersen, N. Pryds, S. Linderoth, P. Larsen, and J. Kjøller, "The determination of dynamic and equilibrium solid/liquid transformation data for $\mathrm{Sn}-\mathrm{Pb}$ using DSC," Journal of Thermal Analysis and Calorimetry, vol. 64, pp. 887-894, 2001. 
[39] M. Oehring, U. Lorenz, F. Appel, and D. Roth-Fagaraseanu, "Microstructure and mechanical properties of a boron containing gamma titanium aluminide alloy in different hot working stages," in Structural Intermetalics 2001 (K. Hemker, D. Dimuduk, H. Clemens, R. Darolia, H. Inui, J. Larsen, V. Sikka, M. Thomas, and J. Whittenberger, eds.), The Minerals, Metals \& Materials Society, 2001.

[40] I. Ohnuma, Y. Fujita, H. Mitsui, K. Ishikawa, R. Kainuma, and K. Ishida, "Phase equilibria in the Ti-Al binary system," Acta mater, no. 48, pp. 3113-3123, 2000.

[41] N. Saunders, "Phase equilibria in multi-component $\gamma$-TiAl based alloys," in Gamma Titanium Aluminides 1999 (Y.-W. Kim, D. Dimiduk, and M. Loretto, eds.), pp. 183188, The Minerals, Metals \& Materials Society, 1999.

[42] Y. Kim and D. Dimiduk, "Effect of boron addition on grain refinement and lamellar formation in wrought-processed gamma TiAl alloys," in Structural Intermetallics 2001 (K. H. et al., ed.), The Minerals, Metals \& Materials Society, 2001.

[43] F. Stein, L. Zhang, M. Palm, and G. Sauthoff, "AlTi alloys with Al-rich titanium aluminides: phase equilibria, evolution of phases, and strength of lamellar $\mathrm{TiAl}+\mathrm{rAl}_{2} \mathrm{Ti}$ alloys," in Structural Intermetallics 2001 (K. H. et al., ed.), The Minerals, Metals \& Materials Society, 2001.

[44] K. Hashimoto, M. Kimura, and Y. Mizuhara, "Alloy design of gamma titanium aluminides based on phase diagrams," Intermetallics 6, pp. 667-672, 1998.

[45] D. Dudzinski, L. Zhao, J. Beddoes, and W. Wallace, "Microstructural evolution of near- $\gamma$ TiA alloys during long-time heat treatments," Scripta Materialia, vol. 35, no. 3, pp. 367-372, 1996.

[46] P. McQuay, D. Dimiduk, and S. Semiatin, "The decomposition of alpha phase during continuous cooling and isothermal transformation in gamma titanium aluminide," Scripta Metallurgica et Materialia, vol. 25, pp. 1689-1694, 1991.

[47] Operating Instructions for DSC Apparatus: DSC $404 C$ Pegasus. Netzsch Thermal Analysis, 1998.

[48] ASM Handbook Volume 3: Alloy Phase Diagrams. ASM International, 1992. 


\section{Appendix A}

\section{Ti-Al Binary Equilibrium Phase Diagrams}

There is some variability in the literature in the results reported by different researchers when it comes to the Ti-Al binary phase diagram. A number of variations of the Ti-Al binary equilibrium phase diagram, from a number of different sources, are included here. The first one, Figure A.1, has been taken as the "correct" phase diagram for this thesis. The Ti-Al phase diagram found in the ASM handbook, Figure A.2, is the one proposed by J.L. Murray in 1987. The main difference between this phase diagram and the others included here is the absence of the $\alpha$-(Ti) region at higher temperatures; the Murray diagram reports $\beta$-(Ti) $+\gamma$-(TiAl) only below the peritectic where as the more recent phase diagrams report $\beta-(\mathrm{Ti})+\alpha-(\mathrm{Ti})$ and $\alpha-(\mathrm{Ti})$ below the peritectic. Figures A.3 and A.4 show the Murray phase diagram in comparison to two others, those put forward by Kattner et al. in 1992 and Okamoto in 1993 respectively. Note the difference with the $\beta$ - $(\mathrm{Ti})+\gamma$-(TiAl) region in the Murray diagram as opposed to the $\alpha$-(Ti) region in the more recent versions. Finally, Figure A.5 shows a phase diagram based on thermodynamic calculations proposed by Saunders in 1999. 


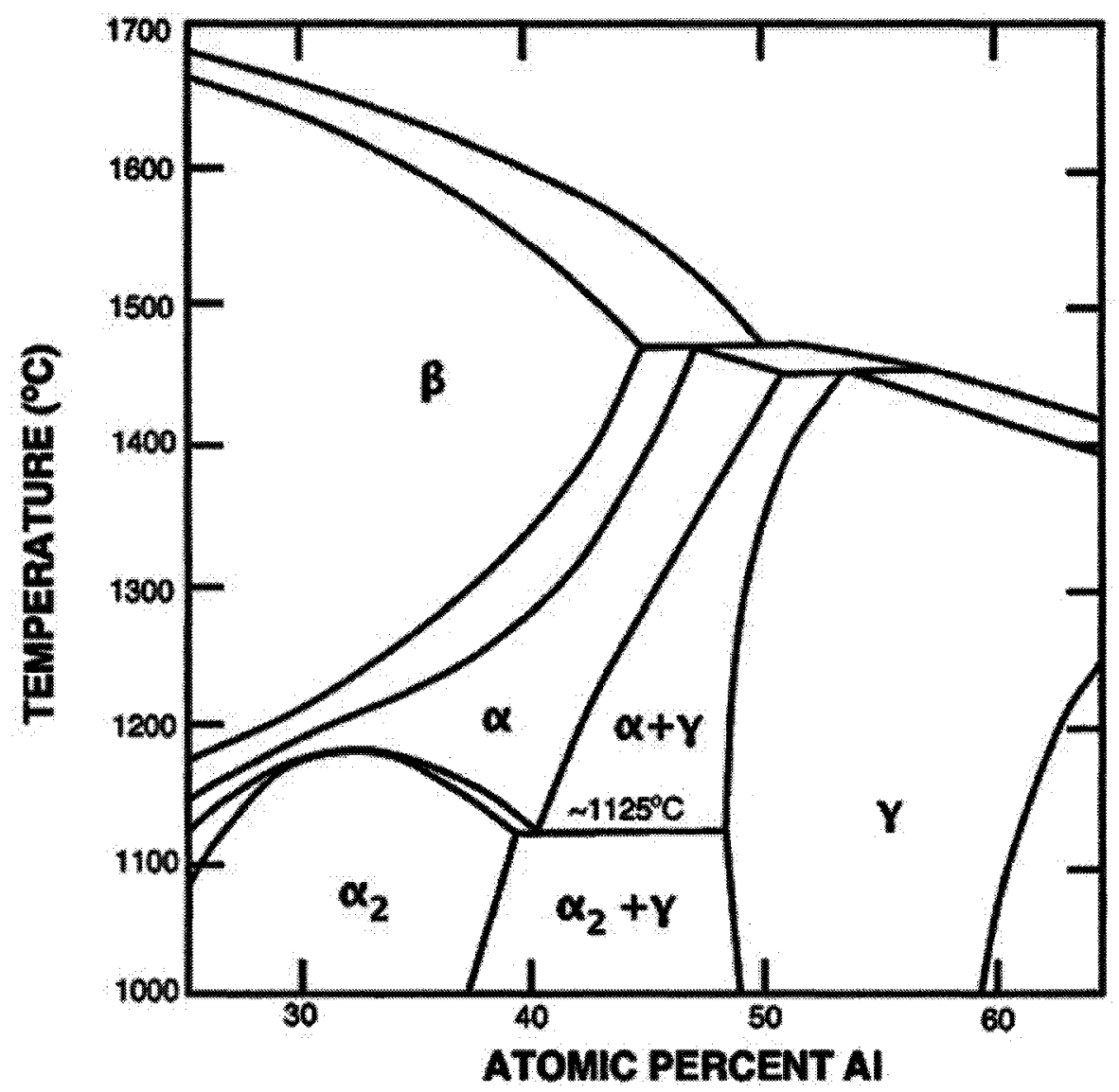

Figure A.1: Part of the binary Ti-Al equilibrium phase diagram, from Semiatin et al. [9]. 


\section{Al-Ti}

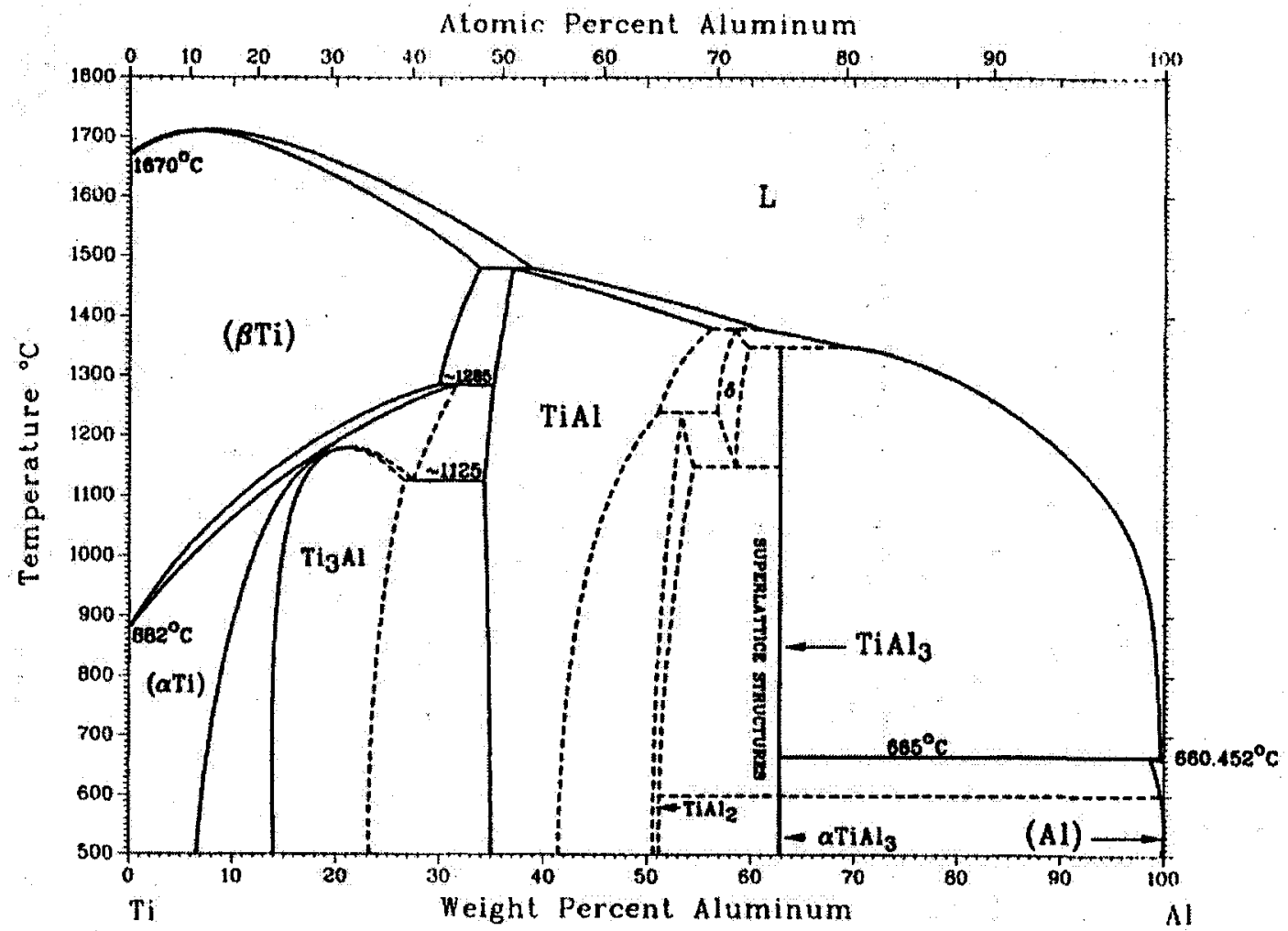

J.L. Murray, 1987

\begin{tabular}{|c|c|c|c|}
\hline Phase & $\begin{array}{c}\text { Composition, } \\
\text { wt } \% \text { Al }\end{array}$ & $\begin{array}{c}\text { Pearson } \\
\text { symbol }\end{array}$ & $\begin{array}{l}\text { Space } \\
\text { group }\end{array}$ \\
\hline$(\beta T i)$ & 0 to 33.8 & $\mathrm{cl} 2$ & $\operatorname{Im} \overline{3} m$ \\
\hline$(\alpha \mathrm{Ti})$ & 0 to 32 & $h P 2$ & $P 6_{3} / m m c$ \\
\hline $\mathrm{Ti}_{3} \mathrm{Al}$ & 14 to 26 & $h P 8$ & $\mathrm{P}_{3} / \mathrm{mmc}$ \\
\hline TIAI & 34 to 56.2 & $t P 4$ & P4/mmm \\
\hline $\mathrm{Ti}_{3} \mathrm{Al}_{5}(\mathrm{a})$ & 44 to 49 & tP32 & $14 / \mathrm{mbm}$ \\
\hline $\mathrm{TiAl}_{2}$ & 51 to 54 & $t / 24$ & $14_{1}$ land \\
\hline$\alpha \mathrm{TiAl}_{2}(\mathrm{~b})$ & $\cdots$ & $o C 12$ & $\mathrm{Cmmm}$ \\
\hline$\delta$ & 57 to 59.8 & (c) & $\cdots$ \\
\hline $\mathrm{TiAl}_{3}$ & 63 & 118 & $14 / \mathrm{mmm}$ \\
\hline$\alpha \operatorname{TiAl}_{2}$ & 63 & (d) & $\ldots$ \\
\hline (Al) & 98.8 to 100 & cF4 & $F m \overline{3} m$ \\
\hline
\end{tabular}

(a) Not an equilibrium phase. (b) Not shown on the assessed diagram. (c) Long-period superlattice structures. (d) Tetragonal; a superstructure of the $\mathrm{DO}_{22}$ lattice

Figure A.2: Ti-Al equilibrium phase diagram, from Murray 1987 [48]. 


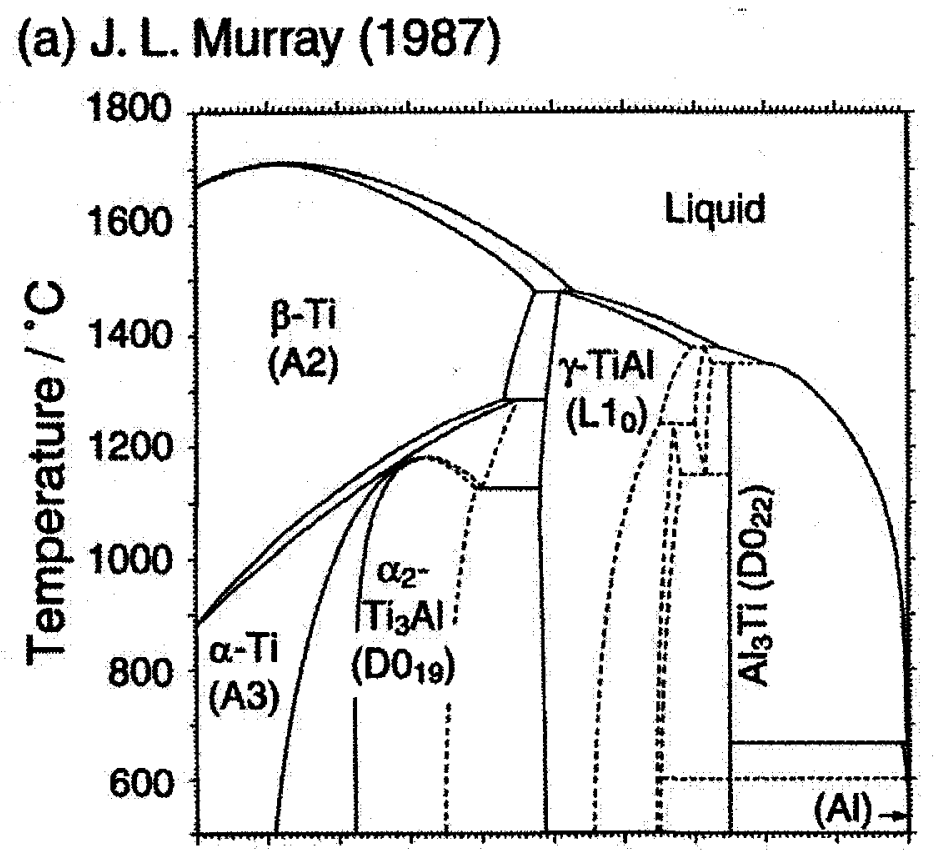

(b) U. R. Kattner (1992)

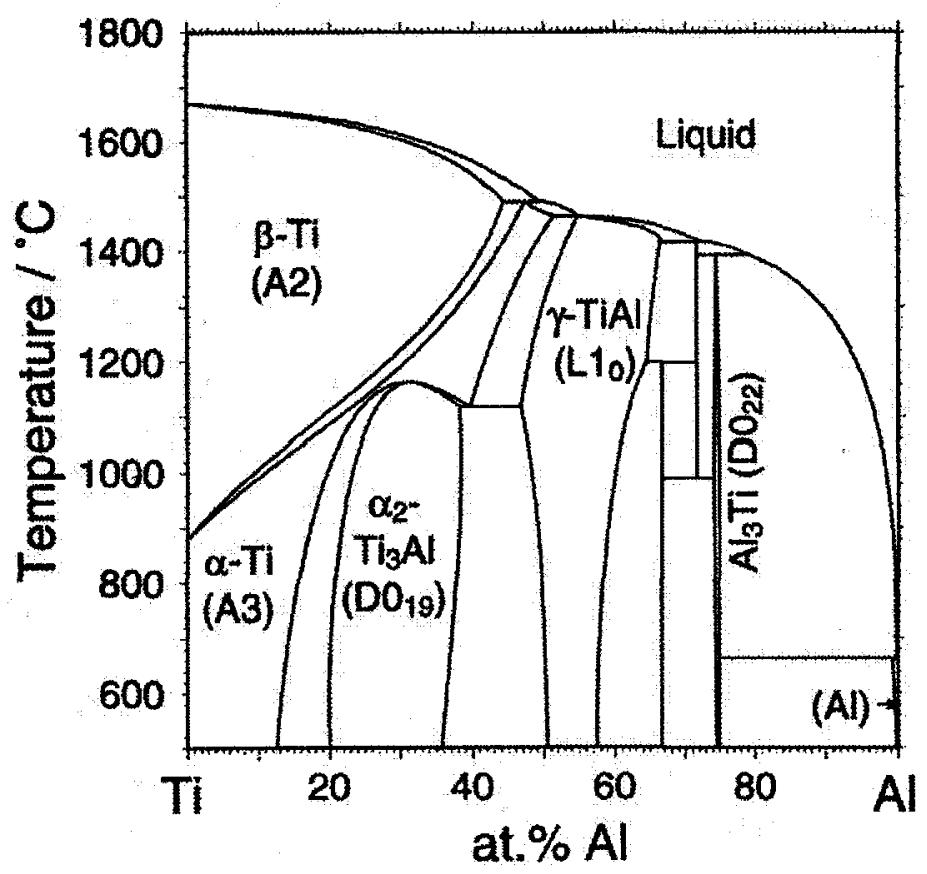

Figure A.3: Ti-Al equilibrium phase diagrams by (a) Murray and (b) Kattner et al. [40]. 

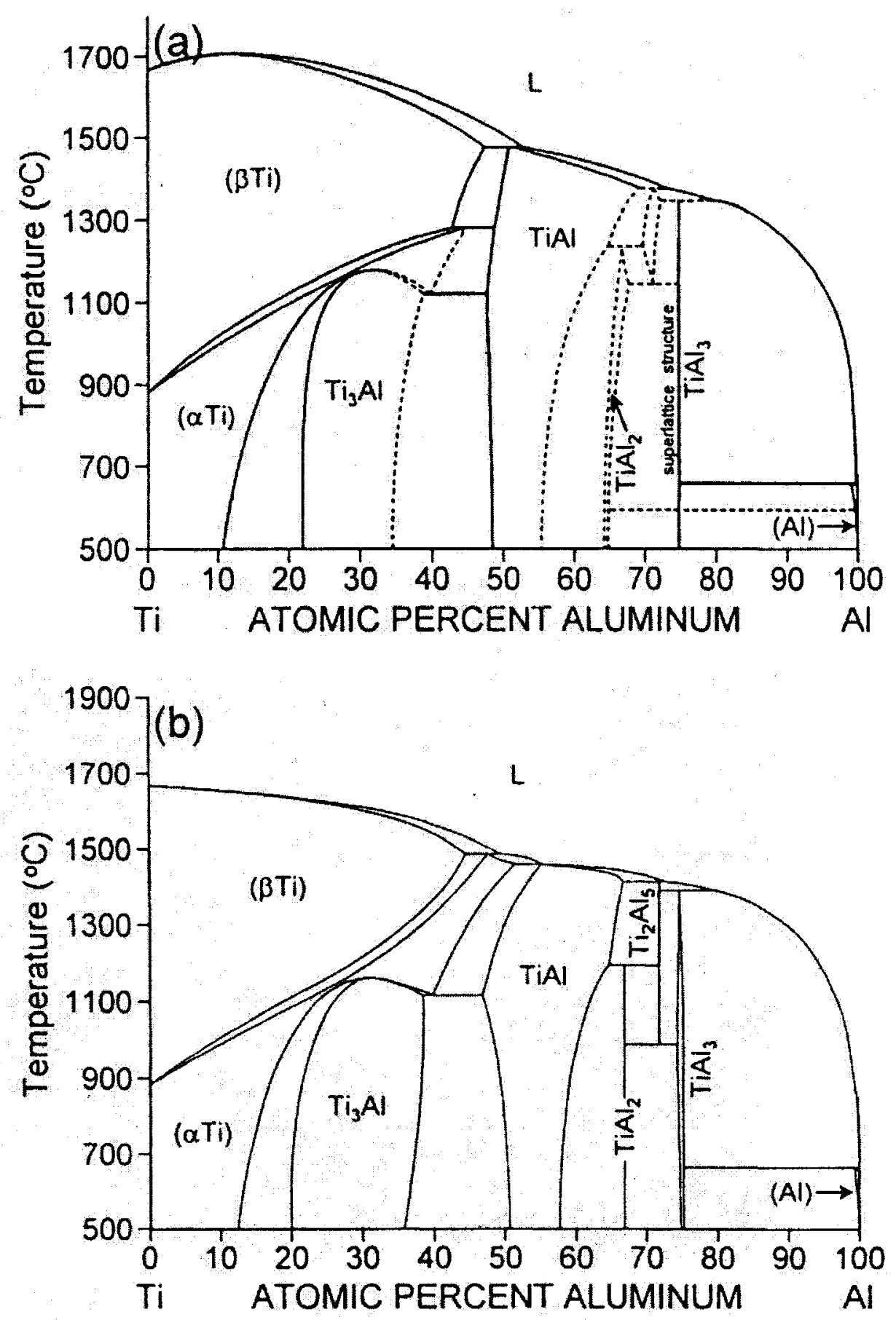

Figure A.4: Ti-Al equilibrium phase diagrams by (a) Murray and (b) Okamoto et al. [14]. 


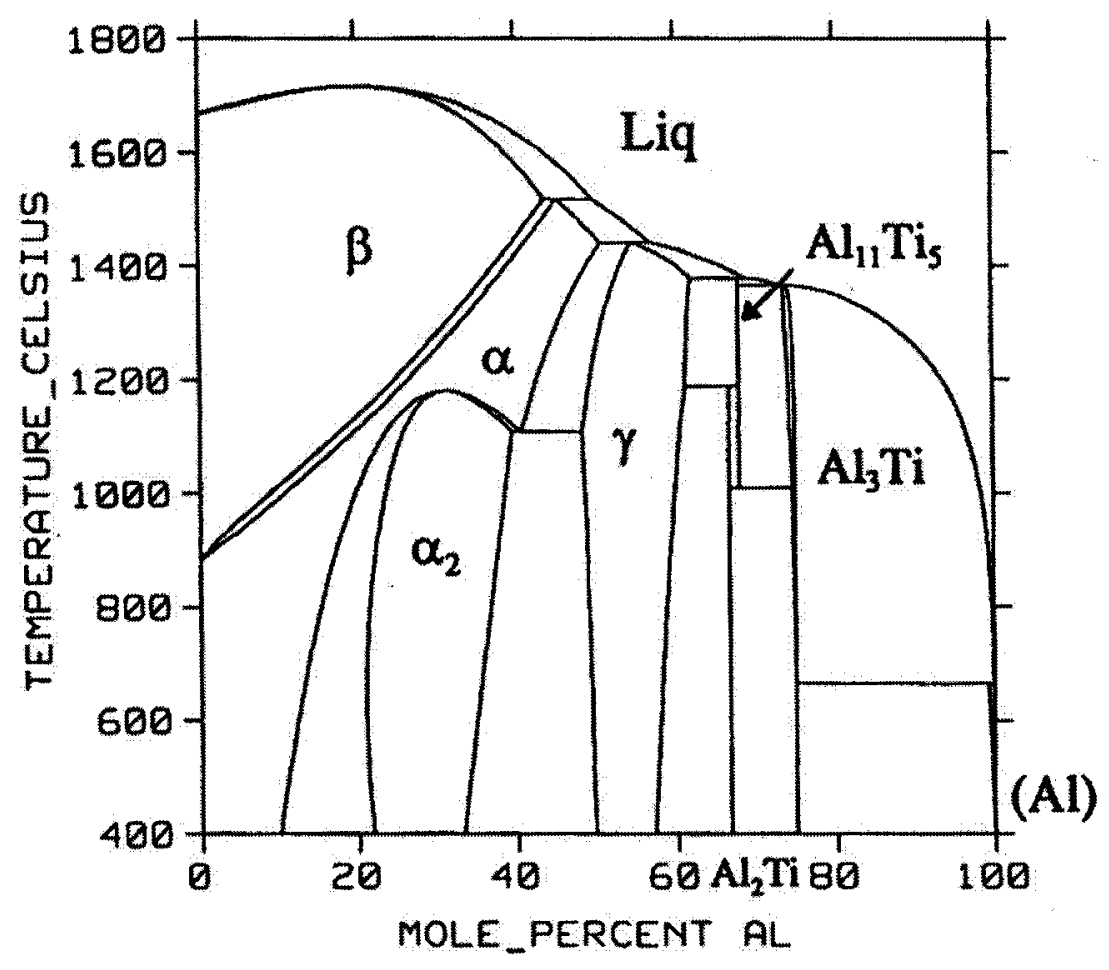

Figure A.5: Binary Ti-Al phase diagram reported by Saunders [41]. 


\section{Appendix B}

\section{DSC Operating Procedures for Test Setup}

This appendix contains setup procedures for running tests on the Carleton DSC. Figure B.1 shows a labelled photograph of the DSC equipment components.

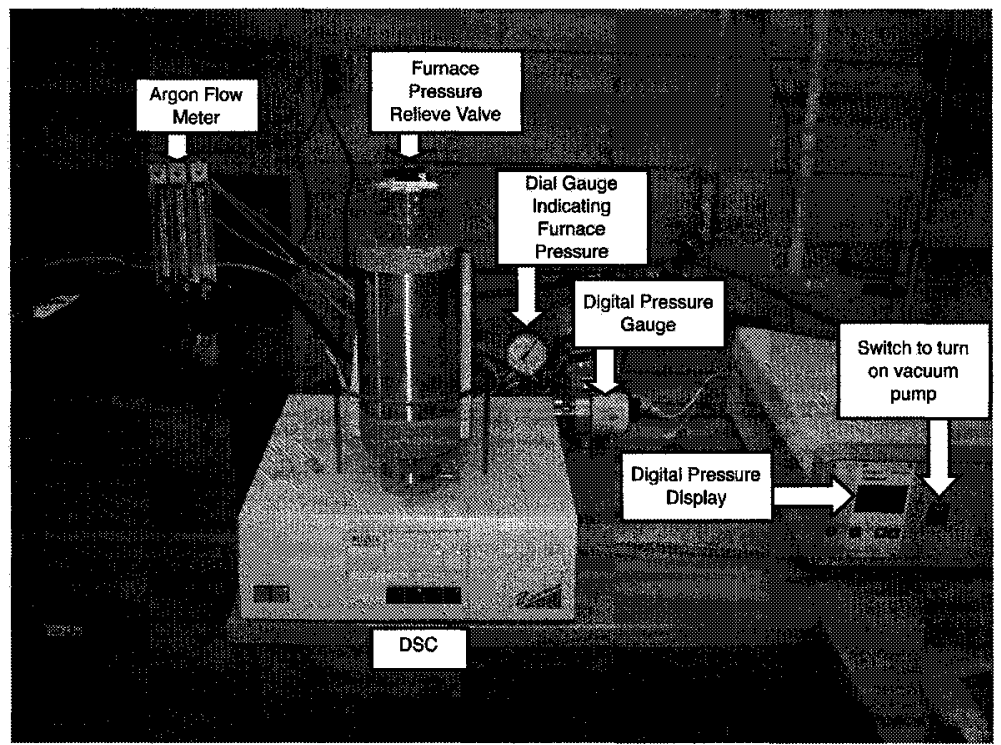

Figure B.1: Photo of the DSC equipment.

Before starting the procedure detailed below please ensure that:

- The Argon supply is on and that the pressure at the tank is 10 psi (max)

- All equipment is turned on

- The pressure relief valve at the top of the DSC furnace chamber is open.

B-1 
1. Open the DSC furnace by pressing the safety button on the right-hand side and the "up" arrow button on the left front panel, see Figure B.2.

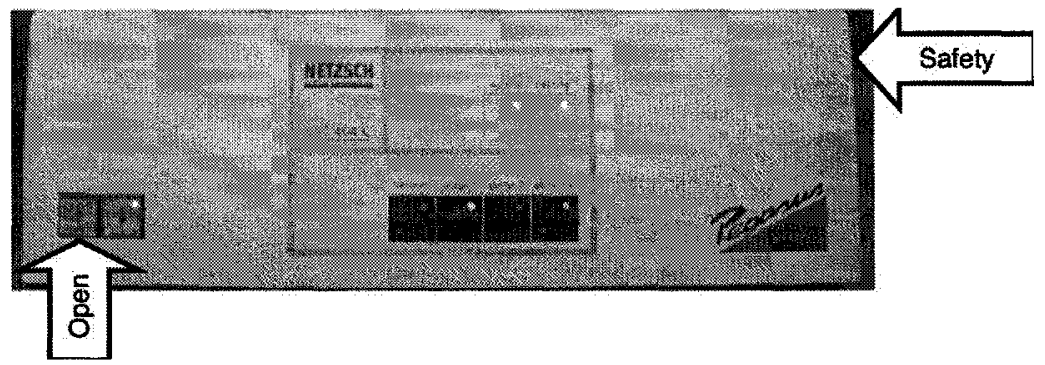

Figure B.2: How to open the DSC furnace.

2. Ensure that the sample and reference crucibles are clean. If cleaning is necessary the crucibles may be cleaned in methanol in the ultrasonic cleaner (eg. if there is adhering powder), or they may be rinsed in acetone and methanol, followed by a distilled water rinse. Dry thoroughly using clean compressed air. Use tweezers to handle crucibles. New crucibles should be cleaned using a bake-out run in the DSC furnace to the same temperature being used for sample runs. This ensures that any contaminants in the crucibles are removed before testing begins.

3. Weigh the reference crucible and record its mass, before and after each run.

4. Weigh and record the mass of the reference material (if used), and place it in the reference crucible.

5. Insert the reference crucible (with reference material) in the reference side of the sample carrier system. The reference side is located on the far side of the DSC sample holder, as indicated in Figure B.3. While inserting the crucible you can brace your hand against the green safety rail.

6. Weigh the sample crucible and record its mass.

7. Ensure that the sample is clean (clean in methanol in the ultrasonic cleaner, rinse with methanol, acetone, then distilled water, and dry using clean compressed air), then weigh. Always used tweezers to handle the sample after it is clean. 


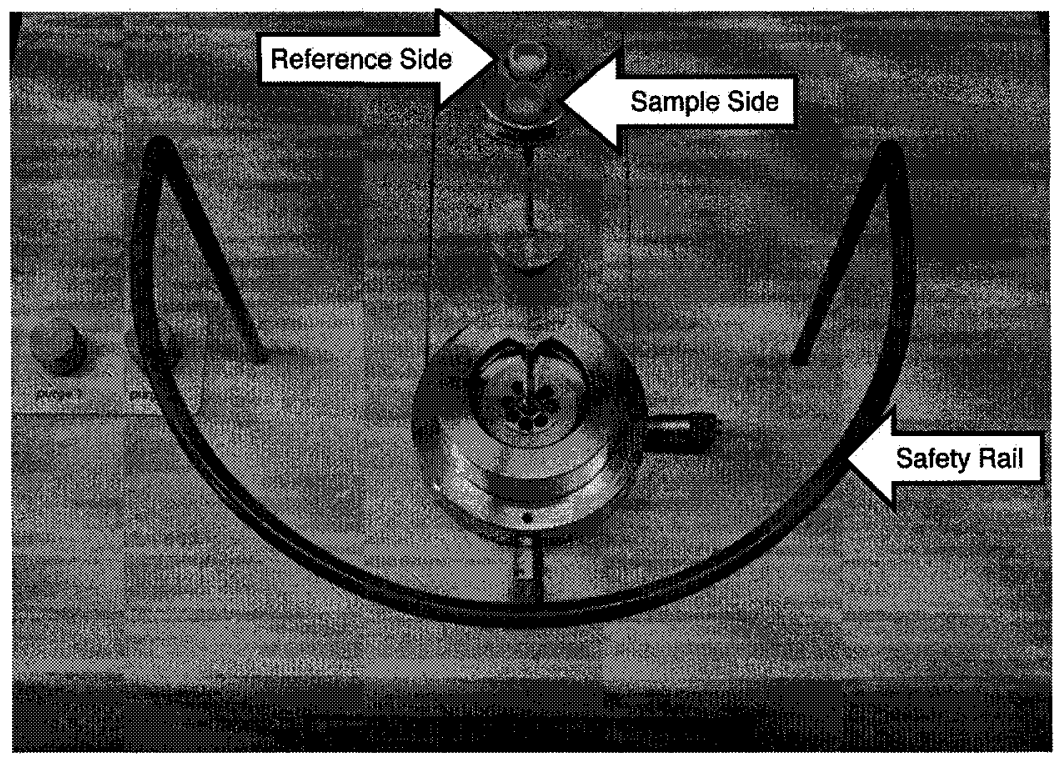

Figure B.3: Sample and reference placement in DSC sample carrier.

8. If the sample will be embedded in inert powder for the DSC run (eg. $\mathrm{Al}_{2} \mathrm{O}_{3}$ or $\mathrm{Y}_{2} \mathrm{O}_{3}$ powder), embed the sample in powder in the crucible at this time, then weigh the sample crucible, sample and powder together. The mass of powder being used can be found by subtracting the crucible and sample masses. If no powder is being used, weight the sample and crucible together and record the mass. Insert in the crucible in the sample side of the sample carrier system. The sample side is located on the near side of the DSC sample holder, as indicated in Figure B.3. While inserting the crucible you can brace your hand against the green safety rail.

9. Close the DSC furnace by pressing the safety button on the right-hand side and the "Down" arrow button on the left front panel, as shown in Figure B.4.

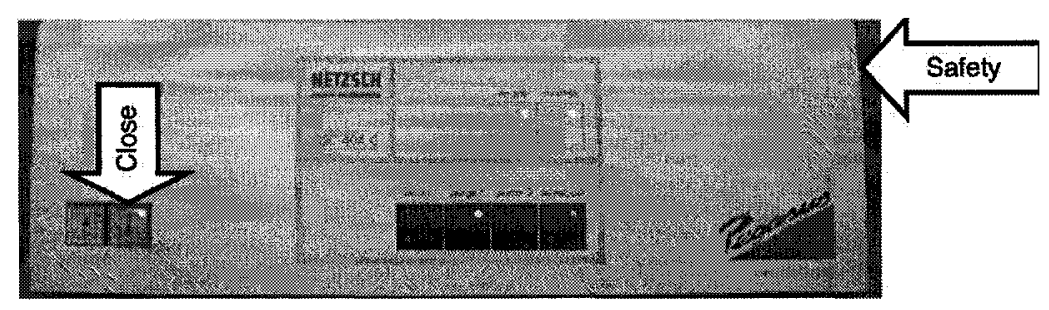

Figure B.4: How to close the DSC furnace. 
10. Turn on the protective gas using the dial on the right side of the flow meter, as indicated in Figure B.5, and adjust the flow to $60-70 \mathrm{~mL} / \mathrm{min}$.

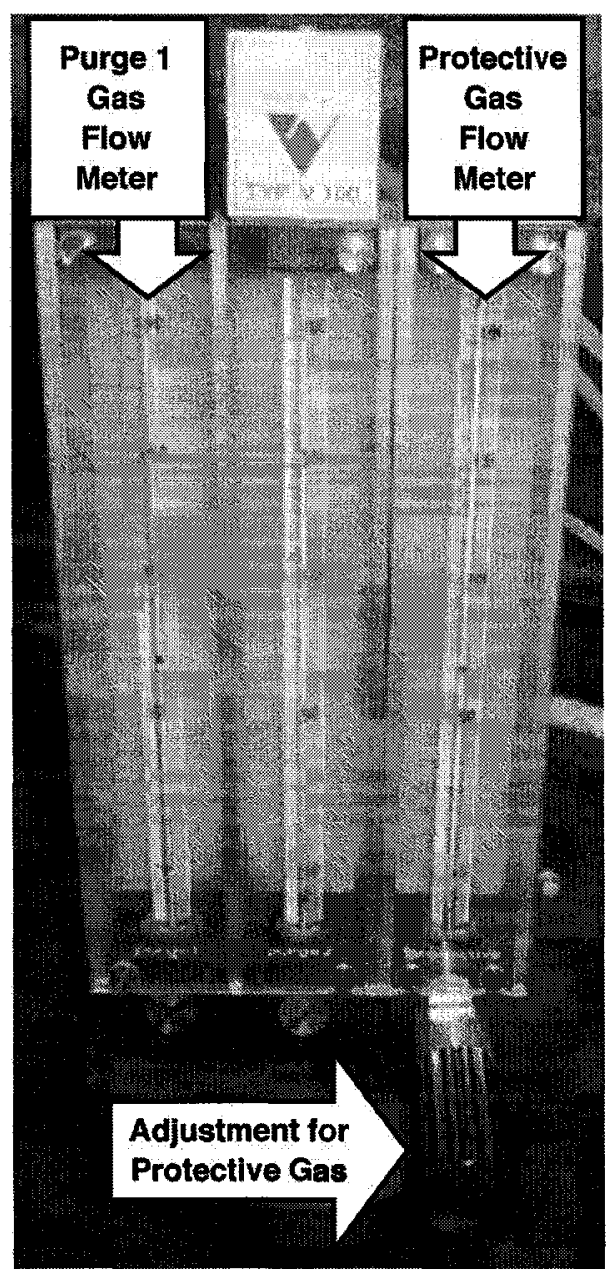

Figure B.5: Flow meter for Purge 1, Purge 2 and Protective gas, with the adjustment knob for protective gas flow indicated.

11. Turn on the purge gas to introduce argon into the furnace by pressing the "purge 1" button on the front panel (the lit green LED indicates that the purge gas is on) and adjusting the "purge 1" needle valve knob on the top of the DSC unit, see Figure B.6. Adjust the needle valve to get a reading on the the flow meter of $60-70 \mathrm{~mL} / \mathrm{min}$ for purge 1 .

12. Close the valve at the top of the DSC furnace by turning $90^{\circ}$ clockwise, and immediately stop the purge gas by pressing the "purge 1" button (LED extinguishes). Close 


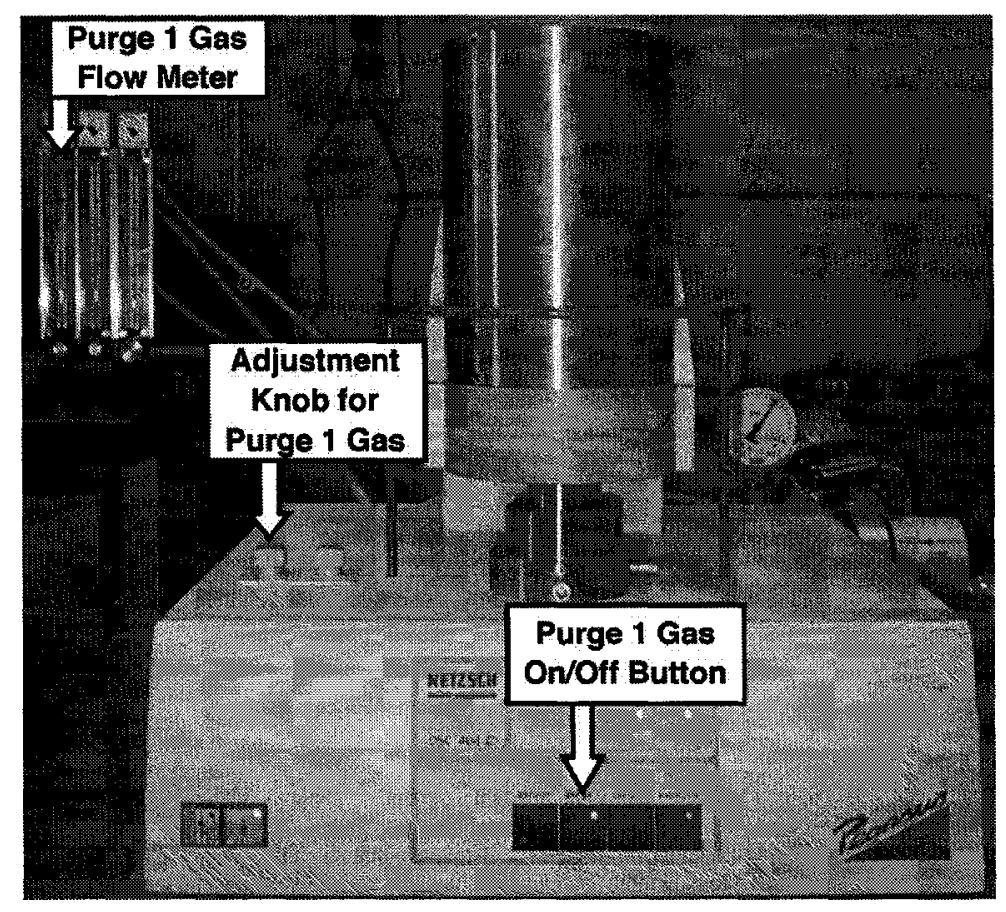

Figure B.6: Adjusting flow of purge 1 gas.

the needle valve controlling purge 1 .

13. Turn on the mechanical vacuum pump by pressing the green switch on the left front of the vacuum control console to evacuate the furnace. The pressure in the furnace is indicated on the digital display next to the vacuum switch and by the gauge at the rear of the DSC, see Figure

B.7.

14. When the mechanical pump has reached steady-state (1.5-2.5 indicated on the digital display), re-introduce the purge 1 gas into the furnace: turn on the "purge 1" button, slowly turn on the needle valve to fully open, turn off the mechanical pump. When the pressure in the furnace, as indicated by the vacuum dial gauge at the rear of the DSC, reaches just above positive turn the mechanical pump back on, then turn off the purge 1 gas (LED off) and close the needle valve.

15. Repeat step 14 . 


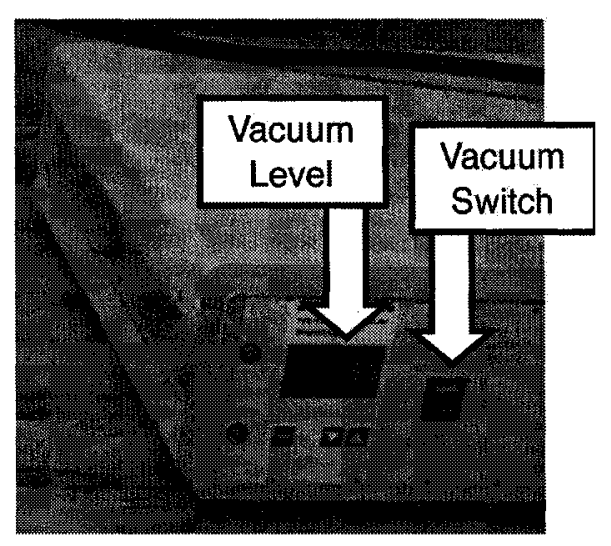

Figure B.7: Vacuum control console.

16. Repeat step 14 , but when the pressure in the furnace reaches just above positive open the pressure valve at the top of the furnace to a $45^{\circ}$ angle (should be able to hear a whistling noise of escaping purge gas). At this point turn the purge 1 needle valve down to an indicated reading of $60-70 \mathrm{~mL} / \mathrm{min}$ on the flow meter.

17. At this point, if the measurement program has been set up, click START STANDBY. Heating is indicated on the DSC front panel by a green LED. Turn on "Furnace Temperature" and "View Signals" under the Diagnosis menu to see the furnace and sample thermocouple temperatures. See Figure B. 8 to see all of these windows as they appear in the DSC 404C measurement software.

18. When the temperature of the sample reaches $100^{\circ} \mathrm{C}$ the START MEASUREMENT button will be activated and can be clicked to begin the heating program and data collection.

19. When the heating program is complete and the furnace has cooled to room temperature, shut of the purge and protective gases (if another test is to be run right away the protective gas can be left on). The sample and reference crucibles may be removed from the furnace, and the crucibles, reference and sample should all be weighed and the finished masses recorded. Clean the crucibles in preparation for the next test. 
B-7

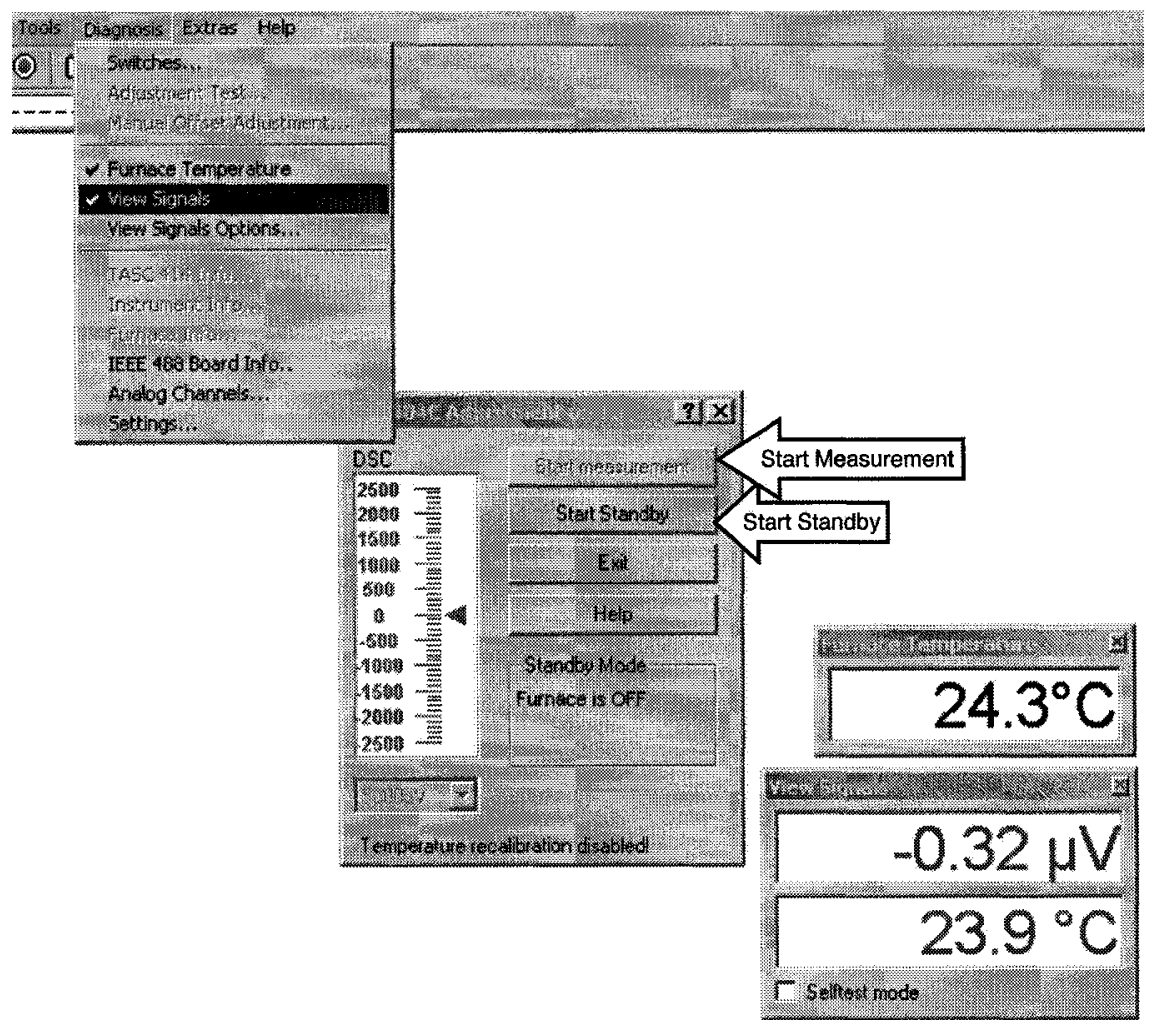

Figure B.8: DSC 404C measurement software Start Standby and Start Measurement. 


\section{Appendix C}

\section{Sample DSC Curves}

This appendix contains a sample DSC curve for each alloy tested: one $20 \mathrm{~K} / \mathrm{min}$ curve is included for each alloy. This gives an overview of the shape of the DSC curve for each alloy, without redundantly reproducing all of the DSC curve that were obtained during testing (since there are multiple DSC curves, at various heating rates, for each alloy). Analysis was done using the Netzsch analysis software. Note that the heating curves are always the upper lines (first heating is red, second heating is magenta), and the cooling curves are always the lower lines (first cooling is dark blue, second cooling is light blue). 


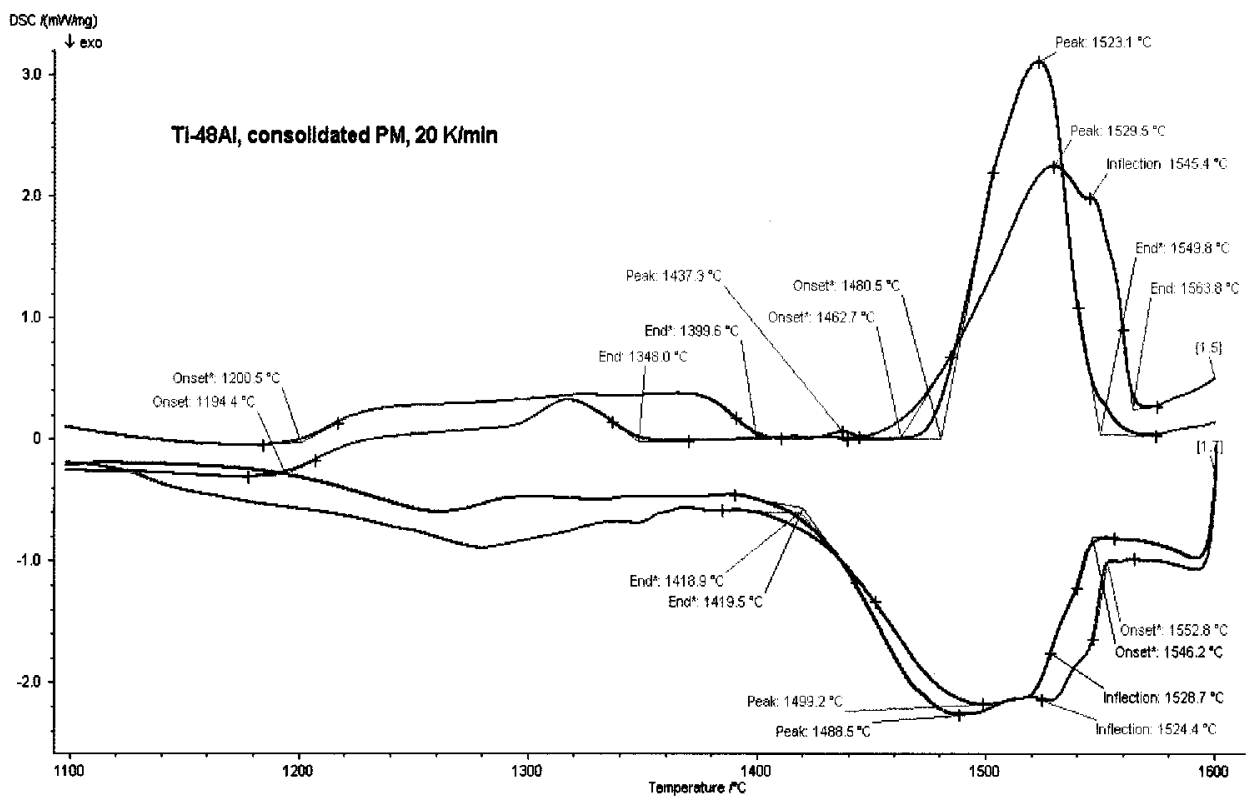

Figure C.1: DSC curve for Ti-48Al, consolidated PM sample, $20 \mathrm{~K} / \mathrm{min}$.

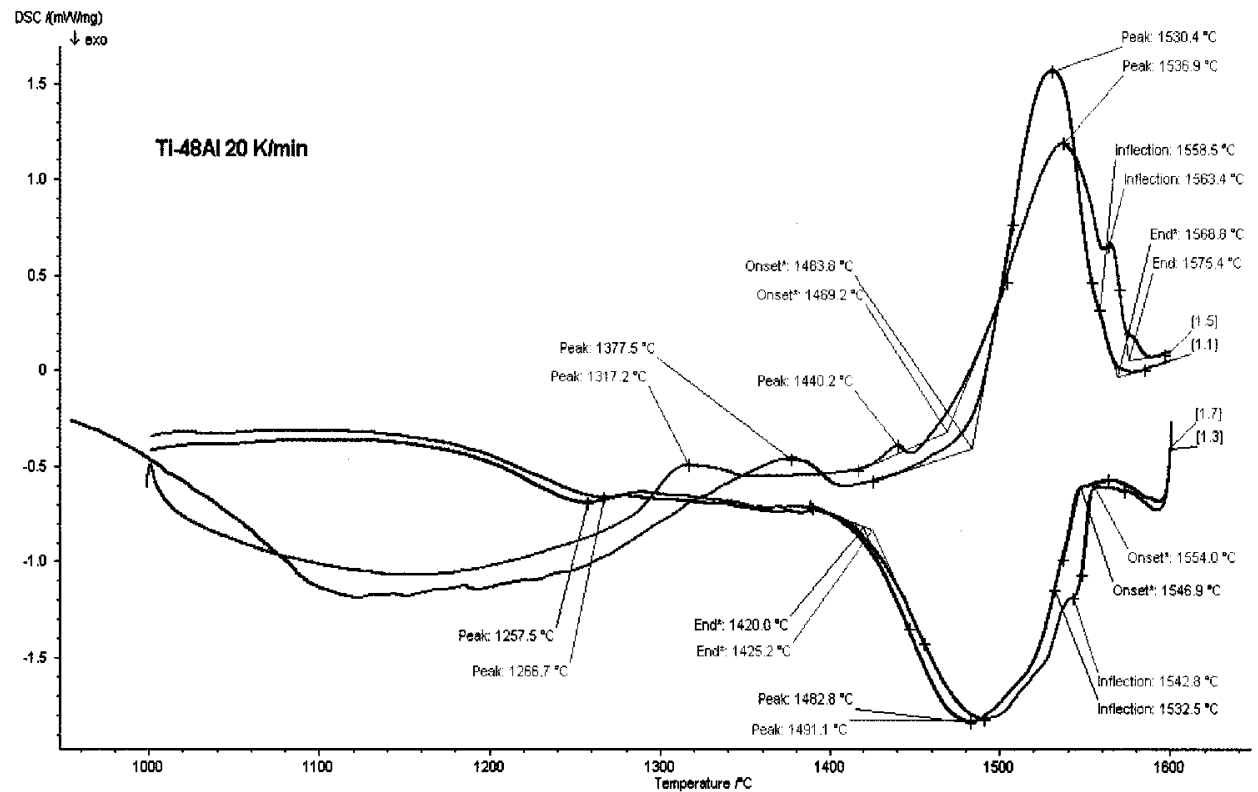

Figure C.2: DSC curve for Ti-48Al, loose PM sample, $20 \mathrm{~K} / \mathrm{min}$. 


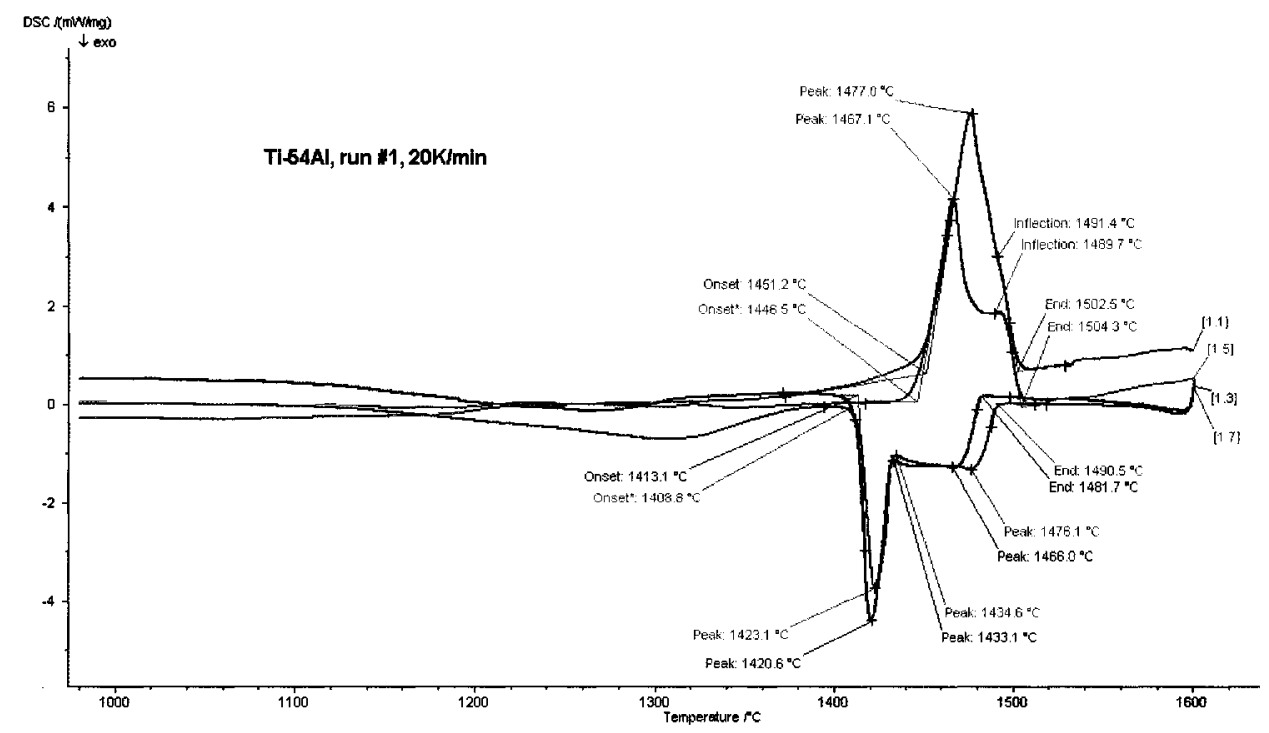

Figure C.3: DSC curve for Ti-54Al, $20 \mathrm{~K} / \mathrm{min}$.

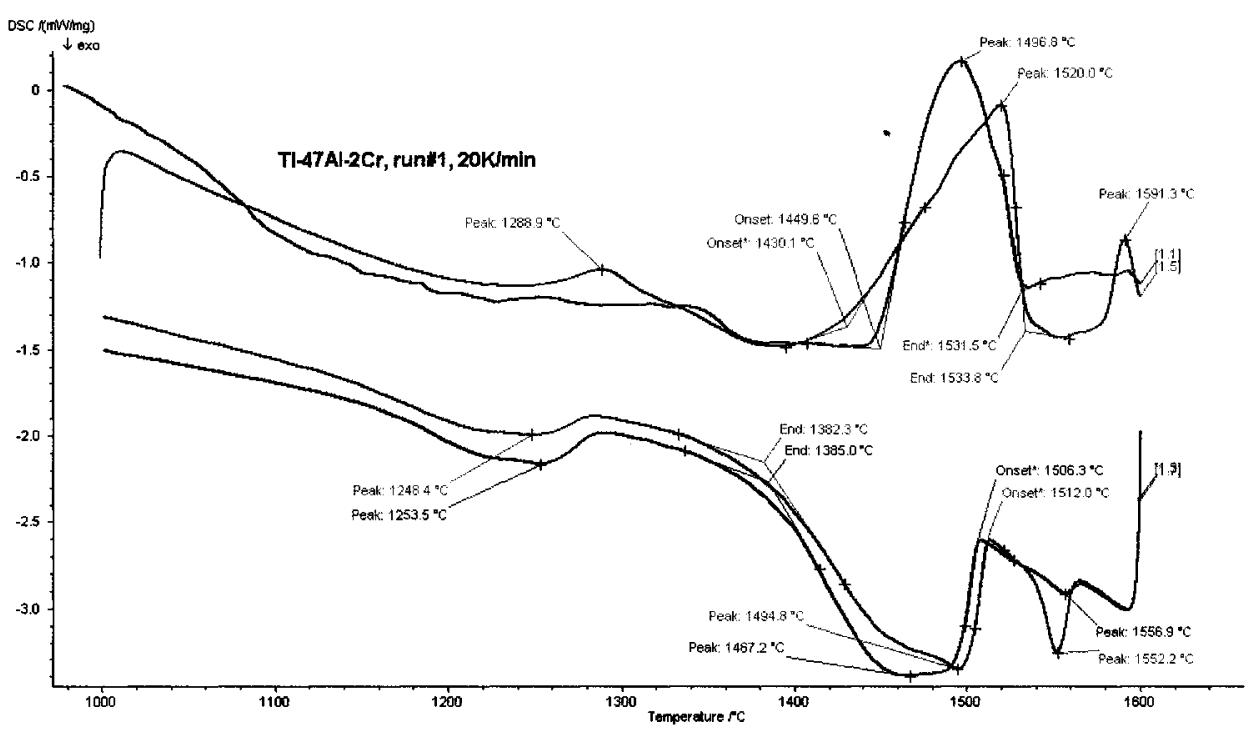

Figure C.4: DSC curve for Ti-47Al-2Cr, $20 \mathrm{~K} / \mathrm{min}$. 


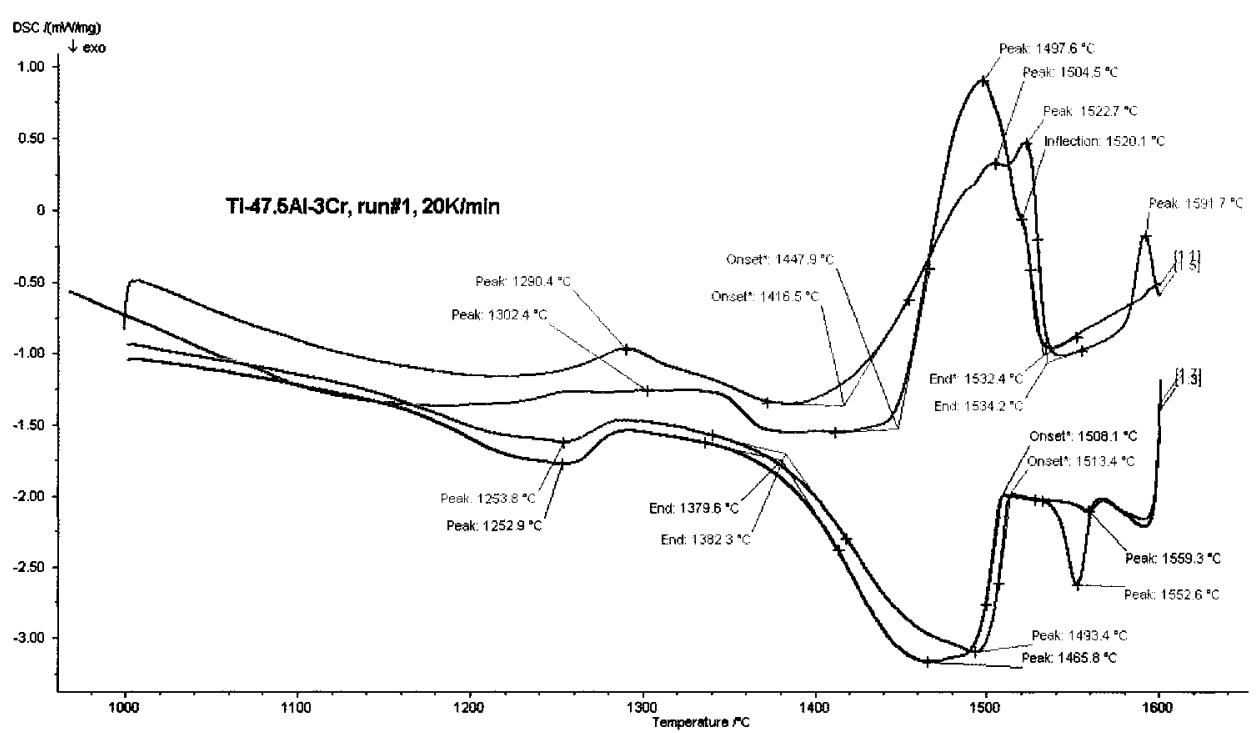

Figure C.5: DSC curve for Ti-47.5Al-3Cr, $20 \mathrm{~K} / \mathrm{min}$.

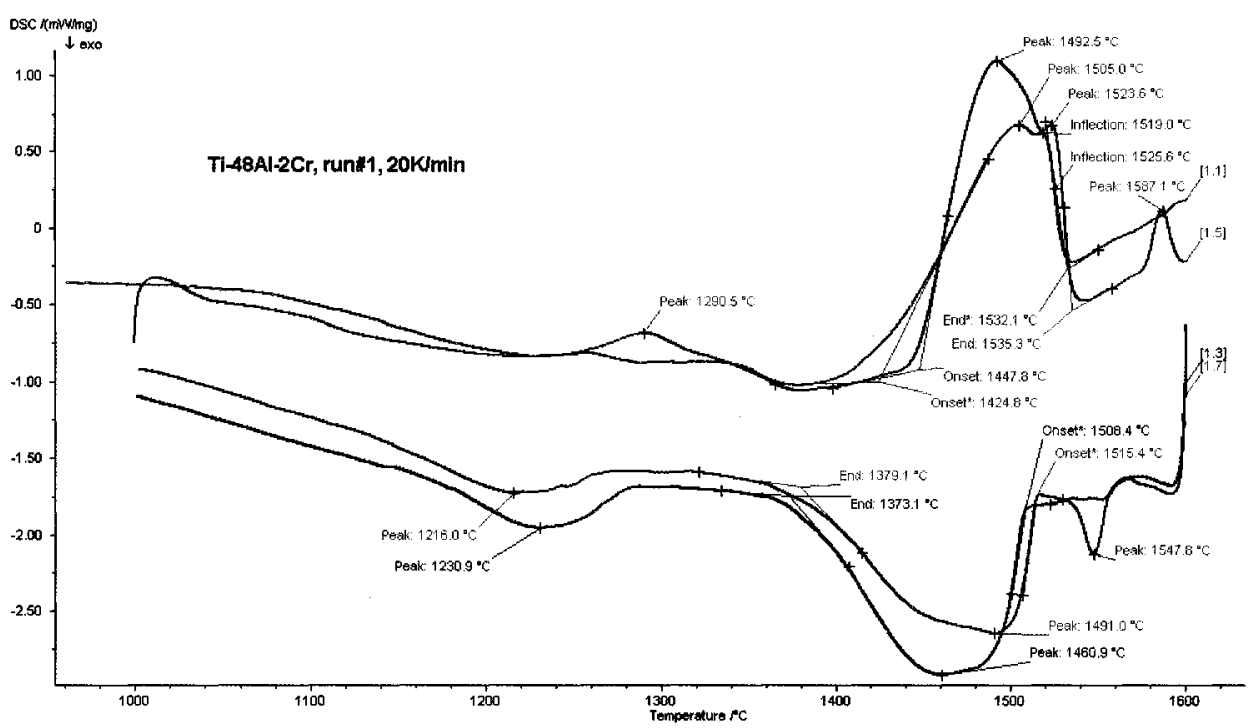

Figure C.6: DSC curve for Ti-48Al-2Cr, $20 \mathrm{~K} / \mathrm{min}$. 


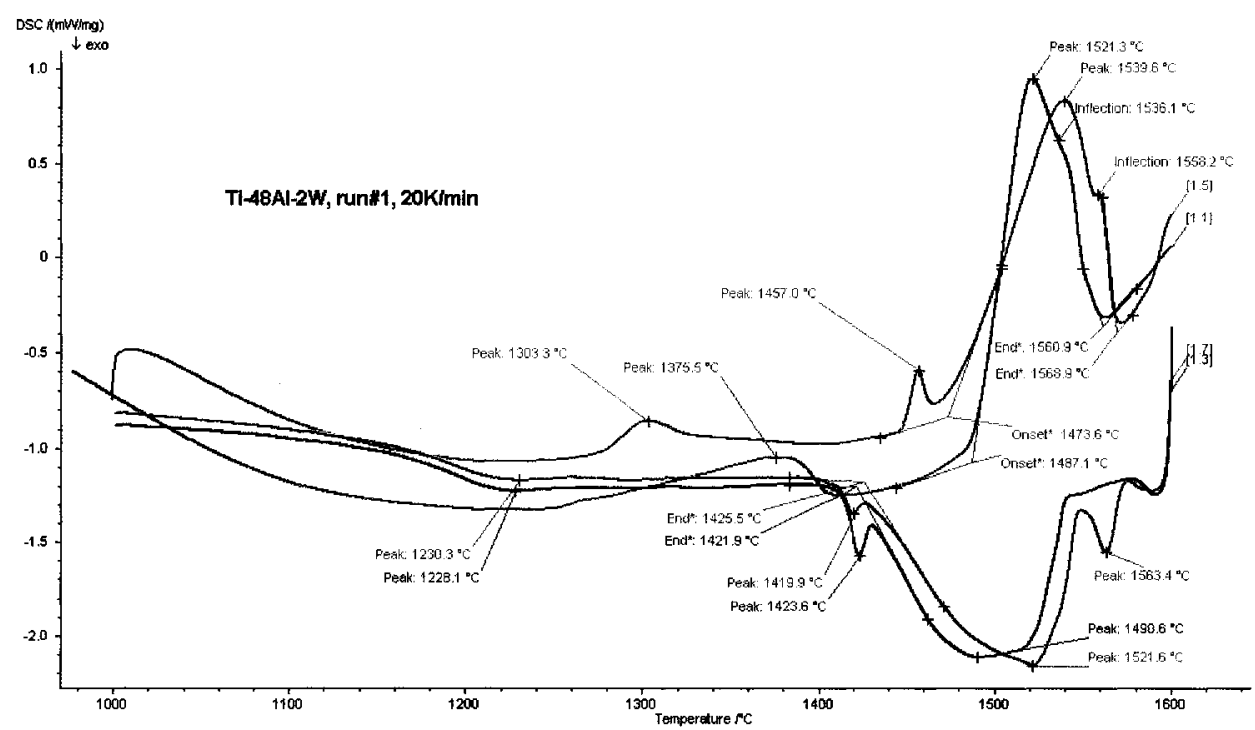

Figure C.7: DSC curve for Ti-48Al-2W, $20 \mathrm{~K} / \mathrm{min}$.

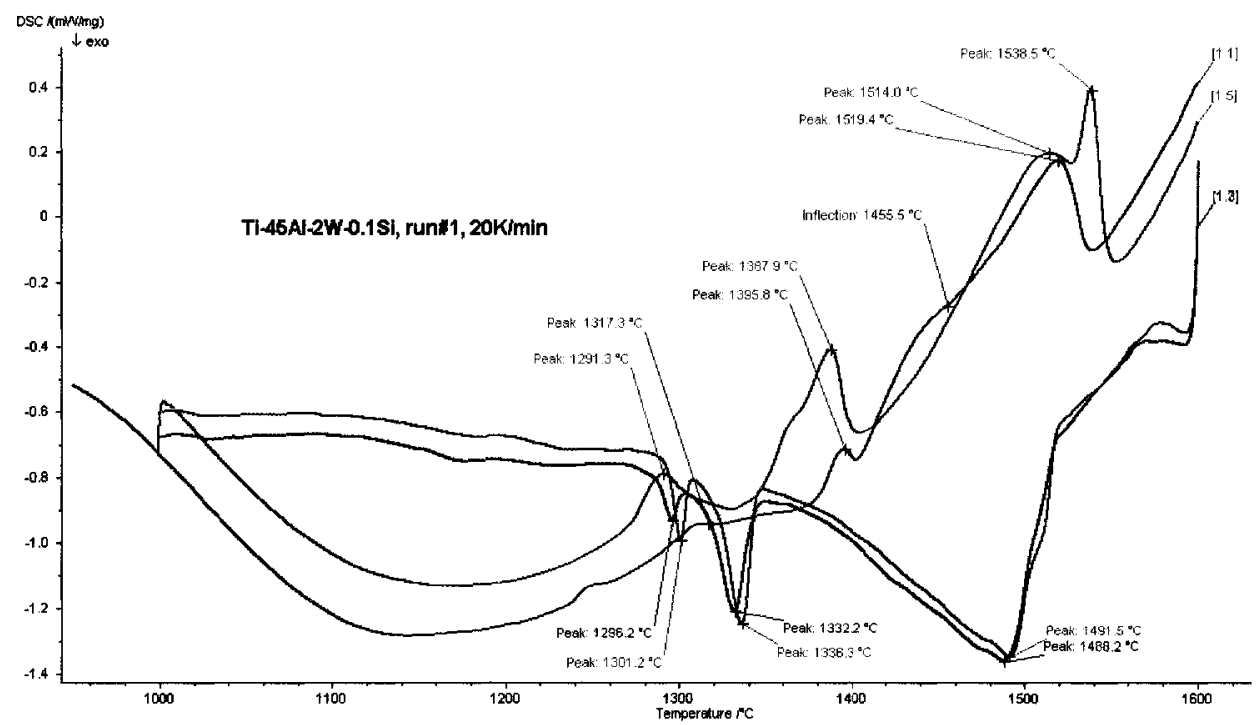

Figure C.8: DSC curve for Ti-45Al-2W-0.1Si, $20 \mathrm{~K} / \mathrm{min}$. 


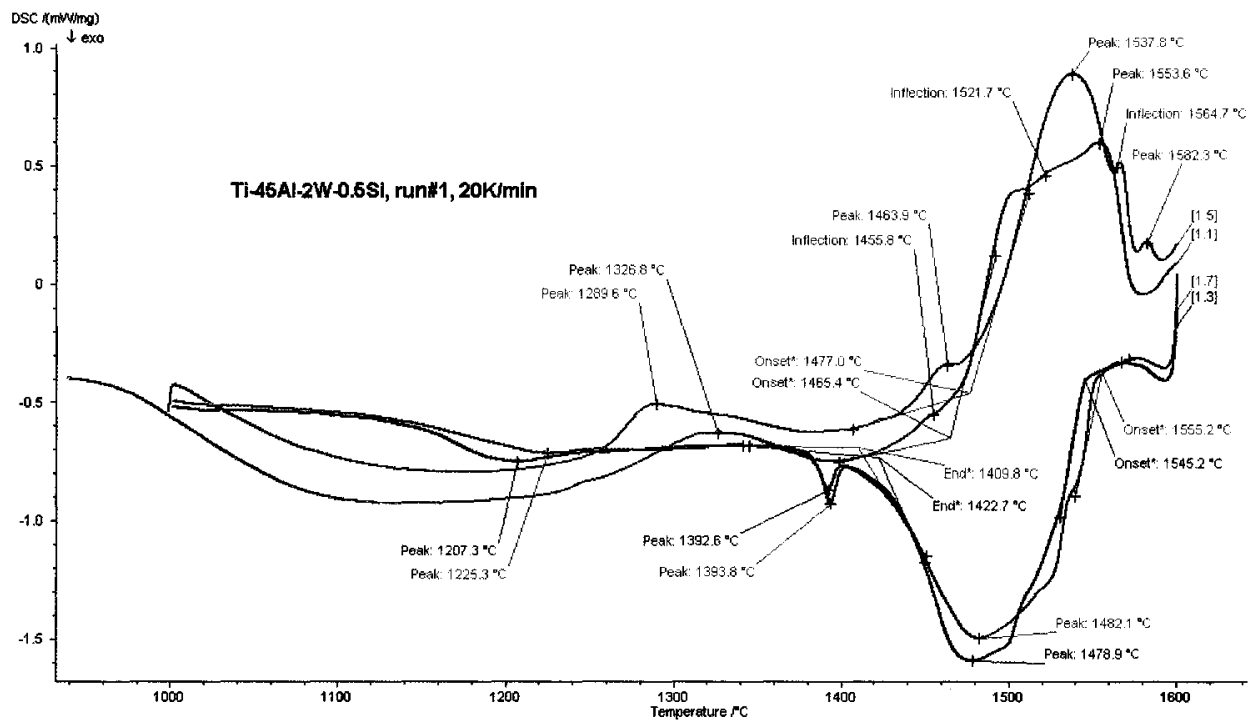

Figure C.9: DSC curve for Ti-45Al-2W-0.5Si, $20 \mathrm{~K} / \mathrm{min}$.

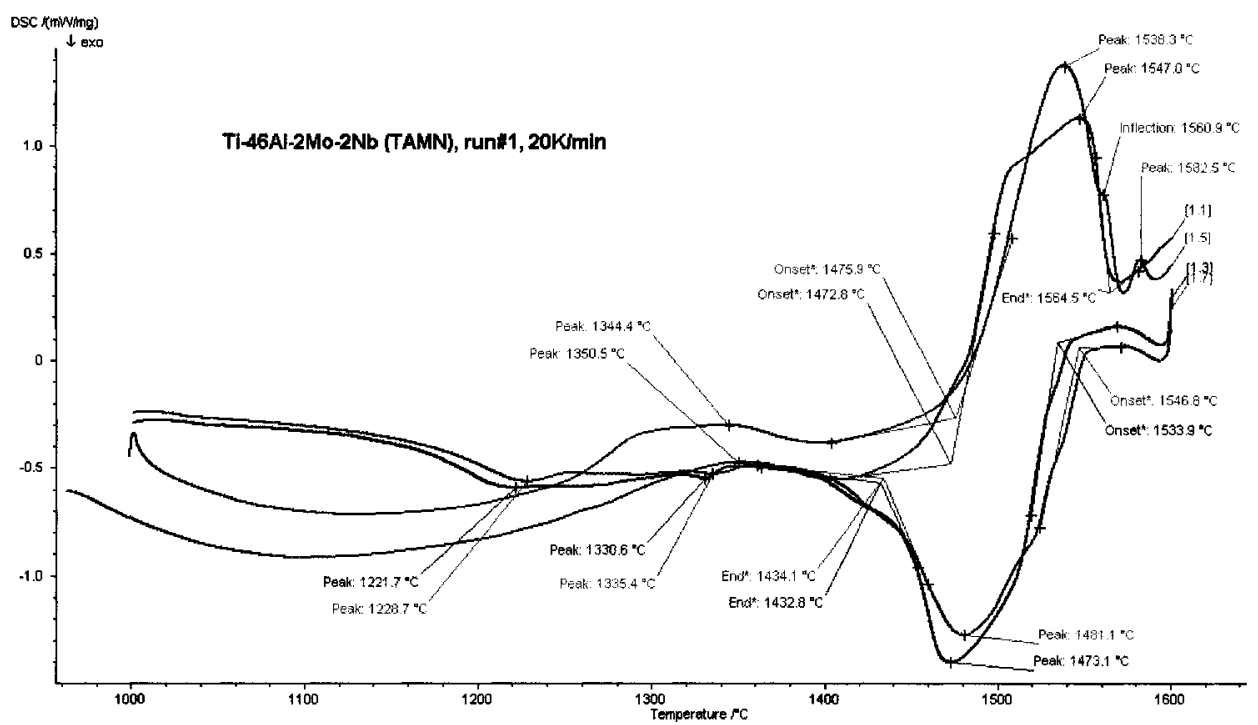

Figure C.10: DSC curve for Ti-46Al-2Mo-2Nb (TAMN), $20 \mathrm{~K} / \mathrm{min}$. 


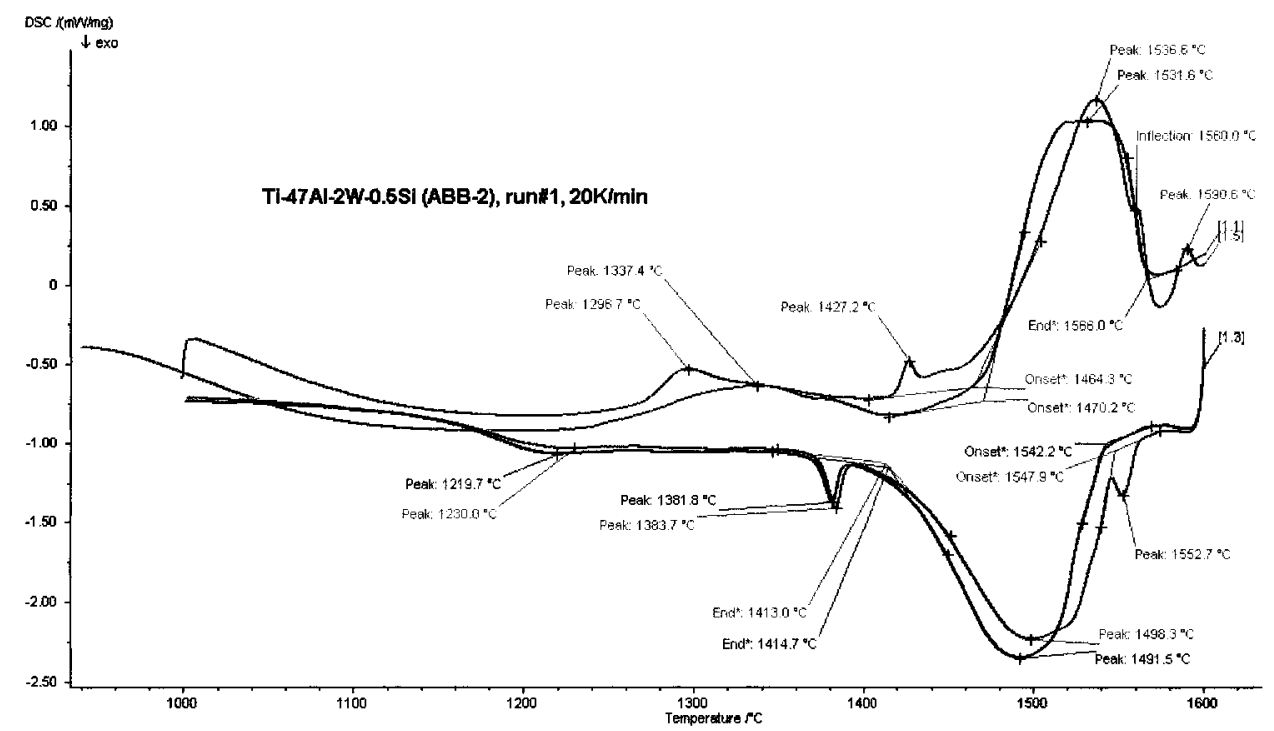

Figure C.11: DSC curve for Ti-47Al-2W-0.5Si (ABB-2), $20 \mathrm{~K} / \mathrm{min}$.

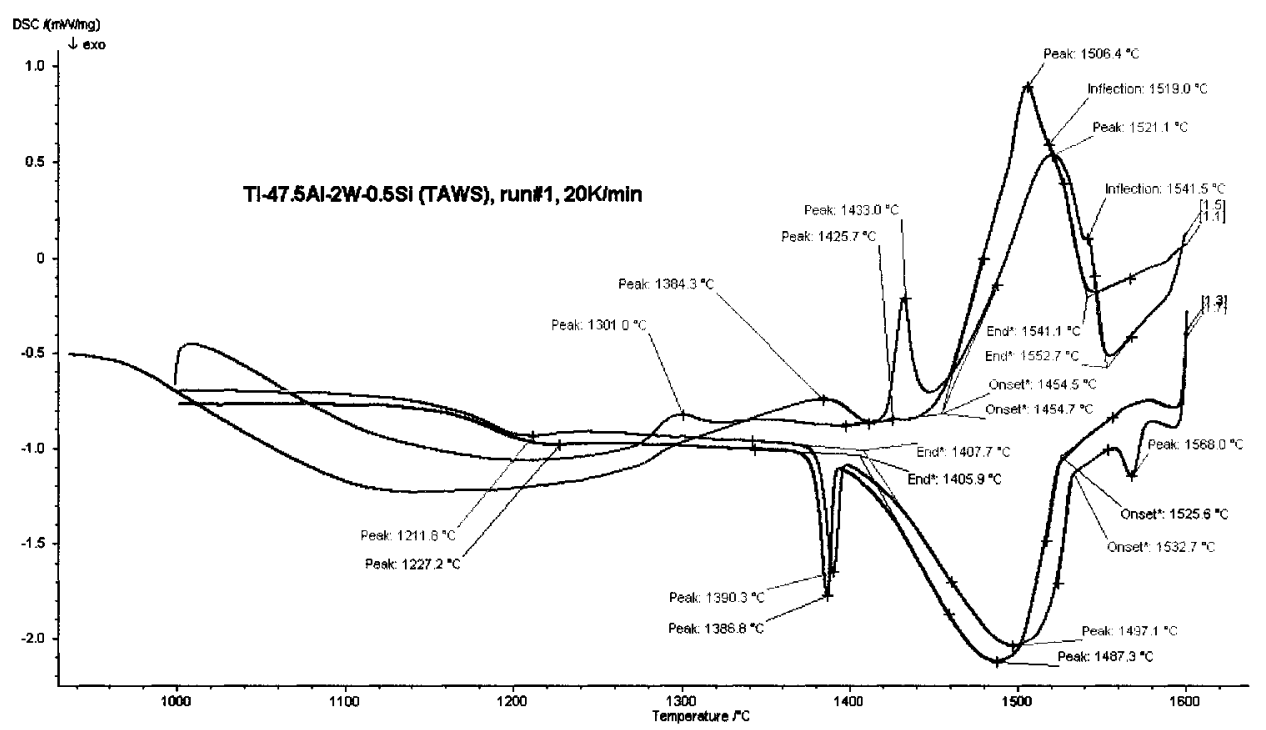

Figure C.12: DSC curve for Ti-47.5Al-2W-0.5Si (TAWS), $20 \mathrm{~K} / \mathrm{min}$. 


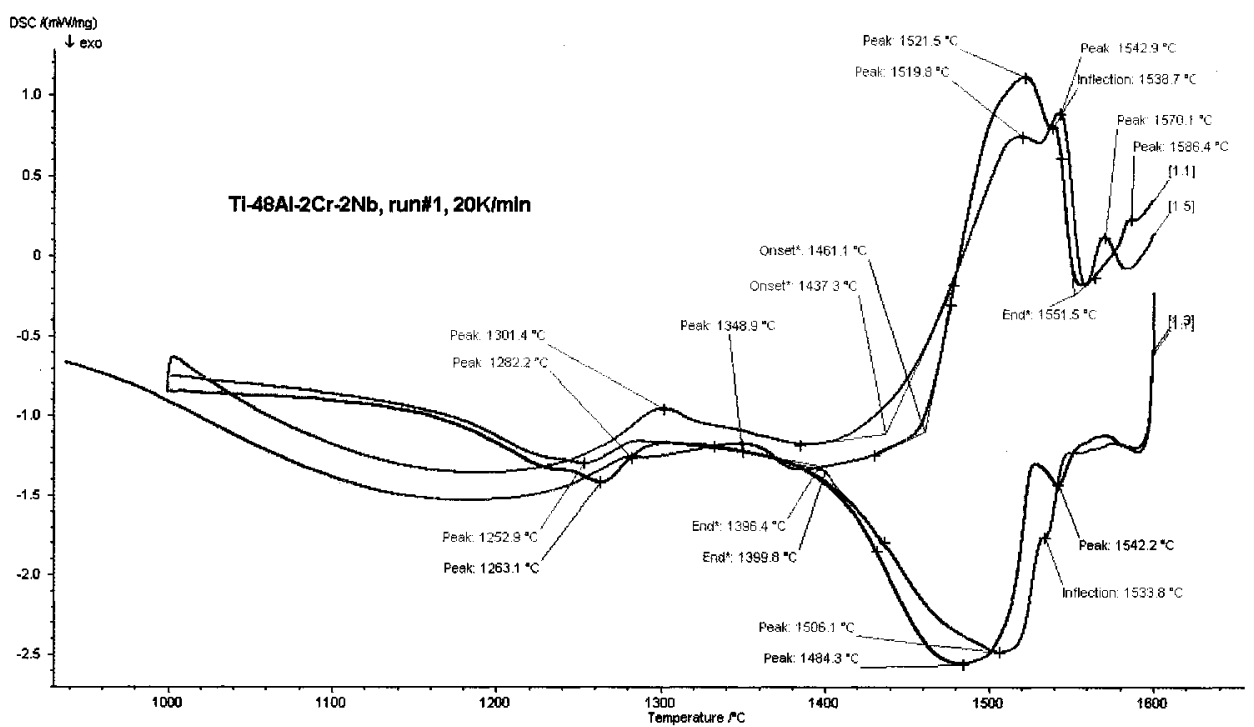

Figure C.13: DSC curve for Ti-48Al-2Nb-2Cr, $20 \mathrm{~K} / \mathrm{min}$.

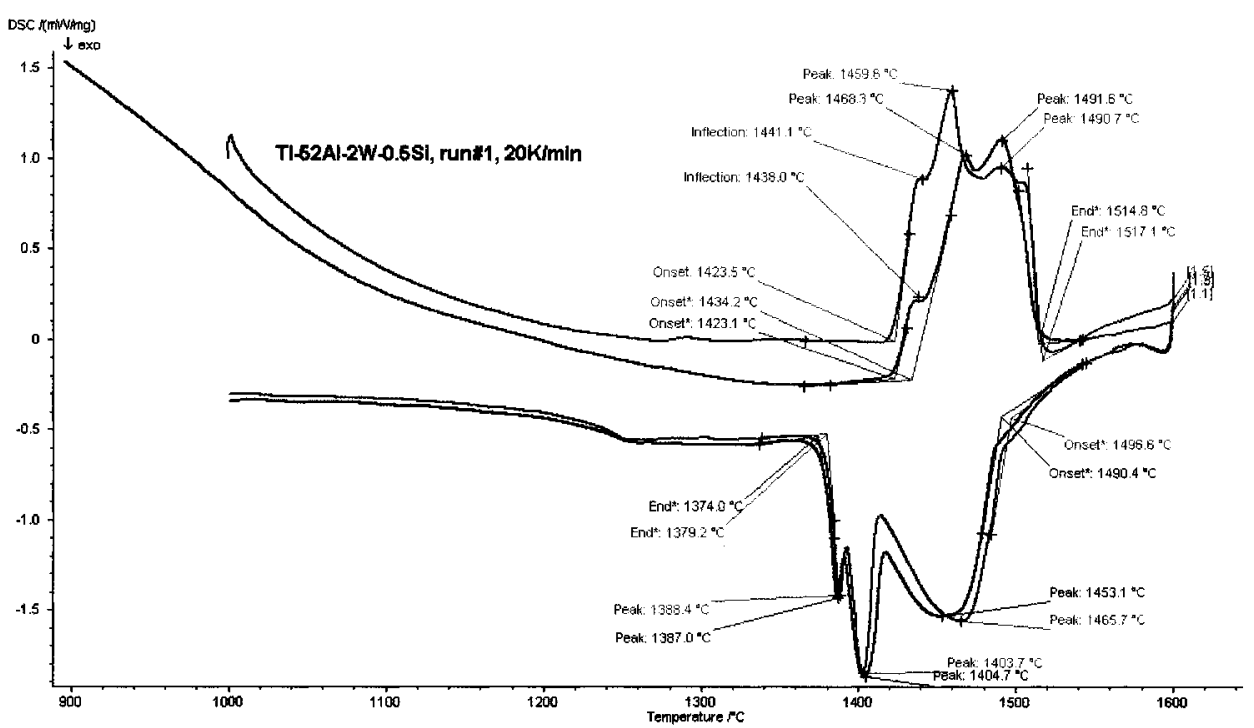

Figure C.14: DSC curve for Ti-52Al-2W-0.5Si, $20 \mathrm{~K} / \mathrm{min}$. 


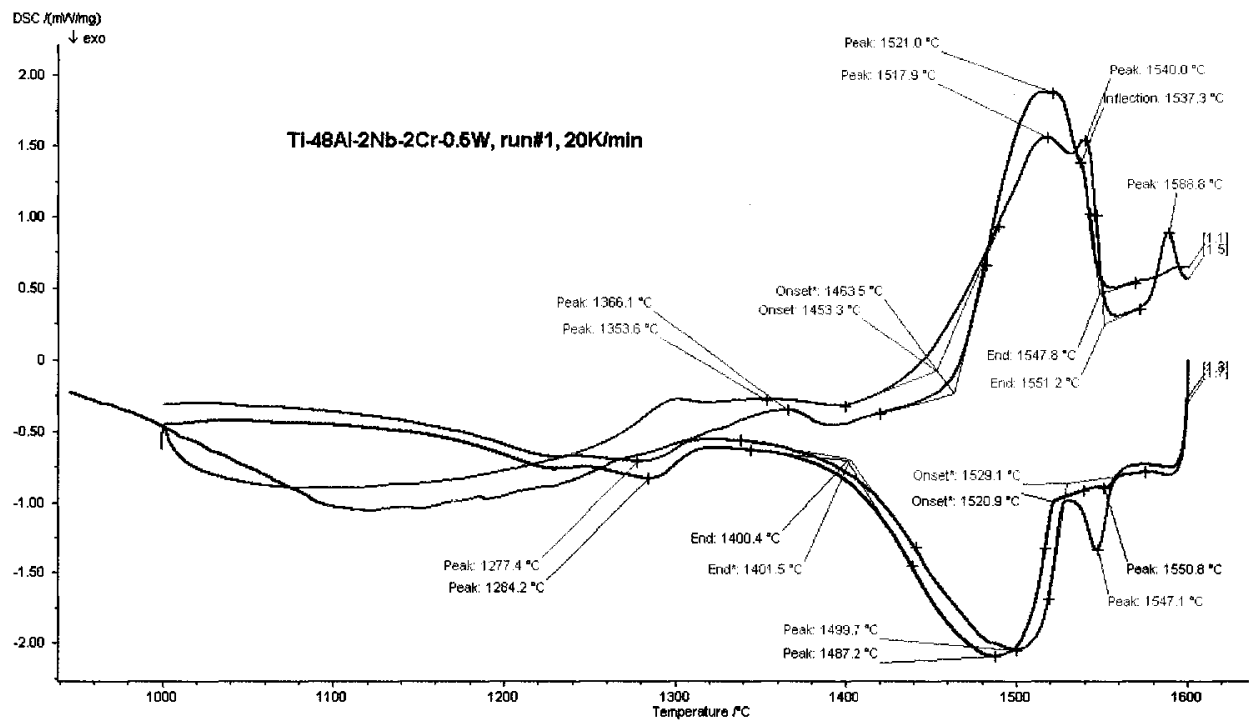

Figure C.15: DSC curve for Ti-48Al-2Nb-2Cr-0.5W, $20 \mathrm{~K} / \mathrm{min}$.

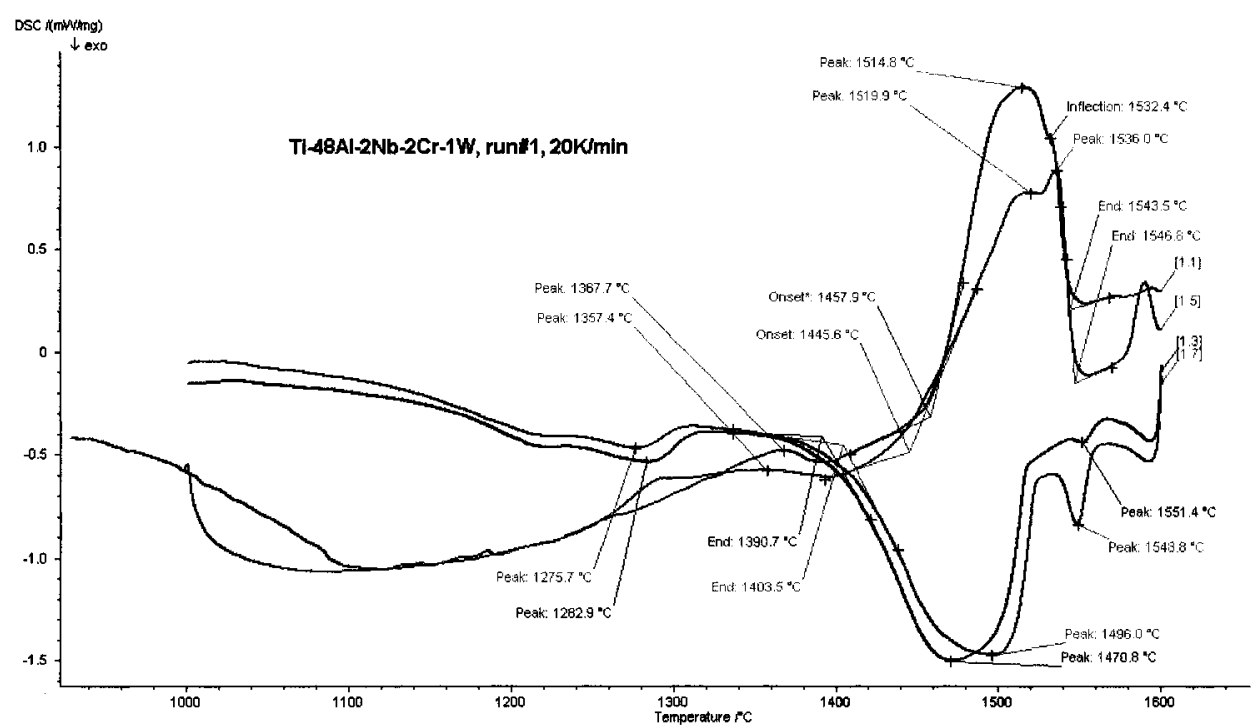

Figure C.16: DSC curve for Ti-48Al-2Nb-2Cr- $1 \mathrm{~W}, 20 \mathrm{~K} / \mathrm{min}$. 


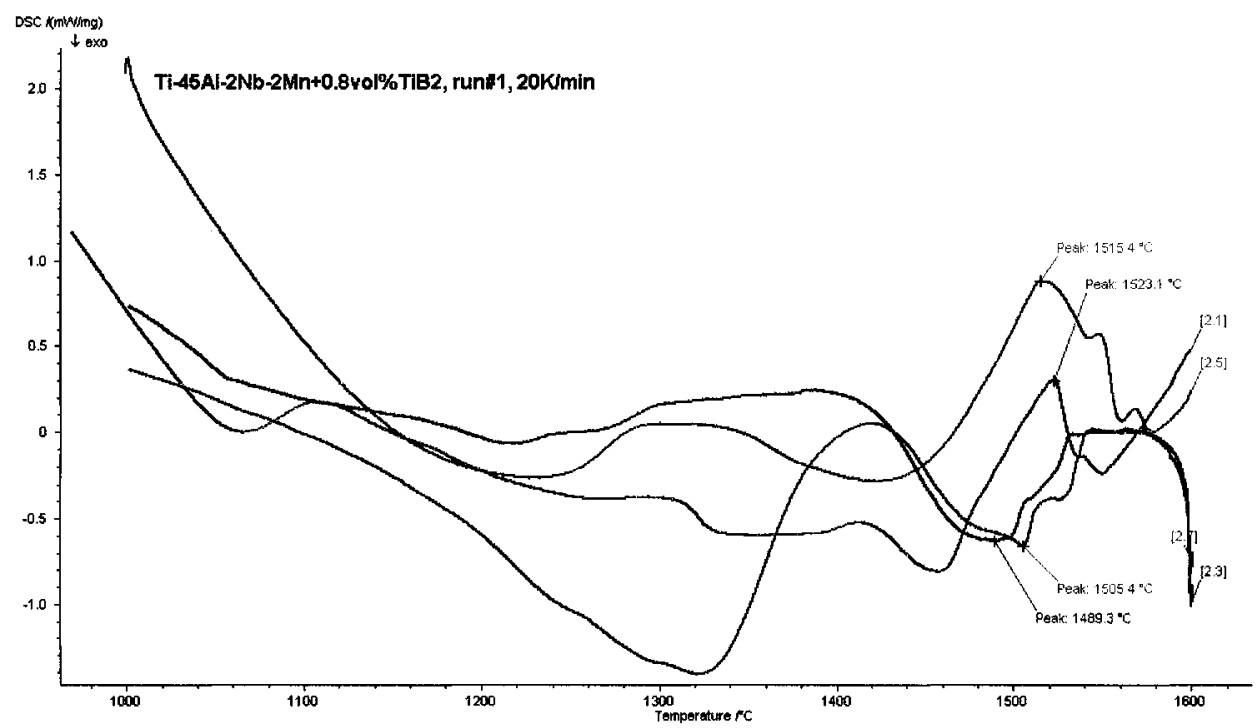

Figure C.17: DSC curve for Ti-45Al-2Nb-2Mn + $0.8 \mathrm{TiB2}(45 \mathrm{XD}), 20 \mathrm{~K} / \mathrm{min}$.

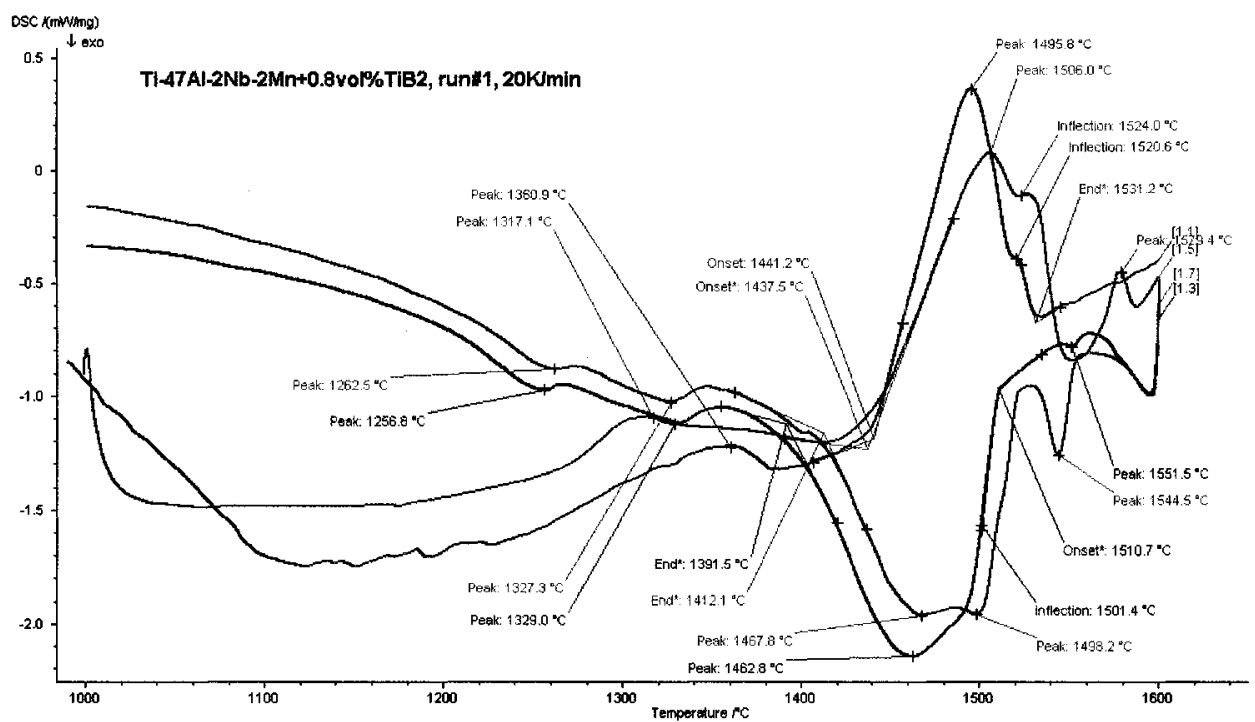

Figure C.18: DSC curve for Ti-47Al-2Nb-2Mn $+0.8 \mathrm{TiB2}(47 \mathrm{XD}), 20 \mathrm{~K} / \mathrm{min}$. 


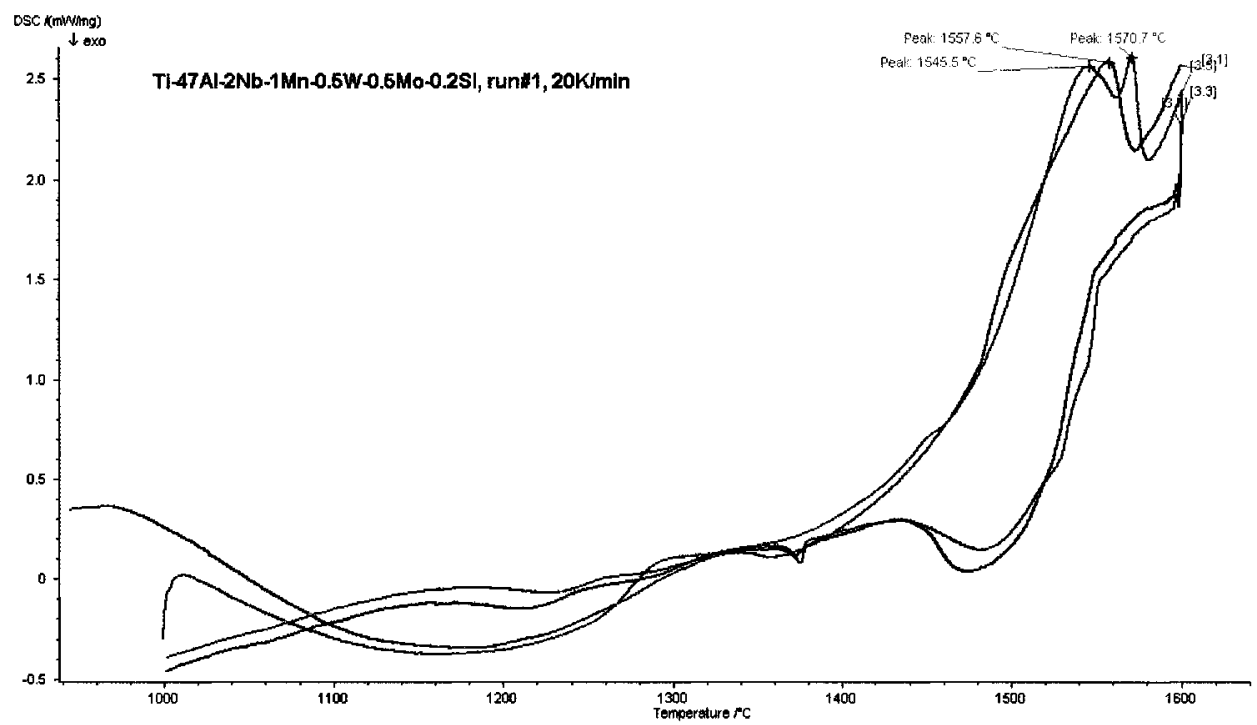

Figure C.19: DSC curve for Ti-47Al-2Nb-1Mn-0.5W-0.5Mo-0.2Si (TiAlWMoSi), $20 \mathrm{~K} / \mathrm{min}$. 